\title{
Operational Overview for UAS Integration in the NAS Project Flight Test Series 3
}

\author{
Steffi B. Valkov ${ }^{1}$, Daniel Sternberg ${ }^{2}$, and Michael Marston ${ }^{3}$ \\ Jacobs Technology, Inc., Edwards, California, 93523
}

\begin{abstract}
The National Aeronautics and Space Administration Unmanned Aircraft Systems Integration in the National Airspace System Project has conducted a series of flight tests intended to support the reduction of barriers that prevent unmanned aircraft from flying without the required waivers from the Federal Aviation Administration. The 2015 Flight Test Series 3, supported two separate test configurations. The first configuration investigated the timing of Detect and Avoid alerting thresholds using a radar equipped unmanned vehicle and multiple live intruders flown at varying encounter geometries. The second configuration included a surrogate unmanned vehicle (flown from a ground control station, with a safety pilot on board) flying a mission in a virtual air traffic control airspace sector using research pilot displays and Detect and Avoid advisories to maintain separation from live and virtual aircraft. The test was conducted over an eight-week span within the R-2508 Special Use Airspace. Over 200 encounters were flown for the first configuration, and although the second configuration was cancelled after three data collection flights, Flight Test 3 proved to be invaluable for the purposes of planning, managing, and execution of this type of integrated flight test.
\end{abstract}

$\begin{array}{ll}\text { ACAS } & = \\ \text { ADS-B } & = \\ \text { AFRC } & = \\ \text { AFTC } & = \\ \text { AGL } & = \\ \text { AIM } & = \\ \text { ARC } & = \\ \text { ATC } & = \\ \text { AUTO } & = \\ \text { C2 } & = \\ \text { CA } & = \\ \text { CAT } & = \\ \text { CBDR } & = \\ \text { CBP } & = \\ \text { CCB } & = \\ \text { CFG } & = \\ \text { CFR } & = \\ \text { CNPC } & = \\ \text { COA } & = \\ \text { COMEX } & = \\ \text { CPA } & = \\ \text { CPDS } & = \\ \text { CRM } & =\end{array}$

\section{Nomenclature}

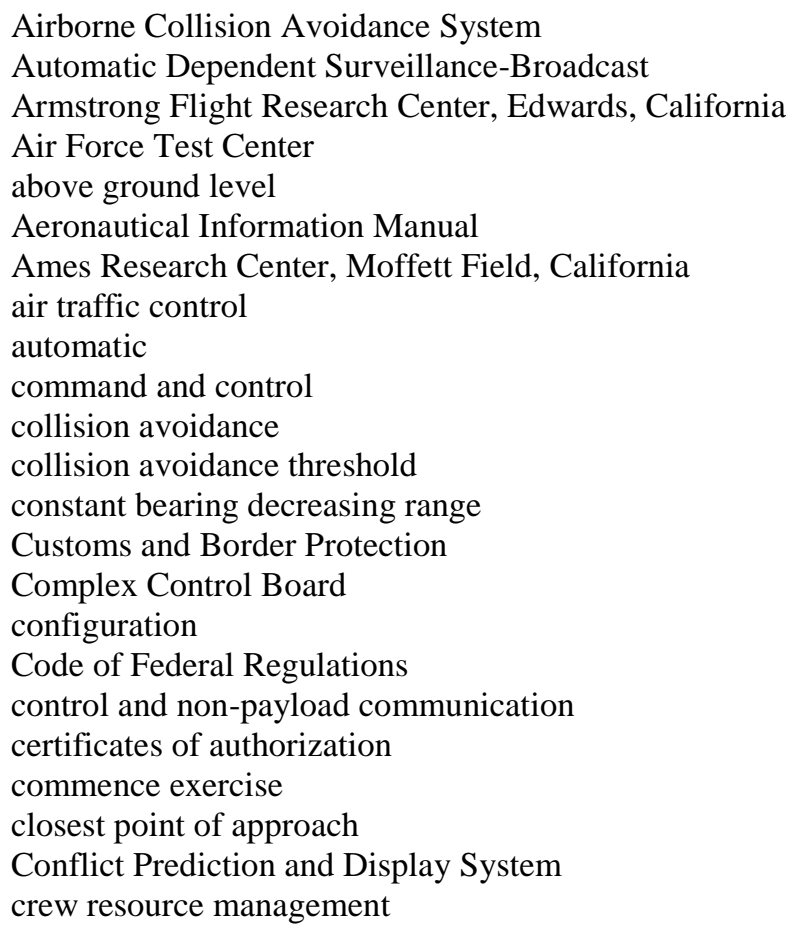

\footnotetext{
${ }^{1}$ Test Coordinator/Director, Operations Engineering, P.O. Box 273/Mail Stop 2134, non-member.

2 Test Director/Conductor, Operations Engineering, P.O. Box 273/Mail Stop 2134, non-member.

${ }^{3}$ Test Conductor/Director, Operations Engineering, P.O. Box 273/Mail Stop 1504, non-member.
} 


\begin{tabular}{|c|c|c|}
\hline CSSA & $=$ & Corrective Self-Separation Alert \\
\hline CST & $=$ & combined systems test \\
\hline $\mathrm{CTF}$ & $=$ & combined test force \\
\hline CVSRF & $=$ & Crew Vehicle Systems Research Facility \\
\hline DAA & $=$ & detect and avoid \\
\hline DAIDALUS & $=$ & Detect and AvoID Alerting Logic for Unmanned Systems \\
\hline DATR & $=$ & Dryden Aeronautical Test Range \\
\hline DD & $=$ & decimal degrees \\
\hline DEEC & $=$ & digital electronic engine control \\
\hline DET3 & $=$ & detachment 3 \\
\hline DGPS & $=$ & differential global positioning system \\
\hline DICES & $=$ & Digital Integrated Communications Electronic System \\
\hline DME & $=$ & distance measuring equipment \\
\hline DMOD & $=$ & distance modification \\
\hline DRR & $=$ & due regard radar \\
\hline DSRL & $=$ & Distributed Simulation Research Laboratory \\
\hline EAFB & $=$ & Edwards Air Force Base \\
\hline EDM & $=$ & engineering development model \\
\hline ENC & $=$ & encounter \\
\hline FAA & $=$ & Federal Aviation Administration \\
\hline FAR & $=$ & Federal Aviation Regulation \\
\hline FDDRL & $=$ & Flight Deck Display Research Laboratory \\
\hline FINEX & $=$ & finish exercise \\
\hline FL & $=$ & flight level \\
\hline FM & $=$ & Full Mission \\
\hline FSE & $=$ & flight systems engineer \\
\hline FT3 & $=$ & Flight Test 3 \\
\hline FT4 & $=$ & Flight Test 4 \\
\hline FTE & $=$ & flight-test engineer \\
\hline FTP & $=$ & flight-test plan \\
\hline $\mathrm{FV}$ & $=$ & FalconView \\
\hline GA-ASI & $=$ & General Atomics Aeronautical Systems, Inc. \\
\hline GCS & $=$ & ground control station \\
\hline GPS & $=$ & global positioning system \\
\hline GRC & $=$ & Glenn Research Center, Cleveland, Ohio \\
\hline GS & $=$ & groundspeed \\
\hline $\mathrm{H} / \mathrm{S}$ & $=$ & high speed \\
\hline HSI & $=$ & Human Systems Integration \\
\hline HUD & $=$ & head-up display \\
\hline IASP & $=$ & Integrated Aviation Systems Program \\
\hline ID & $=$ & identification \\
\hline IFR & $=$ & instrument flight rules \\
\hline IHITL & $=$ & integrated human-in-the-loop \\
\hline ILLA & $=$ & Ikhana lost-link altitude \\
\hline ILLH & $=$ & Ikhana lost-link heading \\
\hline $\mathrm{IMU}$ & $=$ & inertial measurement unit \\
\hline INS & $=$ & Inertial Navigation System \\
\hline INT & $=$ & intruder \\
\hline IP & $=$ & initial point \\
\hline IT\&E & $=$ & Integrated Test and Evaluation \\
\hline ITAR & $=$ & International Traffic in Arms Regulations \\
\hline JADEM & $=$ & Java Architecture for DAA Extensibility and Modeling \\
\hline KBFI & $=$ & ICAO airfield code for King Field in Seattle, Washington \\
\hline KBFL & $=$ & ICAO airfield code for Meadows Field in Bakersfield, California \\
\hline KEDW & $=$ & ICAO airfield code for Edwards Air Force Base, California \\
\hline KGS & $=$ & knots groundspeed \\
\hline
\end{tabular}

American Institute of Aeronautics and Astronautics 


\begin{tabular}{|c|c|c|}
\hline KIAS & $=$ & knots indicated airspeed \\
\hline KPMD & $=$ & ICAO airfield code for Palmdale airfield in Palmdale, California \\
\hline KTAS & $=$ & knots true airspeed \\
\hline KVCV & $=$ & ICAO airfield code for Victorville, California \\
\hline KVNY & $=$ & ICAO airfield code for Van Nuys, California \\
\hline LaRC & $=$ & Langley Research Center, Hampton, Virginia \\
\hline LOS & $=$ & line of sight \\
\hline LRO & $=$ & long range optics \\
\hline LSP & $=$ & launch sequence plan \\
\hline LVC & $=$ & Live Virtual Constructive \\
\hline MACS & $=$ & Multi Aircraft Control System \\
\hline $\mathrm{MC}$ & $=$ & magnetic course \\
\hline MIT & $=$ & Massachusetts Institute of Technology, Lexington, Massachusetts \\
\hline MOA & $=$ & military operating area \\
\hline MOPS & $=$ & Minimum Operational Performance Standards \\
\hline MP & $=$ & maneuver point \\
\hline MR & $=$ & Mission Rule \\
\hline MSL & $=$ & mean sea level \\
\hline NAS & $=$ & National Airspace System \\
\hline NASA & $=$ & National Aeronautics and Space Administration \\
\hline NMAC & $=$ & near mid-air collision \\
\hline NOTAM & $=$ & notice to airmen \\
\hline $\mathrm{O} / \mathrm{S}$ & $=$ & ownship \\
\hline OWG & $=$ & Operations Working Group \\
\hline OWN & $=$ & ownship \\
\hline PIRA & $=$ & Precision Impact Range Area \\
\hline PSSA & $=$ & Preventive Self-Separation Alert \\
\hline PT6 & $=$ & Part Task 6 \\
\hline RA & $=$ & resolution advisory \\
\hline RAIF & $=$ & Research Aircraft Integration Facility \\
\hline RDR & $=$ & radar \\
\hline $\mathrm{REH}$ & $=$ & rehearsal \\
\hline RF & $=$ & radio frequency \\
\hline RGCS & $=$ & research ground control station \\
\hline RSO & $=$ & range safety officer \\
\hline RTB & $=$ & return to base \\
\hline RTCA & $=$ & Radio Technical Commission for Aeronautics \\
\hline $\mathrm{S} / \mathrm{N}$ & $=$ & scenario number \\
\hline SA & $=$ & situational awareness \\
\hline SAA & $=$ & sense and avoid \\
\hline SAAP & $=$ & sense and avoid processor \\
\hline SAF & $=$ & Stand-Alone Facility \\
\hline SC-228 ToR & $=$ & Special Committee-228 Terms of Reference \\
\hline SGT & $=$ & Stinger Ghaffarian Technologies \\
\hline SME & $=$ & subject matter expert \\
\hline SOP & $=$ & standard operating procedures \\
\hline SOR & $=$ & senior operations representative \\
\hline SPORT & $=$ & Space Positioning Optical Radar Tracking \\
\hline SS & $=$ & self-separation \\
\hline SSCA & $=$ & Self-Separation Corrective Alert \\
\hline SSI & $=$ & separation assurance/sense and avoid interoperability \\
\hline SSPT & $=$ & Self-Separation Proximate Traffic \\
\hline SSWA & $=$ & Self-Separation Warning Alert \\
\hline SSWG & $=$ & System Safety Working Group \\
\hline STM & $=$ & surveillance tracking module \\
\hline SUT & $=$ & system under test \\
\hline
\end{tabular}

American Institute of Aeronautics and Astronautics 


$\begin{array}{lll}\text { TA } & = & \text { traffic advisory } \\ \text { TBD } & = & \text { to be determined } \\ \text { TC } & = & \text { Traffic Alert and Collision Avoidance System } \\ \text { TCAS } & = & \text { test coordinator } \\ \text { TCOR } & = & \text { test director } \\ \text { TD } & = & \text { test and Evaluation Command and Control System } \\ \text { TECCS } & = & \text { Terminal Radar Approach Control Facility } \\ \text { TFR } & = & \text { tracker } \\ \text { TRACON } & = & \text { time, space, position information } \\ \text { TRC } & = & \text { Unmanned Aircraft System } \\ \text { TSPI } & = & \text { UAS Integration in the NAS project } \\ \text { UAS } & = & \text { United States Air Force } \\ \text { UAS-NAS } & = & \text { coordinated universal time } \\ \text { USAF } & = & \text { verification and validation } \\ \text { UTC } & = & \text { Visual Basic for Applications } \\ \text { V\&V } & = & \text { visual identification } \\ \text { VBA } & = & \text { visual meteorological conditions } \\ \text { VID } & = & \text { Vigilant Spirit Control Station } \\ \text { VMC } & = & \text { vertical speed indicator } \\ \text { VSCS } & = & \text { vehicle specific module } \\ \text { VSI } & = & \text { well-clear violation } \\ \text { VSM } & \text { waypoint } \\ \text { WCV } & \text { Oakland Air Route Traffic Control Center } \\ \text { WP } & & \end{array}$

\section{Introduction}

$\mathrm{T}$ HE desire and ability to fly Unmanned Aircraft Systems (UAS) in the National Airspace System (NAS) is of increasing urgency. ${ }^{1}$ The application of unmanned aircraft to perform national security, defense, scientific, and emergency management are driving the critical need for less restrictive access by UAS to the NAS. UAS represent a new capability that will provide a variety of services in the government (public) and commercial (civil) aviation sectors. The growth of this potential industry has not yet been realized due to the lack of a common understanding of what is required to safely operate UAS in the NAS. ${ }^{2}$

The National Aeronautics and Space Administration (NASA) UAS Integration in the NAS Project (UAS-NAS) is conducting research in the areas of Separation Assurance/Sense and Avoid Interoperability, Human Systems Integration (HSI), and Communication to support reducing the barriers to routine UAS access to the NAS. This research is broken into two research themes, namely, UAS Integration and Test Infrastructure. UAS Integration focuses on airspace integration procedures and performance standards to enable UAS integration in the air transportation system, covering Sense and Avoid (SAA) performance standards, command and control performance standards, and human systems integration. The focus of Test Infrastructure is to enable development and validation of airspace integration procedures and performance standards, including integrated test and evaluation. In support of the integrated test and evaluation efforts, the project will develop an adaptable and scalable relevant test environment capable of evaluating concepts and technologies for UAS to safely operate in the NAS.

To accomplish this task, the project will conduct a series of human-in-the-loop and flight-test activities that integrate key concepts, technologies, and/or procedures in a relevant air traffic environment. Each of the integrated events will build on the technical achievements, fidelity, and complexity of the previous tests and technical simulations, resulting in research findings that support the development of regulations governing the access of UAS into the NAS.

\section{A. Purpose and Scope}

The integrated Flight Test 3 (FT3) gathered data for UAS researchers for their development and evaluation of a communication system, Sense and Avoid (referred to as Detect and Avoid (DAA) in the Radio Technical Commission for Aeronautics (RTCA) SC 228 ToR) algorithms, and pilot displays for candidate UAS systems in a relevant environment. ${ }^{3}$ The technical goals of FT3 were to: 
1) Perform an end to end traffic encounter test of pilot guidance generated by self-separation (SS) algorithms (aircraft sensor to wind, Traffic Alert and Collision Avoidance System (TCAS) II, and latency uncertainties to the ground control station (GCS) display);

2) Conduct a flight test of the prototype communication system as part of an integrated DAA system;

3) Collect data to inform the preliminary draft of the Minimum Operational Performance Standards (MOPS) for DAA and command and control (C2), to include display and human performance standards in both MOPS. Furthermore, FT3 increased the team's capabilities and reduced the risks associated with building a pertinent flighttest environment moving towards the final flight tests, Flight Test 4 (FT4) and Capstone.

The UAS-NAS project support and participation in the 2014 flight test of the Airborne Collision Avoidance System (ACAS) Xu and SS initial flight test significantly contributed to building up infrastructure, developing procedures, and reducing risk for FT3. The FT3 experiment was divided into two distinct test configurations, each focusing on different aspects of the primary technical goals. The first (described as Pairwise Encounters and Configuration 1) looked at the SS and collision avoidance (CA) algorithms to support the definition of well clear and TCAS integration onto the "ownship" aircraft platform. The second (described as Full Mission (FM), Configuration 2 flights) focused on UAS pilot response times to, and acceptability of, the same SAA alerts, resolutions, and GCS displays under real world uncertainties.

Configuration 1 test execution began on June 15, 2015, was completed on July 27, 2015, and comprised 12 flights and more than 200 test points. NASA Armstrong Flight Research Center (AFRC) (Edwards, California) provided the primary ownship test aircraft for this configuration. Full Mission flights Configuration 2 began concurrently on July 16, 2015, and was concluded early on August 12, 2015. NASA Glenn Research Center (GRC) (Cleveland, Ohio) provided the primary ownship test aircraft for this configuration as well as the Communication system under test (SUT). The Configuration 2 phase conducted three test sorties and nine systems integration sorties, but was unable to achieve the desired performance needed by the primary research stakeholder. Therefore, it was concluded early with plans to further develop the system and proceeded with alternative modeling and simulation data throughout the remainder of 2015 and the beginning of 2016. The test period did not exceed original planned schedule estimates, even though Configuration 1 took longer than expected, and Configuration 2 was concluded early.

Testing facilities are Government owned, managed, leased, or under agreement and fall into two categories:

1. Development Facilities

- Distributed Simulation Research Laboratory (DSRL) at NASA Ames Research Center (ARC) (Moffett Field, California)

- Flight Deck Display Research Laboratory (FDDRL) at NASA ARC

- Research Aircraft Integration Facility (RAIF) at NASA AFRC

- UAS Sense and Avoid Research Lab at Stinger Ghaffarian Technologies (SGT), outside of NASA Langley Research Center (LaRC) (Hampton, Virginia)

- Aircraft Operations Research Hangar at NASA GRC

- Communication Laboratory at NASA GRC

- General Atomics Aeronautical Systems Incorporated (GA-ASI) Gray Butte Flight Operations Facility (Palmdale, California)

- GA-ASI Poway System Integration Lab (Poway, California)

2. $\quad$ Test Facilities

- Crew Vehicle Systems Research Facility (CVSRF) at NASA ARC

- DSRL at NASA ARC

- RAIF at NASA AFRC

- Dryden Aeronautical Test Range (DATR) at NASA AFRC

- Stand Alone Facility (SAF) Mission Control Room at NASA AFRC

- The Radio Frequency (RF) Communications facility at NASA AFRC

- Edwards Air Force Base (EAFB) R-2508 Complex (Edwards, California)

\section{B. Stakeholders}

The NASA Integrated Aviation Systems Program (IASP) provides direction for the UAS-NAS project. The project office had the overall responsibility for the FT3 flight test. NASA ARC, NASA AFRC, NASA GRC, NASA LaRC, GA-ASI, and Honeywell International, Inc. (Morris Plains, New Jersey), supported the project and were participants in the FT3 activity. The following is a brief description of responsibilities: 
- NASA ARC: NASA ARC provided the HSI research requirements for subject pilot evaluation based on performance during scenario events. Subject pilots performed scenario tests from the Research Ground Control Station (RGCS) located at NASA AFRC. Further, the AFRC Integrated Test and Evaluation (IT\&E) team supported the AFRC Live Virtual Constructive (LVC) and provided the virtual air traffic control (ATC) component, which included a "ghost" controller, pseudo pilots, and Oakland air traffic controllers for virtual ATC. ARC also provided AutoResolver/Java Architecture for DAA Extensibility and Modeling (JADEM), one of the SS algorithms used during Configuration 1.

- NASA AFRC: NASA AFRC IT\&E was the responsible test organization for all test missions flown from AFRC. AFRC provided the RGCS for subject pilot evaluation. Further, AFRC hosted the LVC infrastructure for data distribution between NASA ARC, GRC, and LaRC. AFRC also provided some live manned aircraft used as intruders for both configurations. Additionally, AFRC provided NASA 870, "Ikhana" Predator B (General Atomics Aeronautical Systems, Incorporated, Poway, California) as the unmanned aircraft ownship platform for Configuration 1 encounters within the R-2515 airspace.

- NASA GRC: NASA GRC was the participating test organization for all test missions flown with the NASA 608 T-34C (Beechcraft Corporation, Wichita, Kansas) aircraft. GRC provided the communication and control system interface and the UAS surrogate ownship aircraft for use during FM flights. Although initially planned, the NASA GRC S-3B Viking aircraft (Lockheed Corporation, now Lockheed Martin, Bethesda, Maryland) was not available for use as a high-speed ownship/intruder during Configuration 1 testing.

- NASA LaRC: NASA LaRC provided a SS algorithm (Stratway+) that was displayed and evaluated by subject pilots during flight encounters.

- GA-ASI: GA-ASI provided hardware, software, and integration support on the Ikhana UAS and specifically the Due Regard Radar (DRR). GA-ASI also provided pairwise encounter requirements for autonomous aircraft response maneuvers to TCAS alerting, as well as a SS algorithm, the Conflict Prediction and Display System (CPDS), for evaluation.

- Honeywell International, Inc.: Honeywell provided the software for the Surveillance Tracking Module (STM) prototype that contained the Honeywell Fusion Tracker. Honeywell also provided a TCAS II equipped intruder aircraft (N3GC) in support of both configurations. The N3GC aircraft had onboard TCAS recording capability, and that recorded data were made available to the rest of the FT3 test team to support data analysis.

In order to coordinate among these multiple and cross-center stakeholders, an Operations Working Group (OWG) was created for FT3. The OWG, which met weekly on Tuesdays and fortnightly on Fridays prior to testing, discussed all FT3 ground and flight operations topics. The working group was responsible for flight planning and coordination, assigning actions items, safety concerns which would feed into the System Safety Working Group (SSWG), hardware integration and testing discussion, training, and readiness. The OWG was responsible for a large part of the successes in FT3.

\section{Flight-Test Period, Configuration, and Equipage}

NASA 870, known as Ikhana, served as the ownship for the Configuration 1 flight-test series. NASA 608, the GRC T-34C aircraft, served as the ownship for the Configuration 2 flight-test series. Flight-test encounter setups included a single ownship versus a single intruder or a single ownship versus multiple intruders (two maximum). The intruder role was supported by multiple aircraft due to availability and crew rest considerations. All aircraft that participated in this flight test were equipped with navigation systems that use a global positioning system (GPS). All manned intruder aircraft were equipped with TCAS, and the Honeywell C90 King Air was equipped with TCAS II version 7.1. The aircraft required to complete the test series are identified in Table 1. Flight crew are identified in Table 2.

The flight-test period spanned from June 15, 2015 to August 12, 2015. The flight days are detailed in Table 3. Configuration 1 had one check out flight and 11 data collection flights, while Configuration 2 had 12 check out type flights and 3 data collection flights. Along with the aircraft and flight crew assets, an operations mission control team was utilized to manage the overall test effort. The test conductor (TC) was responsible for overall mission success and the coordination of all test assets. The test director (TD) provided flight safety oversight and supported the test conductor by performing all back channel and engineering channel coordination. The Test coordinator (TCOR) acted as the scribe and performed control room supporting tasks. The mission control team was located in the NASA AFRC SAF mission control room for all test missions performed during FT3. Furthermore, engineering coordinators in the LVC, Ikhana GCS, and ARC virtual ATC/pilot coordination facility supported the operation. Table 4 breaks out these teams based on configuration. 
Table 1. Aircraft equipage including sensors, configuration, and additional information. Ownships are highlighted in green, while intruders are in red.

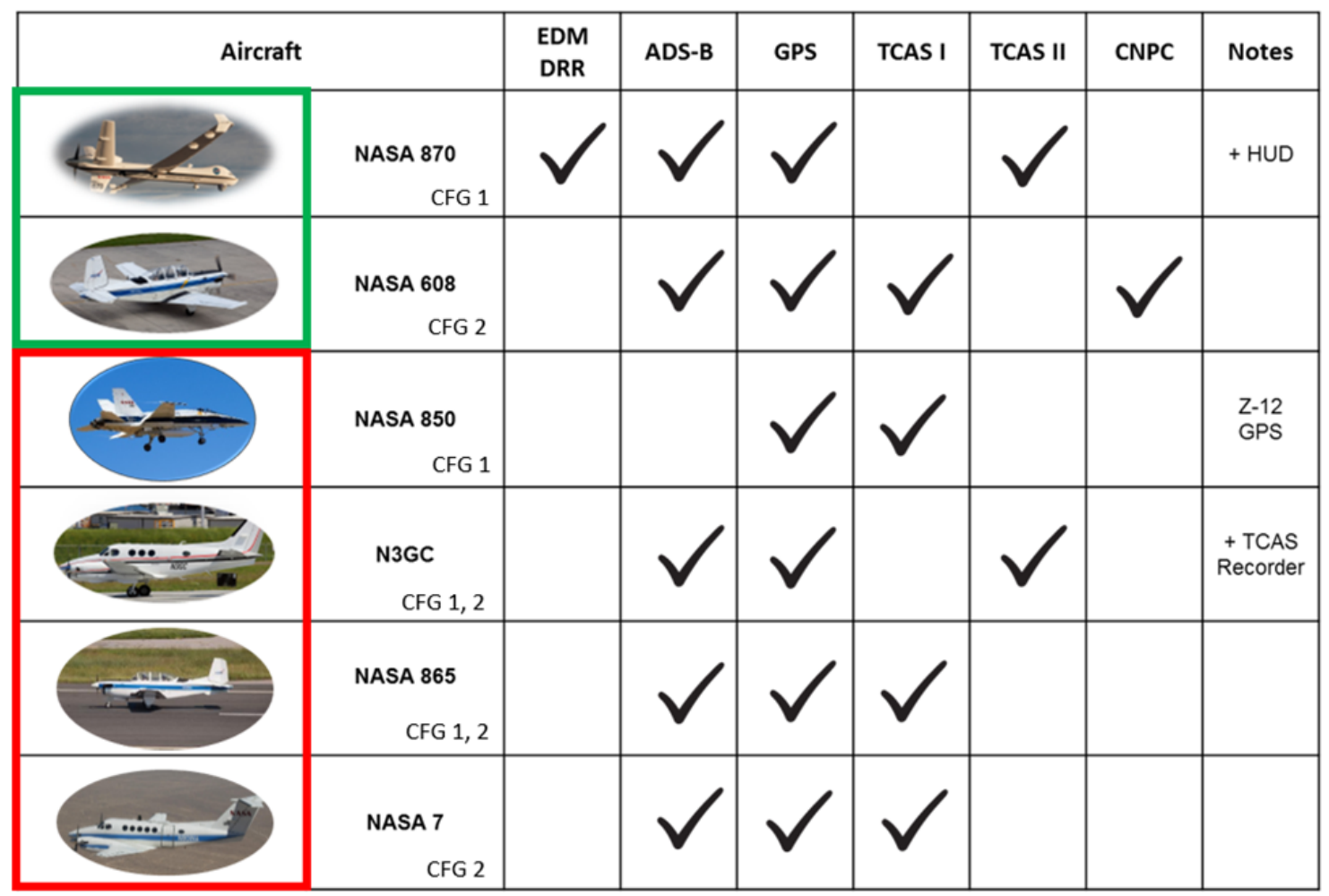

Table 2. Flight Test Series 3 aircraft and flight crew.

\begin{tabular}{|l|l|l|}
\hline \multicolumn{1}{|c|}{ Aircraft } & \multicolumn{1}{c|}{ Role } & NASA Pilots \\
\hline NASA 870 MQ-9 (Ikhana) & Config. 1 Ownship & Air National Guard Pilots \\
\hline N3GC C90 King Air & & DET3 \\
\hline NASA 865 T-34C & Config. 1/2 Intruder & Honeywell Pilots \\
\hline NASA 850 F-18A & Config. 1/2 Intruder & NASA Pilots \\
\hline NASA 7 King Air & $\begin{array}{l}\text { Config. } 1 \text { High-Speed } \\
\text { Intruder }\end{array}$ & NASA Pilots \\
\hline NASA 608 T-34C & Config. 2 Intruder & NASA Pilots \\
\hline RGCS & $\begin{array}{l}\text { Config. } 2 \text { Surrogate } \\
\text { Ownship }\end{array}$ & GRC Pilots \\
\hline & Config. 2 GCS & GRC FTEs \\
\hline
\end{tabular}


Table 3. Summary of flights from Flight Test Series 3 for UAS-NAS, with data collection flights highlighted in green.

\begin{tabular}{|c|c|c|c|c|c|c|c|}
\hline \multicolumn{8}{|c|}{ Configuration 1} \\
\hline Fligh t & Name & Date & Hours & Encounters & A ircraft & SUT/Display & Type \\
\hline 0 & $\mathrm{CHK}$ & June 15,2015 & 6.9 & 0 & NASA 870 & Ikhana & System check-out \\
\hline 1 & DAT A1 & June 17,2015 & 5.0 & 15 & NASA 870, N3GC & Aut oResolver & Fly-through \\
\hline 2 & DAT A2 & June 18,2015 & 4.9 & 23 & NASA $870, N 3 G C$ & Aut oResolver & Fly-through \\
\hline 3 & DAT A3 & June 22,2015 & 4.5 & 20 & NASA 870, N3GC & Aut oResolver & Follow disp lay \\
\hline 4 & DAT A4 & June 24,2015 & 4.7 & 20 & NASA $870, N 3 G C$ & CPDS & T CAS, Radar \\
\hline 5 & DAT A 5 & June 26,2015 & 4.6 & 16 & NASA 870, N3GC, NASA 865 & CPDS & $\begin{array}{l}\text { Low altitude, } \\
\text { Mult iship, TCAS } \\
\text { sequential, T CAS }\end{array}$ \\
\hline 6 & DAT A6 & July 7,2015 & 4.8 & 22 & NASA $870, N 3 G C$ & Stratway+ & Follow disp lay \\
\hline 7 & DAT A7 & July 9,2015 & 4.8 & 23 & NASA 870, N3GC & Stratway+ & Follow disp lay \\
\hline 8 & DAT A8 & July 10,2015 & 4.6 & 20 & NASA 870, N3GC, NASA 865 & Stratway $+/$ CPDS & $\begin{array}{l}\text { Follow disp lay, } \\
\text { Mult iship / Radar }\end{array}$ \\
\hline 9 & DAT A9 & July 21,2015 & 4.8 & 20 & $\begin{array}{l}\text { NASA } 870, \text { NASA } 850 \\
\text { NASA } 865\end{array}$ & Stratway+ & $\begin{array}{l}\text { High speed in truder, } \\
\text { Mult iship }\end{array}$ \\
\hline 10 & DAT A 10 & July 22,2015 & 3.4 & 17 & NASA 870 , NASA 865 & Aut oResolver & Fly-through \\
\hline 11 & DAT A 11 & July 24,2015 & 3.2 & 16 & NASA 870 , NASA 865 & CPDS & T CAS, Zig-Zag, Radar \\
\hline \multicolumn{3}{|r|}{ Totals } & 56.2 & 212 & & & \\
\hline \multicolumn{8}{|c|}{ Configuration 2} \\
\hline Fligh t & Name & Date & Hours & Encounters & A ircraft & SUT/Display & Type \\
\hline 1 & GRC1 & July 13,2015 & 3.1 & 0 & NASA 608 & CNPC & $\begin{array}{l}\text { Charact erization flight } \\
\text { (GRC only) }\end{array}$ \\
\hline 2 & CST 1 & July 16,2015 & 1.3 & 0 & NASA 608 & CNPC & Check-out \\
\hline 3 & CST 2 & July 28,2015 & 3.1 & 2 & NASA 608, NASA 865 & CNPC & Check-out \\
\hline 4 & GRC2 & July 29,2015 & 2.0 & 0 & NASA 608 & INS & Check-out (GRC only) \\
\hline 5 & CST 3 & July 29,2015 & 1.9 & 0 & NASA 608 & $\mathrm{CNPC}$ & Check-out \\
\hline 6 & GRC3 & July 30,2015 & 1.1 & 0 & NASA 608 & CNPC & Check-out (GRC only) \\
\hline 7 & REH1 & August 3,2015 & 3.3 & 4 & NASA 608, NASA 7, N3GC & CNPC & Full mission rehearsal \\
\hline 8 & GRC4 & August 4,2015 & 2.8 & 0 & NASA 608 & CNPC & Check-out (GRC only) \\
\hline 9 & CST 4 & August 4,2015 & 2.9 & 2 & NASA 608, N3GC & $\mathrm{CNPC}$ & Check-out \\
\hline 10 & CST 5 & August 5,2015 & 3.0 & 5 & NASA $608, N 3 G C$ & CNPC & Check-out \\
\hline 11 & $\mathrm{REH} 2$ & August 6,2015 & 1.1 & 0 & NASA 608, NASA 865, N3GC & RGCS/HSI & Cancelled - weather \\
\hline 12 & REH3 & August 7,2015 & 2.8 & 1 & NASA 608, NASA 865, N3GC & RGCS/HSI & Full mission rehearsal \\
\hline 13 & DAT A 1 & A ugust 10,2015 & 2.8 & 8 & NASA 608, NASA 865, N3GC & RGCS/HSI & Dat a collect 1 \\
\hline 14 & DAT A2 & August 11,2015 & 2.7 & 8 & NASA 608, NASA 865, N3GC & RGCS/HSI & Dat a collect 2 \\
\hline 15 & DAT A3 & A ugust 12,2015 & 2.5 & 8 & NASA 608, NASA 865, N3GC & RGCS/HSI & Data collect 3 \\
\hline \multicolumn{3}{|r|}{ Totals } & 36.35 & 38 & & & \\
\hline
\end{tabular}

8

American Institute of Aeronautics and Astronautics 
Table 4. Mission team.

\begin{tabular}{|l|l|}
\hline NASA Test Conductor & Config. $1 / 2$ \\
\hline NASA Test Directors & Config. $1 / 2$ \\
\hline NASA Test Coordinator & Config. $1 / 2$ \\
\hline LVC Engineering Coordinator & Config. $1 / 2$ \\
\hline GCS Engineering Coordinator & Config. 2 \\
\hline Ames Ghost Controller & Config. 2 \\
\hline
\end{tabular}

\section{Flight-Test Information}

Flight Test Series 3 was an intricate operation that included multiple stakeholders, staging locations, and precise coordination. This section outlines the planning that was involved to perform Configurations 1 and 2, which both occurred within the R-2508 Complex.

\section{A. Operating Area}

The operating area for the Configuration 1 flight test occurred in the Restricted Airspace, R-2515, located at EAFB, along with the Buckhorn military operating area (MOA), with operations scheduled and coordinated through the Air Force Test Center (AFTC). Specific airspace scheduled each day during these flight tests included the Four Corners Area, Mercury Spin Area, overflight of the Precision Impact Range Area (PIRA) East/West, and the Buckhorn MOA. These areas within R-2515 are depicted within the yellow shaded area shown in Fig. 1.

This operating area was adequate for the majority of the Configuration 1 encounters. However, there were some encounters that required either or both the intruder and ownship to extend geographically north or west, remaining within R-2515, of the airspace. The extensions were required to either start or complete these encounters. For those encounters where an extension was required to accomplish the test encounter, approval from the controlling agency, Space Positioning Optical Radar Tracking (SPORT), was required. In some cases the extension was not permitted and the encounter was either terminated early or skipped. The Buckhorn MOA was used by the manned intruder aircraft (only) for many of the test encounters.

The operating area for the Configuration 2 flight test required both an R-2508 as well as an R-2515 clearance due to the length of the mission plan, and therefore, included additional organizational cross talk between High Desert Terminal Radar Approach Control Facility (TRACON) and SPORT controlling agencies. The Isabella MOA block $10,000 \mathrm{ft}$ to $16,000 \mathrm{ft}$ MSL and the western portion of R-2515 were used for this configuration. The primary working area for this configuration is shown in Fig. 2.

The fire mission route (depicted in green on Fig. 2) was the ownship route of flight. Given that ownship transited between the Isabella MOA and R-2515, prior coordination with Joshua and SPORT controllers was required to ensure a seamless communication flow from one agency to the next. Although on some of the sorties extra coordination was required, for the majority of these flights, no significant problems were noted.

It is important to note that NASA operations within R-2515 are subject to the priority of United States Air Force (USAF) programs under the AFTC. Generally speaking, NASA is given a general priority that is superseded by most other AFTC operations. Configuration 2 flights were impacted by this low prioritization and required several mitigations that were in one case acceptable, and in two other cases, were inadequate. On one occasion the sortie start time was changed to avoid an airspace conflict, which was acceptable to the test team. On two other occasions the ownship route of flight and the Intruder route needed modification to avoid R-2515 altogether. These modifications, however, were not adequate for the test team.

\section{B. Aircraft Staging and Locations}

During FT3 both intruders and ownship aircraft operated from three different locations. The Honeywell N3GC aircraft operated from Van Nuys, KVNY, for both configurations, and the NASA 608 aircraft operated from both Palmdale, KPMD (during systems check flights) and Bakersfield, KBFL, for the three Configuration 2 mission flights. All other aircraft, Ikhana and intruders, operated from AFRC, KEDW. The geographical separation resulted in some operational challenges that were overcome with mission planning. Figure 3 depicts the staging locations for each aircraft. 


\section{Weather}

FT3 mission rules and an Ikhana standard mission rule required all tests to be conducted in Visual Meteorological Conditions (VMC) and 3 statute miles of visibility with at least 1,000 ft of cloud clearance above and below planned block altitude. Additionally, other Ikhana standard mission rules prohibited flight into known icing conditions as well as transit through visible moisture for repositioning operations. All other participating aircraft complied with their operating limitations as defined by their respective flight manuals for repositioning operations.

No Configuration 1 flights were cancelled due to weather, and all flights were completed as originally scheduled. On Flight 5 the visibility was reduced (due to smoke/haze generated by the Lake fire), although still likely greater than 3 miles; this condition was considered a contributing factor for a mission rule violation when an encounter occurred without the intruder having a visual on Ikhana.

Configuration 2 was impacted by weather with one cancellation on August 6, 2015 when broken cloud layers impacted the northern half of the desired operating airspace. All other Configuration 2 flights were completed as scheduled; however, high winds aloft, greater than $30 \mathrm{kn}$, were noted on several occasions and needed to be accounted for when controlling each individual intercept. High winds aloft resulting in incorrect compensations were a contributing factor to two or possibly more individual encounters not achieving desired alerting results.

\section{Stand Alone Facility Mission Control Room}

The SAF, located at the NASA AFRC main building, was used by the operations team to coordinate, manage, and execute the flight test. The room was configured with three workstations and multiple support stations; one of the three workstations was dedicated to UAS-NAS operations while the other two were used to support other programs (though not concurrently). Each workstation was configured with a Digital Integrated Communications Electronic System (DICES) III voice communication system and several display monitors, shown in Fig. 4. Zeus, Test and Evaluation Command and Control System (TECCS), Ikhana video camera, and Vigilant Spirit Control Station (VSCS) traffic displays provided situational awareness (SA) and two way voice capability to the control room team for test execution.

\section{Control Displays}

The Raytheon (Waltham, Massachusetts) Solipsys Zeus system acted as the primary control display for both TC and TD positions. The Zeus system used surveillance radar information to provide time space position information (TSPI) to the test team. The imbedded range and bearing tool were used to maintain range SA in order to ensure mission rule visual required compliance when applicable. The use of Zeus as the SA and mission control tool for FT3 was required for mission success, and the test was completed with no safety incidents and one mission rule violation.

The upper right two displays (Fig. 4) were repeaters of the SUT data sourced from the LVC. Using these displays the LVC would pipe JADEM, Stratway+, CPDS, and radar information to the SAF. The upper left two displays were used as test support displays and included a repeater of the Ikhana head-up display (HUD) video, which provided TCAS advisory information as well as state information for Ikhana such as altitude, heading, and airspeed. Additional information was available on the upper left displays and included long range optics (LRO) (if active) and access to commercial weather sources.

\section{Test Coordinator Position}

Throughout the FT3 event an additional position was matured to support data collection. The test coordinator position (located to the right of the image in Fig. 4) was a simple workstation that included a desk, large monitor, and computer docking station. The workstation was not restricted to the secure intranet that the TC and TD position required and enabled access to the external network. The team was able to use public access tools such as online aircraft tracking tools, aviation maps, route plotting software, and word processing software products not available on the TC/TD computers.

The primary role for TCOR was to collect test data for use during debriefs as well as this paper. However, being able to access the online tools and additional software proved to be invaluable as it provided information Zeus could not, such as: takeoff and landing TSPI for KVNY, King Field, Seattle, Washington (KBFI), and KPMD; screen captures; simple encounter replay; weather information; access to all planning material; and other administrative data. The operations team found this workstation, mission control room position, and external tools as instrumental to supporting the overall flight-test execution.

\section{E. Mission Information}

Executing FT3 flights required significant coordination. Configuration 1 flights were planned at a rate of three flights per week due to the duration of each sortie and the amount of test cards executed per sortie. Furthermore, flying 
the encounters was user work load intensive with 10 minutes allocated to each encounter and setup required in between runs. Configuration 2 work load was considerably less intensive for the airborne participants as the subject pilot under test was now located in the RGCS, and the overall design of the Full Mission test provided a more controlled environment than is available to a pilot under test operating from an airborne aircraft.

As a pre-requisite to executing Configuration 1 flight tests, a T-1 crew briefing was accomplished the day prior to the event. The T-1 briefing covered, in detail, the following aspects related to the upcoming flight:

- Roll call

- Mission summary

- Mission timeline

- Weather/notice to airmen (NOTAM)s

- UAS status

- Mission information

- GCS status

- Airspace/airfield

- Support assets

- Contingencies

- Miscellaneous

- Flight card review

A flight could be delayed or postponed based on information discussed during the T-1 briefing. All team members were required to participate in the briefing either in person or remotely.

Configuration 2 flights did not require a T-1 briefing for each event. Given the static nature of the fireline route and intruder routes, a T-1 briefing for each flight was considered excessive and any changes were briefed at the preflight briefing conducted 2.5 hours prior to takeoff. Changes were minimal and largely constituted discussion of contingency plans for loss of airspace or weather effects.

All FT3 Configuration 1 flight briefings began at 0415 local time in order to make a 0600 local take off time. The morning briefings covered at a higher level the same information with emphasis on any changes from the previous $\mathrm{T}-1$ briefing. The intent was for this briefing to be about 15 minutes in length. A final go/no-go decision was made at this briefing. After the brief, the team was dismissed to prepare for the flight, and in some cases, additional crew familiarity training was conducted for each display SUT. The SAF was manned at approximately 0545 local time to support any systems troubleshooting or coordination efforts required by the supporting aircraft teams.

In general, flights were planned for approximately 5 hours. One hour of that total flight time was allocated to transit, altimeter calibration, and DAA system startup procedures. The limiting factor for the Ikhana was frequency coordination and typically required an OFF time of 1100 local time for both Satcom and line of sight (LOS) frequencies. For the intruders, fuel available was the limiting factor. The T-34C aircraft could only support up to 3.5 hours of flight. The King Air aircraft could support 4.0 hours, although on a few occasions the N3GC aircraft landed in Victorville, California (KVCV) for fuel and then returned to the test site, which provided the test team an additional 20 minutes of time aloft. Moreover, the longer transit times required by the N3GC aircraft due to operating out of KVNY had to be considered for fuel planning.

A flight debrief was mandatory in order to discuss the flight events of the day, identify any aircraft discrepancies, and discuss test inefficiencies that may have decreased the number of encounters and test objectives achieved. Action items were assigned for issues and lessons learned that needed to be closed out prior to the next flight. A post-flighttest-card review and high level data analysis was conducted as well. If the next flight occurred on the following day, a T-1 briefing was then conducted to review test objectives for that next flight; otherwise the T-1 briefing, as appropriate, was conducted prior to the next test opportunity.

Figures 5 and 6 show the Configuration 1 and 2 timelines, respectively. Start of test day for Configuration 1 flights was typically 0415 local time and completed around 1415 local time, while the Configuration 2 flights started at 1200 local time and the end of test day was approximately 1945 local time.

\section{F. Training and Qualifications}

All visiting flight crew team members were required to participate in a local area familiarization briefing and conduct a local area familiarization flight. In addition, all flight crew and mission team members were required to have obtained current crew resource management (CRM) training. The TC and TD were required to obtain a formal approval from the NASA AFRC Director of Flight Operations in order to serve in that capacity. The requirements for the FT3 test conductor were derived from NASA AFRC Mission Control Procedure. The requirements were tailored from the mission controller section. 


\section{Pre-Test Coordination and Training}

A training event was conducted approximately one month prior to the start of the test. Representatives from all aircraft participants, SUT stakeholders, and IT\&E operations were present. The following is a list of training and coordination conducted.

Administration/Motherhood:

- $\quad$ R-2508 annual refresher training-conducted by R-2508 representatives

- $\quad \mathrm{R}-2515$ detailed training-conducted by R-2515 SPORT representatives

- International Traffic in Arms Regulations (ITAR) constraints

- Basic flight administration expectations

Test Administration:

- Mission rules and Go/No-Go criteria

- Roles and responsibilities

- Terminology

- General flight day timeline

- Communication plan

- Altimeter check

- Success criteria

- Contingencies, aborts, and lost links

Test Execution:

- Specific encounters and test card overview

At the completion of this training event, all stakeholders and aircrew were considered prepared and ready to support the FT3 events in the planned airspace, by all oversight organizations.

\section{System Under Test Training}

SUT training was conducted closer to the actual flight date. Aircrew availability and subject matter expert (SME) availability were the two primary reasons that the training was conducted either as part of the T-1 briefing or following the flight briefing at $0415 \mathrm{~L}$. This training was used to inform the aircrew who would be executing the flight, and what each SME was expecting from them. The following questions were addressed during these exchanges.

- Test configuration: What does the SME/researcher want; on, off, or de-energized?

- Maneuver type: Maneuvering (mitigated) or non-maneuvering (unmitigated)?

- Guidance type: Will the SUT provide directive or descriptive guidance?

- Display under test familiarity: What display will the aircrew be using to gain SA and make a maneuver decision?

- Miscellaneous expectations: Is there anything specific to a particular SUT that the aircrew need to know?

Given that there were multiple SUT being evaluated during FT3, variations were observed in the quantity and quality of training that the aircrew received. Training conducted by the SME on the CPDS system was considered the most thorough, timely, and informative. The CPDS training was conducted the day prior to the flight in a separate presentation with just the operations team present. Representations of CPDS in both picture format as well as a replay of previous simulated events were presented to the crew. In some cases, training and explanation of the SUT were required during the conduct of the flight. Had the training sessions been more thorough, using the CPDS training as an example, more efficiencies would have been gained by the test team and potentially better data collected.

\section{G. Altimeter Calibration}

An altimeter calibration was required for all encounters where the vertical separation between intruders and ownship was less than $500 \mathrm{ft}$. The mission rule was enforced for Configuration 1 flights; however, during Configuration 2, it was waived and not required due to all aircraft having a pilot on board and practicing see and avoid.

\section{Configuration 1}

The altimeter calibration was designed to take out the standard errors found within the pitot-static systems in order to ensure the planned vertical separation was as close to planned as possible. According to Federal Aviation Requirement (FAR) 91.411 and 14 CFR Part 43, Appendix E, aircraft pitot-static systems must be within $75 \mathrm{ft}$ of field elevation when dialed into the local altimeter setting. Additional errors come with changes in altitude and airspeed. Since some of the planned encounters were with a $200-\mathrm{ft}$ vertical separation, it was possible to be much closer with the errors identified above if they were not mitigated with the calibration.

12

American Institute of Aeronautics and Astronautics 
The calibration was conducted at a flight condition that closely approximated all the planned encounters; 140 KIAS and 13,000 ft MSL. In order to accomplish calibration, Ikhana acted as the lead aircraft with intruder aircraft joining on the Ikhana wing in close formation (one aircraft at a time for multiship missions). The Ikhana platform set standard $29.92 \mathrm{inHg}$, and the other aircraft adjusted their altimeter settings to indicate the same altitude readout. At those conditions each participating aircraft observed the difference from Ikhana. The N3GC aircraft consistently showed $60 \mathrm{ft}$-high and the NASA 865 aircraft 100-ft high. The altimeter calibration was performed using the flight card shown in Fig. 7.

\section{Configuration 2}

Although the Configuration 2 encounters were planned at 400 -ft altitude separation, the test team received approval to waive the altimeter calibration as the conduct of such would require approximately 30 minutes to complete, with limited technical and no safety value. For the following reasons the team elected to exclude the altimeter calibration:

- All aircraft set local altimeter settings.

- All participating aircraft are both properly maintained (24-month certification) and perform a ground altimeter check daily based off of known field elevation with local altimeter set $( \pm 75 \mathrm{ft}$ ) prior to takeoff according to the Federal Aviation Administration Aeronautical Information Manual (AIM) 7-2-3, and 14 CFR Part 43, Appendix E.

- All aircraft are TCAS equipped.

- Ownship will be maneuvering (lateral or vertical) away from conflict.

- Configuration 2 encounters are SS alerting encounters where the alerting threshold is 120 seconds prior to the closest point of approach (CPA).

- All participating aircraft are manned and all encounters require visual identification (VID) by $1 \mathrm{nmi}$ between aircraft based off of the TCAS Mission Rule (MR) FT3-9.

- Altimeter calibration data were not required for user interface SUT.

All Configuration 2 encounters were less than 400-ft altitude separation. The team elected to not conduct an altimeter calibration during these flights which impacted operations in the following ways. Positively, the team was able to conduct two fireline route data collection runs per test day. Had an altimeter calibration been conducted, the ability to conduct two runs may have been limited or not possible. However, in some cases, the 400 -ft separation was too great and failed to trigger the appropriate SUT alerting. Had the runs been conducted at $300 \mathrm{or} 200 \mathrm{ft}$ of separation, more encounters would have successfully triggered the desired alerting.

\section{H. Safety and Mission Rules}

All operations were conducted in accordance with NASA AFRC safety policies. A safety representative was present for all operations planning and was responsible for chairing the SSWG. All encounters and configurations were concurred with by the safety representative. The following mission rules were developed in a coordinated effort with the need to maintain approved levels of safety paramount.

Table 5 mission rules were used during Configuration 1 flights. They comprised two sections: the first section is the standard to Ikhana project rules and independent of the supported project; the second being specific to FT3. 
Table 5. Configuration 1 mission rules.

\begin{tabular}{|c|c|c|c|}
\hline $\begin{array}{c}\text { Rule } \\
\#\end{array}$ & Rule description - flight & Rationale/hazard report & Notes \\
\hline \multicolumn{4}{|c|}{ Ikhana standard } \\
\hline 1 & $\begin{array}{l}\text { Any team member may call an abort for pilots to } \\
\text { abort the flight at any time for safety reasons. }\end{array}$ & SOP, FT3-01, FT3-02, FT3-07 & \\
\hline 2 & $\begin{array}{l}\text { Only authorized AFRC employees and AFRC } \\
\text { approved pilots are permitted to operate the aircraft. }\end{array}$ & $\begin{array}{l}\text { Restrict pilots/operators to the } \\
\text { authorized group }\end{array}$ & \\
\hline $3 \mathrm{a}$ & $\begin{array}{l}\text { Only authorized AFRC employees and AFRC } \\
\text { approved system monitors are permitted to operate } \\
\text { the GCS. }\end{array}$ & $\begin{array}{l}\text { Restrict system monitors to the } \\
\text { authorized group }\end{array}$ & \\
\hline $3 b$ & $\begin{array}{l}\text { Only authorized AFRC employee and AFRC } \\
\text { approved Flight Systems Engineers (FSEs) are } \\
\text { permitted to assist the PIC and operate Payloads } \\
\text { from PSO2. }\end{array}$ & $\begin{array}{l}\text { Restrict FSEs to the authorized } \\
\text { group }\end{array}$ & \\
\hline 4 & $\begin{array}{l}\text { Ikhana will be operated according to FAA, AFRC, } \\
\text { USAF, CBP, and General Atomics standard and } \\
\text { emergency procedures. }\end{array}$ & $\begin{array}{l}\text { SOP, AFRC aircraft checklist } \\
\text { for hosting; Space Act } \\
\text { Agreement, FT3-01, FT3-03 }\end{array}$ & \\
\hline 5 & $\begin{array}{l}\text { Flight will remain within R-2515 and in accordance } \\
\text { with any applicable COA restrictions for Predator } \\
\text { B. }\end{array}$ & SOP & \\
\hline 6 & No envelope expansion tests will be performed. & FT3-05, FT3-06, FT3-13 & \\
\hline 8 & $\begin{array}{l}\text { Flights will be conducted in VMC conditions of no } \\
\text { more than moderate turbulence. }\end{array}$ & $\begin{array}{l}\text { SOP } \\
\text { COA requirement - VMC }\end{array}$ & \\
\hline 9 & No flight in known icing conditions. & $\begin{array}{l}\text { Standard Hazard Mitigation } \\
\text { No de-icing capability }\end{array}$ & \\
\hline 10 & $\begin{array}{l}\text { No flight through opaque clouds, nor sustained } \\
\text { flight through translucent clouds. }\end{array}$ & $\begin{array}{l}\text { Standard Hazard Mitigation } \\
\text { No de-icing capability } \\
\text { Laminar flow wing }\end{array}$ & \\
\hline 11 & Monitor weather forecasts for icing conditions. & $\begin{array}{l}\text { Standard Hazard Mitigation } \\
\text { No de-icing capability }\end{array}$ & \\
\hline 12 & No flight over densely populated areas. & $\begin{array}{l}\text { Standard Hazard Mitigation, } \\
\text { Dryden Range Mission Rule }\end{array}$ & \\
\hline 13 & No flights above $45,000 \mathrm{ft}$. & $\begin{array}{l}\text { DEEC envelope clearance has } \\
\text { only been conducted to } 45,000 \mathrm{ft}\end{array}$ & \\
\hline 14 & $\begin{array}{l}\text { Inside R-2515, the AFRC/EAFB RSO has real-time } \\
\text { directive authority, including vehicle destruction, to } \\
\text { the Ikhana pilot. Note: RSO responsibility and } \\
\text { authority may be delegated to the Ikhana PIC as a } \\
\text { result of RSO recommendation and Tech Brief } \\
\text { Committee concurrence. }\end{array}$ & Range Safety Plan & \\
\hline 15 & $\begin{array}{l}\text { If returning with a controllable, but compromised } \\
\text { aircraft, to the best degree possible, the flight path } \\
\text { will avoid over flight of populated areas and major } \\
\text { roads to the maximum extent possible. }\end{array}$ & $\begin{array}{l}\text { AFRC process for Range Safety } \\
\text { Requirement to avoid } \\
\text { population areas, FT3-14 }\end{array}$ & \\
\hline 16 & $\begin{array}{l}\text { If generator out, land at EDW } 22 / 04 \text { with battery } \\
\text { bus voltage at least } 23.6 \mathrm{~V} \text {, otherwise, make a } \\
\text { lakebed landing. }\end{array}$ & $\begin{array}{l}\text { Provides at least }>/=20 \text { minutes } \\
\text { of battery power to land, taxi, } \\
\text { and shutdown aircraft }\end{array}$ & \\
\hline
\end{tabular}

14

American Institute of Aeronautics and Astronautics 
Table 5. Continued.

\begin{tabular}{|c|c|c|c|}
\hline $\begin{array}{c}\text { Rule } \\
\#\end{array}$ & Rule description - flight & Rationale/hazard report & Notes \\
\hline \multicolumn{4}{|c|}{ FT3 specific } \\
\hline FT3-1 & $\begin{array}{l}\text { Test runs will be conducted in VMC with inflight } \\
\text { visibility at least } 3 \text { statute miles. }\end{array}$ & Standard Hazard Mitigation & \\
\hline FT3-2 & $\begin{array}{l}\text { Test runs will be conducted clear of clouds and with } \\
\text { at least } 1000 \text {-ft cloud clearance above and below } \\
\text { the planned test block, including abort maneuvers. }\end{array}$ & $\begin{array}{l}\text { FTP, Standard Hazard } \\
\text { Mitigation }\end{array}$ & \\
\hline FT3-4 & $\begin{array}{l}\text { At the beginning of each test run, pilots will check } \\
\text { their navigational system accuracy; runs with less } \\
\text { than } 500 \text {-ft vertical separation will be aborted if the } \\
\text { predicted error exceeds } 0.1 \mathrm{nmi} \text {. }\end{array}$ & $\begin{array}{l}\text { FTP, Mission Rule, FT3-01, } \\
\text { FT3-02 }\end{array}$ & $\begin{array}{l}\text { Acceptable } \\
\text { error is } \\
0.1 \mathrm{nmi}\end{array}$ \\
\hline FT3-5 & $\begin{array}{l}\text { All participating aircraft will maintain at least } \\
1000 \text {-ft vertical separation from other participating } \\
\text { aircraft between test runs unless visual. Maintain } \\
\text { deconfliction altitude noted on each test card or as } \\
\text { instructed. }\end{array}$ & $\begin{array}{l}\text { FTP, Standard Hazard } \\
\text { Mitigation, FT3-03 }\end{array}$ & \\
\hline FT3-6 & $\begin{array}{l}\text { Intruder aircraft will not climb/descend to scenario } \\
\text { altitude until Ikhana has reestablished its } \\
\text { deconfliction altitude. }\end{array}$ & FTP, Mission Rule, FT3-03 & \\
\hline FT3-7 & $\begin{array}{l}\text { The test run will be aborted if a UAS loses LOS } \\
\text { link. }\end{array}$ & Hazard Mitigation FT3-03 & $\begin{array}{l}\text { This MR is } \\
\text { not applicable } \\
\text { during low } \\
\text { altitude test } \\
\text { runs. }\end{array}$ \\
\hline FT3-8 & $\begin{array}{l}\text { The test run will be reset if timing constraints of } \pm 5 \\
\text { to } \pm 10 \text { seconds (as defined for each test encounter) } \\
\text { cannot be met by a minimum of } 120 \text { seconds prior } \\
\text { to CPA. }\end{array}$ & FTP, Hazard Mitigation & $\begin{array}{l}\text { Number of } \\
\text { seconds is } \\
\text { test run/point } \\
\text { specific } \\
\text { Some test } \\
\text { runs/points } \\
\text { will be } \\
\text { greater than } \\
120 \text { seconds } \\
\text { of steady } \\
\text { state } \\
\text { variables. }\end{array}$ \\
\hline FT3-9 & $\begin{array}{l}\text { For all test encounters where vertical separation is } \\
\text { less than } 500 \mathrm{ft} \text {, the test run will be aborted if all } \\
\text { manned aircraft do not have visual on all } \\
\text { participating aircraft at any point inside } 1 \mathrm{nmi} \\
\text { separation. }\end{array}$ & FTP, Hazard Mitigation & \\
\hline $\begin{array}{l}\text { FT3- } \\
10\end{array}$ & $\begin{array}{l}\text { During auto TCAS runs, the test run will be aborted } \\
\text { if Ikhana begins an automatic maneuver in the } \\
\text { opposite direction than expected for that test } \\
\text { encounter. }\end{array}$ & Hazard Mitigation, FT3-01 & \\
\hline $\begin{array}{l}\text { FT3- } \\
11\end{array}$ & $\begin{array}{l}\text { The test run will be aborted if any aircraft is off- } \\
\text { track by more than } 0.1 \mathrm{nmi} \text { inside } 1 \text { minute to CPA. }\end{array}$ & FTP, Mission Rule, FT3-01 & \\
\hline $\begin{array}{l}\text { FT3- } \\
12\end{array}$ & $\begin{array}{l}\text { The manned intruder pilot will not follow a TCAS } \\
\text { contrary to the pre-briefed abort procedures unless } \\
\text { they have reason to believe the RA is generated by } \\
\text { non-participating traffic and they have SA on } \\
\text { ownship position. }\end{array}$ & FTP, Hazard Mitigation & \\
\hline
\end{tabular}


Table 5. Concluded.

\begin{tabular}{|c|c|c|c|}
\hline $\begin{array}{c}\text { Rule } \\
\#\end{array}$ & Rule description - flight & Rationale/hazard report & Notes \\
\hline $\begin{array}{l}\text { FT3- } \\
13\end{array}$ & $\begin{array}{l}\text { Update of the appropriate Ikhana Lost Link Mission } \\
\text { variables (Entry Waypoint, ILLH, ILLA) will be } \\
\text { verified, by both aircrew and the Mission Director, } \\
\text { prior to commencing each test run. }\end{array}$ & $\begin{array}{l}\text { FTP, Hazard Mitigation, FT3- } \\
01, \text { FT3-03 }\end{array}$ & $\begin{array}{l}\text { Lost link } \\
\text { mission } \\
\text { identified on } \\
\text { each test card. }\end{array}$ \\
\hline $\begin{array}{l}\text { FT3- } \\
14\end{array}$ & $\begin{array}{l}\text { When not on a test run, Ikhana crew will ensure } \\
\text { SAAP Maneuver Mode is set to ADVISORY or } \\
\text { OFF. }\end{array}$ & Mission Rule, FT3-02 & \\
\hline $\begin{array}{l}\text { FT3- } \\
15\end{array}$ & $\begin{array}{l}\text { Anytime below } 5000-\mathrm{ft} \text { AGL, SAAP auto } \\
\text { maneuvering modes will be ADVISORY or OFF. }\end{array}$ & Mission Rule, FT3-02, FT3-19 & \\
\hline $\begin{array}{l}\text { FT3- } \\
16\end{array}$ & $\begin{array}{l}\text { Confirm each aircraft's nav system time matches } \\
\text { the UTC time hack given in the pre-flight brief. }\end{array}$ & Mission Rule & \\
\hline $\begin{array}{l}\text { FT3- } \\
17\end{array}$ & $\begin{array}{l}\text { The test run will be aborted if any aircraft is off } \\
\text { altitude by more than } 50 \mathrm{ft} \text { toward other aircraft } \\
\text { inside } 1 \text { minute to CPA. }\end{array}$ & $\begin{array}{l}\text { FTP, Standard Hazard } \\
\text { Mitigation, FT3-01 }\end{array}$ & \\
\hline $\begin{array}{l}\text { FT3- } \\
18\end{array}$ & $\begin{array}{l}\text { A } 200 \text {-foot minimum vertical separation shall be } \\
\text { maintained for all test geometries. }\end{array}$ & Mission Rule & \\
\hline $\begin{array}{l}\text { FT3- } \\
19\end{array}$ & $\begin{array}{l}\text { Flight operations outside of the approved mission } \\
\text { flight envelope for Ikhana are prohibited during test } \\
\text { encounters }\end{array}$ & FT3-14 & \\
\hline $\begin{array}{l}\text { FT3- } \\
20\end{array}$ & $\begin{array}{l}\text { A side-by-side altitude calibration will be } \\
\text { performed between aircraft for any mission that } \\
\text { includes an encounter less than } 500-\mathrm{ft} \text { vertical } \\
\text { separation. }\end{array}$ & Mission Rule & $\begin{array}{l}\text { Applicable to } \\
\text { Configuration } \\
1 \mathrm{a} \text { and } 1 \mathrm{~b}\end{array}$ \\
\hline
\end{tabular}

Table 6 lists the mission rules applicable to Configuration 2 flights. Since Ikhana was not participating, the list is significantly reduced and supplanted with platform specific flight manual operational limitations. 
Table 6. Configuration 2 mission rules.

\begin{tabular}{|c|c|c|c|}
\hline $\begin{array}{c}\text { Rule } \\
\#\end{array}$ & Rule description - flight & Rationale/hazard report & Notes \\
\hline \multicolumn{4}{|c|}{ FT3 Configuration 2 Specific } \\
\hline $\begin{array}{l}\text { FT3- } \\
1\end{array}$ & $\begin{array}{l}\text { Test runs will be conducted in VMC with inflight } \\
\text { visibility at least } 3 \text { statute miles. }\end{array}$ & Standard Hazard Mitigation & \\
\hline $\begin{array}{l}\text { FT3- } \\
2\end{array}$ & $\begin{array}{l}\text { Test runs will be conducted clear of clouds and with } \\
\text { at least } 1000 \text {-ft cloud clearance above and below } \\
\text { the planned test block, including abort maneuvers. }\end{array}$ & $\begin{array}{l}\text { FTP, Standard Hazard } \\
\text { Mitigation }\end{array}$ & \\
\hline $\begin{array}{l}\text { FT3- } \\
4\end{array}$ & $\begin{array}{l}\text { At the beginning of each test run, pilots will check } \\
\text { their navigational system accuracy; runs with less } \\
\text { than } 500 \text {-ft vertical separation will be aborted if the } \\
\text { predicted error exceeds } 0.1 \text { nmi. }\end{array}$ & $\begin{array}{l}\text { FTP, Mission Rule, FT3-01, } \\
\text { FT3-02 }\end{array}$ & $\begin{array}{l}\text { Acceptable } \\
\text { error is } 0.1 \mathrm{nmi}\end{array}$ \\
\hline $\begin{array}{l}\text { FT3- } \\
9\end{array}$ & $\begin{array}{l}\text { For all test encounters where vertical separation is } \\
\text { less than } 500 \mathrm{ft} \text {, the test run will be aborted if all } \\
\text { manned aircraft do not have visual on all encounter } \\
\text { aircraft at any point inside } 1 \mathrm{nmi} \text { separation. }\end{array}$ & FTP, Hazard Mitigation & $\begin{array}{l}\text { Lateral and } \\
\text { Vertical vectors } \\
\text { may be applied } \\
\text { prior to an abort } \\
\text { to maintain } \\
\text { applicable } \\
\text { separation. }\end{array}$ \\
\hline $\begin{array}{l}\text { FT3- } \\
12\end{array}$ & $\begin{array}{l}\text { The manned intruder pilot will not follow a TCAS } \\
\text { contrary to the pre-briefed abort procedures unless } \\
\text { they have reason to believe the RA is generated by } \\
\text { non-participating traffic and they have SA on } \\
\text { ownship position. }\end{array}$ & FTP, Hazard Mitigation & \\
\hline $\begin{array}{l}\text { FT3- } \\
16\end{array}$ & $\begin{array}{l}\text { Confirm each aircraft's nav system time matches } \\
\text { the UTC time hack given in the pre-flight brief. }\end{array}$ & Mission Rule & \\
\hline $\begin{array}{l}\text { FT3- } \\
18\end{array}$ & $\begin{array}{l}\text { A } 200-\mathrm{ft} \text { minimum vertical separation shall be } \\
\text { maintained for all test geometries. }\end{array}$ & Mission Rule & \\
\hline $\begin{array}{l}\text { FT3- } \\
21\end{array}$ & $\begin{array}{l}\text { Intentional ownship vertical maneuvers towards } \\
\text { intruder aircraft shall not be made within } \\
60 \text { seconds of CPA during live intruder encounters. }\end{array}$ & Mission Rule & \\
\hline
\end{tabular}

Additionally, during all FT3 flights a senior operations representative (SOR) was required to be present in the SAF. The SOR acted as a spokesperson for the NASA AFRC Director of Flight Operations and their responsibility was to monitor general conduct of the flight-test operations, monitor the team's real-time decisions, and initiate the Aircraft Incident Response Procedure in the case of an aircraft mishap.

\section{Flight Execution}

The Flight Test Series 3 was split into two distinct phases: Pairwise Encounters (Configuration 1) and FM Encounters (Configuration 2).

To test the multiple cases that a UAS could encounter using the specific SUT in the NAS, a variety of encounters were planned for every stakeholder. For each scenario, an intruder(s) would fly towards the ownship at a relative angle against the ownship path. The angles were chosen to test the full capability of each of the equipped sensors, with angles designed as far as the radar azimuth could reach. Encounters also tested the fidelity of the systems to sense changes in altitude. Several permutations included the ownship or intruder climbing or descending while the other stayed in level flight, or a double "blunder" maneuver. Each type of maneuver had its own objective for SS or CA.

An extensive flight-test matrix was created to track over 300 unique encounters. The matrix included information on which SUT was being tested, angles of the intruder(s), groundspeeds, altitudes, initial points (IP), CPA, flight path coordinates, priority, sensors selected, tolerances, and other pertinent information. The flight-test matrix was designed to automatically populate FT3 flight cards with this information. Additionally, a wind adjust matrix for CPA timing was created for encounters requiring to fly an airspeed (as opposed to groundspeed).

Coordination between the ownship, SAF, and intruder for timing at CPA and individual maneuver requirements from the SUT researchers was critical for mission success. Mission briefs (involving all aircraft crew and test support 
personnel) and training were performed prior to each Configuration 1 flight due to the unique nature of daily encounters. These briefs/training were imperative in the success of Configuration 1.

\section{A. Configuration 1: Pairwise Encounters}

This test configuration evaluated the advisories generated by the SS and CA Algorithms fed by data from live aircraft during flight. Flight Test Configuration 1 was further defined into two distinct groups, Configuration 1a and 1b. Configuration 1a involved flight-test encounters using the NASA Ikhana aircraft as the low-speed ownship. Configuration $1 \mathrm{~b}$ planned for use of a high-speed ownship aircraft. However, the aircraft planned for Configuration $1 \mathrm{~b}$ ultimately could not support the FT3 event.

In these tests the Ikhana ownship aircraft was flown against either one or two manned intruder aircraft. Both SS and CA algorithms were evaluated. The SS algorithms were evaluated using both mitigated and unmitigated encounters. Unmitigated, also known as fly-through and non-maneuvering encounters, were designed for each aircraft to fly the route as planned all the way to the CPA regardless of the alerting displayed. These encounters evaluated each SUT ability to estimate trajectories, predict miss distances at CPA, and generate proper alerting and maneuver guidance. The mitigated encounters were designed for the test aircrew to maneuver the ownship aircraft away from the Collision Avoidance Threshold (CAT) or Near Mid-Air Collision (NMAC) thresholds and maintain a well-clear distance between intruder and ownship. Table 7 categorizes each SUT.

Table 7. Breakdown of SUTs for Configuration 1, with primary and secondary objectives and types of maneuvers noted.

\begin{tabular}{|l|l|l|l|l|l|}
\hline SUT & Researcher/Developer & SS & CA & Mitigated & Unmitigated \\
\hline JADEM & Ames Research Center & Primary & Secondary & Yes & Yes \\
\hline Stratway+ & Langley Research Center & Primary & Secondary & Yes & Yes \\
\hline CPDS & GA - ASI \& TU Delft & Primary & Secondary & Yes & No \\
\hline Radar & GA - ASI & Primary & Secondary & No & Yes \\
\hline TCAS & GA - ASI & Secondary & Primary & Yes & No \\
\hline
\end{tabular}

Based on requirements from researchers, a nomenclature was developed to capture the needs of each scenario. The name of each encounter included four parts:

- Type of encounter (low speed, high speed, or multiship).

- Altitude offset between the ownship and intruder(s) (If multiship, the smaller vertical profile would be represented).

- Vertical profile.

- Angle of the intruder flying relative to the ownship path (For some letter indices, two angles were defined to accommodate multiship encounters).

The full set of nomenclature definitions are shown in Fig. 8. This nomenclature would help define and distinguish encounters, and give a quick, simple assessment of the type of encounter being performed.

\section{Configuration la Low-Speed Ownship}

Configuration 1a encounters used a low-speed ownship ( $<210 \mathrm{KGS})$. Some of these encounters (noted) consisted of a high-speed intruder ( $\geq 210 \mathrm{KGS})$.

a. ARC (AutoResolver) Pairwise Encounter Geometries - The ARC low-speed ownship Pairwise Encounters were designed to test the AutoResolver/JADEM algorithm. The algorithm was further divided into two, AutoResolver 1 and 2, with different alerting thresholds. ARC encounters were divided in three types: fly-through/maneuvering climbs/descents/level (Fig. 9), fly-through alerting TCAS (Fig. 10), and high-speed intruder. The vertical profiles for the fly-through/maneuvering encounters is shown in Fig.11. The following is an explanation of each.

Aircraft in the fly-through scenarios flew toward a target CPA of 0-nmi horizontal offset. Actual CPA was not critical since any CPA could be compared to the CPA predictions. It was desirable, however, to fly close enough to 
trigger a SS alert. The maneuver encounters were scenarios in which the pilot maneuvered the aircraft as directed by the specific SS display.

These fly-through/maneuvering encounters tested various angles into: $0^{\circ}, 45^{\circ}, 90^{\circ}, 110^{\circ}, 180^{\circ}$, and a $45^{\circ}$ and $90^{\circ}$ blunder. All encounters had a minimum 1,000-ft vertical separation that was offset artificially within the algorithm, so as to make the ownship and intruder appear co-altitude.

The TCAS/Self Assurance/Sense and Avoid Interoperability (SSI) encounters were designed to evaluate interoperability between TCAS and SS systems. SS systems are expected to keep the ownship well clear of an intruder. Although well clear is not specifically defined to avoid alerting the intruder TCAS; alerting TCAS can generally be considered not well clear. Ideally, the SS alert would trigger long before the TCAS alert.

These encounters were designed simply as a fly-through to gather data. Because the vertical profile was planned to go as close as $300 \mathrm{ft}$, a build-up approach was used; the encounters were flown first at 1,000 ft, then $500 \mathrm{ft}$, and finally, $300 \mathrm{ft}$. To stay consistent, all of these encounters employed the 3,000-ft lateral separation (although only the 300 -ft encounters required the lateral offset). These encounters had an angle into of $0^{\circ}, 45^{\circ}$, and $90^{\circ}$.

The vertical profiles for all of ARC low-speed intruder encounters is shown in Fig. 11. For the flythrough/maneuver encounters, angles $0^{\circ}, 45^{\circ}$, and $90^{\circ}$ required climb/descent airspeed as opposed to groundspeed, and are explained in detail later in this paper. Angles $110^{\circ}, 180^{\circ}$, turning $45^{\circ}$, and turning $90^{\circ}$ had 1,000 - $\mathrm{ft}$ vertical separation. Fly-through alerting TCAS had 1,000-ft, 500-ft, and 300-ft separation.

As mentioned, ARC required cases with a high-speed intruder to mimic jet aircraft conditions. The angles for these encounters were $0^{\circ}, 45^{\circ}, 90^{\circ}$, and overtaking $180^{\circ}$. These encounters were done both as a fly-through and a maneuver performed with required 1,000-ft vertical separation, shown in Fig. 12.

b. ARC Indicated Airspeed Encounter Wind Matrix - ARC required some of their encounters to be run with indicated airspeed. Thus, a wind matrix was used to correlate to the established test paradigm of flying with groundspeed. To validate the ARC simulation results for AutoResolver/JADEM, a slightly different approach was required for their climbing and descending encounters. Because their simulations were built using KIAS as opposed to knots groundspeed (KGS), the researcher requested that all of these climb/descent encounters be flown with a constant airspeed. However, this posed a problem for CPA timing. All other encounters were designed with groundspeed in mind, so that daily variable winds aloft would not affect the timing of the encounter. To mitigate this problem for the ARC climb/descent encounters, a wind adjust matrix was built to help with timing and variable winds.

As depicted in Table 8, the wind adjust matrix used a spreadsheet format to calculate relative timing from the IP. Each series of climb/descent encounters (L13, L14, L15, and L16) were designed to start at a specific altitude. Using this altitude, a knots true airspeed (KTAS) was calculated for the desired airspeed. Once current winds were input (green boxes, wind speed, and wind direction) simple trigonometry was used to show the headwind the aircraft would experience for that encounter based on encounter angle. Distance adjust value was then calculated (more or less distance traveled for the encounter) based on headwind and the leg length. Although the researcher originally wished to communicate this distance adjust to the pilots, operationally it made more sense to communicate a time adjust. Therefore, two additional values were calculated: the groundspeed the aircraft would experience based on the headwind and true airspeed at altitude, and finally a time adjust was calculated using the simple formula time = distance/rate, using the distance adjust and groundspeed. 
Table 8. ARC wind adjust matrix.

\begin{tabular}{|c|c|c|c|c|c|}
\hline \multicolumn{6}{|c|}{ TIME BASED WIND DRIFT ADJUSTMENT FOR KIAS CLIMB/DESCENT ENCOUNTERS } \\
\hline \multicolumn{6}{|l|}{ Version: 22Jun2015 } \\
\hline Wind Speed (kt) & 10 & & + & \multirow{2}{*}{\multicolumn{2}{|c|}{$\begin{array}{l}\text { later IP crossing } \\
\text { earlier IP crossing }\end{array}$}} \\
\hline Wind Direction (deg) & 258 & & - & & \\
\hline Leg Length (min) & 3 & & & & \\
\hline \multicolumn{6}{|c|}{ L13 Series: Climbing Intruder, 140 KIAS, Initial Alt $=12500 \mathrm{ft}$} \\
\hline KTAS at Initial Alt = & 169 & & & & \\
\hline Encounter Angle & $\begin{array}{c}\text { Aircraft } \\
\text { Heading } \\
\text { (deg) }\end{array}$ & Headwind (kt) & $\begin{array}{c}\text { Distance } \\
\text { Adjust } \\
\text { (nmi) }\end{array}$ & $\begin{array}{c}\text { Ground } \\
\text { Speed }(k t)\end{array}$ & $\begin{array}{c}\text { Time } \\
\text { Adjust } \\
\text { (sec) }\end{array}$ \\
\hline A - 0 deg & 78 & -10.0 & 0.5 & 179.0 & 10.1 \\
\hline C - 45 deg & 33 & -7.1 & 0.4 & 176.1 & 7.2 \\
\hline D - 90 deg & 258 & 10.0 & -0.5 & 159.0 & -11.3 \\
\hline \multicolumn{6}{|c|}{ L14 Series: Descending Intruder, $140 \mathrm{KIAS}$, Initial Alt $=16000 \mathrm{ft}$} \\
\hline KTAS at Initial Alt = & 178.6 & & & & \\
\hline Encounter Angle & $\begin{array}{c}\text { Aircraft } \\
\text { Heading } \\
\text { (deg) }\end{array}$ & Headwind $(\mathrm{kt})$ & $\begin{array}{c}\text { Distance } \\
\text { Adjust } \\
\text { (nmi) }\end{array}$ & $\begin{array}{c}\text { Ground } \\
\text { Speed }(k t)\end{array}$ & $\begin{array}{c}\text { Time } \\
\text { Adjust } \\
\text { (sec) }\end{array}$ \\
\hline A - 0 deg & 78 & -10.0 & 0.5 & 188.6 & 9.5 \\
\hline C - $45 \mathrm{deg}$ & 33 & -7.1 & 0.4 & 185.7 & 6.9 \\
\hline D - 90 deg & 258 & 10.0 & -0.5 & 168.6 & -10.7 \\
\hline \multicolumn{6}{|c|}{ L15 Series: Climbing Ownship, $120 \mathrm{KIAS}$, Initial Alt $=12000 \mathrm{ft}$} \\
\hline KTAS at Initial Alt $=$ & 143.8 & & & & \\
\hline Encounter Angle & $\begin{array}{c}\text { Aircraft } \\
\text { Heading } \\
\text { (deg) }\end{array}$ & Headwind (kt) & $\begin{array}{c}\text { Distance } \\
\text { Adjust } \\
\text { (nmi) }\end{array}$ & $\begin{array}{c}\text { Ground } \\
\text { Speed }(k t)\end{array}$ & $\begin{array}{c}\text { Time } \\
\text { Adjust } \\
\text { (sec) }\end{array}$ \\
\hline A - 0 deg & 258 & 10.0 & -0.5 & 133.8 & -13.5 \\
\hline C- 45 deg & 258 & 10.0 & -0.5 & 133.8 & -13.5 \\
\hline D - 90 deg & 348 & 0.0 & 0.0 & 143.8 & 0.0 \\
\hline \multicolumn{6}{|c|}{ L16 Series: Descending Ownship, 120 KIAS, Initial Alt $=16000 \mathrm{ft}$} \\
\hline KTAS at Initial Alt = & 153.3 & & & & \\
\hline Encounter Angle & $\begin{array}{c}\text { Aircraft } \\
\text { Heading } \\
\text { (deg) }\end{array}$ & Headwind (kt) & $\begin{array}{c}\text { Distance } \\
\text { Adjust } \\
\text { (nmi) }\end{array}$ & $\begin{array}{c}\text { Ground } \\
\text { Speed }(k t)\end{array}$ & $\begin{array}{c}\text { Time } \\
\text { Adjust } \\
\text { (sec) }\end{array}$ \\
\hline A - 0 deg & 258 & 10.0 & -0.5 & 143.3 & -12.6 \\
\hline C- 45 deg & 258 & 10.0 & -0.5 & 143.3 & -12.6 \\
\hline D-90 deg & 348 & 0.0 & 0.0 & 153.3 & 0.0 \\
\hline
\end{tabular}

For each of the encounters of this type, the TC would ask the winds aloft for the climbing or descending aircraft. The values were input into the matrix, and the spreadsheet would automatically calculate a time adjust from the IP. The TC would then communicate this value back to the airborne players. A positive value indicated to the aircraft to 20

American Institute of Aeronautics and Astronautics 
begin the descent that many seconds after IP crossing. A negative value indicated to the aircraft to begin the descent that many seconds before the IP crossing.

During later flights and for simplicity, values were adjusted to be called out in increments of 5 seconds since the aircrew found this solution to be easier to implement while performing the dynamic encounters. This compromise led to successful climb/descent encounters and the researcher received good data when the matrix was used correctly.

c. LaRC (Stratway+) Pairwise Encounter Geometries - NASA LaRC provided SS encounters to test and collect data on the SS algorithm Stratway+ (now called Detect \& AvoID Alerting Logic for Unmanned Systems (DAIDALUS)). The LaRC series of maneuvering scenarios was designed to collect data to validate CPA predictions and validate the Stratway+ solution well-clear band data during live flight-test conditions. The encounters also operated on the edge of the TCAS resolution advisory (RA) envelope and ensured Stratway+ guidance provided maneuver bands to operate outside the RA envelope of TCAS II. Most encounters were set at 3,000-ft lateral planned CPA with 400- or 500-ft vertical offset.

All of the LaRC encounters required a lateral maneuver (mitigated) and were divided into low-speed ownship level/climb/descent/double blunder (Figs. 13, 14, and 15), low-speed intruder multiship (Figs. 16, 17, and 18), highspeed intruder (Fig. 19), and high-speed intruder multiship (Figs. 20 and 21).

Encounter geometries were flown at $0^{\circ}, 20^{\circ}, 45^{\circ}, 90^{\circ}$, and $135^{\circ}$ angle into. The $135^{\circ}$ geometry was of particular interest to evaluate the effectiveness of Stratway+ in a late intruder discovery scenario where radar is operating at the edge of its azimuth. Multiple runs were conducted with varying sensor selections.

Vertical maneuvers represented further evaluation of the Stratway+ algorithm performance and also engaged the TCAS II RA envelope. Additionally, a double blunder encounter was added for FT3, to gauge the solution space of Stratway+. Climb/descent encounters had a 500-ft vertical separation and required a 1,000-fpm climb or descent.

The multiple intruder series of scenarios were designed to constrain the solution space presented to the pilot and to evaluate the Stratway+ solution well-clear band data. Stratway+ was designed to present well-clear maneuver space as the union of all threats and a solution space which provides guidance well clear of all intruders. These scenarios increased the complexity of the solution band data presented to the pilot as there were solutions which were constrained to either side of the aircraft course. For an SAA system to operate effectively in the NAS, it must be able to solve a multiple intruder scenario even though this type of setup may be a very low probability situation.

All multiship encounters had a 500-ft vertical separation between ownship and intruder, and all were level flight/level maneuvers to introduce the first stage of this complexity which is planned to be continued in Flight Test (FT) 4 . The multiship encounters included several permutations: $0^{\circ} / 0^{\circ}, 20^{\circ} / 20^{\circ}, 0^{\circ} / 45^{\circ}, 45^{\circ} / 90^{\circ}, 0^{\circ} / 90^{\circ}, 0^{\circ} / 135^{\circ}$, and 90\% $/ 135^{\circ}$ angles into, as depicted in Figs. 16, 17, and 18.

The high-speed intruder encounter series of scenarios were designed to evaluate the effectiveness of the Stratway+ algorithm when engaging intruders operating at speeds typically encountered with commercial jet transport aircraft transiting below Class A airspace. The increased intruder speed shortened the available pilot reaction time and provided faster closure while the ownship started to execute the maneuver to remain well clear. It was also of interest to evaluate if alerting times effective at lower closure rates with slower intruders would remain sufficient with higher closure speeds.

For Stratway+, high-speed intruder encounters were performed at $400-\mathrm{ft}$ vertical separation and at angles into of $0^{\circ}, 45^{\circ}, 90^{\circ}$, and $135^{\circ}$ (Fig. 19). Additionally, multiship encounters were performed with a high-speed intruder with 500 -ft vertical separation. These encounters' permutations include: $0^{\circ} / 45^{\circ}, 0^{\circ} / 90^{\circ}$, and $0^{\circ} / 135^{\circ}$. Figures 20 and 21 detail the high-speed and low-speed intruder for each.

d. General Atomics CPDS Pairwise Encounter Geometries - General Atomics provided their SS algorithm, CPDS, TCAS type encounters, and radar encounters. The first group of encounters that was provided from General Atomics was to test the SS algorithm CPDS. Five single intruder encounters were provided for CPDS: one at 400-ft vertical separation and four at 500-ft vertical separation. Each of these encounters, all low speed, had the intruder performing a $45^{\circ}$ standard rate turn blunder into the path of the ownship.

CPDS also required three multiship encounters. Each featured an intruder performing a $45^{\circ}$ standard rate turn blunder into the path of the ownship, as well as a second intruder constraining the solution space. These encounters were designed with the first intruder at $400 \mathrm{ft}$ above ownship and the second at $500 \mathrm{ft}$ below ownship. The following is a detailed description of the encounters and their main objectives, which is summarized in Table 9. 
Table 9. CPDS objective and encounter overview.

\begin{tabular}{|l|l|}
\hline Objective & Encounters \\
\hline $1 a$ & $\mathrm{~L} 52 \mathrm{M}(2), \mathrm{L} 52 \mathrm{M}(3)$ \\
\hline $1 \mathrm{~b}$ & $\mathrm{~L} 52 \mathrm{M}(1), \mathrm{L} 52 \mathrm{M}(5)$ \\
\hline $1 \mathrm{c}$ & $\mathrm{L} 52 \mathrm{M}(4)$ \\
\hline $2 \mathrm{a}$ & $\mathrm{M} 79 \mathrm{X}(2)$ \\
\hline $2 \mathrm{~b}$ & $\mathrm{M} 79 \mathrm{X}(1)$ \\
\hline $2 \mathrm{c}$ & $\mathrm{M} 79 \mathrm{X}(3)$ \\
\hline 3 & $\mathrm{~L} 52 \mathrm{M}(2)$ with L52M(3) \\
\hline
\end{tabular}

CPDS Objectives - The CPDS researcher provided a characteristic set of objectives that created complex geometries unique to the encounters of this algorithm.

1) Test the current system/algorithms beyond the situation in which an intruder traverses the various SS alert states in the way that would happen if the conflict geometry already exists outside of the temporal limit defining SelfSeparation Proximate Traffic (SSPT).

- Objective 1a: Test the system for situations in which well clear is resolved by intruder maneuver while having status Corrective Self-Separation Alert (CSSA) before Self-Separation Warning Alert (SSWA) occurs. Loss of well clear is predicted and after the intruder alert status has become Self-Separation Corrective Alert (SSCA), the intruder maneuvers in such a way that well clear will not be violated.

- Objective 1b: Test the system for situations in which an intruder becomes CSSA due to a maneuver within the 75-25 seconds to the well-clear boundary. In these situations the predictability in terms of time remaining until SSWA cannot be deduced from the time the yellow band intersected the ownship track or the time traffic became SSCA.

- Objective 1c: Test the system for situations in which the intruder SS alert state due to a maneuver cycles from normal to CSSA to normal.

2) Same objectives as Objective 1, but with an additional constraint on the solution space.

- Objective 2a: Test the system for situations in which well clear is resolved by intruder maneuver while having status CSSA (before SSWA occurs). Loss of well clear is predicted and after the intruder alert status has become SSCA, the intruder maneuvers in such a way that well clear will not be violated.

- Objective 2b: Test the system for situations in which an intruder becomes CSSA due to a maneuver within the 75-25 seconds to the well-clear boundary. In these situations the predictability in terms of time remaining until SSWA cannot be deduced from the time the yellow band intersected the ownship track or the time traffic became SSCA.

- Objective 2c: Test the system for situations in which the intruder SS alert state, due to a maneuver, transitions from normal to CSSA to normal.

3) Test the conflict probe function for the most opposite impacts of wind on the same conflict geometry.

Desired UAS Pilot Performance - A pilot's response to the display is also critical in evaluating the algorithm. The desired UAS pilot performance in the task of remaining well clear comprises two aspects:

1) Timely detection of all conflicts (future loss of well clear) that will require a maneuver to prevent them from occurring unless the intruder resolves it in time, and appropriate execution of the maneuver (timing and magnitude) that prevents the otherwise occurring well-clear violation.

2) A minimum of unnecessary maneuvering; minimum maneuvers are significant for the prevention of:

- Situations in which the pilot initiates a maneuver to remain well clear whereas the continuation of the current direction and velocity would not have resulted in a loss of well clear.

- Situations in which ownship maneuvers due to a temporary predicted loss of well clear outside the 85-second threshold use for the SSPT.

- Situations in which the maneuver performed by the pilot to remain well clear is far more severe than necessary.

Requirements for CPDS Conflict Geometries (Fig. 22) - Given the objectives, the following three types of encounters were needed: 
1) To meet the first two subparts of objective 1: Encounters that are predicted to result in a loss of well clear at a time to CPA larger than 120 seconds, but are resolved by the intruder maneuvering between 75 and $25+$ to be determined (TBD) margin seconds to well clear.

2) To meet the second subpart of objective 1 and second subpart of objective 2: Encounters in which the intruder maneuvers within 110 seconds to CPA in such a way that the predicted distance at CPA crosses the well-clear Distance MODification (DMOD) threshold.

3) To meet the third subpart of objective 1 and third subpart of objective 2: Encounters that only during the maneuver of the intruder cause a predicted loss of well clear with a time to CPA that always remains above 60 seconds.

Requirements for the second intruder (Fig. 23) - To meet objective 2, the trajectory for the second intruder must meet the following requirements:

1) The second intruder is not used to generate a geometry which causes a predicted loss of well clear.

2) The second intruder is not intended to maneuver, unless necessitated by an (unplanned) maneuver of Ikhana.

3) The second intruder is to be positioned in such a way that during the encounter with intruder 1 (with 'during' defined as the period Ikhana being at least from 120 seconds to moment until the predicted loss of well clear with intruder 1 occurs), the intruder will be a Preventative Self-Separation Alert (PSSA) (using the proposed update to the PSSA specification).

4) The second intruder is to be positioned in such a way that within 10 seconds of the start of a standard rate turn to the left of Ikhana, the PSSA becomes CSSA.

e. General Atomics Radar Pairwise Encounter Geometries - The next set of encounters provided by General Atomics were designed to test the Engineering Development Module (EDM) DRR. Test encounter geometries provided by GA-ASI collected data on the performance of the company provided EDM radar system and to help inform the SC-228 radar working group MOPS. The EDM radar performance operating at low altitudes was unknown, thus during FT3, test encounters were planned to explore how the radar performs at low altitude with ground clutter affecting target resolution. Figure 24 depicts the planned low altitude radar flight-test geometries. The minimum test altitude was 1,000-ft AGL based off the highest ground feature located along the flight path of the encounter. Both the ownship (Ikhana) and the intruder performed 1,000-ft AGL runs, but at no time did an encounter participant operate below 1,000 ft. Eight low altitude radar runs were planned. All low altitude encounters performed had a vertical separation of 1,000 ft, 3,000-ft lateral offset, and were all flown head-on.

Further, GA-ASI required performance testing of the EDM radar to determine targeting capabilities at the azimuth limits of the radar system (Fig. 25), performance of the system of the radar when the intruder is persisting on the beam (Fig. 26), as well as, system performance of the radar during intruder acceleration maneuvering called a "Zig-Zag" encounter (Fig. 27).

Constant bearing, decreasing range (CBDR) encounters for radar held the intruder at a relative angle of either $110^{\circ}$ or $90^{\circ}$ bearing to the ownship. These encounters were longer than most, being flown for 5 or 6 minutes to collect additional radar data. The encounters included climbs and descents with 500 -ft vertical separation, and were performed in level flight with a minimum of $300-\mathrm{ft}$ vertical separation.

The Zig-Zig encounter, although depicted with defined angles in Fig. 27, could change during the flight; as long as the aircraft were continuously accelerating, researchers would be receiving the data they required. This encounter was flown with $1,000-\mathrm{ft}$ vertical separation.

f. General Atomics TCAS Pairwise Encounter Geometries - General Atomics provided simple to complex TCAS type encounters. The CA performance encounters were designed to test the full range of TCAS Resolution Advisories (i.e., preventive and corrective) and when executed automatically, to test the performance of the vehicle response in a real world environment. Climbing/descending ownship and intruders were included to capture realistic encounter dynamics of the Phase I DAA MOPS definition of transition. These encounters also served to capture radar performance data all the way through a CA maneuver.

Figures 28 and 29 depict the mitigated single intruder TCAS runs that were designed to further investigate the threshold between collision avoidance and SS boundaries. Runs were planned in a variety of geometries and used a buildup approach starting with 500 - $\mathrm{ft}$ vertical separation and building up to $300-\mathrm{ft}$ vertical separation encounters, running in advisory and then automatic (AUTO) mode. Vertical blunder type maneuvers were planned with ownship maneuvers, intruder maneuvers, and some encounters where both ownship and intruder perform vertical maneuvering toward each other with a minimum of $500-\mathrm{ft}$ separation at the completion of the encounter. Angles into for these encounters included $0^{\circ}, 20^{\circ}, 45^{\circ}, 90^{\circ}, 135^{\circ}$, and $160^{\circ}$.

Several of the CA performance encounters included multiple threat aircraft. While not traditional "multi-threat" encounters as defined by TCAS, these encounters were designed to generate TCAS RAs one at a time or sequentially. 
These encounters did not directly test the TCAS multi-threat logic, but were designed to test the dynamics of multiple TCAS RAs generated in different directions. The encounter was timed to induce one TCAS RA, followed by a "clear of conflict," followed by another RA in the opposite direction to the first. These encounters were the most complex to be tested during FT3. A buildup approach was used for this type starting at 300-ft vertical separation with Ikhana operating in advisory mode. Once the $300-\mathrm{ft}$ encounter had been cleared in advisory, the encounter would be performed in AUTO mode at 300-ft vertical separation. Once 300-ft encounters were cleared, $200-\mathrm{ft}$ vertical separation would be tested using the same buildup approach. As mentioned later in this paper, researchers stated on the flight day that advisory only 300-ft encounters were suitable for their data collection (thus only M67Q and M68Q were performed, and in advisory mode). Figure 30 shows the planned top view of these TCAS multiship sequential encounters, and Figs. 31 and 32 show the vertical profile views.

\section{Configuration $1 b$ High-Speed Ownship}

Configuration $1 \mathrm{~b}$ encounters required a high-speed ownship ( $\geq 210 \mathrm{KGS})$. Unfortunately due to time constraints and unavailability of the high-speed ownship, these encounters were not completed.

In addition to low-speed encounters, ARC desired pairwise encounter geometries in the high-speed category to test the AutoResolver algorithm. A high-speed ownship (210 and $250 \mathrm{KGS}$ ) was necessary to test the limits of their algorithm, with a low-speed (130 KGS) intruder. The planned angles into for this configuration were $0^{\circ}, 45^{\circ}, 90^{\circ}$, and an overtaking $180^{\circ}$, seen in Fig. 33. The high-speed encounters would test the fly-through (unmitigated) case, as well as maneuvering based on algorithm directive (mitigated). All high-speed ownship scenarios had planned 1,000-ft vertical separation for safety.

\section{Matrix Development}

A comprehensive flight-test matrix was built for FT3 based on researcher requirements and the geometries described above. The encounters were grouped into sections by their encounter angle or type: head on $0^{\circ}, 45^{\circ}, 90^{\circ}$, $135^{\circ}$, high-speed participant, radar, TCAS, and CPDS.

Originally, researchers from LaRC, ARC, and General Atomics each provided their own set of maneuvers and requirements in spreadsheet format. These requirements were consolidated into one matrix by personnel at LaRC, and this spreadsheet was inherited by AFRC and extensively expanded upon. Flight planning by AFRC began with this version, gathering requirements for the type of maneuver being performed, altitudes, groundspeeds, and sensors.

The purpose of the matrix was to provide a centralized spreadsheet to input all required research geometries, plan the flight in the approved airspace, and populate the flight cards with information and requirements for each encounter.

The matrix was built in Microsoft Excel ${ }^{\circledR}$ (Microsoft Corporation, Redmond, Washington) and used Visual Basic for Applications (VBA) (Microsoft Corporation, Redmond, Washington) for calculating pertinent values, such as GPS coordinates in multiple formats. Look-up tables were used on several occasions and especially to populate Ikhana lostlink mission for each encounter based on CPA. Additionally, Excel was useful for calculating IP to maneuver point (MP) and CPA using dead-reckoning equations. The following is a breakdown of the parameters, some of which are shown in Table 10. 
Table 10. Pairwise encounters scenario matrix.

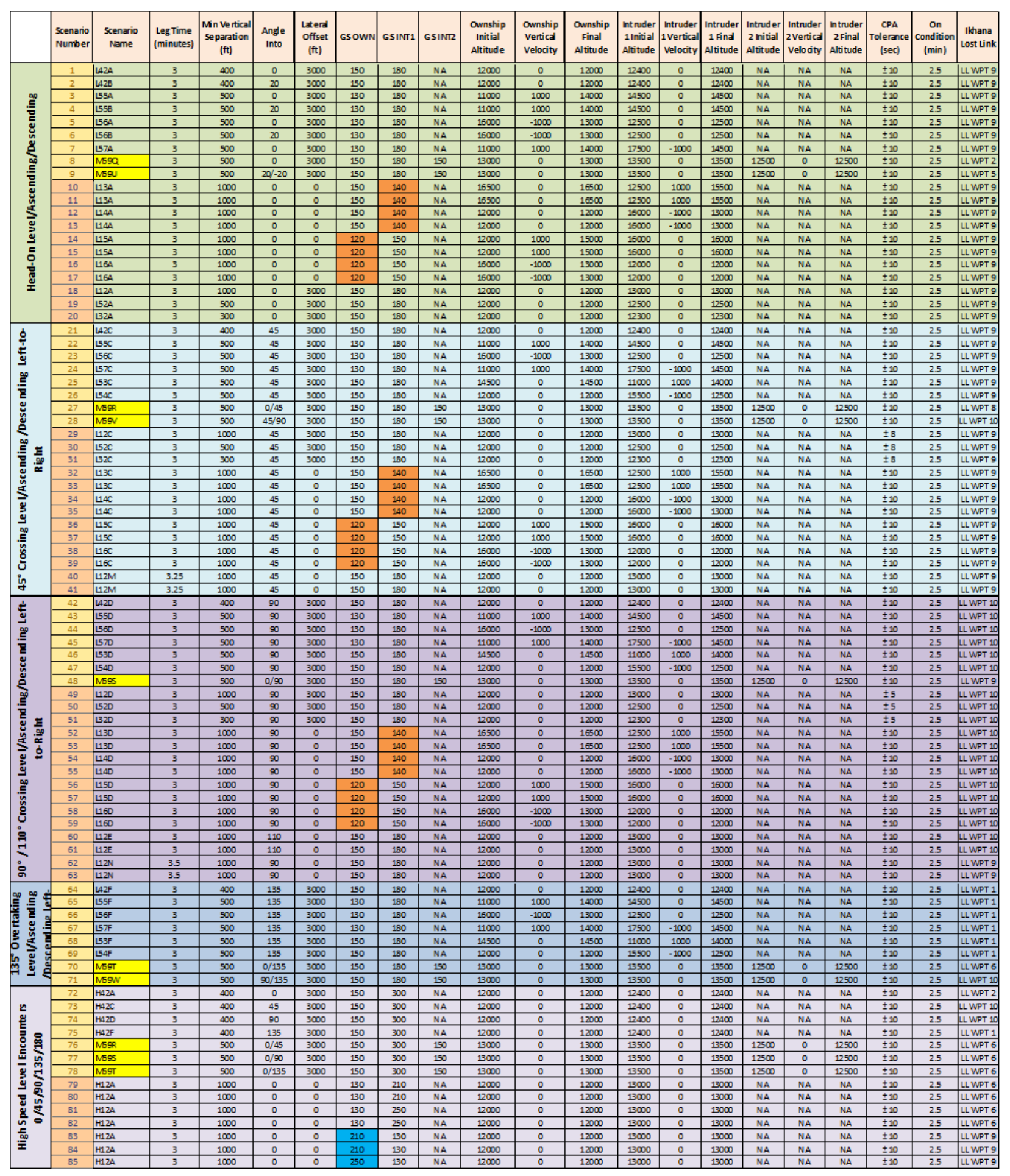

- Scenario number $(\mathrm{S} / \mathrm{N})$ : The scenario number (Table 10) was the most critical number for each encounter. This number served as an identification number for the unique geometry, flight altitude, and other relevant information. Although encounters could have the same scenario name, the number was unique. The $\mathrm{S} / \mathrm{N}$ was used throughout the entire flight test, from the matrix for building the encounter, to encounter prioritization, and finally, for creating the flight-test cards.

American Institute of Aeronautics and Astronautics 
- Scenario name: Scenario names (Table 10) were based on the pairwise encounters nomenclature. The scenario name was a quick reference to gain SA on what type of encounter was being performed. The scenario number could be the same for two or more encounters.

- Scenario name (old nomenclature): Previously, encounters had a naming convention developed from researchers at ARC. Later, the naming convention was refined and modified to the version currently being used. The old nomenclature was kept on the matrix as a trace to the original required encounter.

- Ownship (OWN) True Course: This value was used to calculate GPS coordinates (magnetic course was later calculated on the flight cards themselves).

- Leg time: Time for the encounter from Commence Exercise (COMEX); leg time (Table 10) included some buffer for setting up the encounter geometry. Most encounters had 3-minute legs, with some maneuvering encounters (3.25 minutes, 3.5 minutes), low altitude radar (3.5 minutes), and CBDR radar (5 minutes, 6 minutes).

- Minimum vertical separation: Smallest vertical separation between ownship and intruder(s) for the encounter at CPA (Table 10); if the vertical separation necessary for an encounter was $\leq 500 \mathrm{ft}$, a lateral offset was required for safety.

- Angle into: Relative angle of the intruder(s) into the ownship for that geometry (Table 10); this value was used to calculate GPS coordinates.

- Lateral offset: A lateral offset (Table 10$)$ of half a nautical mile $(\sim 3,000 \mathrm{ft})$ was calculated into the geometry for encounters with a vertical separation of $\leq 500 \mathrm{ft}$. The offset was to ensure that if a visual was not acquired according to mission rule, there would still be a safety buffer.

- Ground Speed (GS) OWN: Groundspeed of the ownship in knots (Table 10); depending on what the researcher wanted to test, the groundspeed varied between encounters. Most low-speed encounters had a GS of 130 or 150 KGS. High-speed encounters required an ownship GS of $\geq 210$ KGS. Groundspeed was preferred for calculations since it did not have to take wind into account. For some encounters, an airspeed of 120 KIAS was required. GPS coordinates were provided for these encounters from the researcher

- GS Intruder 1 (INT1): Most encounters required the intruder(s) (Table 10) to fly at 150 or 180 KGS. For high-speed encounters, intruders were required to fly $\geq 210$ KGS. For some encounters, an airspeed of 140 KIAS was required.

- GS Intruder 2 (INT2): Multiship encounters only had low-speed intruders (Table 10) for Flight Test Series 3. Thus, all intruder 2 groundspeeds were 150 or 180 KGS.

- Ownship initial altitude: Altitudes chosen for each encounter (Table 10) took Ikhana and intruder flight performance into consideration, as well as airspace. Encounters began 10K-20K ft MSL. Low altitude radar encounters took the highest point on the terrain $(3,200 \mathrm{ft} \mathrm{MSL})$ and added 1,000 ft for the flight level. Thus 4,200 ft MSL was the lowest flown altitude.

- Ownship vertical velocity: For some encounters, a climb or descent was required by the ownship (Table 10). Rates required were either 1,000 fpm (climb) or -1,000 fpm (descent).

- Ownship final altitude: Once more, the final altitude (Table 10) was within the block of $10 \mathrm{~K}-20 \mathrm{~K} \mathrm{ft} \mathrm{MSL} \mathrm{or}$ $1,000 \mathrm{ft}$ above the highest terrain point.

- INT1 initial altitude: The initial altitude (Table 10) of INT1 was identical to the ownship.

- INT1 vertical velocity: The vertical velocity (Table 10) of INT1 was identical to the ownship.

- INT1 final altitude: The final altitude (Table 10) of INT1 was identical to the ownship.

- INT2 initial altitude: The initial altitude (Table 10) of INT2 was identical to the ownship.

- INT2 vertical velocity: The vertical velocity (Table 10) of INT2 was identical to the ownship.

- INT2 final altitude: The final altitude (Table 10) of INT2 was identical to the ownship.

- CPA OWN: The CPA of the ownship was one of its most important parameters. The CPA was the point where the ownship and intruder(s) would be nearest in space for each encounter. Within R-2515, 11 different ownship CPAs were chosen for all Pairwise Encounters. CPAs were chosen to accommodate for the 3-minute legs in the airspace (as well as the longer radar legs), plan sun angles for manned intruders, and were used to build the Ikhana lost-link mission. Additionally, the CPAs made it easier to group encounters based on matching CPA when building these geometries in Zeus for SAF SA. Finally, the CPAs were used in a lookup table to build GPS coordinates for all geometries.

- CPA OWN latitude/longitude: Chosen latitude and longitude for each CPA in decimal degrees (DD) format. The CPA latitude/longitude was found using FalconView (FV). 
- IP OWN: The IP of the ownship was chosen to fit within the airspace and to accommodate for the 3-minute (or longer) legs. The IP served as the point where the encounter would start and where the aircraft needed to be at the COMEX. Each IP had an identification number based on its coordinates, and for encounters that used the same IP, an identical IP identification (ID) was used. The IP was also used on the flight cards for reference on the top view (Fig. 34) and coordinates.

- IP OWN latitude/longitude: Calculated latitude and longitude of the ownship IP from the CPA using dead reckoning equations, in DD format.

- IP OWN distance meaning equipment (DME): Calculated distance in nautical miles from the CPA to the IP for ownship.

- IP intruder: The same procedure was used for the intruder IP as for the ownship.

- IP INT latitude/longitude: Calculated latitude and longitude of the IP for the intruder from the CPA in DD format.

- IP INT DME: Calculated distance in nautical miles from the CPA to the IP for intruder.

- CPA INT: Similar to the ownship, the CPAs for the intruder were also grouped based on GPS coordinates. However, since the geometries for the intruders were built around the geometries for the ownship, there were many more CPAs for intruders than for the ownship due to various angles into, groundspeeds, et cetera.

- CPA INT lattitude/longitude: Calculated latitude and longitude of the intruder CPA in DD. The CPA for the intruder was either the same as the ownship ( $>500-\mathrm{ft}$ vertical separation) or calculated to be $3,000 \mathrm{ft}$ away ( $\leq 500$-ft vertical separation) from ownship CPA using the relative angle into.

- MP INT: For some encounters, a maneuver was required in the middle of the encounter for the intruder to create a blunder type scenario. Maneuver points once again held the same ID if they had the same GPS coordinates.

- MP INT latitude/longitude: Calculated latitude and longitude in DD that the intruder was expected to begin the standard rate turn to the CPA.

- On condition: Each encounter required that the aircraft be on condition (Table 10) a certain number of seconds from CPA. The on condition was to ensure that the researcher's algorithm would have enough time to pick up the aircraft in the encounter for the required conditions (speeds, altitudes, vertical speed, et cetera). Most encounters had a requirement of being on condition for 2.5 minutes ( 0.5 minutes for setting up) for the total 3-minute legs required.

- Tolerance: A carryover from the Airborne Collision Avoidance System (ACAS) Xu flight test; the tolerance (Table 10) for an encounter was the number of seconds that each aircraft could be away from the CPA and still achieve the correct alerting for that encounter. Most encounters had a timing of $\pm 5,8$, or 10 seconds. This value was determined from simulation by the researchers or from previous experience. As time went on, it became apparent that tolerance was not as critical for FT3 (especially for the maneuvering encounters) as much as achieving stable conditions.

- Ikhana lost link: In the event that Ikhana would lose link, a lost-link mission (Table 10) was programmed into the flight computer. The lost-link mission was based on the CPA the ownship would be heading to for that encounter. For this reason, it was critical for the Ikhana team to have all CPAs prior to flight testing so they could build this mission. The lost-link mission was input into the flight matrix using a lookup table based on CPA.

It is important to note that once all geometries were built, they were geo-referenced in FV to ensure they fit in the assigned airspace or gave enough maneuverability space for all aircraft participants. If they did not, the CPA and GPS coordinates were iterated until a suitable geometry was achieved.

The flight-test matrix also included a section showing the scenario number, priority, and what sensors would be required for that encounter. Encounters for a particular flight day were chosen in this way. Thus the matrix provided the basic requirements for execution, safety mitigation, and prioritization for planned FT3 scenarios.

\section{Flight Card Description}

Flight cards for Configuration 1 were developed based on cards created during the ACAS Xu flight test by personnel from Massachusetts Institute of Technology (MIT) Lincoln Laboratory (Lexington, Massachusetts). These flight cards, which were atypical, were used for similar type encounters during that flight test.

Due to the success of that program and card clarity, a similar format was used for Flight Test Series 3. With the collaborative effort of FT3 Ikhana Operations, AFRC IT\&E Operations, and researcher input; the product was designed to provide a simple, easy to use, and easily modifiable card that met researcher requirements for mission 
success. The cards also presented a familiar format to that of an instrument approach plate which enabled the aircrew to quickly determine test parameters and critical flight information.

An additional factor that was taken into the design was that of human factors: throughout all scenario cards for Configuration 1, a standard color format was selected:

- Ownship and middle altitude aircraft was green.

- Intruder 1 and higher altitude aircraft was red.

- Intruder 2 and lower altitude aircraft was blue.

This color scheme was chosen for its quick SA for the customer and easy cockpit use. The issue of color blindness was considered, but since all of the test pilots had been through physical examination that checks for color blindness, it was a non-factor.

The flight cards were a tremendous success, both visually and for being highly informative and practical. Kudos were received from Ikhana and guest aircrew, intruder aircrew, and industry stakeholders alike.

Flight Cards were built in Excel and were directly linked to the flight-test matrix. The matrix had the capability of auto-populating much of the information for the card based on look-up tables from the scenario number: IP/CPA names and coordinates, altitudes, headings, velocities, distances, groundspeeds, lost-link mission for Ikhana, oncondition timing, and CPA tolerances. Manual input was required for the sensor selection, deconfliction altitudes, notes, and abort procedures.

The top down view is a geo-referenced image that was built in FV, and furthermore auto-generated by a program called Excel2FV. Excel2FV plotted and created FV files automatically by taking user-grouped identical geometries from Excel as an input. Once the geometries/files were created, IP/CPA icons were manually added onto the FV files and an image file was created. These image files were moved to Microsoft PowerPoint ${ }^{\circledR}$ (Microsoft Corporation, Redmond, Washington) and aircraft icons added. The top-down views were then pasted onto the flight cards.

Vertical profiles were built in Microsoft PowerPoint ${ }^{\circledR}$. Groups of similar encounters were easily pasted onto the flight cards.

The cards were designed to fit on an 8.5 in $\times 11$ in sheet of paper, with one half dedicated to ownship and the other to intruder. The layout allowed users to either cut the deck in half or fold their card to the one of interest. For multiship, an additional sheet of standard size paper was required.

Since there were over 200 test points, over 200 unique flight cards were created in this fashion for Configuration 1. Each flight card had its own spreadsheet and the cards were later converted into PDF, packaged into a document for that particular flight day, and distributed in soft- and hard-copy format to all FT3 participants.

Figures 34 and 35 show an example of the flight cards used for Configuration 1. The following is a breakdown of card sections.

a. Ownship - Ownship cards showed the aircraft route of flight as green. Below are the main card sections, listed alphabetically, and a brief explanation for each:

- Abort altitude: This altitude is defined as the safe escape altitude the aircraft were expected to immediately hold and maintain if an abort is called. For the ownship, abort altitudes required no maneuver other than to remain level, or during climbs and descents to level off at the identified level-off altitude. The encounter would end if an abort was called. The abort altitude provided each participating aircraft at least 1,000 ft of vertical separation.

- Abort heading: The abort heading is the heading to maintain or fly to in the case of an abort. The encounter would end if an abort was called.

- Aircraft role: This section specified whether the aircraft was the ownship, Intruder 1, or Intruder 2.

- Aircraft: The call sign of the aircraft for that test card is shown.

- Card number: The card numbers were chosen the day of flight and represented the flight order.

- Card type version: Cards went through several iterations before reaching their final version (9). The reason for versions was to keep track of all format updates made during the production of cards. Changes from version to version included additional information added to the top view, notes section added, updated encounter instructions, et cetera.

- CPA: The CPA was the predicted point where the ownship and intruder(s) would be closest vertically and laterally. For encounters less than $500 \mathrm{ft}$ in separation, this CPA had a $0.5 \mathrm{nmi}$ lateral offset. Each CPA had a unique number (i.e. CPA7) and if GPS coordinates for a CPA repeated, the same CPA number would be used. The coordinates listed were in two forms for use by the Ikhana operators and intruders. CPAs were denoted by a triangle symbol.

- COMEX: Each encounter had a COMEX, a time where all participants needed to be positioned at the IP or ready to commence the run. 
- Configuration: The flight-test series configuration, for Configuration 1 consisted of two types: 1a (low-speed ownship) and 1b (high-speed ownship).

- CPA tolerance: Tolerance was based on requirements from the researchers' simulations. The tolerance required the aircraft to be at the CPA within that number of seconds from each other. Typically the value was $\pm 5,8$, or 10 seconds.

- Deconfliction altitude: The deconfliction altitude was the altitude that the aircraft would fly in between test points.

- Encounter instructions: These instructions were radio instructions as well as what to expect from the TC. The instructions also showed at least how much time the aircraft needed to be on condition for that run (step 3). On condition was typically $2.5,3$, or 3.5 minutes depending on the encounter length.

- Final altitude: The final altitude was the expected altitude at the CPA.

- Groundspeed: Encounter horizontal velocity parameter for all participating aircraft was included. For Flight Test Series 3, all speeds were constant (no acceleration). As mentioned, some encounters required airspeed; Airspeed was specified on those unique cards and highlighted.

- Ikhana lost link: Each Ikhana CPA had a single waypoint on a lost-link mission that the aircraft would go to in the event of this condition.

- IP: The IP was the point in space where the aircraft would need to be for COMEX. Each IP had a unique number (i.e. IP16), and if GPS coordinates for an IP repeated, the same IP number would be used. The coordinates listed were in two forms for use by the Ikhana operators and intruders. IPs were denoted by a square symbol.

- IP to CPA in nautical miles: The distance between IP and CPA in nautical miles was included, for reference.

- Magnetic course: Expected Magnetic Course (MC) was shown between the IP to CPA.

- Ownship (O/S) pilot instructions: These instructions were specific to that geometry/SUT that the pilot had to execute.

- Profile view: The profile view was the side view of the encounters, showing initial and final altitudes at IP and CPA respectively, abort procedures (dashed lines), and vertical separation.

- Scenario name: This name was a quick reference to the type of encounter being executed, using the scenario nomenclature. For more information, see Fig. 8.

- Scenario number: This number was unique to each encounter. In fact, it carried through from the flight-test matrix and was critical to building the cards based on lookup tables. For a full list of scenario numbers, see Table 10.

- Sensor selected: Ikhana had several sensors that could be selected or deselected based on researcher requirements for that encounter. "Selected" meant that track data were being fed into the SUT. Automatic Dependent Surveillance-Broadcast (ADS-B), radar, and/or TCAS data could be selected, as well as "Tracker," which would fuse all three.

- Start altitude: The start altitude is the aircraft starting altitude at the IP.

- SUT: Each encounter had a particular display, or SUT. The choices were AutoResolver 1 or 2, Stratway+, or CPDS.

- TCAS mode: The TCAS mode would be selected depending on if Ikhana should perform a maneuver based on TCAS alerts. "OFF" meant that no TCAS alerts would be received, "Advisory" would show the alerts to the pilot and let them decide whether to maneuver based on the guidance, and "AUTO" would enable the flight control computer to automatically take control and maneuver based on TCAS alerts.

- Time adjust: The time adjust was useful for airspeed encounters.

- Time hack: A time hack based off of Coordinated Universal Time (UTC) as displayed in the SAF was performed prior to starting encounters. The time hack allowed all participants to sync up their clocks prior to COMEX. Time hack was called by the TC, and although each card had a section provided to record the hack, it was only performed once (for each aircraft) every flight day.

- Top view: The top view was the geo-referenced top view of the encounter based off of FV showing what the ideal case would look like. CPA and IP are shown for the aircraft for that particular card.

- Vertical velocity: The vertical velocity was the climb or descent rate of the aircraft in feet per minute.

- VID notice: If an encounter was $<500 \mathrm{ft}$ in vertical separation, a notice was displayed on the top view to warn participants that a VID was required by $1 \mathrm{nmi}$ lateral separation or an abort would be called.

b. Intruder - Intruder cards showed the aircraft route of flight as either red (Intruder 1) or blue (Intruder 2). However, the cards were almost identical to the ownship cards: 
- No sensor select: The intruder aircraft did not have the same sensor selection capabilities for inputting to the SUT; thus, this section was not required.

- Intruder pilot instructions: These instructions varied from the ownship and gave SA to the pilot and how the ownship would be performing.

- Maneuver point: The MP was the point the intruder aircraft was expected to fly to and then perform a standard rate turn to another set of coordinates. The MP was denoted by a circle symbol. The MP was not depicted on the example card.

\section{B. Configuration 2: Full Mission Encounters}

Full Mission flight encounters, also identified as Configuration 2, followed a pre-planned flight plan that represents a fictitious fireline route mission flown in Oakland Center Class E airspace (ZOA) that has been previously used for Integrated Human in the Loop (IHITL) and Full Mission simulation exercises conducted by researchers at NASA ARC. FT3 Full Mission would gather real flight data to improve simulation. In order to be successful, these encounters involved an even larger coordination effort than Configuration 1. Like Configuration 1, ownship and intruder aircraft needed to communicate on timing, weather, and airspace information. However, due to the integrated nature of Configuration 2, coordination with virtual ATC was required to conduct the virtual encounters. Although the data collection portion did not achieve the researchers' desired results, from an operational perspective, the integration of RGCS pilot, virtual ATC, TC/TD, live ownship, and live intruders was smooth and nearly seamless.

These missions involved a single ownship aircraft (UAS surrogate T-34C) navigating a flight plan, two live intruder aircraft performing flight encounters that were generally scripted, but had flexibility in execution to accommodate real-time changes during the test runs, and finally, multiple virtual intruders that were not displayed to the airborne aircrew, but the ownship aircraft maneuvered to avoid based off inputs executed by the subject pilot located in the RGCS. Each live intruder encounter with the UAS Surrogate ownship were 1v1 encounters. Figure 36 shows the ownship fireline route and the expected paths and intercepts of the two live intruders (Intruder 1-red, Intruder 2-blue). Figure 37 shows the ownship, Intruder 1, and Intruder 2 routes overlaid, as well as expected live and virtual encounters.

The NASA 608 aircraft acted as a surrogate UAS for this configuration. The aircraft was directly controlled laterally by the RGCS pilot, and the NASA 608 pilot would perform other maneuvers such as airspeed and altitude changes, received by the research computer from VSCS, and relayed to an on board tablet. To the RGCS pilot, the route appeared to be in ZOA airspace on the VSCS display.

\section{Fireline Route Development}

The following stakeholders helped develop the Configuration 2 event:

- ARC: IT\&E team members represented the virtual ATC team and the ARC HSI interests. They were responsible for integrating the route depicted above into ZOA airspace (Fig. 38) and with the restrictions required for flight in R-2508.

- ARC: HSI team members were the primary research team. The encounter intercepts they developed would put the test pilot under heavy working conditions in order to evaluate the display.

- AFRC: IT\&E team members were responsible for local R-2508 and R-2515 coordination as well as overall flight execution. AFRC was responsible for relaying the information to ARC HSI/IT\&E to create a temporary flight restriction (TFR) and slightly modify the fireline route on one waypoint.

- R-2508 CCB: The Complex Control Board (CCB) is the governing body for the R-2508 complex and as such represented High Desert TRACON (Edwards, California) as well as USAF R-2515 interests.

- GRC Communication: The GRC team was responsible for the T-34 NASA 608 aircraft during Configuration 2.

\section{Constraints and Limitations}

The Configuration 2 ownship was controlled by the RGCS, whose subject pilot under test was immersed in a virtual ATC, ZOA, and environment. Where aircrew in Configuration 1 flights maneuvered according to the display, aircrew in Configuration 2 coordinated with ATC as if they were actually operating an aircraft in the Oakland Center airspace. Furthermore, ownship maneuvers were less predictable in Configuration 2 and resulted in missed encounters as discussed later in this paper.

Transiting from High Desert TRACON (Joshua) control to SPORT control needed prior coordination and in some cases imposed minor delays, on the order of minutes, while the controllers conducted hand overs. Although entry and 
use of the Isabella MOA was essentially guaranteed for participating aircraft with a Sage or Pancho clearance, entry into R-2515 was not guaranteed as NASA aircraft are assigned a lower priority than many USAF programs.

\section{Flight Card Description}

Due to its unique nature, full mission flight cards were completely developed by AFRC IT\&E Operations for Flight Test Series 3. Because of the distinctive and repeating route for each flight day, one set of cards was created that was used every day: Ownship, Intruder 1, and Intruder 2.

These cards were produced to be easy to use by the airborne users and other ground participants, not designed for the pilot using the SUT (RGCS). The cards were made to clearly show where live encounters were to occur, from what waypoints and holding patterns the intruder pilots should maneuver, and from where the ownship should expect fused reality virtual encounters.

Using the same color scheme but reversed altitudes from Configuration 1:

- Ownship and middle altitude aircraft were green.

- Intruder 1 and lower altitude aircraft were red.

- Intruder 2 and higher altitude aircraft were blue.

As in Configuration 1, Configuration 2 cards were built in Microsoft Excel®. However, since all coordinates and geometries were provided by ARC IT\&E Operations (and there was only one fireline route), the cards were created manually. The geo-referenced top view images were again created in FV and also manually. The following is a breakdown and description of unique elements on each of the Configuration 2 flight cards. Figures 39, 40, and 41 depict the flight cards used for Configuration 2.

a. Ownship - The ownship card depicted the aircraft route of flight as green. Below are the main cards sections, listed alphabetically, and a brief explanation for each:

- Abort procedure: For Configuration 2, the word "abort" did not have the same meaning as in Configuration 1. Since the tracks for Configuration 2 were much longer ( 40 minutes), an abort simply meant that the intruder aircraft would increase vertical separation (to obtain a separation of at least $500 \mathrm{ft}$ between aircraft) and continue the encounter. If visual was not acquired within the 1-nmi range, the pilots would call "blind" and the TC would instruct them to hold level, climb, or descend, as required.

- Aircraft role: This section specified whether the aircraft was the ownship, Intruder 1, or Intruder 2.

- Aircraft: This section specified the call sign of the aircraft for that test card.

- COMEX: Although there are several sections to input COMEX, the fireline route only had one COMEX at the beginning of the mission. This section was therefore used to show at what time an intruder would push to CPA instead.

- Configuration: This section was the flight-test series configuration. Configuration 2 had one Full Mission.

- Deconfliction altitude: Altitude aircraft would fly in between test points. A carry over from Configuration 1, ultimately participants stayed at their encounter altitude in between runs for efficiency.

- Distance: This section was the distance between IP waypoint (WP) and encounter WP in nautical miles, for reference.

- Fly-to WP: The Fly-to WP is the point the aircraft is expected to fly-to if there is no encounter. For a couple of encounters (3, and 4) the Fly-to WP is used since the live encounter WP is not on the flight plan for the ownship.

- Holding pattern: This section shows the ownship holding pattern before COMEX and the start of the fireline route.

- Live encounter number: This section denotes which live encounter on the fireline is being shown. The route had 4 live encounters (1, and 3 - intruder 1, and 2, and 4 - intruder 2).

- Live encounter WP: This section was the WP at which the intruder is heading to, and the live encounter, will occur.

- Live encounter: Live encounters occur with one ownship and one intruder (no multiship for Configuration 2).

- Magnetic course: This section shows the expected MC at waypoint.

- $\mathrm{O} / \mathrm{S}$ encounter altitude: This section was the expected altitude of the ownship at the live encounter.

- $\mathrm{O} / \mathrm{S}$ encouter magnetic course: This section was the expected magnetic course of the ownship at the live encounter.

- Ownship airspeed: This section shows the expected airspeed of the ownship at the live encounter.

- Profile view: This section was the side view of the encounter showing expected altitudes and vertical separation for the ownship and intruder. 
- TFR: A virtual TFR was added to the fireline route to keep all aircraft west of specific test areas (per a request from airspace coordination).

- Top view: This section was the geo-referenced top view of the fireline route showing what the ideal case would look like. The top view shows both the live and virtual encounters, as well as the TFR and holding patterns.

- VID notice: Since all live encounters were $<500 \mathrm{ft}$ for Configuration 2, a notice was displayed on the top view to warn participants that a VID was required by 1-nmi lateral separation or an abort would be called.

- Virtual encounter: These encounters were only visible to the RGCS pilot. They were displayed to the aircraft pilots to show where a maneuver would be expected by the ownship from RGCS.

- Waypoints: This section shows a list of waypoints for the aircraft to follow for the fireline.

b. Intruder 1- The intruder 1 card depicted the aircraft route of flight as red. Below are the main cards sections and a brief explanation for each:

- Waypoint IP: This section denotes the waypoint the intruder aircraft was expected to push out from. This waypoint was denoted as a square symbol and labeled so that the intruder could have quick SA on where to push from.

- Holding pattern 1: Intruder 1 had two separate holding patterns. This one was before encounter 1 and located in the southwest.

- Holding pattern 2: This holding pattern was before encounter 3 on the fireline (the intruder 1 second encounter) and located in the northeast.

c. Intruder 2 - The intruder 2 card depicted the aircraft route of flight as blue. Below are the main cards sections and a brief explanation for each:

- Holding pattern 1: This holding pattern was before encounter 2 on the fireline (the intruder 2 first encounter) and located in the southeast.

- Holding pattern 2: This holding pattern was before encounter 4 on the fireline (the intruder 2 second encounter) and located in the north.

\section{Flight Summary and Data}

This section describes the results observed by the operations team in both configurations of the flight test. The results were tabulated and distributed to the test team.

\section{A. Configuration 1}

Configuration 1 flight points were conducted from June 17, 2015, to July 24, 2015. Flight cards (divided into sections by day) that were flown for Configuration 1 are shown in Appendices A-K.

Scenarios were prioritized in the following ways:

- Priority based on researcher input (Priority 1,2,3, and 4)

- Build up approach (higher to lower vertical separation, advisory to auto, and less to greater complexity)

- Ease of flight (airspace transition from one encounter to next)

- Repeating geometries grouped

- Sun angle consideration

Figure 42 shows an overview of all planned scenarios for Configuration 1. Test points not completed are grayed out. Test points that are crossed out were removed from the flight schedule by the researcher (deemed unnecessary for mission success).

An altimeter calibration was performed for flights with a vertical separation of less than $500 \mathrm{ft}$. This calibration was performed in order to ensure that the scenario would achieve the correct alerting for the researchers' algorithms and TCAS SUT.

The subjective analysis is according to AFRC Ops and may differ from researchers' opinions. Test points are shown in order flown. Flight duration is based on the time in the air of the ownship. COMEX is written in local time. Traffic advisories (TAs) and RAs are noted. Altitudes are flight level MSL and at CPA or maneuver start. Sensors selected for that encounter are shown (ADS-B, radar, TCAS, Tracker). The last three columns are timing from CPA (+ is to arrive after, - is to arrive before) or maneuver suggested by display (if type is "Follow"). Boxes with a "-" denote missing data. $[R]$ is repeat. Tables 11-21 show Configuration 1 flight data. 
Table 11. Configuration 1, flight 1 data.

\begin{tabular}{|c|c|c|c|c|c|c|c|c|c|c|c|c|c|c|c|c|c|}
\hline Flight & \multicolumn{17}{|c|}{1} \\
\hline SUT & \multicolumn{17}{|c|}{ AutoRes olver } \\
\hline Duration & \multicolumn{17}{|c|}{5 hours } \\
\hline Intruder(s) & \multicolumn{17}{|c|}{ N3GC } \\
\hline \multirow{16}{*}{ Data } & \# & Scenario & Type & COMEX & O/S Alt. & TA/RA & Int1 Alt. & TARA & Int2 Alt. & TARA & ADS-B & RDR & TCAS & TRC & O/S & Int1 & \begin{tabular}{|l|}
$\ln 22$ \\
\end{tabular} \\
\hline & 1 & 18-L12A & Fly-through, AR1 & 0758 & 120 & & 130 & TA & NA & NA & $\mathrm{x}$ & $x$ & $x$ & $x$ & -10 & -10 & NA \\
\hline & 2 & 19-L52A & Fly-through, AR1 & 0810 & 120 & & 125 & & NA & NA & $x$ & $x$ & $x$ & & 0 & -2 & NA \\
\hline & 3 & 20-L32A & Fly-through, AR1 & 0820 & 120 & RA & 123 & & NA & NA & $x$ & $x$ & $x$ & $\mathrm{x}$ & +10 & +8 & NA \\
\hline & 4 & 29-L12C & Fly-through, AR1 & 0834 & 120 & & 130 & & NA & NA & $x$ & $x$ & $x$ & $\mathrm{X}$ & +2 & +10 & NA \\
\hline & 5 & 49-L12D & Fly-through, AR1 & 0843 & 120 & & 130 & & N/A & NA & $\mathrm{X}$ & $x$ & $\mathrm{X}$ & $\mathrm{X}$ & 0 & +6 & NA \\
\hline & 6 & 60-L12E & Fly-through, AR1 & 0855 & 120 & & 130 & & N/A & NA & $x$ & $x$ & $x$ & $\mathrm{X}$ & +10 & +10 & NA \\
\hline & 7 & 40-L12M & Fly-through, AR1 & 0910 & 140 & & 150 & & NA & NA & $x$ & $x$ & $x$ & $x$ & +15 & +23 & NA \\
\hline & 8 & 62-L12N & Fly-through, AR1 & 0923 & 140 & & 150 & & NA & NA & $x$ & $x$ & $x$ & $\mathrm{X}$ & +0 & +1 & NA \\
\hline & 9 & 12-L14A & Fly-through, AR1 & 0938 & 120 & TA & 130 & & NA & NA & $x$ & $x$ & $x$ & $\mathrm{X}$ & +8 & -7 & NA \\
\hline & 10 & 34-L14C & Fly-through, AR1 & 0950 & 120 & & 130 & & N/A & NA & $x$ & $x$ & $x$ & $\mathrm{X}$ & +6 & -20 & NAA \\
\hline & 11 & 54-L14D & Fly-through, AR1 & 1000 & 120 & & 130 & & NA & NA & $x$ & $x$ & $x$ & $x$ & -1 & +5 & NA \\
\hline & 12 & 30-L52C & Fly-through, AR1 & 1013 & 120 & & 125 & & N/A & NA & $x$ & $x$ & $\mathrm{X}$ & $x$ & - & - & NA \\
\hline & 13 & 30-L52C $[R]$ & Fly-through, AR1 & 1023 & 120 & & 125 & & N/A & NA & $x$ & $x$ & $x$ & $\mathrm{X}$ & -2 & -5 & NA \\
\hline & 14 & 50-L52D & Fly-through, AR1 & 1033 & 120 & & 125 & & NA & NA & $x$ & $x$ & $x$ & $\mathrm{X}$ & -20 & +9 & NA \\
\hline & 15 & 50-L52D $[R]$ & Fly-through, AR1 & 1043 & 120 & & 125 & & NA & NA & $x$ & & & $\mathrm{X}$ & -10 & +6 & NA \\
\hline
\end{tabular}

Notes: Altimeter calibration was performed (the N3GC aircraft $+50 \mathrm{ft}$ ). Level acceleration was performed. Artificial offset was applied for 1,000-ft runs. $300 \mathrm{ft}$ non-head-on encounters were not allowed due to no ADS-B in $\mathrm{SAF}$. This flight used wind matrix for climb/descent encounters.

Encounters:

- $1-$ good

- $2-$ good

- $3-$ O/S RA, good

- 4 - INT1 start off angle $\sim 30$ degrees MC, good

- 5 - good

- $6-$ good

- 7 - run 3 minutes instead of 3.25 minutes, INT1 turn late, bad

- 8 - good

- 9 - wind adjust -10 seconds, TA to climb rather than descend $(\mathrm{O} / \mathrm{S})$, good

- 10 - wind adjust +7 seconds, INT1 late, bad

- 11 - wind adjust -12 seconds, good

- 12 - ABORT lost VID

- $13-$ good

- $14-\mathrm{O} / \mathrm{S}$ late, bad

- 15 - good

Airspace: Requested Buckhorn, SPORT raised flight test to flight level (FL)140 then FL150 (temporary) due to MQ-9 lasing in West Range; affected runs 7, and 8.

Barometer/Visibility: $29.92 \mathrm{in} / \mathrm{Hg}$, clear

Wind: 1 - O/S 251/20, INT1 220/10, 8 - O/S 205/18, INT1 195/20, 10 - INT1 256/10, 11 - INT1 210/17

Bottom line: Overall, test points were conducted well. The wind matrix had some errors and went through its first iteration. Although ADS-B was not functional in the SAF, the test was still able to continue for $300-\mathrm{ft}$ "head-on" $(0$ degrees angle into) encounters. Additionally, Fusion (Tracker) was seeing problems with tracks. Nonetheless, the researcher was pleased with data since there was no "real world" data previous to this flight. A decision was made to audibly announce TA/RA alerts for proceeding flights (all platforms). 
Table 12. Configuration 1, flight 2 data.

\begin{tabular}{|c|c|c|c|c|c|c|c|c|c|c|c|c|c|c|c|c|c|}
\hline Flight & \multicolumn{17}{|c|}{2} \\
\hline SUT & \multicolumn{17}{|c|}{ AutoRes olver } \\
\hline Duration & \multicolumn{17}{|c|}{4.9 hours } \\
\hline Intruder(s) & \multicolumn{17}{|c|}{ N3GC } \\
\hline \multirow{24}{*}{ Data } & \# & Scenario & Type & COMEX & O/S Alt. & TA/RA & Int1 Alt. & TARA & Int2 Alt. & TARA & ADS-B & $\mathrm{RDR}$ & TCAS & TRC & $\mathrm{O} / \mathrm{S}$ & Int1 & Int2 \\
\hline & 1 & 31-L32C & Fly-through, AR1 & 0643 & 120 & TA/RA & 123 & TA & NA & NA & $\mathrm{X}$ & & & & -2 & -2 & NA \\
\hline & 2 & 51-L32D & Fly-through, AR1 & 0653 & 120 & TA/RA & 123 & TARA & NA & N/A & $x$ & & & & +8 & +6 & NAA \\
\hline & 3 & 10-L13A & Fly-through, AR1 & 0704 & 165 & & 155 & & NA & NA & & $\mathrm{X}$ & & $\mathrm{X}$ & 0 & -10 & NA \\
\hline & 4 & 32-L13C & Fly-through, AR1 & 0715 & 165 & & 155 & & NA & NA & $\mathrm{x}$ & & & & +8 & -30 & NA \\
\hline & 5 & 52-L13D & Fly-through, AR1 & 0725 & 165 & & 155 & & NA & NA & & & $\mathrm{X}$ & $\mathrm{X}$ & +4 & +10 & NA \\
\hline & 6 & 16-L16A & Fly-through, AR1 & 0735 & 136 & & 120 & & NA & NA & $\mathrm{x}$ & & & & 0 & +10 & NA \\
\hline & 7 & 38-L16C & Fly-through, AR1 & 0745 & 130 & & 120 & & NA & NA & $\mathrm{x}$ & $\mathrm{x}$ & $\mathrm{x}$ & $\mathrm{x}$ & -2 & +1 & NA \\
\hline & 8 & 58-L16D & Fly-through, AR1 & 0755 & 130 & & 120 & & NA & NAA & $x$ & $x$ & $x$ & $x$ & +7 & +2 & NAA \\
\hline & 9 & 14-L15A & Fly-through, AR1 & 0805 & 150 & & 160 & & NA & NA & $x$ & $x$ & $\mathrm{X}$ & $x$ & +18 & -2 & NA \\
\hline & 10 & $36-L 15 C$ & Fly-through, AR1 & 0817 & 150 & & 160 & & NA & NA & $\mathrm{X}$ & $\mathrm{X}$ & $\mathrm{X}$ & $\mathrm{X}$ & +5 & +4 & NA \\
\hline & 11 & 56-L15D & Fly-through, AR1 & 0826 & 150 & & 160 & & NA & NA & $\mathrm{x}$ & $\mathrm{x}$ & $\mathrm{X}$ & $\mathrm{x}$ & +5 & +7 & NA \\
\hline & 12 & 10-L13A & Fly-through, AR2 & 0835 & 165 & & 155 & & NA & NA & $x$ & $\mathrm{x}$ & $\mathrm{X}$ & $\mathrm{x}$ & +9 & -7 & NA \\
\hline & 13 & 32-L13C & Fly-through, AR2 & 0845 & 165 & & 155 & & NA & NA & $\mathrm{x}$ & $\mathrm{x}$ & $\mathrm{x}$ & $\mathrm{x}$ & +5 & -15 & NA \\
\hline & 14 & 52-L13D & Fly-through, AR2 & 0855 & 165 & & 155 & & NA & NA & $\mathrm{x}$ & $\mathrm{x}$ & $\mathrm{x}$ & $\mathrm{x}$ & 0 & +28 & NA \\
\hline & 15 & 16-L16A & Fly-through, AR2 & 0905 & 130 & & 120 & & NA & NA & $x$ & $\mathrm{x}$ & $\mathrm{X}$ & $\mathrm{x}$ & +6 & -1 & NA \\
\hline & 16 & 38-L16C & Fly-through, AR2 & 0916 & 130 & & 120 & & NA & NA & $\mathrm{x}$ & $\mathrm{x}$ & $\mathrm{X}$ & $\mathrm{x}$ & +3 & +3 & NA \\
\hline & 17 & 58-L16D & Fly-through, AR2 & 0925 & 130 & & 120 & & NA & NA & $\mathrm{x}$ & $\mathrm{x}$ & $\mathrm{X}$ & $\mathrm{x}$ & -15 & +8 & NA \\
\hline & 18 & 12-L14A & Fly-through, AR2 & 0935 & 120 & & 135 & & NA & NA & $x$ & $x$ & $\mathrm{X}$ & $x$ & +1 & -20 & NA \\
\hline & 19 & 34-L14C & Fly-through, AR2 & 0945 & 120 & TA & 130 & TA & NA & NA & $x$ & $x$ & $x$ & $x$ & +4 & -10 & NA \\
\hline & 20 & 54-L14D & Fly-through, AR2 & 0955 & 120 & TA & 130 & & NA & NA & $\mathrm{x}$ & $\mathrm{x}$ & $\mathrm{x}$ & $\mathrm{x}$ & +5 & +17 & NA \\
\hline & 21 & 60-L12E & Fly-through, AR2 & 1005 & 120 & & 130 & & NA & NA & $x$ & $x$ & $\mathrm{x}$ & $x$ & - & - & N/A \\
\hline & 22 & 60-L12E[R] & Fly-through, AR2 & 1011 & 120 & & 130 & & NA & NA & $x$ & $x$ & $\mathrm{X}$ & $x$ & +1 & +4 & NA \\
\hline & 23 & 40-L12M & Fly-through, AR2 & 1020 & 120 & & 130 & & NA & NA & & $\mathrm{x}$ & $\mathrm{x}$ & $\mathrm{x}$ & -3 & -4 & NA \\
\hline
\end{tabular}

Notes: Altimeter calibration was performed (the N3GC aircraft $+60 \mathrm{ft}$ ). Artificial offset was applied for 1,000-ft runs. This flight used wind matrix climb/descent encounters. O/S collected additional ADS-B data after run 23.

Encounters:

- $1-$ O/S RA good

- 2 - O/S RA descend, INT1 RA climb, good

- 3 - wind adjust +13 seconds, INT1 off course $~ 130$ KIAS, good

- 4 - no wind adjust communication, relax vertical speed indicator (VSI), bad

- 5 - raised INT1 start altitude FL130, wind adjust -20 seconds, relax VSI, good

- 6 - wind adjust +15 seconds, good

- 7 - wind adjust +8 seconds, wind died to $16 \mathrm{kn}$ by end, set 1,100 VSI for Ikhana $=1,000$ VSI, good

- 8 - wind adjust -19 seconds, good

- 9 - wind adjust +20 seconds, O/S sped up KIAS, good

- 10 - wind adjust +5 seconds, O/S sped up KIAS, good

- 11 - wind adjust -10 seconds, sped up KIAS, good

- 12 - no wind adjust, good

- 13 - wind adjust +12 seconds, good

- $\quad 14$ - wind adjust -26 seconds, climb too early (should have reset), bad

- $\quad 15$ - wind adjust +20 seconds, good

- 16 - wind adjust +8 seconds, good

- 17 - decision: no wind adjust, O/S early/INT1 late (whole run), bad

- 18 - wind adjust +12 seconds, late start descent with overshoot, bad

- 19 - wind adjust +5 seconds, good 
- 20 - wind adjust +18 seconds (opposite of wind matrix), good

- 21 - reset, INT1 too slow to make CPA

- $22-$ good

- 23 - good

Airspace: No Buckhorn below FL130 and above FL200 (temporary); did not affect runs.

Barometer/Visibility: $29.92 \mathrm{in} / \mathrm{Hg}$, clear

Wind: 1 - O/S 274/23, INT1 274/27, 3 - O/S 282/15, INT1 296/17, 4 - INT1 289/20, 5 - INT1 265/18, 6 - O/S 282/15, 7 - O/S 285/25, 8 - O/S 270/15, 9 - O/S 285/20, 10 - O/S 290/19, 11 - O/S 300/10, 12 - INT1 252/21, 13 O/S 270/20, INT1 252/16, 14 - INT1 281/23, 15 - O/S 280/22, 16 - O/S 285/22, 17 - O/S 260/11, 18 - INT1 264/13, 19 - INT1 288/21, 20 - INT1 256/16

Bottom line: Overall, test points were conducted well. Additional errors were present in the wind matrix that were corrected after this flight. The team was getting into a flow that helped with obtaining more test runs for this day.

3. Flight 3: June 22, 2015

Table 13. Configuration 1, flight 3 data.

\begin{tabular}{|c|c|c|c|c|c|c|c|c|c|c|c|c|c|c|c|c|c|}
\hline Flight & \multicolumn{17}{|c|}{3} \\
\hline SUT & \multicolumn{17}{|c|}{ AutoRes olver } \\
\hline Duration & \multicolumn{17}{|c|}{4.5 hours } \\
\hline Intruder(s) & \multicolumn{17}{|c|}{ N3GC } \\
\hline \multirow{21}{*}{ Data } & \# & Scenario & Type & COMEX & O/S Alt. & TA/RA & Int1 Alt. & \begin{tabular}{|l|} 
TARA \\
\end{tabular} & Int2 Alt. & TARA & ADS-B & $\mathrm{RDR}$ & TCAS & TRC & $\mathrm{O} / \mathrm{S}$ & Int1 & Int2 \\
\hline & 1 & 61-L12E & Follow AR1 & 0650 & 120 & & 130 & & NA & NA & $x$ & & & & R007 & 0 & NA \\
\hline & 2 & 41-L12M & Follow AR1 & 0659 & 120 & & 130 & & NA & NA & $x$ & & & & R007 & +5 & NA \\
\hline & 3 & 63-L12N & Follow AR1 & 0710 & 120 & & 130 & & NA & NA & $x$ & & & & R007 & +10 & NA \\
\hline & 4 & 13-L14A & Follow AR1 & 0722 & 120 & & 135 & & NA & NA & $x$ & & & & R007 & +4 & NA \\
\hline & 5 & $35-L 14 C$ & Follow AR1 & 0731 & 120 & & 140 & & NA & NA & $x$ & & & & R277 & - & NA \\
\hline & 6 & 55-L14D & Follow AR1 & 0742 & 120 & & 150 & & NA & NA & $x$ & & & & R287 & +3 & NA \\
\hline & 7 & 15-L15A & Follow AR1 & 0753 & 135 & & 160 & & NA & NA & $x$ & & & & L.227 & 0 & NA \\
\hline & 8 & 37-L15C & Follow AR1 & 0803 & 140 & & 160 & & NA & NA & $x$ & & & & L217 & -2 & NA \\
\hline & 9 & 57-L15D & Follow AR1 & 0812 & 150 & & 160 & & NA & NA & $x$ & & & & None & +2 & NA \\
\hline & 10 & 11-L13A & Follow AR1 & 0822 & 165 & & 145 & TA & NA & NA & $x$ & & & & R277 & +16 & NA \\
\hline & 11 & 33-L13C & Follow AR1 & 0833 & 165 & & 135 & TA & NA & NA & $x$ & & & & R277 & \begin{tabular}{l|l|}
-7 & \\
\end{tabular} & NA \\
\hline & 12 & 53-L13D & Follow AR1 & 0844 & 165 & & 150 & & NA & NA & $x$ & & & & R277 & +14 & NA \\
\hline & 13 & 17-L16A & Follow AR1 & 0854 & 145 & & 120 & & NA & NA & $x$ & & & & R287 & 0 & NA \\
\hline & 14 & 39-L16C & Follow AR1 & 0905 & 148 & & 120 & & NA & NA & $\mathrm{x}$ & & & & R287 & -5 & NA \\
\hline & 15 & 59-L16D & Follow AR1 & 0917 & 148 & & 120 & & NA & NA & $x$ & & & & None & 0 & NA \\
\hline & 16 & 61-L12E & Follow AR2 & 0928 & 120 & & 130 & & NA & NA & $x$ & & & & L317 & -90 & NA \\
\hline & 17 & 41-L12M & Follow AR2 & 0940 & 120 & & 130 & & NA & NA & $x$ & & & & R277 & +15 & NA \\
\hline & 18 & 63-L12N & Follow AR2 & 0950 & 120 & & 130 & & NA & NA & $x$ & & & & R277 & +12 & NA \\
\hline & 19 & 13-L14A & Follow AR2 & 1002 & 120 & & 145 & & NA & NA & $x$ & & & & R277 & \begin{tabular}{|l|}
-20 \\
\end{tabular} & NA \\
\hline & 20 & 35-L14C & Follow AR2 & 1013 & 120 & & 143 & & NA & NA & $x$ & & & & R267 & -15 & NA \\
\hline
\end{tabular}

Notes: Altimeter calibration was performed (the N3GC aircraft $+60 \mathrm{ft}$ ). Artificial offset was applied for 1,000-ft runs. This flight used wind matrix climb/descent encounters. All runs were ADS-B only (due to poor Fusion performance).

Encounters:

- $\quad 1$ - INT1 ground speed 10-15 low, good

- 2 - seems excessive turn, bad

- 3 - good

- 4 - wind adjust +5 seconds, good

- 5 - wind adjust +5 seconds, good

- 6 - wind adjust -5 seconds, good

- 7 - wind adjust -25 seconds, good

- $\quad 8-29.97$ (ground), wind adjust -20 seconds, good

- $\quad 9$ - wind adjust +5 seconds, $\mathrm{O} / \mathrm{S}$ slow and late, bad

American Institute of Aeronautics and Astronautics 
- 10 - wind adjust +10 seconds, good

- 11 - wind adjust +10 seconds, good

- $\quad 12$ - wind adjust -20 seconds, INT1 request reset, good

- 13 - wind adjust -5 seconds, maneuver and level off, good

- 14 - wind adjust -5 seconds, maneuver and level off, good

- $\quad 15$ - wind adjust +5 seconds, maneuver and level off, $\mathrm{O} / \mathrm{S}$ request reset (too fast), bad

- 16 - CBDR, merged, bad

- $17-\mathrm{O} / \mathrm{S}$ request reset, good

- 18 - CBDR, merged, bad

- 19 - wind adjust 0 seconds, INT1 request reset, good

- 20 - wind adjust +10 seconds, INT1 request reset, good

Airspace: R-2515 FL200 and below, Buckhorn FL100 and above, R-2515 SPORT stay FL120 and above; did not affect runs.

Barometer/Visibility: $29.95 \mathrm{in} / \mathrm{Hg}$, clear

Wind: 3 - INT1 221/19, 4 - INT1 209/7, 5 - INT1 207/5, 6 - INT1 294/8, 7 - O/S 257/18, INT1 204/13, 8 - O/S 237/15, INT1 160/3, 9 - O/S 217/8, INT1 217/10, 10 - O/S 203/6, INT1 194/22, 11 - O/S 224/10, INT1 232/13, 12 O/S 167/6, INT1 225/20, 13 - O/S 220/8, INT1 223/21, 14 - O/S 217/8, INT1 256/12, 15 - O/S 195/7, INT1 232/18, 19 - O/S 237/18, INT1 180/10, 20 - O/S 244/15, INT1 232/14

Bottom Line: Overall, test points were conducted well, but maneuvers were only of acceptable quality. Display of VSCS (seen in SAF) was showing identical directive maneuvers for different encounters. The directive guidance was thought odd as each encounter was of a new geometry. Wind matrix worked well for this flight day. This flight was the first case where it seemed CPA timing was not as important as intent for maneuvering encounters; algorithm only needed to be alerted, followed by $\mathrm{O} / \mathrm{S}$ maneuver.

4. Flight 4: June 24, 2015

Table 14. Configuration 1, flight 4 data.

\begin{tabular}{|c|c|c|c|c|c|c|c|c|c|c|c|c|c|c|c|c|c|}
\hline Flight & \multicolumn{17}{|c|}{4} \\
\hline SUT & \multicolumn{17}{|c|}{ CPDS } \\
\hline Duration & \multicolumn{17}{|c|}{4.7 hours } \\
\hline Intruder(s) & \multicolumn{17}{|c|}{ N3GC } \\
\hline \multirow{21}{*}{ Data } & \# & Scenario & Type & COMEX & O/S Alt. & TA/RA & Int1 Alt. & TA/RA & Int2 Alt. & TA/RA & ADS-B & RDR & TCAS & TRC & $\mathrm{O} / \mathrm{S}$ & Int1 & Int2 \\
\hline & 1 & 137-L53C & TCAS Advisory & 0640 & 145 & & 137 & TA & N/A & NA & $x$ & $x$ & $x$ & & -2 & +5 & NA \\
\hline & 2 & 137-L53C [R] & TCAS Advisory & 0650 & 145 & TA/RA & 140 & TA/RA & N/A & NA & $\mathrm{x}$ & $x$ & $\mathrm{x}$ & & -5 & -6 & NA \\
\hline & 3 & 137-L53C & TCAS AUTO & 0702 & 145 & TA/RA & 140 & TA/RA & N/A & NA & $\mathrm{x}$ & $\mathrm{x}$ & $\mathrm{x}$ & & +25 & 0 & NA \\
\hline & 4 & 146-L54D & TCAS Advisory & 0720 & 120 & TA & 130 & TA & NA & NA & $x$ & $\mathrm{x}$ & $x$ & & -12 & -8 & NA \\
\hline & 5 & 146-L54D [R] & TCAS Advisory & 0730 & 120 & TA/RA & 125 & TA/RA & NA & NA & $x$ & $x$ & $\mathrm{x}$ & & 0 & +5 & NA \\
\hline & 6 & 146-L54D & TCAS AUTO & 0741 & 120 & TA/RA & 125 & TA/RA & NA & NA & $x$ & $x$ & $x$ & & 0 & 0 & $\mathrm{NA}$ \\
\hline & 7 & 140-L55A & TCAS Advisory & 0753 & 135 & & 145 & & N/A & NA & $x$ & $x$ & $x$ & & +5 & +3 & NA \\
\hline & 8 & 140-L55A [R] & TCAS Advisory & 0804 & 140 & TA/RA & 145 & TA/RA & NA & NA & $\mathrm{x}$ & $\mathrm{x}$ & $\mathrm{x}$ & & +13 & +5 & $\mathrm{NA}$ \\
\hline & 9 & 140-L55A & TCAS AUTO & 0813 & 140 & TA/RA & 145 & TA/RA & N/A & NA & $x$ & $x$ & $x$ & & -2 & +3 & $\mathrm{NA}$ \\
\hline & 10 & 151-L56F & TCAS Advisory & 0823 & 125 & TA/RA & 120 & TA/RA & NA & NA & $\mathrm{x}$ & $x$ & $x$ & & -7 & -2 & NA \\
\hline & 11 & 151-L56F & TCAS AUTO & 0833 & 125 & TA/RA & 120 & TA/RA & NA & NA & $x$ & $x$ & $x$ & & - & 0 & NA \\
\hline & 12 & 115-L32G & Radar CBDR (110) & 0841 & 120 & TA/RA & 123 & TA & NA & NA & & $\mathrm{x}$ & & & -40 & -30 & NA \\
\hline & 13 & 121-L32G & Radar CBDR (90) & 0855 & 120 & TA/RA & 123 & TA/RA & NA & NA & $x$ & $x$ & & & - & -30 & $\mathrm{NA}$ \\
\hline & 14 & 115-L32G [R] & Radar CBDR (110) & 0909 & 120 & TA/RA & 124 & TA/RA & NA & NA & $x$ & $x$ & & & -30 & -60 & NA \\
\hline & 15 & 117-L53G & Radar CBDR (110) & 0923 & 165 & TA/RA & 160 & TA/RA & NA & NA & $\mathrm{x}$ & $\mathrm{x}$ & & & -30 & -30 & NA \\
\hline & 16 & 124-L55G & Radar CBDR (90) & 0936 & 170 & TA/RA & 175 & TA/RA & N/A & NA & $x$ & $x$ & & & -30 & -40 & $\mathrm{NA}$ \\
\hline & 17 & 128-L32A & TCAS Advisory & 0955 & 120 & TA/RA & 123 & TA/RA & N/A & NA & $\mathrm{x}$ & $\mathrm{x}$ & $\mathrm{x}$ & & +7 & -1 & NA \\
\hline & 18 & 128-L32A & TCAS AUTO & 1005 & 120 & TA/RA & 123 & TA/RA & NA & NA & $x$ & $x$ & $\mathrm{x}$ & & +6 & +5 & NA \\
\hline & 19 & 129-L32C & TCAS Advisory & 1015 & 120 & TA/RA & 123 & TA/RA & NA & NA & $\mathrm{x}$ & $\mathrm{x}$ & $\mathrm{x}$ & & -7 & -4 & NA \\
\hline & 20 & 129-L32C & TCAS AUTO & 1025 & 120 & TA/RA & 123 & TA/RA & NA & NA & $x$ & $\mathrm{x}$ & $\mathrm{x}$ & & -3 & -7 & NA \\
\hline
\end{tabular}

Notes: Altimeter calibration was performed (the N3GC aircraft $+80 \mathrm{ft}$ ). 
Encounters:

- 1 - no RA, bad

- 2 - raised INT1 start altitude FL115, O/S RA climb, good

- 3 - raised INT1 start altitude FL115, O/S RA climb, good

- 4 - multiple rolex, no RA, bad

- 5 - lowered INT1 start altitude FL150, O/S RA descend, good

- 6 - lowered INT1 start altitude FL150, O/S RA descend, good

- 7 - no RA, bad

- 8 - raised O/S start altitude FL115, O/S RA descend, good

- 9 - raised O/S start altitude FL115, O/S RA do not climb, good

- $10-\mathrm{O} / \mathrm{S}$ RA do not descend, good

- $11-$ O/S RA do not descend, good

- $12-$ O/S RA do not climb, INT1 fast, bad

- $13-\mathrm{O} / \mathrm{S}$ RA descend, INT1 slow, bad

- 14 - angle $\sim 106^{\circ}$, good

- 15 - raised INT1 start altitude FL120, INT1 descend 1100 fpm, good

- 16 - raised O/S altitude FL120, O/S RA do not climb, good

- $17-$ O/S RA do not climb, good

- 18 - O/S RA descend, good

- $19-$ O/S RA descend, did not descend, bad

- $20-$ O/S RA descend, good

Airspace: Buckhorn active FL200 and below, later cleared FL120-200; did not affect runs.

Barometer/Visibility: $29.91 \mathrm{in} / \mathrm{Hg}$, clear

Wind: 1 - O/S 167/17, INT1 160/16, 2 - O/S 152/17, INT1 141/20, 3 - O/S 168/9, INT1 156/19, 4 - O/S 147/13, INT1 195/8, 5 - O/S 134/13, INT1 231/6, 6 - O/S 134/13, INT1 278/7, 7 - O/S 184/12, INT1 188/12, 8 - O/S 185/10, INT1 192/10, 9 - O/S 190/10, INT1 calm, 10 - O/S 200/10, INT1 240/19, 11 - O/S 280/6, INT1 calm, 13 - O/S 188/12, INT1 188/17, 14 - O/S 192/12, INT1 178/18, 15 - O/S 222/13, 219/15, 16 - O/S 169/16, INT1 188/11, 17 O/S 205/16, INT1 155/13, 18 - O/S 208/17, INT1 calm, 19 - O/S 205/15, INT1 161/11, 20 - O/S 209/15, INT1 176/21

Bottom Line: Some starting altitudes needed to be raised or lowered (500 ft) real time in order for aircraft to achieve desired performance and trigger RAs. Once the altitudes were adjusted, the TCAS system was successfully tested and Ikhana performed maneuvers that were expected for the particular encounter and in the milestone AUTO mode. For radar CBDR encounters, the N3GC aircraft attempted to use a bearing tool on board the aircraft; although the tool itself was effective, the encounter angle itself was not completely understood by the crew. Thus, the relative angle of several of the radar encounters was incorrect. For the encounters where the angle was correct, the radar data were deemed good by the researcher. Altitude redlines were made to proceeding flights cards to meet aircraft performance based on the outcome of this flight. CBDR cards were modified for proceeding flights to better highlight how to perform this type of encounter. 
Table 15. Configuration 1, flight 5 data.

\begin{tabular}{|c|c|c|c|c|c|c|c|c|c|c|c|c|c|c|c|c|c|}
\hline Flight & \multicolumn{17}{|c|}{5} \\
\hline SUT & \multicolumn{17}{|c|}{ CPDS } \\
\hline Duration & \multicolumn{17}{|c|}{4.6 hours } \\
\hline Intruder(s) & \multicolumn{17}{|c|}{ N3GC, NASA865 } \\
\hline \multirow{17}{*}{ Data } & \# & Scenario & Type & COMEX & O/S Alt. & TA/RA & Int1 Alt. & TA/RA & Int2 Alt. & TA/RA & ADS-B & RDR & TCAS & TRC & $\mathrm{O} / \mathrm{S}$ & Int1 & Int2 \\
\hline & 1 & 108-L12A & Radar low alt. & 0637 & 052 & & 062 & & NA & NA & & $\mathrm{x}$ & & & -2 & +2 & N/A \\
\hline & 2 & 107-L12A & Radar low alt. & 0647 & 042 & & 052 & & N/A & NA & $\mathrm{x}$ & $x$ & & & -8 & +1 & NA \\
\hline & 3 & 112-L11A & Radar low alt. & 0657 & 062 & & 052 & & NA & NA & $x$ & $x$ & & & 0 & +2 & NA \\
\hline & 4 & 111-L11A & Radar low alt. & 0708 & 052 & & 042 & & NA & NA & $x$ & $x$ & & & +9 & 0 & N/A \\
\hline & 5 & 169-M79X & Fly-through, CPDS & 0822 & 130 & TA/RA & 134 & TA/RA & 125 & & $x$ & & $x$ & & RT & +10 & +5 \\
\hline & 6 & 170-M79X & Fly-through, CPDS & 0834 & 130 & & 134 & & 125 & & $x$ & & $x$ & & - & - & - \\
\hline & 7 & 171-M79X & Fly-through, CPDS & 0846 & 130 & TA & 134 & TA & 125 & & $x$ & & $x$ & & +2 & 0 & -4 \\
\hline & 8 & 160-M67Q & TCAS Advisory & 0858 & 133 & TA/RA & 14 & TA/RA & 13 & TA & $x$ & $x$ & $x$ & & - & - & - \\
\hline & 9 & 161-M68Q & TCAS Advisory & 0909 & 137 & TA/RA & 14 & TA/RA & 13 & TA & $x$ & $x$ & $x$ & & 0 & - & +8 \\
\hline & 10 & 165-L52M & Fly-through, CPDS & 0924 & 120 & TA & 125 & TA & NA & NA & $x$ & & $x$ & & +10 & +15 & NA \\
\hline & 11 & 166-L52M & Fly-through, CPDS & 0937 & 120 & TA & 125 & TA & NA & NA & $x$ & & $x$ & & +10 & 0 & N/A \\
\hline & 12 & 167-L52M & Fly-through, CPDS & 0947 & 120 & TA & 125 & TA & NA & NA & $x$ & & $x$ & & -9 & 0 & NA \\
\hline & 13 & 168-L52M & Follow CPDS & 0957 & 120 & TA/RA & 125 & TA/RA & NA & NA & $x$ & & $x$ & & RT & -3 & NA \\
\hline & 14 & 164-L42M & Follow CPDS & 1007 & 120 & TA/RA & 125 & RA & NA & NA & $x$ & & $x$ & & LT & 0 & NA \\
\hline & 15 & 132-L31A & TCAS Advisory & 1018 & 123 & & 120 & & NA & NA & $x$ & $x$ & $x$ & & - & - & NA \\
\hline & 16 & 132-L31A & TCAS AUTO & 1028 & 123 & & 120 & & N/A & NA & $x$ & $x$ & $x$ & & 0 & +5 & NA \\
\hline
\end{tabular}

Notes: Altimeter calibration was performed (the N3GC aircraft $+60 \mathrm{ft}$, the NASA 865 aircrarft $+190 \mathrm{ft}$ ). Additional 200 -ft encounters were planned, but not performed (TCAS sequential); alerting achieved with 300 -ft separation (runs 8, 9).

Encounters:

- $1-$ good

- $2-$ good

- $3-\operatorname{good}$

- 4-good

- $5-\mathrm{O} / \mathrm{S}$ was not supposed to maneuver (+not called out), INT1 RA climb, good

- 6 - INT1 heading wrong on maneuver, good

- $7-\operatorname{good}$

- 8 - O/S RA climb, about 20 seconds then O/S RA descend, NO VID INT2 on O/S, good

- 9 - O/S RA descend, about 8 seconds then O/S RA climb, good

- $10-$ good

- $11-$ good

- 12 - good

- 13 - RA INT1 monitor vertical speed, good

- 14 - INT1 RA adjust vertical speed, good

- 15 - O/S RA climb, INT1 RA adjust vertical speed, good

- $16-$ O/S RA climb, INT1 RA descend, good

Airspace: Received Buckhorn early FL100-200.

Barometer/Visibility: $29.99 \mathrm{in} / \mathrm{Hg}$, hazy (due to Lake wildfire)

Wind: 12 - O/S 160/13, INT1 158/19, 14 - O/S 169/14, INT1 150/11

Bottom Line: Considering the challenging geometries and conditions (weather), this flight collection day was excellent. The first multiship live UAS encounter in flight-test history was performed (runs 5, 6, and 7). First low altitude radar runs were performed to test DRR on Ikhana (runs 1, 2, 3, and 4). The TCAS multiship sequential encounters (runs 8, and 9) ran smoothly and safely, all triggering expected alerting in advisory mode. Although a mission rule was violated (run 8, no VID), at no point did the pilots or any other team member feel unsafe or that the 
flight could not continue. Additional, directive guidance was given to pilots concerning VID after run 8 and in proceeding flights.

6. Flight 6: July 7, 2015

Table 16. Configuration 1, flight 6 data.

\begin{tabular}{|c|c|c|c|c|c|c|c|c|c|c|c|c|c|c|c|c|c|}
\hline Flight & \multicolumn{17}{|c|}{6} \\
\hline SUT & \multicolumn{17}{|c|}{ Stratway+ } \\
\hline Duration & \multicolumn{17}{|c|}{4.8 hours } \\
\hline Intruder(s) & \multicolumn{17}{|c|}{ N3GC } \\
\hline \multirow{23}{*}{ Data } & $\#$ & Scenario & Type & COMEX & O/S Alt. & TA/RA & Int1 Alt. & TA/RA & Int2 Alt. & TA/RA & ADS-B & $\mathrm{RDR}$ & TCAS & TRC & $\mathrm{O} / \mathrm{S}$ & Int1 & Int2 \\
\hline & 1 & $25-L 53 C$ & Follow Stratw ay+ & 0645 & 145 & TA & 130 & TA & N/A & NA & & $x$ & & & RT & 0 & NA \\
\hline & 2 & 46-L53D & Follow Stratway+ & 0655 & 145 & TA/RA & 135 & TA/RA & NA & NA & & $x$ & & $x$ & RT & 0 & NA \\
\hline & 3 & 68-L53F & Follow Stratway+ & 0707 & 145 & & 120 & & NA & NA & $\mathrm{x}$ & & & $\mathrm{x}$ & LT & 0 & NA \\
\hline & 4 & 26-L54C & Follow Stratw ay+ & 0717 & 120 & TA & 145 & TA & N/A & NA & & $\mathrm{x}$ & & $\mathrm{x}$ & RT & 0 & NA \\
\hline & 5 & 47-L54D & Follow Stratway+ & 0727 & 120 & TA & 135 & TA & N/A & NA & & $x$ & & $x$ & RT & +3 & NA \\
\hline & 6 & 69-L54F & Follow Stratway+ & 0736 & 120 & & 137 & & N/A & NA & $x$ & & & $x$ & LT & +7 & NA \\
\hline & 7 & 5-L56A & Follow Stratway+ & 0746 & 142 & TA & 125 & TA & NA & NA & & $x$ & & $x$ & RT & -2 & NA \\
\hline & 8 & 6-L56B & Follow Stratway+ & 0756 & 141 & TA/RA & 125 & TA/RA & N/A & NA & & $x$ & & $x$ & LT & 0 & NA \\
\hline & 9 & 23-L56C & Follow Stratway+ & 0808 & - & TA/RA & 125 & TA/RA & N/A & NA & $x$ & $x$ & & $x$ & None & -10 & NA \\
\hline & 10 & 44-L56D & Follow Stratway+ & 0817 & 150 & TA & 125 & TA & N/A & NA & $x$ & $x$ & & $x$ & RT & +3 & NA \\
\hline & 11 & 66-L56F & Follow Stratway+ & 0825 & 130 & & 125 & & N/A & NA & & $\mathrm{x}$ & & & None & +7 & NA \\
\hline & 12 & 66-L56F [R] & Follow Stratway+ & 0842 & 140 & & 125 & & NA & NA & & $\mathrm{x}$ & & & LT & early & NA \\
\hline & 13 & 1-L42A & Follow Stratway+ & 0852 & 120 & TA/RA & 124 & TA/RA & N/A & NA & & $x$ & & & RT & 0 & NA \\
\hline & 14 & 2-L42B & Follow Stratway+ & 0902 & 120 & TA/RA & 124 & RA & NA & NA & $\mathrm{x}$ & $x$ & $\mathrm{x}$ & $x$ & LT & -13 & NA \\
\hline & 15 & $21-L 42 C$ & Follow Stratway+ & 0912 & 120 & TA/RA & 124 & TA/RA & N/A & NA & $x$ & $x$ & $x$ & $x$ & LT & 0 & NA \\
\hline & 16 & $42-L 42 D$ & Follow Stratway+ & 0922 & 120 & TA & 124 & TA & NA & NA & $x$ & $x$ & $x$ & $x$ & LT & 0 & NA \\
\hline & 17 & 64-L42F & Follow Stratway+ & 0940 & 120 & & 124 & & N/A & NA & $x$ & $x$ & $x$ & $x$ & LT & 0 & NA \\
\hline & 18 & $20-\mathrm{L} 32 \mathrm{~A}$ & Follow Stratway+ & 0950 & 120 & $T A$ & 124 & TA & N/A & NA & $x$ & $x$ & $x$ & $x$ & RT & +2 & NA \\
\hline & 19 & $31-\mathrm{L} 32 \mathrm{C}$ & Follow Stratw ay+ & 1005 & 130 & TA/RA & 133 & TA/RA & NA & NA & & $x$ & & & LT & +2 & NA \\
\hline & 20 & $51-\mathrm{L} 32 \mathrm{D}$ & Follow Stratway+ & 1015 & 130 & TA & 133 & TA & N/A & NA & & $x$ & & & LT & 0 & NA \\
\hline & 21 & 68-L53F & Follow Stratway+ & 1027 & 145 & & 125 & & N/A & NA & & $x$ & $x$ & & LT & -1 & NA \\
\hline & 22 & 69-L54F & Follow Stratway+ & 1037 & 120 & & 145 & & NA & NA & $\mathrm{x}$ & $x$ & $\mathrm{x}$ & & LT & early & NA \\
\hline
\end{tabular}

Notes: Altimeter calibration was performed (the N3GC aircraft $+60 \mathrm{ft}$ ). What looked like a level acceleration was performed (should not have been). All climb/descent leg altitudes were redlined prior to flight to achieve "run-in" type encounters for Stratway+.

Encounters:

- $1-$ good

- 2 - odd run $(\mathrm{O} / \mathrm{S}$ maneuver into INT1), good

- 3 -good

- 4 - VSCS split track, band issues (almost terminate run), bad

- 5 - vertical velocity noise in Stratway+, good

- 6 - good

- 7 - split track, good

- 8 - INT1 RA descend, good

- 9 - maintained heading, O/S RA do not descend, INT1 RA descend, bad

- 10 - split track, good

- 11 - maintained heading, $\mathrm{O} / \mathrm{S}$ fast, bad

- 12 - TC push INT1 faster (210 KGS), terminate early due to north airspace activity, good

- $13-$ O/S RA descend, INT1 RA climb, good

- $14-$ O/S RA descend, INT1 RA climb, good

- $15-$ O/S RA do not climb, INT1 RA monitor vertical speed, good

- 16 - good

- 17 - changed Stratway+ sensitivity, laptop problem and multiple rolex, good

39

American Institute of Aeronautics and Astronautics 
- $\quad 18$ - INT1 ended at higher altitude $(+100 \mathrm{ft})$, good

- $19-$ good

- $20-$ good

- $21-$ good

- $22-$ good

Airspace: Multiple calls to SPORT were unanswered. Stay above FL105 (did not affect runs). SPORT called combat laser, request stay above FL130 (affected runs 19, and 20). Later stay above FL100 (did not affect runs).

Barometer/Visibility: 29.97in/Hg, clear

Wind: 4 - O/S 170/25, INT1 180/19, 7 - O/S 189/7, INT1 175/18, 10 - O/S 193/6.5, INT1 207/24, 13 - O/S 160/17, INT1 176/20, 18 - O/S 178/13, INT1 169/20, 19 - O/S 191/19, INT1 134/19, 21 - O/S 176/10, INT1 191/13

Bottom Line: The bulk of the data were good, but the "split tracks" that kept occurring on VSCS were thought too distracting/incorrect for subsequent days. Thus, in proceeding flights the native Stratway+ display was used in the Ikhana GCS instead of the algorithm being fed through VSCS.

7. Flight 7: July 9, 2015

Table 17. Configuration 1, flight 7 data.

\begin{tabular}{|c|c|c|c|c|c|c|c|c|c|c|c|c|c|c|c|c|c|}
\hline Flight & \multicolumn{17}{|c|}{7} \\
\hline SUT & \multicolumn{17}{|c|}{ Stratway+ } \\
\hline Duration & \multicolumn{17}{|c|}{4.8 hours } \\
\hline Intruder(s) & \multicolumn{17}{|c|}{ N3GC } \\
\hline \multirow{24}{*}{ Data } & $\#$ & Scenario & Type & COMEX & O/S Alt. & TA/RA & Int1 Alt. & TA/RA & Int2 Alt. & TA/RA & ADS-B & RDR & TCAS & TRC & $\mathrm{O} / \mathrm{S}$ & $\operatorname{lnt1}$ & Int2 \\
\hline & 1 & 22-L55C & Follow Stratw ay+ & 0653 & 132 & TA/RA & 145 & TA/RA & NA & N/A & & $x$ & & & R275 & - & N/A \\
\hline & 2 & 43-L55D & Follow Stratw ay+ & 0703 & 125 & & 145 & & NA & NA & & $x$ & & & R050 & +2 & NA \\
\hline & 3 & 65-L55F & Follow Stratw ay+ & 0713 & 127 & & 145 & & NA & NA & $x$ & & & & L060 & +20 & N/A \\
\hline & 4 & 24-L57C & Follow Stratw ay+ & 0725 & 122 & TA & 167 & TA & N/A & NA & & $x$ & & & R265 & 0 & NA \\
\hline & 5 & 45-L57D & Follow Stratw ay+ & 0735 & 118 & TA & 162 & TA & N/A & NA & & $\mathrm{X}$ & & & L330 & +5 & N/A \\
\hline & 6 & 67-L57F & Follow Stratw ay+ & 0743 & 119 & & 16 & & NA & NA & $x$ & & & & L060 & +10 & N/A \\
\hline & 7 & 7-L57A & Follow Stratw ay+ & 0755 & 120 & TA & 158 & TA & NA & NA & & $x$ & $x$ & $x$ & R270 & - & NA \\
\hline & 8 & 3-L55A & Follow Stratw ay+ & 0807 & 131 & & 145 & & NA & NA & & $x$ & $x$ & $x$ & L200 & 0 & $\mathrm{~N} / \mathrm{A}$ \\
\hline & 9 & 4-L55B & Follow Stratw ay+ & 0819 & 120 & TA & 145 & TA & N/A & NA & & & $x$ & $x$ & L225 & +1 & NA \\
\hline & 10 & 21-L42C & Follow Stratw ay+ & 0830 & 120 & TA/RA & 124 & TA/RA & N/A & NA & $\mathrm{x}$ & $\mathrm{X}$ & $x$ & $\mathrm{x}$ & R260 & 0 & N/A \\
\hline & 11 & 42-L42D & Follow Stratw ay+ & 0840 & 120 & TA & 124 & TA & NA & NA & $x$ & $x$ & $x$ & $x$ & L330 & +5 & N/A \\
\hline & 12 & 64-L42F & Follow Stratw ay+ & 0848 & 120 & TA & 124 & TA & N/A & NA & $x$ & $x$ & $x$ & $x$ & R130 & 0 & NA \\
\hline & 13 & 26-L54C & Follow Stratw ay+ & 0900 & 120 & & 132 & & NA & NA & $x$ & $x$ & $x$ & $x$ & R285 & 0 & N/A \\
\hline & 14 & 47-L54D & Follow Stratw ay+ & 0909 & 120 & TA/RA & 126 & TA/RA & NA & NA & & $x$ & & & L230 & - & NA \\
\hline & 15 & 47-L54D & Follow Stratway+ & 0920 & 120 & TA & 140 & TA & N/A & NA & $x$ & $x$ & $x$ & $x$ & R030 & +4 & NA \\
\hline & 16 & 22-L55C & Follow Stratw ay+ & 0930 & 131 & TA & 145 & TA & N/A & NA & $x$ & $x$ & $x$ & $x$ & R270 & 0 & NA \\
\hline & 17 & 43-L55D & Follow Stratw ay+ & 0940 & 127 & & 145 & & N/A & NA & $x$ & $x$ & $x$ & $x$ & R060 & 0 & N/A \\
\hline & 18 & 65-L55F & Follow Stratw ay+ & 0948 & - & & 145 & & N/A & NA & & $x$ & & & L050 & early & N/A \\
\hline & 19 & 24-L57C & Follow Stratw ay+ & 0958 & 124 & TA & 168 & TA & N/A & NA & $x$ & $x$ & $x$ & $x$ & R270 & 0 & NA \\
\hline & 20 & 45-L57D & Follow Stratway+ & 1007 & - & TA/RA & - & TA & N/A & NA & $x$ & $x$ & $x$ & $x$ & R055 & +5 & N/A \\
\hline & 21 & 67-L57F & Follow Stratw ay+ & 1016 & 140 & TA & 145 & TA & NA & NA & & & $x$ & & None & - & N/A \\
\hline & 22 & 25-L53C & Follow Stratway+ & 1026 & 145 & TA & 130 & TA & N/A & NA & $x$ & & & & R270 & -9 & N/A \\
\hline & 23 & 46-L53D & Follow Stratw ay+ & 1036 & 145 & TA/RA & 125 & $\mathrm{TA}$ & N/A & NA & $x$ & & & & R045 & 0 & NA \\
\hline
\end{tabular}

Notes: Altimeter calibration was performed (the N3GC aircraft $+60 \mathrm{ft}$ ). All climb/descent leg altitudes were redlined prior to flight to achieve "merge intent" type encounters for Stratway+. This flight used native Stratway+ display in Ikhana GCS.

Encounters:

- $1-$ O/S RA descend, INT1 RA climb, TC slowed INT1 $10 \mathrm{kn}$, good

- $2-\mathrm{O} / \mathrm{S}$ large deviation from CPA, good

- 3 - TC slowed INT1 $10 \mathrm{kn}$, good

- 4 - performed maneuver but did not turn back, bad

- 5 - good

American Institute of Aeronautics and Astronautics 
- 6 - TC slowed INT1 $10 \mathrm{kn}$, resumed speed at turn, good

- 7 - good

- 8 - good

- $9-$ good

- $10-$ O/S RA do not climb, INT1 RA monitor speed

- $11-\operatorname{good}$

- 12 - good

- $13-$ good

- 14 - O/S RA do not climb, INT1 RA maintain vertical speed, good

- 15 - late turn back on course, good

- $16-$ good

- $17-$ good

- 18 - terminate early due to no airspace north, good

- $19-$ good

- 20 - 200-ft excursion, O/S RA descend, good

- 21 - no banding, bad

- 22 - good

- $23-$ O/S RA climb, good

Airspace: SPORT stay FL105-200 (did not affect runs), C-17 FL060 and below (did not affect runs). FT3 multiple spillouts north of airspace (coordinated minutes prior with SPORT).

Barometer/Visibility: $29.81 \mathrm{in} / \mathrm{Hg}$, haze layer, good visibility at altitude

Wind: 1 - O/S 220/15.5, INT1 235/12, 4 - O/S 191/17, INT1 228/24, 7 - O/S 193/16, INT1 233/26, 8 - O/S 206/15, INT1 238/17, 11 - O/S 174/11, INT1 209/9, 13 - O/S 180/19, INT1 250/16, 15 - O/S 200/12, INT1 234/16, 16 - O/S 205/15, INT1 195/16, 18 - O/S 190/11, INT1 218/7, 19 - O/S 200/14, INT1 237/19, 22 - O/S 220/20, INT1 $180 / 21$

Bottom Line: Overall, encounters were good and using the native Stratway+ display helped the O/S pilots better understand the banding which they needed to fly. Intruder aircraft had timing issues this day (caused several rolex calls), but did not affect runs. 
Table 18. Configuration 1, flight 8 data.

\begin{tabular}{|c|c|c|c|c|c|c|c|c|c|c|c|c|c|c|c|c|c|}
\hline Flight & \multicolumn{17}{|c|}{8} \\
\hline SUT & \multicolumn{17}{|c|}{ Stratway+, CPDS } \\
\hline Duration & \multicolumn{17}{|c|}{4.6 hours } \\
\hline Intruder(s) & \multicolumn{17}{|c|}{ N3GC, NASA865 } \\
\hline \multirow{21}{*}{ Data } & $\#$ & Scenario & Type & COMEX & O/S Alt. & TA/RA & Int1 Alt. & TA/RA & Int2 Alt. & TA/RA & ADS-B & RDR & TCAS & TRC & $\mathrm{O} / \mathrm{S}$ & Int1 & Int2 \\
\hline & 1 & 8-M59Q & Follow Stratw ay+ & 0646 & 130 & TA & 135 & TA & 125 & & & $x$ & & & L330 & +1 & +3 \\
\hline & 2 & 8-M59Q & Follow Stratw ay+ & 0656 & 130 & TA & 135 & TA & 125 & & $x$ & $x$ & $x$ & $x$ & L040 & +2 & +4 \\
\hline & 3 & 28-M59V & Follow Stratw ay+ & 0705 & 130 & TA & 135 & TA & 125 & TA & & $x$ & & & R290 & 0 & +8 \\
\hline & 4 & 28-M59V & Follow Stratw ay+ & 0715 & 130 & TA & 135 & TA & 125 & TA & $x$ & $x$ & $x$ & $x$ & $\mathrm{R} 290$ & +5 & +4 \\
\hline & 5 & 71-M59W & Follow Stratw ay+ & 0725 & 130 & TA & 135 & TA & 125 & TA & $x$ & & & & L370 & +4 & +11 \\
\hline & 6 & 71-M59W & Follow Stratway+ & 0735 & 130 & TA & 135 & & 125 & TA & $x$ & $x$ & $x$ & $x$ & L300 & +3 & +5 \\
\hline & 7 & 9-M59U & Follow Stratw ay+ & 0745 & 130 & & 135 & & 125 & TA & & $x$ & & & R370 & +1 & 0 \\
\hline & 8 & 27-M59R & Follow Stratw ay+ & 0755 & 130 & TA/RA & 135 & TA/RA & 125 & & & $x$ & & & R310 & +6 & 0 \\
\hline & 9 & 48-M59S & Follow Stratw ay+ & 0805 & 130 & TA & 135 & TA & 125 & TA & & $x$ & & & R330 & +1 & 0 \\
\hline & 10 & 70-M59T & Follow Stratw ay+ & 0815 & 130 & TA/RA & 135 & TA/RA & 125 & TA & $x$ & & & & L270 & +10 & 0 \\
\hline & 11 & 9-M59U & Follow Stratw ay+ & 0827 & 130 & TA/RA & 135 & & 125 & TA & $x$ & $x$ & $x$ & $x$ & R300 & 0 & +5 \\
\hline & 12 & 27-M59R & Follow Stratw ay+ & 0854 & 130 & TA & 135 & TA & 125 & & $x$ & $x$ & $x$ & $x$ & $\mathrm{R} 270$ & +1 & -4 \\
\hline & 13 & 48-M59S & Follow Stratw ay+ & 0905 & 130 & TA & 135 & TA & 125 & TA & $x$ & $x$ & $x$ & $x$ & R285 & +2 & 0 \\
\hline & 14 & 70-M59T & Follow Stratw ay+ & 0915 & 130 & TA & 135 & TA & 125 & TA & $x$ & $x$ & $x$ & $x$ & R303 & +4 & +5 \\
\hline & 15 & 63-L12N & Follow Stratw ay+ & 0927 & 120 & & 130 & & $\mathrm{~N} / \mathrm{A}$ & N/A & $x$ & & & & R330 & -20 & N/A \\
\hline & 16 & 63-L12N & Follow Stratw ay+ & 0935 & 120 & & 130 & & $\mathrm{~N} / \mathrm{A}$ & N/A & $x$ & $x$ & $x$ & $x$ & R302 & -15 & NA \\
\hline & 17 & 63-L12N & Follow Stratw ay+ & 0943 & 120 & & 130 & & $\mathrm{~N} / \mathrm{A}$ & NA & & $x$ & & & R300 & -15 & N/A \\
\hline & 18 & 122-L31G & Radar CBDR (90) & 0953 & 120 & TA/RA & 123 & TA/RA & N/A & N/A & & $x$ & & $x$ & -40 & -50 & N/A \\
\hline & 19 & 122-L31G [R] & Radar CBDR (90) & 1010 & 120 & TA/RA & 123 & TA/RA & $\mathrm{N} / \mathrm{A}$ & N/A & & $x$ & & $x$ & - & - & NA \\
\hline & 20 & 125-L54G & Radar CBDR (90) & 1022 & 110 & TA/RA & 115 & TA/RA & N/A & NA & & $x$ & & $x$ & - & - & NA \\
\hline
\end{tabular}

Notes: Altimeter calibration was performed (the N3GC aircraft $+60 \mathrm{ft}$, NASA 865 aircraft $+100 \mathrm{ft}$ ). All climb/descent leg altitudes were redlined prior to flight to achieve merge intent type encounters for Stratway+. This flight used native Stratway+ display in Ikhana GCS. TCAS on the NASA 865 aircraft showed Ikhana $300 \mathrm{ft}$ high; runs 18,19 , and 20 radar runs with CPDS display.

Encounters:

- $1-$ good

- 2 - good

- $3-\operatorname{good}$

- $4-\operatorname{good}$

- $5-$ good

- $6-$ good

- 7 - good, INT2 late TA from INT1

- 8 - INT1 RA monitor vertical speed, good

- 9 - good, INT2 late TA from INT1

- 10 - O/S RA maintain level, INT1 monitor/adjust vertical speed, INT2 TA from INT1, good

- $\quad 11-\mathrm{O} / \mathrm{S}$ RA do not descend, INT2 TA from INT1

- $12-\operatorname{good}$

- 13 - good, INT2 TA from INT1

- 14 - good, INT2 TA from INT1

- $15-$ good

- $16-$ good

- $17-\operatorname{good}$

- 18 - INT1 RA descend, INT1 (fast) ahead of O/S, bad

- 19 - angle about $80^{\circ}$ instead of $90^{\circ}$, O/S RA climb, INT1 RA descend, good

- 20 - angle $95^{\circ}$ most of run and $110^{\circ}$ at the end, O/S RA descend, INT1 RA monitor vertical speed, good 
Airspace: Stay below FL230 Buckhorn (did not affect runs). Spin aircraft FL110 and above 45 minutes (did not affect runs).

Barometer/Visibility: $29.86 \mathrm{in} / \mathrm{Hg}$, clear

Wind: 1 - O/S 270/3, 9 - O/S 265/11, INT1 223/5, INT2 calm, 15 - O/S 145/10, INT1 194/15

Bottom Line: Overall data were good. Second day of multiship encounters went smoothly as the first. Adjusting the vertical profile caused a lot more alerting for Stratway+ (good). Runs 18, 19, and 20 gathered good radar data due to change in altitude and better understanding of angle requirements from pilots.

9. Flight 9: July 21, 2015

Table 19. Configuration 1, flight 9 data.

\begin{tabular}{|c|c|c|c|c|c|c|c|c|c|c|c|c|c|c|c|c|c|}
\hline Flight & \multicolumn{17}{|c|}{9} \\
\hline SUT & \multicolumn{17}{|c|}{ Stratway+ } \\
\hline Duration & \multicolumn{17}{|c|}{4.8 hours } \\
\hline Intruder(s) & \multicolumn{17}{|c|}{ NASA850, NASA865 } \\
\hline \multirow{21}{*}{ Data } & $\#$ & Scenario & Type & COMEX & O/S Alt. & TA/RA & Int1 Alt. & TA/RA & Int2 Alt. & TA/RA & ADS-B & RDR & TCAS & TRC & $\mathrm{O} / \mathrm{S}$ & Int1 & Int2 \\
\hline & 1 & 72- $\mathrm{H} 42 \mathrm{~A}$ & Follow Stratw ay+ & 0705 & 120 & TA & 124 & & NA & NA & & $x$ & $x$ & $x$ & L055 & +20 & NA \\
\hline & 2 & $72-\mathrm{H} 42 \mathrm{~A}$ & Follow Stratw ay+ & 0715 & 120 & TA/RA & 124 & & NA & NA & & $x$ & $x$ & & L045 & - & N/A \\
\hline & 3 & $73-\mathrm{H} 42 \mathrm{C}$ & Follow Stratw ay+ & 0723 & 120 & TA/RA & 124 & TA & N/A & NA & & $x$ & $x$ & $x$ & R270 & +25 & N/A \\
\hline & 4 & $73-\mathrm{H} 42 \mathrm{C}$ & Follow Stratw ay+ & 0733 & 120 & TA/RA & 124 & & $\mathrm{~N} / \mathrm{A}$ & N/A & & $x$ & $x$ & & L215 & -6 & NA \\
\hline & 5 & 74-H42D & Follow Stratway+ & 0741 & 120 & TA & 124 & & N/A & NA & & $x$ & $x$ & $x$ & L330 & - & NA \\
\hline & 6 & 74-H42D & Follow Stratw ay+ & 0751 & 120 & TA & 124 & TA & NA & NA & & $x$ & $x$ & & L320 & - & NA \\
\hline & 7 & $75-\mathrm{H} 42 \mathrm{~F}$ & Follow Stratway+ & 0800 & 120 & & 124 & & N/A & NA & & $x$ & $x$ & $x$ & L045 & -5 & NA \\
\hline & 8 & $75-\mathrm{H} 42 \mathrm{~F}$ & Follow Stratw ay+ & 0808 & 120 & TA/RA & 124 & & NA & NA & & $x$ & $x$ & & L010 & 0 & NA \\
\hline & 9 & 23-L56C & Follow Stratway+ & 0835 & 145 & TA/RA & 125 & & NA & NA & $x$ & $x$ & $x$ & $x$ & R270 & - & NA \\
\hline & 10 & 44-L56D & Follow Stratw ay+ & 0843 & 142 & TA & 125 & TA & $\mathrm{N} / \mathrm{A}$ & NA & $x$ & $x$ & $x$ & $x$ & L335 & -10 & NA \\
\hline & 11 & 66-L56F & Follow Stratw ay+ & 0851 & 152 & & 125 & TA & NA & NA & $x$ & $x$ & $x$ & $x$ & L060 & - & NA \\
\hline & 12 & 31-L32C & Follow Stratw ay+ & 0901 & 120 & TA/RA & 123 & TA & N/A & NA & $x$ & $x$ & $x$ & $x$ & L220 & -5 & NA \\
\hline & 13 & 51-L32D & Follow Stratway+ & 0910 & 120 & TA & 123 & TA & N/A & NA & $\mathrm{X}$ & $x$ & $x$ & $x$ & R020 & 0 & N/A \\
\hline & 14 & 23-L56C & Follow Stratway+ & 0926 & 145 & & 125 & TA & N/A & NA & & $x$ & & & L200 & -20 & NA \\
\hline & 15 & 44-L56D & Follow Stratw ay+ & 0935 & 152 & & 125 & TA & $\mathrm{N} / \mathrm{A}$ & NA & & $x$ & & & L330 & +5 & NA \\
\hline & 16 & 66-L56F & Follow Stratw ay+ & 0944 & 145 & TA/RA & 125 & TA & $\mathrm{N} / \mathrm{A}$ & NA & & $x$ & & & L045 & - & NA \\
\hline & 17 & 66-L56F & Follow Stratway+ & 0955 & 152 & & 125 & TA & N/A & NA & & $x$ & & $x$ & L030 & -20 & N/A \\
\hline & 18 & 76-M59R & Follow Stratw ay+ & 1015 & 130 & TA/RA & 135 & TA & 125 & TA & & $x$ & $x$ & $x$ & L220 & - & - \\
\hline & 19 & 76-M59R & Follow Stratway+ & 1025 & 130 & TA & 135 & & 125 & TA & & $x$ & $x$ & & R295 & - & - \\
\hline & 20 & 77-M59S & Follow Stratw ay+ & 1035 & 130 & TA & 135 & & 125 & TA & & $x$ & $x$ & $x$ & R340 & +10 & 0 \\
\hline
\end{tabular}

Notes: Altimeter calibration was performed (The NASA 850 aircraft $+140 \mathrm{ft}$, the NASA 865 aircraft $+100 \mathrm{ft}$ ). All climb/descent leg altitudes were redlined prior to flight to achieve merge intent type encounters for Stratway+. Used native Stratway+ display in Ikhana GCS; runs 1-12 INT1 (NASA 850 aircraft), runs 9-17 INT1 (NASA 865 aircraft), runs18-20 INT1 (NASA 850 aircraft), INT2 (NASA 865 aircraft).

Encounters:

- $1-$ good

- $2-\operatorname{good}$

- $3-\operatorname{good}$

- $4-$ O/S RA do not climb, good

- 5 - slow to develop and INT1 lagging, bad

- 6 - good

- 7 - became tail chase run, good

- 8 - good

- 9 - TC increase INT1 $10 \mathrm{kn}$, INT1 started FL120 instead of 125, good

- $10-\mathrm{O} / \mathrm{S}$ fast, INT1 started FL123 instead of 125, bad

- 11 - INT1 off course on IP, bad

- $12-$ O/S RA do not climb, good

- $13-\operatorname{good}$

American Institute of Aeronautics and Astronautics 
- $14-$ good

- 15 - INT1 fast TC request go card speed, good

- $16-\mathrm{O} / \mathrm{S}$ RA do not descend, O/S fast, INT1 increased speed, good

- $17-$ good

- $18-$ good

- $19-$ good

- $20-$ good

Airspace: Fly below FL200 (did not affect runs), received Buckhorn FL100-200.

Barometer/Visibility: $29.97 \mathrm{in} / \mathrm{Hg}$, clear

Wind: $12-\mathrm{O} / \mathrm{S} 212 / 5$

Bottom Line: Flight 9 was another successful flight day for Stratway+ and the first ever high-speed multiship encounters. As the previous multiship encounters, these encounters went surprisingly smoothly and gave good data for the researcher. Although INT1 was late/early to the CPA for many of the encounters, numerous of these runs were successful due to the intent of the intruder; Stratway+ displayed good alerting for the O/S pilot.

10. Flight 10: July 22, 2015

Table 20. Configuration 1, flight 10 data.

\begin{tabular}{|c|c|c|c|c|c|c|c|c|c|c|c|c|c|c|c|c|c|}
\hline Flight & \multicolumn{17}{|c|}{10} \\
\hline SUT & \multicolumn{17}{|c|}{ AutoResolver } \\
\hline Duration & \multicolumn{17}{|c|}{3.4 hours } \\
\hline Intruder(s) & \multicolumn{17}{|c|}{ NASA865 } \\
\hline \multirow{18}{*}{ Data } & $\#$ & Scenario & Type & COMEX & O/S Alt. & TA/RA & Int1 Alt. & TA/RA & Int2 Alt. & TA/RA & ADS-B & $\mathrm{RDR}$ & TCAS & TRC & $\mathrm{O} / \mathrm{S}$ & Int1 & Int2 \\
\hline & 1 & 41-L12M & Follow AR1 & 0635 & 120 & & 130 & TA & N/A & NA & $\mathrm{x}$ & & & & 280 & -15 & NA \\
\hline & 2 & 63-L12N & Follow AR1 & 0645 & 120 & TA & 130 & TA & N/A & NA & $x$ & & & & 280 & -20 & NA \\
\hline & 3 & 61-L12E & Follow AR1 & 0655 & 120 & TA & 130 & TA & N/A & NA & $x$ & & & & R010 & +5 & N/A \\
\hline & 4 & 13-L14A & Follow AR1 & 0705 & 120 & TA & 144 & TA & N/A & N/A & $x$ & & & & R280 & -8 & N/A \\
\hline & 5 & 35-L14C & Follow AR1 & 0715 & 120 & TA & 147 & TA & N/A & NA & $\mathrm{x}$ & & & & R280 & -3 & NA \\
\hline & 6 & 55-L14D & Follow AR1 & 0725 & 120 & TA & 147 & TA & NA & NA & $x$ & & & & L320 & - & NA \\
\hline & 7 & 15-L15A & Follow AR1 & 0735 & 138 & & 160 & & N/A & NA & $x$ & & & & L230 & 0 & N/A \\
\hline & 8 & 37-L15C & Follow AR1 & 0745 & 135 & & 160 & & N/A & NA & $\mathrm{x}$ & & & & R270 & -25 & NA \\
\hline & 9 & 57-L15D & Follow AR1 & 0755 & 132 & & 160 & & N/A & NAA & $x$ & & & & L330 & +8 & N/A \\
\hline & 10 & 11-L13A & Follow AR1 & 0805 & 165 & TA & 140 & TA & N/A & NA & $x$ & & & & R270 & 0 & NA \\
\hline & 11 & 33-L13C & Follow AR1 & 0815 & 165 & & 138 & & N/A & NA & $\mathrm{x}$ & & & & R280 & +3 & N/A \\
\hline & 12 & 53-L13D & Follow AR1 & 0825 & 165 & TA & 140 & TA & N/A & NA & $x$ & & & & L330 & +12 & NA \\
\hline & 13 & 18-L12A & Fly-through, AR1 & 0835 & 120 & & 130 & TA & N/A & NA & & $\mathrm{x}$ & & $x$ & Some & - & NA \\
\hline & 14 & 29-L12C & Fly-through, AR1 & 0845 & 120 & & 130 & TA & N/A & NA & & $\mathrm{x}$ & & $x$ & None & -4 & N/A \\
\hline & 15 & 49-L12D & Fly-through, AR1 & 0855 & 120 & & 130 & TA & N/A & NA & & $x$ & & $x$ & -30 & +9 & NA \\
\hline & 16 & 18-L12A & Fly-through, AR1 & 0905 & 120 & & 130 & & NA & NA & $x$ & $x$ & $x$ & $x$ & +12 & +10 & N/A \\
\hline & 17 & 29-L12C & Fly-through, AR1 & 0915 & 120 & & 130 & TA & NA & NA & $\mathrm{x}$ & $x$ & $\mathrm{x}$ & $\mathrm{x}$ & +5 & -4 & NA \\
\hline
\end{tabular}

Notes: There was no altimeter calibration (all runs $>500 \mathrm{ft}$ ) for this flight. Artificial offset was applied for 1,000-ft runs.

Encounters:

- $1-$ good

- $2-$ good

- 3 - good

- 4 - wind adjust 0 seconds, good

- 5 - wind adjust +20 seconds, good

- 6 - wind adjust -10 seconds, good

- 7 - wind adjust -10 seconds, $\mathrm{O} / \mathrm{S}$ kept climbing after maneuver, good

- 8 - wind adjust -20 seconds, $\mathrm{O} / \mathrm{S}$ kept climbing after maneuver, good

- 9 - wind adjust +20 seconds, good

- 10 - wind adjust -5 seconds, INT1 max performance on climb, good

American Institute of Aeronautics and Astronautics 
- $\quad 11$ - wind adjust +20 seconds, good

- 12 - wind adjust -10 seconds, good

- 13 - intermittent headings, fly-through, bad

- 14 - no headings, fly-through, bad

- 15 - both aircraft too fast, O/S arrive early, INT1 corrected, bad

- $16-\mathrm{O} / \mathrm{S}$ airspeed low at start of run, good

- $17-$ good

Airspace: Buckhorn received FL100-200, F-35 at FL220 (did not affect runs); later in day stay FL110-170 (did not affect runs).

Barometer/Visibility: $29.86 \mathrm{in} / \mathrm{Hg}$, clear

Wind: 4 - O/S 215/15, INT1 168/38, 5 - O/S 220/14, INT1 180/26, 6 - O/S 175/13, INT1 187/30, 7 - O/S 210/15, INT1 180/20, 8 - O/S 210/20, INT1 180/25, 9 - O/S 170/15, INT1 230/24, 10 - O/S 210/20, INT1 160/30, 11 - INT1 180/25, 12 - O/S 200/20, INT1 190/22

Bottom Line: Overall it was a good, smooth day of data collection. This day had no aborts, rolex calls, or resets; a first for FT3. The wind matrix worked well for the climb/descent encounters.

\section{Flight 11: July 24, 2015}

Table 21. Configuration 1, flight 11 data.

\begin{tabular}{|c|c|c|c|c|c|c|c|c|c|c|c|c|c|c|c|c|c|}
\hline Flight & \multicolumn{17}{|c|}{11} \\
\hline SUT & \multicolumn{17}{|c|}{ CPDS } \\
\hline Duration & \multicolumn{17}{|c|}{3.2 hours } \\
\hline Intruder(s) & \multicolumn{17}{|c|}{ NASA865 } \\
\hline \multirow{17}{*}{ Data } & \# & Scenario & Type & COMEX & O/S Alt. & TA/RA & Int1 Alt. & TA/RA & Int2 Alt. & TA/RA & ADS-B & RDR & TCAS & TRC & $\mathrm{O} / \mathrm{s}$ & Int1 & Int2 \\
\hline & 1 & 168-L52M & Follow CPDS & 0633 & 120 & TA & 125 & TA & NA & NA & $\mathrm{x}$ & & & & R275 & -2 & NA \\
\hline & 2 & 164-L42M & Follow CPDS & 0643 & 120 & TA/RA & 124 & TA & NA & NA & $x$ & & & & L250 & +13 & NA \\
\hline & 3 & 159-L57D & TCAS Advisory & 0652 & 140 & TA/RA & 145 & TA & NA & NA & $x$ & $x$ & $x$ & & +7 & +7 & NA \\
\hline & 4 & 130-L32D & TCAS Advisory & 0702 & 120 & TA/RA & 123 & TA & NA & NA & $\mathrm{x}$ & $\mathrm{x}$ & $\mathrm{x}$ & & +10 & +16 & NA \\
\hline & 5 & 131-L32F & TCAS Advisory & 0710 & 120 & TA/RA & 123 & TA & NA & NA & $x$ & $x$ & $x$ & & +7 & -3 & NA \\
\hline & 6 & 152-L32B & TCAS Advisory & 0720 & 120 & TA/RA & 123 & TA & NA & NA & $x$ & $x$ & $x$ & & +10 & +7 & NA \\
\hline & 7 & 153-L32G & TCAS Advisory & 0730 & 120 & TA/RA & 123 & TA & NA & NA & $\mathrm{x}$ & $\mathrm{x}$ & $\mathrm{x}$ & & +2 & +5 & NA \\
\hline & 8 & 154-L32H & TCAS Advisory & 0738 & 120 & TA/RA & 123 & TA & N/A & NA & $x$ & $x$ & $x$ & & +15 & +15 & NA \\
\hline & 9 & 155-L31B & TCAS Advisory & 0747 & 123 & TA/RA & 120 & TA & NA & NA & $\mathrm{x}$ & $\mathrm{x}$ & $x$ & & - & - & NA \\
\hline & 10 & 156-L31G & TCAS Advisory & 0756 & 123 & TA/RA & 120 & TA & N/A & NA & $x$ & $x$ & $x$ & & +5 & +1 & NA \\
\hline & 11 & 157-L31H & TCAS Advisory & 0805 & 123 & TA/RA & 120 & & NA & NA & $\mathrm{x}$ & $\mathrm{x}$ & $\mathrm{x}$ & & +5 & +9 & NA \\
\hline & 12 & 127-L12P & Radar Zig Zag & 0815 & 120 & & 130 & TA & NA & NA & & $x$ & & $x$ & +3 & +10 & NA \\
\hline & 13 & 116-L31G & Radar CBDR (110) & 0824 & 123 & $\mathrm{RA}$ & 120 & TA & NAA & NA & & $x$ & & $x$ & - & - & NA \\
\hline & 14 & 135-L31F & TCAS Advisory & 0832 & 123 & TA/RA & 120 & TA & NA & NA & $\mathrm{x}$ & $\mathrm{x}$ & $\mathrm{x}$ & & +8 & +1 & NA \\
\hline & 15 & 126-L56G & Radar CBDR (90) & 0842 & 115 & TA/RA & 110 & TA & $\mathrm{N} / \mathrm{A}$ & NA & & $x$ & & $x$ & -30 & -32 & NA \\
\hline & 16 & 120-L56G & Radar CBDR (110) & 0856 & 115 & RA & 110 & & NA & NA & & $x$ & & $x$ & -20 & -30 & NA \\
\hline
\end{tabular}

Notes: Altimeter calibration was performed (NASA 865 aircraft $+100 \mathrm{ft}$ ).

Encounters:

- 1 - virtual offset $500 \mathrm{ft}$, good

- 2 - O/S RA descend, good

- $3-$ O/S RA do not climb, good

- $4-$ O/S RA do not climb, good

- 5 - O/S RA do not climb, good

- $6-$ O/S RA do not climb, good

- 7 - O/S RA descend (before run start), O/S RA descend, INT1 fly 190 kn per TC

- 8 - O/S RA do not climb, good

- $9-$ O/S RA climb to FL130, good

- 10 - O/S RA climb FL130, INT1 on O/S camera, good

- $11-$ O/S RA do not descend (before run start), O/S RA climb to FL130, good

American Institute of Aeronautics and Astronautics 
- 12 - lagged slightly, good

- 13 - O/S RA climb, outside radar field of view, bad

- $14-$ O/S RA climb, good

- $15-$ O/S RA do not descend, good

- 16 - O/S RA do not descend, INT1 hold 200 kn per TC, good

Airspace: Buckhorn received FL100-200.

Barometer/Visibility: $29.92 \mathrm{in} / \mathrm{Hg}$, slight haze

Wind: Altitude calibration - O/S 230/25

Bottom Line: An additional day of data collection of the CPDS and radar encounters was well received. Due to the previous practice of doing these types of encounters, the aircrews and ops team were well prepared, and the data collected was good. Although the Zig-Zag (run 12) encounter was expected to be an S-turn, the researchers were still pleased with the data received. The extra TCAS encounters also allowed all geometries shown on the "pinwheel" to be flown. This particular day also used the "wing flash" (run 13) technique to acquire VID, something that was considered for future testing.

\section{B. Configuration 2}

Configuration 2 flights were conducted from July 13, 2015, to August 12, 2015. Table 22 shows a summary of these flight days. A total of 12 preparation flights (Combined Systems Test (CST), Inertial Navigation System (INS), Rehearsal (REH) flights) and 3 data collection flights were performed. As mentioned, the Control and Non-Payload Communication (CNPC) and surrogate system was not ready for test and did not meet perceived requirements after these 3 runs. Thus, additional data runs were cancelled for Configuration 2 only. For the rehearsal runs, a truncated route was flown on some flight days. Data runs flew the entire route. Additionally, an altimeter calibration was not performed for Configuration 2 since the aircraft were simulating a normal flight environment. GRC flights are GRC only as the participant (NASA 608); CSTs, REHs, and data flights involved GRC, AFRC, and ARC using the LVC environment. Tables $23-37$ show Configuration 2 flight data.

Table 22. All flights for Configuration 2, including CSTs, rehearsals, data collection flights, and cancelled data collection flights.

\begin{tabular}{|c|c|c|c|c|c|c|c|c|}
\hline Flight & Date & $\begin{array}{l}\text { Day of } \\
\text { Week }\end{array}$ & $\begin{array}{c}\text { System Under } \\
\text { Test }\end{array}$ & Encounter Types & $\begin{array}{c}\text { Planned LIVE } \\
\text { Encounters }\end{array}$ & $\begin{array}{l}\text { Flown LIVE } \\
\text { Encounters }\end{array}$ & $\begin{array}{c}\text { LIVE Points } \\
\text { Achieved }\end{array}$ & $\begin{array}{c}\text { Virtual Points } \\
\text { Flown }\end{array}$ \\
\hline GRC 1 & 13-Jul-15 & $\mathrm{M}$ & CNPC & (None) & 0 & 0 & 0 & 0 \\
\hline CST 1 & $16-J u l-15$ & Th & CNPC & Targets of Opportunity & 0 & 0 & 0 & 0 \\
\hline CST 2 & 28-Jul-15 & $\mathrm{Tu}$ & CNPC & Live & 4 & 2 & 0 & 0 \\
\hline GRC 2 & 29-Jul-15 & W & INS & (None) & 0 & 0 & 0 & 0 \\
\hline CST 3 & 29-Jul-15 & $w$ & CNPC & (None) & 0 & 0 & 0 & 0 \\
\hline GRC 3 & 30-Jul-15 & Th & CNPC & (None) & 0 & 0 & 0 & 0 \\
\hline Rehearsal 1 & 3-Aug-15 & $\mathrm{M}$ & CNPC & Live & 8 & 4 & 0 & 0 \\
\hline GRC 4 & 4-Aug-15 & $\mathrm{Tu}$ & CNPC & (None) & 0 & 0 & 0 & 0 \\
\hline CST 4 & 4-Aug-15 & $\mathrm{Tu}$ & CNPC & Live, Virtual & 4 & 2 & 0 & 2 \\
\hline CST 5 & 5-Aug-15 & W & CNPC & Live, Virtual & 6 & 5 & 0 & 9 \\
\hline Rehearsal 2 & 6-Aug-15 & Th & CNPC & (None) & 8 & 0 & 0 & 0 \\
\hline Rehearsal 3 & 7-Aug-15 & $\mathrm{F}$ & CNPC & Live & 8 & 1 & 0 & 0 \\
\hline Data 1 & 10-Aug-15 & $\mathrm{M}$ & HSI/RGCS & Live, Virtual & 8 & 8 & 7 & 11 \\
\hline Data 2 & 11-Aug-15 & $\mathrm{Tu}$ & $\mathrm{HSI} / \mathrm{RGCS}$ & Live, Virtual & 8 & 8 & 6 & 9 \\
\hline Data 3 & 12-Aug-15 & W & $\mathrm{HSI} / \mathrm{RGCS}$ & Live, Virtual & 8 & 8 & 5 & 10 \\
\hline Data 4 & 13-Aug-15 & Th & $\mathrm{HSI} / \mathrm{RGCS}$ & \multicolumn{5}{|c|}{ CANCELLED } \\
\hline Data 5 & 17-Aug-15 & $\mathrm{M}$ & $\mathrm{HSI} / \mathrm{RGCS}$ & \multicolumn{5}{|c|}{ CANCELLED } \\
\hline Data 6 & 18-Aug-15 & $\mathrm{Tu}$ & HSI/RGCS & \multicolumn{5}{|c|}{ CANCELLED } \\
\hline Data 7 & 19-Aug-15 & W & $\mathrm{HSI} / \mathrm{RGCS}$ & \multicolumn{5}{|c|}{ CANCELLED } \\
\hline Data 8 & 20-Aug-15 & Th & $\mathrm{HSI} / \mathrm{RGCS}$ & \multicolumn{5}{|c|}{ CANCELLED } \\
\hline Data 9 & 21-Aug-15 & $\mathrm{F}$ & HSI/RGCS & \multicolumn{5}{|c|}{ CANCELLED } \\
\hline Data 10 & 24-Aug-15 & $\mathrm{M}$ & HSI/RGCS & \multicolumn{5}{|c|}{ CANCELLED } \\
\hline & & & & Totals & 62 & 38 & 18 & 41 \\
\hline
\end{tabular}


Table 23. Configuration 2, flight 1 data.

\begin{tabular}{|c|c|}
\hline Flight & GRC 1 \\
\hline SUT & CNPC \\
\hline Duration & 3.1 hours \\
\hline Intruder(s) & None \\
\hline
\end{tabular}

Notes: RF Characterization Flight, the NASA 608 aircraft flew the fireline route once as planned to gather data on the CNPC RF radiation pattern. The fireline route was flown a second time with a 10-mile buffer to account for expected deviations during the Configuration 2 flight test.

2. Flight 2: July 16, 2015

Table 24. Configuration 2, flight 2 data.

\begin{tabular}{|c|c|}
\hline Flight & CST 1 \\
\hline SUT & CNPC \\
\hline Duration & 1.3 hours \\
\hline Intruder(s) & None \\
\hline
\end{tabular}

Notes: Flight 2 was an initial system checkout flight to verify command and control function with RGCS and establish valid data flow to the LVC environment from the ADS-B system using targets of opportunity. Issues were observed:

1) Up to 15 -second delay from RGCS command to the NASA 608 response.

2) ADS-B targets were incorrectly displayed on the VSCS and LVC systems. ADS-B traffic was stacked in columns.

3. Flight 3: July 28, 2015

Table 25. Configuration 2, flight 3 data.

\begin{tabular}{|c|c|}
\hline Flight & CST 2 \\
\hline SUT & CNPC \\
\hline Duration & 3.1 hours \\
\hline Intruder(s) & NASA865 \\
\hline
\end{tabular}

Notes: Flight to verify ADS-B issues were fixed. Issues observed:

1) Remote GRC team unavailable to start Vehicle Specific Module (VSM) scripts.

2) INS state information stale.

3) Research computer $\mathrm{C} 2$ script crashed multiple times.

4) ADS-B traffic data exhibits incorrect conversion to latitude/longitude.

5) Airspeed not shown on VSCS.

6) LVC Gateway crashed after 1 minute of initializing the GRC VSM script.

Encounters: The NASA 865 aircraft practiced the first leg of the route for INT2 at FL144, while troubleshooting issues for the NASA 608 aircraft . COMEX 0820 performed encounter for WP 2 as INT1; performed encounter for WP 15 as INT1.

Airspace: Some activity, moved the NASA 865 aircraft to INT1 holding and route.

Barometer/Visibility: $29.92 \mathrm{in} / \mathrm{Hg}$, hazy, but workable

Wind: WP 2 encounter INT1 - 320/11

Bottom Line: For the intruder, it was easier to skip through to waypoints and save time instead of following the pattern on the flight cards. Calls were being made in minutes and seconds to CPA, but it was mentioned by the pilots they preferred whole minutes, which was difficult to implement. From an operational perspective, all participants needed to be ready at flight time. For future flights, all participants arrived on time. 
Table 26. Configuration 2, flight 4 data.

\begin{tabular}{|c|c|}
\hline Flight & GRC 2 \\
\hline SUT & INS \\
\hline Duration & 2 hours \\
\hline Intruder(s) & None \\
\hline
\end{tabular}

Notes: GRC led flight test to troubleshoot INS issues observed during last flight.

Encounters: None.

5. Flight 5: July 29, 2015

Table 27. Configuration 2, flight 5 data.

\begin{tabular}{|c|c|}
\hline Flight & CST 3 \\
\hline SUT & CNPC \\
\hline Duration & 1.85 hours \\
\hline Intruder(s) & None \\
\hline
\end{tabular}

Notes: RGCS/LVC systems connected for 30 minutes at the end of the flight. Issues observed:

1) LVC Gateway software crashed multiple times at around 1 minute after the GRC VSM traffic script was started.

2) ARC Multi Aircraft Control System (MACS) observer station never received O/S data.

Encounters: None.

6. Flight 6: July 30, 2015

Table 28. Configuration 2, flight 6 data.

\begin{tabular}{|c|c|}
\hline Flight & GRC 3 \\
\hline SUT & CNPC \\
\hline Duration & 1.1 hours \\
\hline Intruder(s) & None \\
\hline
\end{tabular}

Notes: GRC led flight test to troubleshoot LVC issues. The afternoon system checkout flight was cancelled due to weather.

Encounters: None. 
Table 29. Configuration 2, flight 7 data.

\begin{tabular}{|c|c|c|c|c|c|c|c|c|c|c|c|}
\hline Flight & \multicolumn{11}{|c|}{ Rehearsal 1} \\
\hline SUT & \multicolumn{11}{|c|}{ CNPC } \\
\hline Duration & \multicolumn{11}{|c|}{3.3 hours } \\
\hline Intruder(s) & \multicolumn{11}{|c|}{ NASA7, N3GC } \\
\hline \multirow{6}{*}{ Data } & $\#$ & Scenario & Type & Push & O/S Alt. & TA/RA & Int1 Alt. & TA/RA & Int2 Alt. & TA/RA & Result \\
\hline & \multicolumn{11}{|c|}{ Fireline 1 - COMEX 1637} \\
\hline & 1 & ENC1 & Live & 16:38:58 & 140 & & 136 & TA & NA & NA & - \\
\hline & 2 & ENC2 & Live & 16:45:36 & 140 & & N/A & NA & 144 & TA/RA & 16:46:15 Left turn, int2 RA climb 100ft \\
\hline & 3 & ENC3 & Live & 17:06:00 & 140 & & 136 & TA & NA & NA & 16:57:29 Left turn \\
\hline & 4 & ENC4 & Live & 17:07:30 & 140 & & N/A & NA & 144 & TA & 17:10:40 Left turn \\
\hline
\end{tabular}

Notes: There were no virtual encounters, but some LVC gateway problems at the beginning of the flight day. The LVC required multiple system restarts. The NASA 608 aircraft originally could not go into navigation mode for any runs.

Encounters:

- 1 - no lateral offset, bad

- 2 - no VID, bad

- $3-\operatorname{good}$

- 4-good

Airspace: No data.

Barometer/Visibility: $29.88 \mathrm{in} / \mathrm{Hg}$, changed to $29.85 \mathrm{in} / \mathrm{Hg}$ at 1630 local time

Wind: O/S 220/20, INT1 250/13, INT2 197/11

Bottom Line: Although it was useful to practice the live encounters, to do a full rehearsal, virtual traffic would have been required as well.

8. Flight 8: August 4, 2015

Table 30. Configuration 2, flight 8 data.

\begin{tabular}{|c|c|}
\hline Flight & GRC 4 \\
\hline SUT & CNPC \\
\hline Duration & 2.8 hours \\
\hline Intruder(s) & None \\
\hline
\end{tabular}

Notes: This flight had good O/S data and traffic from the VSM. Heading/altitude/speed changes looked good.

Encounters: None.

9. Flight 9: August 4, 2015

Table 31. Configuration 2, flight 9 data.

\begin{tabular}{|c|c|c|c|c|c|c|c|c|c|c|c|}
\hline Flight & \multicolumn{11}{|c|}{ CST 4} \\
\hline SUT & \multicolumn{11}{|c|}{ CNPC } \\
\hline Duration & \multicolumn{11}{|c|}{2.9 hours } \\
\hline Intruder(s) & \multicolumn{11}{|c|}{ N3GC } \\
\hline \multirow{6}{*}{ Data } & $\#$ & Scenario & Type & Push & O/S Alt. & TA/RA & Int1 Alt. & TA/RA & Int2 Alt. & TA/RA & Result \\
\hline & \multicolumn{11}{|c|}{ Fireline 1 - COMEX 1707} \\
\hline & 1 & ENC2 & Live & 17:13:45 & 140 & & N/A & NA & 144 & TA/RA & 17:12:43 Left turn, int2 RA climb \\
\hline & 2 & ENC4 & Live & 17:36:00 & 140 & & N/A & NA & 144 & TA & 17:31:59 Left turn \\
\hline & \multicolumn{11}{|c|}{ Fireline 2 - COMEX 1808} \\
\hline & 1 & VE1 & Virtual & & 140 & & $(140)$ & & N/A & NA & All virtual encounters \\
\hline
\end{tabular}


Notes: This flight had good live traffic, and bad virtual. Inertial Measurement Unit (IMU) data were stale on multiple occasions. The NASA 608 aircraft was able to go into navigation mode.

Encounters:

1) Fireline 1

- $1-$ good

- 2 - good

2) Fireline 2: all virtual, only for testing scripts

Airspace: Predator FL100-210, F-18 aircraft; did not affect runs.

Barometer/Visibility: $29.89 \mathrm{in} / \mathrm{Hg}$, ENC4 29.90, hazy

Wind: INT2 237/27, Encounter (ENC) 4 INT2 226/30

Bottom Line: Actual performance for the NASA 608 aircraft was approximately $500 \mathrm{fpm}$ (as opposed to the required 1,000 fpm). On this flight day, it became absolutely clear there was a disconnect between the systems at AFRC and the systems at/near GRC. What should have been the second day of data collection was the 9th check flight.

10. Flight 10: August 5, 2015

Table 32. Configuration 2, flight 10 data.

\begin{tabular}{|c|c|c|c|c|c|c|c|c|c|c|c|}
\hline Flight & \multicolumn{11}{|c|}{ CST 5} \\
\hline SUT & \multicolumn{11}{|c|}{ CNPC } \\
\hline Duration & \multicolumn{11}{|c|}{3 hours } \\
\hline Intruder(s) & \multicolumn{11}{|c|}{ N3GC } \\
\hline \multirow{18}{*}{ Data } & \# & Scenario & Type & Push & O/S Alt. & TA/RA & Int1 Alt. & TA/RA & Int2 Alt. & TA/RA & Result \\
\hline & \multicolumn{11}{|c|}{ Fireline 1 - COMEX 1528} \\
\hline & 1 & VE1 & Virtual & & 140 & & - & & NA & NA & Virtual intruder passed too early. \\
\hline & 2 & ENC1 & Live & 15:31:14 & 140 & & 136 & TA & NA & NA & 15:33:34 Left turn (due to WP or command?) \\
\hline & 3 & ENC2 (virt) & Virtual & & 140 & & (144) & & NA & NA & 15:38:30 Right turn \\
\hline & 4 & ENC3 & Live & $15: 42: 05$ & 140 & & 136 & TA & NA & NA & 15:39:18 Left turn, climb to 145 (later) \\
\hline & 5 & VE2 & Virtual & & 140 & & - & & NA & NA & Fly-through WP7 to WP9 \\
\hline & \multicolumn{11}{|c|}{ Fireline 2 - COMEX 1603} \\
\hline & 1 & VE1 & Virtual & & 140 & & (145) & & N/A & NA & Fly-through WP1 to WP2 \\
\hline & 2 & ENC1 & Live & 16:05:58 & 140 & & 136 & TA & NA & NA & 16:07:14 Right turn and climb \\
\hline & 3 & ENC2 (virt) & Virtual & & 148 & & (144) & & NA & NA & Descend 140 , turn left \\
\hline & 4 & VE2 & Virtual & & 140 & & - & & NA & NA & Fly-through \\
\hline & \multicolumn{11}{|c|}{ Fireline 3 - COMEX 1636} \\
\hline & 1 & VE1 & Virtual & & 140 & & (145) & & NA & NA & Fly-through \\
\hline & 2 & ENC1 & Live & $16: 40: 02$ & 141 & & 136 & TA & NA & NA & 16:40:46 Expect climb \\
\hline & 3 & VE2 & Virtual & & 138 & & (144) & & NA & NA & 16:45:50 Left turn, climb to 140 \\
\hline & 4 & VE3 & Virtual & & 140 & & (144) & & N/A & NA & Right turn \\
\hline & 5 & ENC4 & Live & 16:53:00 & 140 & & NA & NA & 154 & & 16:57:01 Right turn \\
\hline
\end{tabular}

Notes: This flight had stale tracks on the LVC system. Even after reboot, the VSCS had stale data. The NASA 608 aircraft was receiving commands from RGCS late or did not see them. The N3GC aircraft acted as INT1 for Fireline 1, INT1 for Fireline 2, and both INT1/INT2 for Fireline 3. At the end of flight, the NASA 608 aircraft was asked to fly a cardinal direction (due west), but the direction did not look correct in any of the ground displays.

Encounters:

1) Fireline 1

- 1 - stale data, bad

- 2 - INT1 late, bad

- $3-$ good

- 4-good

- 5 - RGCS did not have control of the NASA 608 aircraft, bad

2) Fireline 2

- $1-$ good

- $2-$ good 
- $3-\operatorname{good}$

- $4-\operatorname{good}$

3) Fireline 3

- $1-\operatorname{good}$

- $2-\operatorname{good}$

- $3-\operatorname{good}$

- $4-\operatorname{good}$

- 5 - INT2 climbed to check vertical velocity

Airspace: F-35 aircraft with tanker coming in to R-2515, may not use airspace for up to 2 hours (did not affect runs).

Barometer/Visibility: $29.91 \mathrm{in} / \mathrm{Hg}$, good

Wind: INT1 227/29, Fireline 2 ENC 1 INT1 199/22, Fireline 3 ENC 1 INT1 225/24

Bottom Line: Due to the fuel capacity of the O/S, 3 full runs would not be possible for any of the data runs as planned. Either the fireline had to be truncated (as was done this flight day) or less runs could be performed per day.

\section{Flight 11: August 6, 2015}

Table 33. Configuration 2, flight 11 data.

\begin{tabular}{|c|c|}
\hline Flight & Rehearsal 2 \\
\hline SUT & CNPC \\
\hline Duration & 1.1 hours \\
\hline Intruder(s) & NASA865, N3GC \\
\hline
\end{tabular}

Notes: Encounters were cancelled due to weather. All aircraft flew to altitude, but could not establish VMC. At end of flight, the NASA 608 aircraft flew on its own to troubleshoot a magnetic course problem.

Encounters: None.

Airspace: No data.

Barometer/Visibility: 29.95 in/Hg, virga/rain, clouds at FL145

Wind: No data.

Bottom Line: The weather was too poor to perform encounters this day. The event was unfortunate since it seemed that this day would be the first day where all systems were functional.

\section{Flight 12: August 7, 2015}

Table 34. Configuration 2, flight 12 data.

\begin{tabular}{|c|c|}
\hline Flight & Rehearsal 3 \\
\hline SUT & CNPC \\
\hline Duration & 2.8 hours \\
\hline Intruder(s) & NASA865, N3GC \\
\hline
\end{tabular}

Notes: This flight began as a rehearsal flight, but turned into a CST. ARC was showing traffic somewhere close to the North Pole.

Encounters: The N3GC return to base (RTB) 1641 local time; only flew a partial encounter due to problems with scripts. COMEX was set to 1731 local time and a $500 \mathrm{fpm}$ descent (FL140 to 136) by the NASA 865 aircraft at ENC 2 was performed; TA received.

Airspace: F-35 NOTAM, but cancelled (did not affect runs). Affected takeoff time: 1530 as opposed to 1430 .

Barometer/Visibility: $29.84 \mathrm{in} / \mathrm{Hg}$

Wind: 265/37

Bottom Line: Continuing troubleshooting the entire system since software changes were made on the NASA 608 computer without informing other team members. During the encounter, TC/TD were uncertain if visual had been picked up since a "negative visual" was called. A visual was picked up after the encounter by the pilots, but there was still uncertainty on the ground. Thus it was communicated to only call positive visuals during flights. 
Table 35. Configuration 2, flight 13 data.

\begin{tabular}{|c|c|c|c|c|c|c|c|c|c|c|c|}
\hline Flight & \multicolumn{11}{|c|}{ Data Collect 1} \\
\hline SUT & \multicolumn{11}{|c|}{ HSI } \\
\hline Duration & \multicolumn{11}{|c|}{2.8 hours } \\
\hline Intruder(s) & \multicolumn{11}{|c|}{ NASA865, N3GC } \\
\hline \multirow{22}{*}{ Data } & $\#$ & Scenario & Type & Push & O/S Alt. & TA/RA & Int1 Alt. & TA/RA & Int2 Alt. & TA/RA & Result \\
\hline & \multicolumn{11}{|c|}{ Fireline 1 - COMEX 1510} \\
\hline & 1 & VE1 & Virtual & & 140 & & (145) & & N/A & NA & Clear of conflict 15:12:56 \\
\hline & 2 & ENC1 & Live & 15:45:15 & 141 & & 136 & TA & N/A & NA & $15: 16: 03 \mathrm{O} / \mathrm{S}$ turned right \\
\hline & 3 & ENC2 & Live & $15: 17: 15$ & 141 & & N/A & NA & 145 & TA & 15:19:39 turning left \\
\hline & 4 & VE2 & Virutal & & 141 & & - & & NA & NA & Left turn \\
\hline & 5 & VE3 & Virtual & & 141 & & $(145)$ & & N/A & NA & - \\
\hline & 6 & VE3.5 & Virtual & & 141 & & - & & N/A & NA & Fly-through \\
\hline & 7 & VE4 & Virtual & & 141 & & $(143)$ & & N/A & NA & 15:36:07 L273 \\
\hline & 8 & VE5 & Virtual & & 141 & & $(135)$ & & NA & NA & Fly-through \\
\hline & 9 & ENC3 & Live & 15:41:37 & 141 & & 137 & TA & NA & NA & 17:04:01 RT \\
\hline & 10 & ENC4 & Live & 15:42:39 & 141 & & $\mathrm{~N} / \mathrm{A}$ & NA & 145 & TA/RA & 15:50:42 L248, int2 O/S RA climb 100ft \\
\hline & \multicolumn{11}{|c|}{ Fireline 2 - COMEX 1610} \\
\hline & 1 & VE1 & Virtual & & 141 & & $(145)$ & & NA & NA & Fly-through \\
\hline & 2 & ENC1 & Live & 16:12:48 & 141 & TA & 137 & TA & NA & NA & 16:15:06 R168 \\
\hline & 3 & ENC2 & Live & 16:17:12 & 141 & TA & N/A & NA & 144 & TA & 16:21:43 R129 \\
\hline & 4 & VE2 & Virtual & & 141 & & (145) & & NA & NA & 16:29:32 L107 \\
\hline & 5 & VE3 & Virtual & & 141 & & (144) & & NA & NA & 16:34:33 L263 \\
\hline & 6 & VE4 & Virtual & & 141 & & (145) & & NA & NA & Fly-through \\
\hline & 7 & VE5 & Virtual & & 141 & & $(135)$ & & N/A & NA & Fly-through \\
\hline & 8 & ENC3 & Live & 16:38:14 & 141 & & (137) & TA & N/A & NA & 16:41:46 R326, South 319 \\
\hline & 9 & ENC4 & Live & 16:40:49 & 141 & & $\mathrm{~N} / \mathrm{A}$ & NA & 145 & TA & 16:47:13 R344 \\
\hline
\end{tabular}

Notes: The NASA 865 aircraft was seeing the NASA 608 aircraft $200 \mathrm{ft}$ above.

Encounters:

1) Fireline 1

- 1 - good

- 2 - course correction, bad

- $3-\operatorname{good}$

- $4-$ good

- $5-$ good

- $6-$ good

- $7-$ good

- 8 - good

- $9-$ good

- 10 - some stale data on RGCS, INT2 RA climb $100 \mathrm{ft}$, good

2) Fireline 2

- $1-$ good

- $2-$ good

- $3-$ good

- $4-$ good

- 5 - good

- $6-$ good

- $7-$ good

- 8 - good

- 9 - good

Airspace: F-16 aircraft south of highway 58, could not use WP 5 for a short time (did not affect runs).

52

American Institute of Aeronautics and Astronautics 
Barometer/Visibility: $29.86 \mathrm{in} / \mathrm{Hg}$, clear at FL140, haze at FL120 and below

Wind: INT2 152/19, Fireline 2 INT2 ENC 2 201/28

Bottom Line: Overall, it was a good flight day. A few problems were discovered, like turning prior to a WP 5 versus of flying into it; what the researchers expected and what was done did not coincide. Additionally, ENC 4 was expected to be a "beak-to-beak" encounter. A correction was made to the flight cards for a different intruder heading to create this geometry.

\section{Flight 14: August 11, 2015}

Table 36. Configuration 2, flight 14 data.

\begin{tabular}{|c|c|c|c|c|c|c|c|c|c|c|c|}
\hline Flight & \multicolumn{11}{|c|}{ Data Collect 2} \\
\hline SUT & \multicolumn{11}{|c|}{ HSI } \\
\hline Duration & \multicolumn{11}{|c|}{2.7 hours } \\
\hline Intruder(s) & \multicolumn{11}{|c|}{ NASA865, N3GC } \\
\hline \multirow{20}{*}{ Data } & \# & Scenario & Type & Push & O/S Alt. & TA/RA & Int1 Alt. & TA/RA & \begin{tabular}{|l|} 
Int2 Alt. \\
\end{tabular} & TA/RA & Result \\
\hline & \multicolumn{11}{|c|}{ Fireline 1 - COMEX 1510} \\
\hline & 1 & VE1 & Virtual & & 141 & & (145) & & NA & NA & Fly-through \\
\hline & 2 & ENC1 & Live & 15:12:47 & 141 & & 136 & & NA & NA & 15:14:59 L111 \\
\hline & 3 & ENC2 & Live & 15:18:55 & 141 & & N/A & NA & 144 & TA & No maneuver \\
\hline & 4 & VE2 & Virutal & & 141 & & (139) & & NA & NA & 15:25:38 R148 \\
\hline & 5 & VE3 & Virtual & & 141 & & (145) & & NA & NA & Fly-through \\
\hline & 6 & VE4 & Virtual & & 141 & & (135) & & NA & NA & Fly-through \\
\hline & 7 & ENC3 & Live & 15:38:34 & 141 & & 136 & TA & NA & NA & 15:41:39 R301 \\
\hline & 8 & ENC4 & Live & 15:43:00 & 141 & TA & NA & NA & 145 & TA/RA & 15:47:39 L272 \\
\hline & \multicolumn{11}{|c|}{ Fireline 2 - COMEX 1606} \\
\hline & 1 & VE1 & Virtual & & 141 & & (145) & & NA & NA & 16:08:28 L111 \\
\hline & 2 & ENC1 & Live & $16: 08: 48$ & 141 & TA & 136 & TA & NA & NA & 16:11:06 L115 \\
\hline & 3 & ENC2 & Live & $16: 14: 34$ & 141 & TA & NA & NA & 145 & TA & 16:17:56 R113, R133 \\
\hline & 4 & VE2 & Virtual & & 141 & & (140) & & NA & NA & Left \\
\hline & 5 & VE3 & Virtual & & 141 & & (145) & & NA & NA & 16:25:10 L076 \\
\hline & 6 & VE4 & Virtual & & 141 & & - & & NA & NA & Fly-through \\
\hline & 7 & VE5 & Virtual & & 141 & & (135) & & NA & NA & 16:33:29 R334 \\
\hline & 8 & ENC3 & Live & 16:34:50 & 141 & & 136 & TA & NA & NA & No maneuver \\
\hline & 9 & ENC4 & Live & $16: 37: 47$ & 141 & TA & N/A & NA & 145 & TA/RA & 16:42:27 L262 \\
\hline
\end{tabular}

Notes: The N3GC aircraft was showing $100 \mathrm{ft}$ high on Zeus temporarily.

Encounters:

1) Fireline 1

- $1-\operatorname{good}$

- $2-\operatorname{good}$

- $3-\mathrm{bad}$

- $4-\operatorname{good}$

- $5-\operatorname{good}$

- $6-\operatorname{good}$

- $7-\mathrm{O} / \mathrm{S}$ seemed to head too much south, INT1 RA descend $100 \mathrm{ft}$, good

- $8-\operatorname{good}$

2) Fireline 2

- $1-\operatorname{good}$

- $2-\operatorname{good}$

- $3-\operatorname{good}$

- 4 -good

- $5-\operatorname{good}$

- 6 - good

- $7-\operatorname{good}$ 
- 8 - INT1 not enough run-in, bad

- 9 - INT2 RA climb

Airspace: Temporarily restricted from using WP 5 (did not affect runs).

Barometer/Visibility: Fireline 1: $29.87 \mathrm{in} / \mathrm{Hg}$, Fireline 2: $29.86 \mathrm{in} / \mathrm{Hg}$, clear

Wind: INT1 190/25, INT2 182/36, Fireline 2: ENC1 INT1 158/25, ENC2 INT2 189/29

Bottom Line: Another seemingly good flight day. Although the researchers mentioned that only 6 of the 8 encounters were usable, real flight data was gathered and considered beneficial. The heading changed employed a day prior for one of the encounters was also more successful.

15. Flight 15: August 12, 2015

Table 37. Configuration 2, flight 15 data.

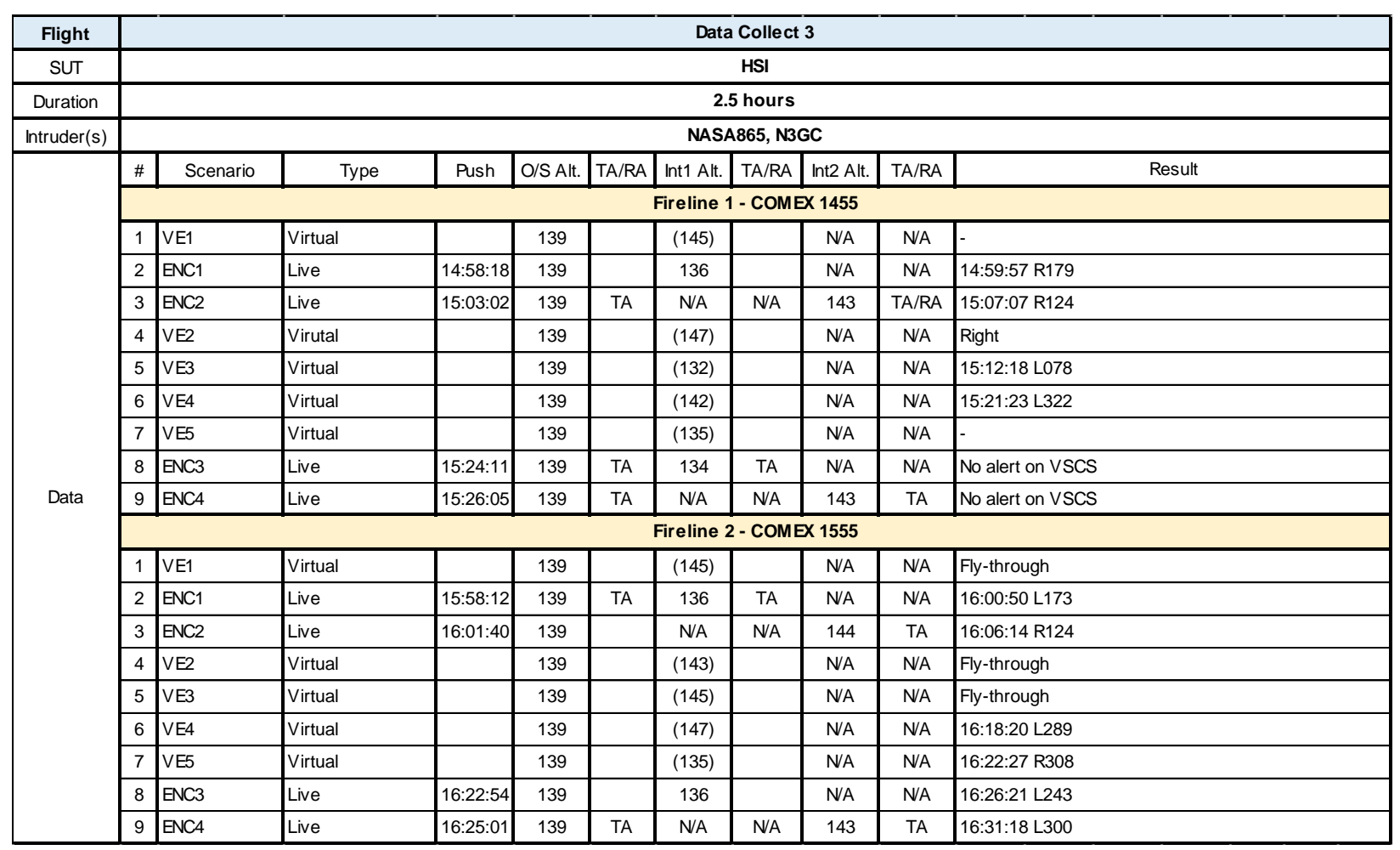

Notes: There was a problem observed with RGCS only sending a WP command once when off autopilot. This day marked the highest barometric pressure seen during Flight Test Series 3, topping out at $30.02 \mathrm{inHg}$. The barometric pressure was showing the NASA 608 aircraft $100 \mathrm{ft}$ low on Zeus. During the phase of no alerting during Fireline 1, ADS-B targets were showing frozen for the ghost controller.

Encounters:

1) Fireline 1

- $1-\operatorname{good}$

- $2-$ good

- 3 - INT2 RA climb, good

- 4-good

- 5 - good

- 6 - good

- 7 - good

- 8 - no alerting, bad

- 9 - no alerting, bad

2) Fireline 2

- 1 - good 
- 2 - target freeze on the NASA 608 aircraft, INT1 RA descend $100 \mathrm{ft}$, bad

- $3-$ good

- $4-$ good

- $5-$ good

- $6-$ good

- $7-$ good

- 8 - good

- 9 - altitude seemed incorrect, bad

Airspace: No data.

Barometer/Visibility: Fireline 1: $30.02 \mathrm{in} / \mathrm{Hg}$; Fireline 2: $30.00 \mathrm{in} / \mathrm{Hg}$, clear, but slight haze

Wind: INT1 185/20, INT2 185/20, Fireline 2: INT1 180/28, INT2 227/22

Bottom Line: This day did not seem as successful as others, due to only achieving 5 of the 8 planned live intruder points. Problems with the RGCS/VSCS and also the barometric pressure affected system performance. Flight 15 was also the final flight day before additional Configuration 2 flights were cancelled. The researchers recognized that they were not getting the type of data and alerting they required, and also, the system was not acting the way it was thought to (VSCS, et cetera). The decision was made to end the test and gather lessons learned to make improvements to the fireline and further flight testing of the full mission.

\section{Operational Observations and Lessons Learned}

The many months of planning and coordination were a key factor in the success of the Flight Test Series 3 Configuration 1. Although successful, lessons learned can be drawn and built into future similar flight testing, especially concerning events that lead to Configuration 2 . The following are some of the lessons learned from Flight Test Series 3.

\section{A. Configuration 1 and Configuration 2 Flight Tests are Distinct and Separate}

The two flight-test configurations were considered as a single test event. A limited amount of time was available between the two configurations to complete all necessary planning, integrating, and approval briefings. The following highlights the distinctions between the two configurations.

The workload was significantly different. Configuration 1 flights were workload intensive. As many as 30 encounters were planned during a flight and each encounter was allotted only 10 minutes to complete, including setup. Aircrew needed to navigate to new coordinates, understand the upcoming encounter geometry, and setup to make the IP within 5 to 10 seconds of the start of the exercise. Each encounter was distinct and required the aforementioned steps to be re-executed each time. Additionally, up to 3 early morning flights were performed per week, adding to crew rest and fatigue considerations.

Configuration 2 flights were significantly less intensive for the airborne participants. The majority of the test decisions were made by the RGCS, a ground based resource. The airborne participants simply ensured the aircraft was on the planned parameters while the ground element directed the ownship maneuvers. Furthermore, from one run to the next the encounters did not change. Each intruder executed the same two encounters while the ownship expected the same four encounters changed only by the response of the ground element and basic environmental factors such as winds aloft. Configuration 2 flights were afternoon flights, and flow daily.

That being said, the ownship maneuvers were less predictable in this configuration. The pilot in the RGCS changed from one flight to the next which resulted in a variation of responses to the presented encounters. On one occasion a pilot skipped an encounter altogether having requested and been granted approval by the virtual ATC controller.

A key factor to the success of both configurations during flight was the support provided from the SAF team members and especially the TC. In terms of mission success, the TC was responsible for observing the timing of each encounter, reporting and taking winds aloft into consideration, and noting the overall development of each live encounter. The TC/TD tremendously reduced the aircrew workload and put the burden of success tasks to the SAF test team.

Recommendation: Decrease the number of flights per week for early morning sorties (or increase the duration of each sortie). Reduce the planned number of test encounters per sortie in order to provide more time to execute each run. Increase the number of test sorties in order to complete the desired test points. Allocate more time between configurations. The additional time will help ensure success criteria is clearly understood. Clearly communicate the differences between the two configurations more as test phases than simply configurations. 


\section{B. Configuration 2 Flights were Cancelled after 3 of 10 Data Collection Flights and Configuration 1b was Not Attempted}

On August 12, 2015, the Configuration 2 flight test was terminated with only 3 of 10 data collection flights completed. Although 15 flights in total had been completed, 12 of them were system check and troubleshooting events. Additional details on the effectiveness and suitability of the Configuration 2 system are subject to ongoing analysis and not available at the time of drafting this paper. ARC-HSI determined that the flight-test data would not adequately suit their objectives and recommended termination of the remaining flights. To mitigate, ensuring adequate development time prior to FT4 or subsequent flight tests is paramount. The addition of system check periods with a long enough time to allow system enhancements, changes, or fixes, should be mandatory.

Additionally, the aircraft planned for the Configuration $1 \mathrm{~b}$ high-speed ownship test event, the GRC S-3B, was not able to meet the development time constraints and was not in the desired flight-test configuration for FT3. Similar to the case of Configuration 2, additional time is required for development and system checks. Unlike Configuration 2, the decision to forgo Configuration $1 \mathrm{~b}$ was not as critical, since the researchers felt the data acquired with the lowspeed ownship, Ikhana, was adequate for this phase of the flight test.

\section{Multiple Operating/Staging Locations Decreased Efficiency in Test Execution}

Operating from KEDW, KVNY, KPMD, and KBFL was a challenge to ensure efficient test execution. On multiple occasions, supporting aircraft were held at their staging locations for ATC clearances. Additionally, the offsite aircraft needed a higher bingo fuel in order to return to their staging location. During Configuration 1 events, one or possibly two more encounters per flight could have been completed if all aircraft were in the same location.

During Configuration 2 flights the remote staging location of the NASA 608 aircraft was planned to add the ability for a 3rd fireline run; however, the T-34 was too fuel limited and could not attempt a 3rd run regardless of staging location, and therefore negated the primary benefit of being located off site. Furthermore, the amount of troubleshooting conducted with the NASA 608 aircraft, LVC, and RGCS would have benefitted significantly from being in the same location.

Recommendation: Base all aircraft together at AFRC for FT4 and subsequent flight-test events.

\section{Low Priority within R-2515 Resulted in Missed Flight-Test Opportunities}

Both test configurations were impacted by low prioritization. Configuration 2 operations were more significantly impacted since the routes of flight for both ownship and intruder aircraft utilized more of the airspace than Configuration 1 required and were therefore more in conflict with other airspace users. Additionally, Configuration 2 flights started at 1500 local time which was an impacted time of day (although this operation time was chosen at the recommendation of USAF airspace management personnel).

Configuration 1 operations within the Mercury Spin and Four Corners work areas were more contained within known UAS working areas and were therefore less impacted by other users. However, on some occasions the FT3 participating aircraft were restricted to certain altitude blocks or lateral bounds which decreased the amount of encounters completed while the team waited for the traffic to clear. Configuration 1 flights started at 0600 local time and, in general, operations occurring between 0600 to 0800 local time tend to experience little to no conflicts with other traffic.

Recommendation: For complex routing like the Configuration 2 route, it would increase the mission success rate if the route of flight remains clear of R-2515. Additionally, planning for early morning operations (from 0600 to 0800 local time) will likely increase the success rate for executing and completing the test as planned.

\section{E. An Intruder was within $1 \mathrm{nmi}$ and Less Than 500-ft Vertical Separation without Being Visual on Ikhana}

Background data: During Flight 5 of Configuration 1, while conducting a challenging multi intruder sequential TCAS encounter, the first intruder did not acquire a visual acquisition (or callout) of Ikhana and reported the miss after the encounter had been completed. Further, personnel within the SAF did not recognize the missed call or query the intruder aircrew to call out the visual. The flight was completed without further incident. The missed visual violated the FT3-9 mission rule.

Analysis: After post-flight discussion it was determined that hazy conditions, test point complexity, and an inside cockpit focus were significant contributors to the mission rule violation. It was also determined that preplanned routing which maintained a $0.5 \mathrm{nmi}$ lateral and $300-\mathrm{ft}$ vertical separation was able to maintain an adequate level of safety, although should not be relied upon as a the sole mitigation.

Mission relation: Should any manned aircraft fail to acquire visual during FT4 or subsequent tests, the consequence may lead to a closer than planned encounter (either laterally or vertically) and may increase the chances of a midair collision. 
Recommendation/conclusion: The test team developed CRM procedures to help aircrew determine when the visual boundary, $1 \mathrm{nmi}$, was approaching:

- The new procedures became a mandatory briefing item.

- The TC was responsible for notifying all participants that the next encounter would require a visual.

- The TC would provide range calls over the radio.

- At approximately $1.5 \mathrm{nmi}$ separation a "Check Visual" call was made giving the aircrew $\sim 5$ seconds to acquire a visual or abort the encounter.

No further violations occurred after Flight 5 and these additional procedures should be carried forward into future flight-test events.

\section{F. Configuration 1b was Not Attempted}

Background data/analysis: The aircraft planned for this test event, the GRC S-3B, was not able to meet the development time constraints and was not in the desired flight-test configuration for FT3.

Recommendation/conclusion: The other research teams felt that the data acquired with the Ikhana ownship were adequate and the Configuration 1 objectives were met.

\section{G. Planning for Nominal and Off Nominal Conditions was Not Clear or Distinct Enough}

Some discussion in brief and debrief was spent on the differences between lost-link altitude and deconfliction altitude during the briefing and debrief. The discussion resulted in some confusion on which altitude the aircraft should fly after the encounter. The following are the expectations and recommendations from the operations group.

Deconfliction altitude: This altitude is the planned altitude listed on the card that all aircraft should be at after completing the encounter and with TC coordination. Deconfliction altitude is a nominal condition.

Lost-link altitude: This altitude is the altitude Ikhana will be at in a contingency event where the aircraft loses link. It is designed to keep the aircraft predictable for the other intruder aircraft for a short period of time prior to Ikhana proceeding to lost-link holding points. The lost link altitude is an off nominal condition, and the altitude does not need to mirror that of nominal conditions.

\section{H. Haze, Clouds, and Wind Aloft Affecting Encounters}

Environmental factors impacted FT3 in the following ways:

Haze due to smoke from southern California wildfires reduced the visibility at the aircraft operating altitude enough that it was a contributing factor to the mission rule violation. It is of note that later in the flight visibility at higher altitudes was significantly better.

Clouds, broken layers, caused the cancellation of one Configuration 2 mission rehearsal flight. No other flights were significantly impacted.

Winds aloft were sometimes greater than $30 \mathrm{kn}$. Station keeping was affected for Configuration 1 flights and made arriving at the IP on time challenging. For Configuration 2 flights, the intercept was significantly impacted by high winds and in some cases caused missed encounters.

Recommendation: It is important for aircrew to assess the environmental conditions and make recommendations to the TC. Should a haze or cloud layer decrease the visuals, the TC needs to be informed and all participants can make accurate assessments and decisions. In most cases a shift in test altitude would mitigate the haze layer problem. A mitigation for high winds aloft is to develop a tool for the TC/TD to determine push times that account for winds aloft.

\section{Understanding Success Criteria and Training Operators was Critical to Mission Success}

Over the course of FT3, the test team seemed to struggle to understand what the exact success criteria was for each SUT. Since there were multiple SUTs, the success criteria was not the same from one to another, and this situation was not always clear to the team. For Configuration 1 the following were SUT: JADEM, Stratway+, radar, TCAS, and CPDS. Each system utilized a different display. Training was conducted by each SUT researcher, and with the researcher present during their respective flights, mission success was maximized. It is noteworthy to point out that the training conducted by the CPDS researcher was the most effective and required the least amount of intervention during the flight itself. In the other system cases, the researcher had to provide instruction in real time to ensure correct data were being generated.

Recommendation: In order to emulate the desired training, the operations team will provide a template for future test events that identifies what training is required, a format for presenting the material, and a schedule of when it will be accomplished. Additionally, a clear understanding of what the researcher expects out of the SUT will be explained 
to the test team. An example of why proper training is required is in one case during FT3, a system was de-energized by the test team when the researcher, in fact, wanted to deselect a component of the system.

J. Separate Truth Source for Positional Data from Each Aircraft Were Not Available for Post Flight Analysis Post-flight analysis of TSPI information was not a requirement for FT3. However, for higher fidelity evaluation of the radar, TCAS, and CPDS, a TSPI truth source such as Differential Global Positioning System (DGPS) would have been beneficial. Additionally, the time and geolocation sync from one data source to another was not easily and clearly determined resulting in significant post processing to sync all data sources.

Recommendation: A truth data source should be considered standard equipment for any flight-test operation. Incorporate DGPS or suitable TSPI data source on each intruder and ownship aircraft. Ensure all data being collected are time synced.

\section{Researcher Observations and Lessons Learned}

Discussion with researchers post flight test summarized the success of FT3 and outlined findings that will be beneficial to future test activities such as FT4.

\section{A. FT3 Configuration 1 Successfully Completed the Major Objectives for all SUT}

All stakeholders considered this phase a success and in many cases a first for their SUT.

ARC team members collected good data that will be used to update their simulation model and support future test efforts including Part Task 6 (PT6) and verification and validation (V\&V) of MOPS, and FT4. The data supports operational concept developments for aircraft in the cruise phase of flight.

LaRC team members collected more data in one flight-test event than had been collected in past simulated events. The data will be used to update their simulation model and help develop Phase I MOPS for SC-228 and eventually the Federal Aviation Administration. Additionally, FT3 was the first time a multi intruder encounter was conducted for these purposes. For LaRC, many successful scenarios were completed and all objectives were met, and they will continue to find areas for improvement.

CPDS teams consider FT3 a success at collecting several corner case scenarios that challenge both the algorithm and aircrew judgment and decision making based off the CPDS displays. All data analyzed to date appear to correlate with simulation.

The TCAS and radar stakeholders from GA-ASI both report good data collected for their systems and intend to implement enhancements based off the data collected. The TCAS alerts presented to the crews were within TCAS specifications, but crews recommended some user interface changes that better help them get instant SA once a TCAS message is displayed.

The HSI teams were not able to use the data from Configuration 2 flights for technical reasons, still being analyzed.

\section{B. ARC and LaRC Requested all Test Aircraft Keep Heading and Airspeed More Stable in Future Test Events}

Both teams noted in preliminary data analysis that in some cases the aircraft would change airspeed or heading in order to arrive at CPA at the planned time. Although this correction was intended and permitted, up to 90 seconds from CPA the changes in aircraft state perturbed the researchers' desired data to a minimal extent. In follow on test events, the research teams request aircrew accept the aircraft conditions at the IP as long as they are within timing tolerances. One way to mitigate errors is to add real-time monitoring of the ownship and intruder speeds, heading, altitude, predicted CPA, et cetera. Further planning is required for FT4 to ensure accurate understanding of the success criteria, and on condition parameters will be constrained to help mitigate perturbations.

\section{VSCS Displays Did not Function for ARC and LaRC}

For both teams, the planned SUT display did not function correctly. The LaRC team determined that there was not enough granularity in the display for crews to make accurate heading change decisions. They reverted to the Stratway+ native displays on subsequent flight days.

The ARC team used VSCS for all of their planned encounters, but for the encounters that provided directive guidance, the display did not function correctly. Integration issues between AutoResolver and the VSCS display gave inaccurate headings and turn directions to the crews, which resulted in skewed data for those runs that required the aircrew to maneuver per the guidance. The ARC team did not have an alternative display available. For FT4, resources should be assigned to ensure proper integration between AutoResolver and VSCS. 


\section{Radar Vertical Speed Indications were Not Filtered}

The SUT stakeholders that used the radar as a contributing sensor were expecting filtered radar data. Their algorithms noted significant shifts in vertical speed that would have been dampened out if filtered. However, the GAASI radar team understood that filtering to be inherent to the system that used the data, as opposed to imbedded with the radar itself. Since there are no clear requirements for what a certified radar system should do, GA-ASI intends to implement a filtered data stream for FT4.

\section{E. An FT4 Data Collection Plan is Desired}

SC-228 representatives as well as the FT3 research teams noted that the data collection plan and implementation for FT3 resulted in some inconsistencies that may be reduced with a more detailed collection effort. As noted, multiple data sources with different time syncs needed to be post processed. Specifically, the data from the N3GC aircraft was a relative time sync as opposed to a GPS time. Planning for a common time sync and installation of a truth source data system for test aircraft should help mitigate this issue.

\section{Conclusion}

Flight Test 3 gathered excellent data for each system under test. This successful outcome is largely attributed to the experience that was acquired from the Airborne Collision Avoidance System Xu self-separation initial flight test flown in December 2014. Configuration 1 was a tremendous success thanks to the training, member participation, integration/testing, and in-depth analysis of the flight points. Although Configuration 2 flights were cancelled after 3 data collection flights due to various problems, the lessons learned will help the Unmanned Aircraft System integration in the National Airspace System (UAS-NAS) project move forward successfully in future flight phases.

The hope is for other projects conducting flight tests to take the methods and lessons learned in this flight activity and apply them to their own activities for executing a successful mission. 


\section{Appendix A \\ Flight 1}

20150617

Order of Cards

Ver 1

Flight 1

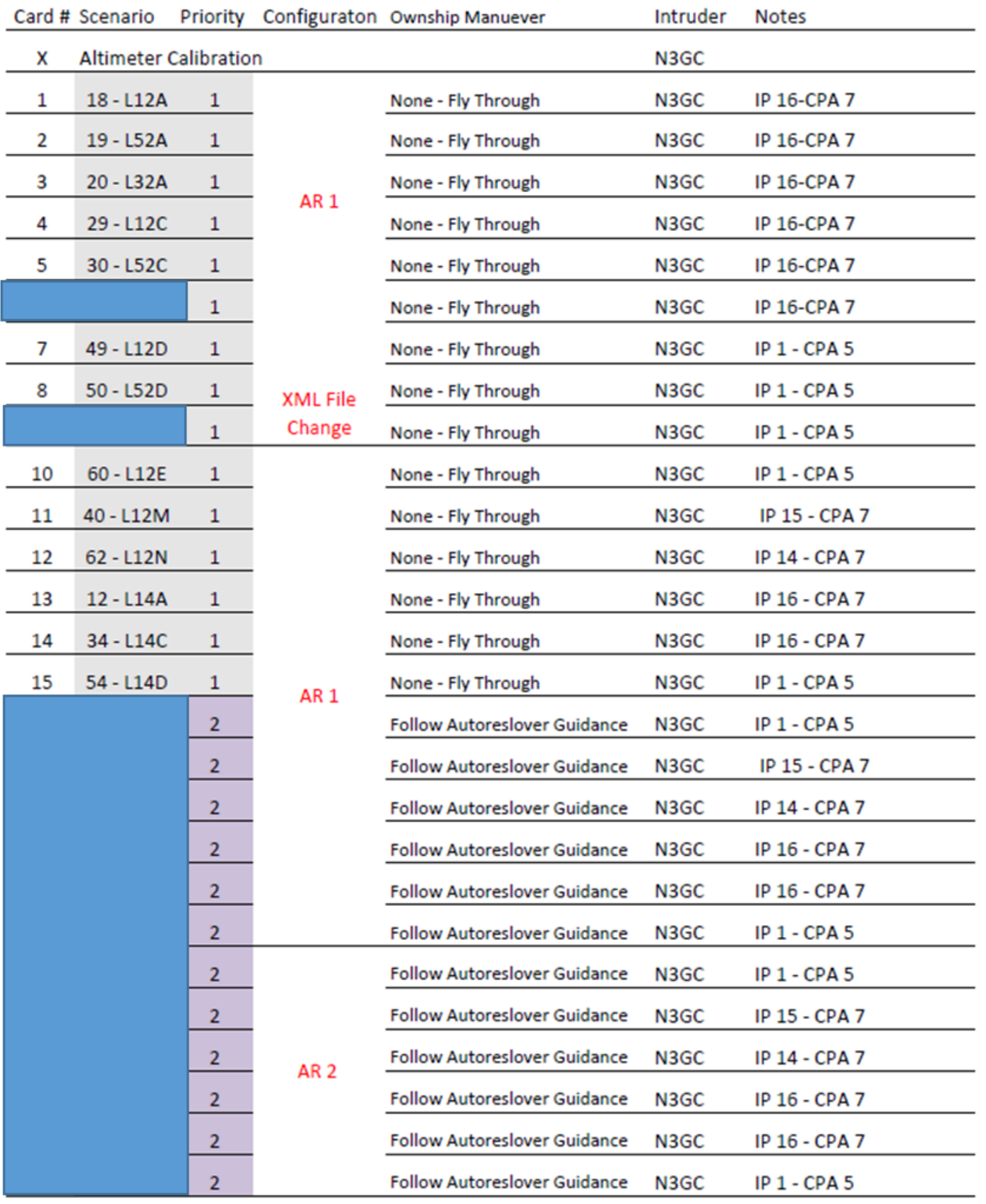

60

American Institute of Aeronautics and Astronautics 


\section{Appendix B}

Flight 2

20150618

Order of Cards

Ver 1

Flight 2

Card \# Scenario Priority Configuraton Ownship Manuever

Intruder

Notes

\begin{tabular}{|c|c|c|c|c|c|c|}
\hline $\mathrm{x}$ & \multicolumn{3}{|c|}{ Altimeter Calibration } & \multicolumn{3}{|c|}{ N3GC } \\
\hline 1 & $31-\mathrm{L} 32 \mathrm{C}$ & 1 & \multirow[b]{2}{*}{ XML Change } & None - Fly Through & N3GC & \\
\hline 2 & $51-L 32 D$ & 1 & & None - Fly Through & N3GC & \\
\hline 3 & $10-\mathrm{L} 13 \mathrm{~A}$ & 1 & \multirow[b]{6}{*}{ XML Change } & None - Fly Through & N3GC & \multirow{24}{*}{ Artifical Offset } \\
\hline 4 & $32-\mathrm{L} 13 \mathrm{C}$ & 1 & & None - Fly Through & N3GC & \\
\hline 5 & $52-$ L13D & 1 & & None - Fly Through & N3GC & \\
\hline 6 & $16-\mathrm{L} 16 \mathrm{~A}$ & 1 & & None - Fly Through & N3GC & \\
\hline 7 & $38-\mathrm{L} 16 \mathrm{C}$ & 1 & & None - Fly Through & N3GC & \\
\hline 8 & $58-L 16 D$ & 1 & & None - Fly Through & N3GC & \\
\hline 9 & $14-\mathrm{L} 15 \mathrm{~A}$ & 1 & \multirow[b]{3}{*}{ AR 2 / XML } & None - Fly Through & N3GC & \\
\hline 10 & $36-\mathrm{L} 15 \mathrm{C}$ & 1 & & None - Fly Through & N3GC & \\
\hline 11 & $56-$ L15D & 1 & & None - Fly Through & N3GC & \\
\hline 12 & $10-$ L13A & 4 & \multirow{15}{*}{ XML Change } & None - Fly Through & N3GC & \\
\hline 13 & $32-\mathrm{L} 13 \mathrm{C}$ & 4 & & None - Fly Through & N3GC & \\
\hline 14 & $52-L 13 D$ & 4 & & None - Fly Through & N3GC & \\
\hline 15 & $16-\mathrm{L} 16 \mathrm{~A}$ & 4 & & None - Fly Through & N3GC & \\
\hline 16 & $38-\mathrm{L} 16 \mathrm{C}$ & 4 & & None - Fly Through & N3GC & \\
\hline 17 & $58-L 16 D$ & 4 & & None - Fly Through & N3GC & \\
\hline 18 & $12-\mathrm{L} 14 \mathrm{~A}$ & 4 & & None - Fly Through & N3GC & \\
\hline 19 & $34-\mathrm{L} 14 \mathrm{C}$ & 4 & & None - Fly Through & N3GC & \\
\hline 20 & $54-$ L14D & 4 & & None - Fly Through & N3GC & \\
\hline 21 & $60-\mathrm{L} 12 \mathrm{E}$ & 4 & & None - Fly Through & N3GC & \\
\hline \multirow[t]{5}{*}{22} & \multirow[t]{5}{*}{$40-$ L12M } & 4 & & None - Fly Through & N3GC & \\
\hline & & 4 & & None - Fly Through & N3GC & \\
\hline & & 4 & & None - Fly Through & N3GC & \\
\hline & & 4 & & None - Fly Through & N3GC & \\
\hline & & 4 & & None - Fly Through & N3GC & \\
\hline
\end{tabular}

61

American Institute of Aeronautics and Astronautics 


\section{Appendix C \\ Flight 3}

20150622

Order of Cards

Ver 1

Flight 3

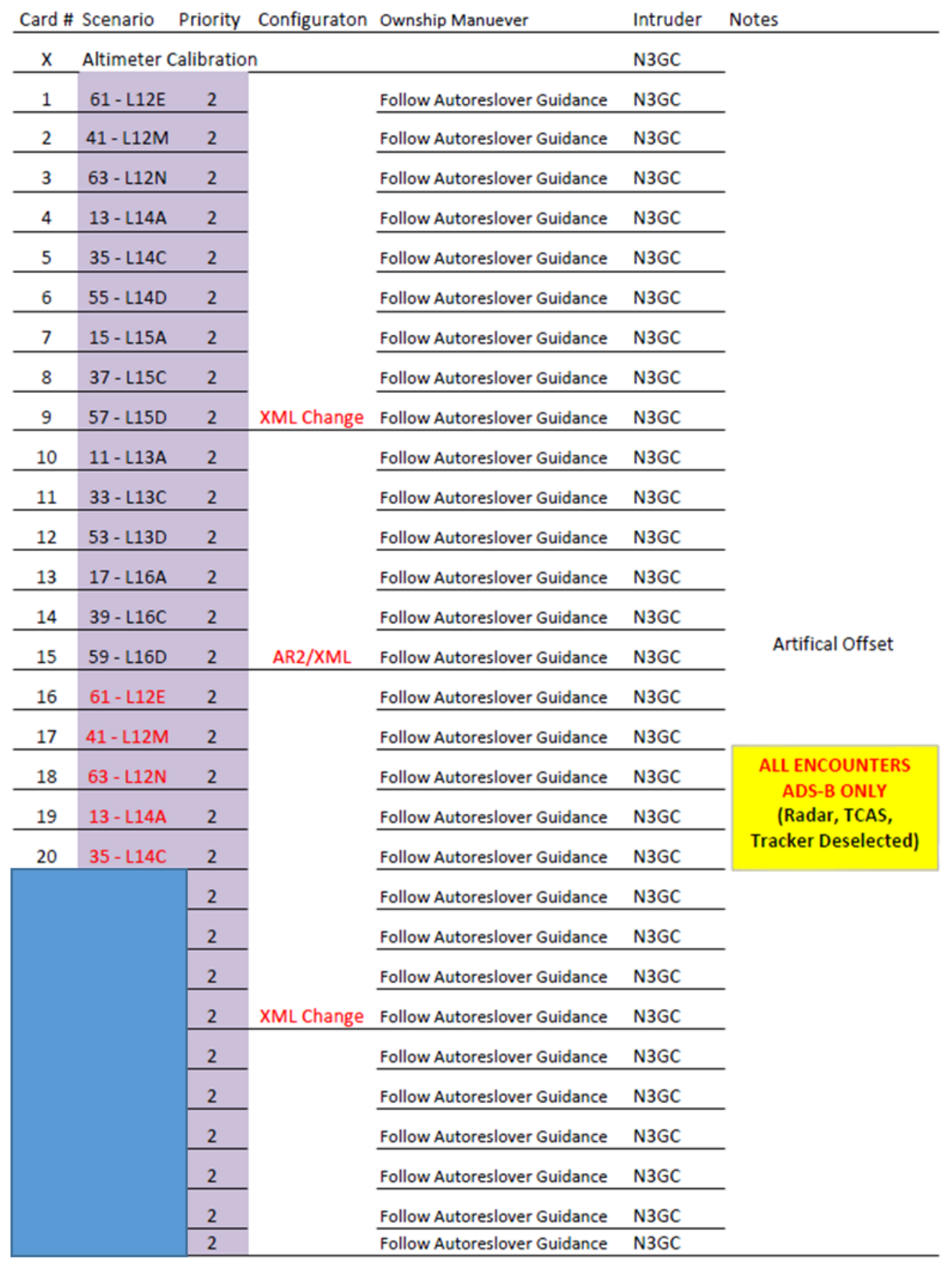

62

American Institute of Aeronautics and Astronautics 


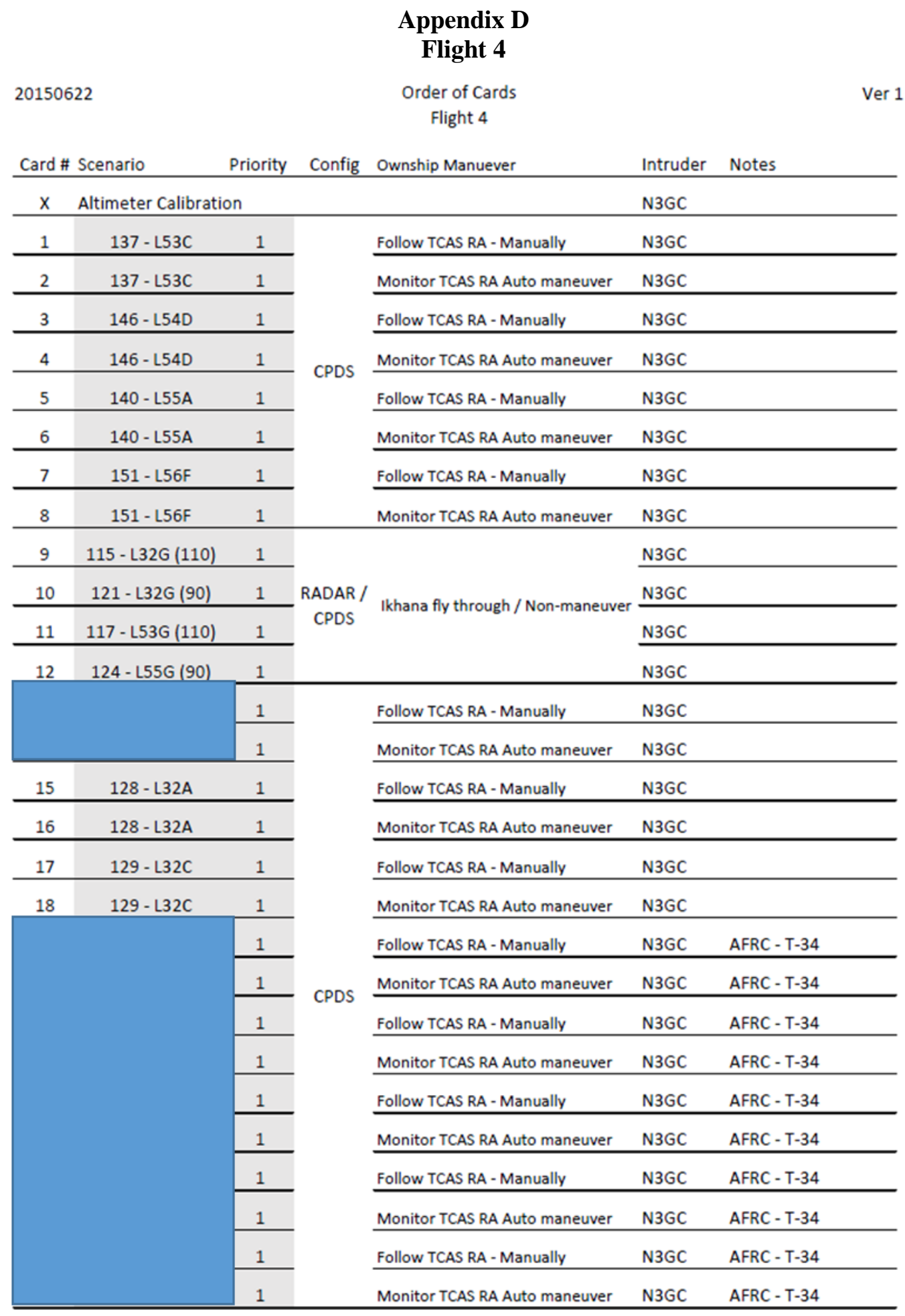

63

American Institute of Aeronautics and Astronautics 


\begin{tabular}{|c|c|c|c|c|c|c|c|}
\hline & & & & $\begin{array}{c}\text { Appendix E } \\
\text { Flight } 5\end{array}$ & & & \\
\hline 201506 & & & & $\begin{array}{l}\text { Order of Cards } \\
\text { Flight } 5\end{array}$ & & & Ver 1 \\
\hline Card \# & Scenario & Priority & Config & Ownship Manuever & Intruder & Notes & \\
\hline 1 & 108 - L12A (2) & 1 & & & $\mathrm{~N} 3 \mathrm{GC}$ & LOS unlikely & \\
\hline 2 & 107 - L12A (1) & 1 & Altitude & Non-Maneuvering / & N3GC & LOS unlikely & \\
\hline 3 & $112-\operatorname{L11A}(2)$ & 1 & Radar & Cooperative & N3GC & LOS unlikely & \\
\hline 4 & 111 - L11A (1) & 1 & & & N3GC & LOS unlikely & \\
\hline 5 & $164-L 42 M$ & 1 & & & $\mathrm{~N} 3 \mathrm{GC}$ & Virtual Offset \& ADVISORY & \\
\hline 6 & $165-\operatorname{L5} 2 \mathrm{M}(1)$ & 1 & & $\begin{array}{c}\text { Maneuver based on CPDS } \\
\text { display }\end{array}$ & N3GC & Virtual Offset \& ADVISORY & \\
\hline 7 & $166-\operatorname{L5} 2 \mathrm{M}(2)$ & 1 & CPDS & Intruder turns in front or & N3GC & Virtual Offset \& ADVISORY & \\
\hline 8 & $167-\operatorname{L52M}(3)$ & 1 & & behind Ownship & N3GC & Virtual Offset \& ADVISORY & \\
\hline 9 & 168 - L52M (4) & 1 & & & N3GC & Virtual Offset \& ADVISORY & \\
\hline 10 & $169-\operatorname{M79X}(1)$ & 1 & & & N3GC/865 & & \\
\hline 11 & $170-M 79 \times(2)$ & 1 & CPDS & $\begin{array}{l}\text { Maneuver based on CPDS } \\
\text { display }\end{array}$ & $\mathrm{N} 3 \mathrm{GC} / 865$ & & \\
\hline 12 & $171-\operatorname{M79X}(3)$ & 1 & & & $\mathrm{~N} 3 \mathrm{GC} / 865$ & & \\
\hline 13 & $160-M 67 Q$ & 1 & & Manual & $\mathrm{N} 3 \mathrm{GC} / 865$ & & \\
\hline & & 1 & & Manual & N3GC/865 & & \\
\hline & & 1 & TCAS & Auto & N3GC/865 & & \\
\hline 16 & $161-M 68 Q$ & 1 & Sequential & Manual & N3GC/865 & & \\
\hline & & 1 & & Manual & N3GC/865 & & \\
\hline & & 1 & & Auto & $\mathrm{N} 3 \mathrm{GC} / 865$ & & \\
\hline 19 & $132-$ L31A & 1 & & Manual & & & \\
\hline 20 & $132-$ L31A & 1 & & Auto & & & \\
\hline & & 1 & & Manual & & & \\
\hline & & 1 & TCAS & Auto & & & \\
\hline & & 1 & & Manual & & & \\
\hline & & 1 & & Auto & & & \\
\hline & & 1 & & Manual & & & \\
\hline & & 1 & & Auto & & & \\
\hline
\end{tabular}




\section{Appendix F}

Flight 6

Order of Cards

Ver 1

Flight 6

\begin{tabular}{|c|c|c|c|c|c|c|}
\hline Card \# & Scenario & Priority & Configuraton & Ownship Manuever & Intruder & Notes \\
\hline $\mathrm{x}$ & Altimeter $\mathrm{C}$ & alibratio & & & N3GC & \\
\hline 1 & $25-L 53 C$ & 1 & \multirow{29}{*}{ Stratway+ } & Follow Stratway+ Display & $\mathrm{N} 3 \mathrm{GC}$ & \\
\hline 2 & $46-L 53 D$ & 1 & & Follow Stratway+ Display & N3GC & \\
\hline 3 & $68-\mathrm{L} 53 \mathrm{~F}$ & 1 & & Follow Stratway+ Display & $\mathrm{N} 3 \mathrm{GC}$ & \\
\hline 4 & $26-L 54 C$ & 1 & & Follow Stratway+ Display & N3GC & \\
\hline 5 & $47-L 54 D$ & 1 & & Follow Stratway+ Display & N3GC & \\
\hline 6 & $69-\mathrm{L} 54 \mathrm{~F}$ & 1 & & Follow Stratway+ Display & N3GC & \\
\hline 7 & $5-L 56 A$ & 1 & & Follow Stratway+ Display & N3GC & \\
\hline 8 & $6-\mathrm{L} 56 \mathrm{~B}$ & 1 & & Follow Stratway+ Display & N3GC & \\
\hline 9 & $23-\mathrm{L} 56 \mathrm{C}$ & 1 & & Follow Stratway+ Display & N3GC & \\
\hline 10 & $44-\mathrm{L} 56 \mathrm{D}$ & 1 & & Follow Stratway+ Display & N3GC & \\
\hline 11 & $66-\mathrm{L} 56 \mathrm{~F}$ & 1 & & Follow Stratway+ Display & N3GC & \\
\hline 12 & $1-\mathrm{L} 42 \mathrm{~A}$ & 1 & & Follow Stratway+ Display & N3GC & \\
\hline 13 & $2-L 42 B$ & 1 & & Follow Stratway+ Display & N3GC & \\
\hline 14 & $21-L 42 C$ & 1 & & Follow Stratway+ Display & $\mathrm{N} 3 \mathrm{GC}$ & \\
\hline 15 & $42-L 42 D$ & 1 & & Follow Stratway+ Display & N3GC & \\
\hline 16 & $64-\mathrm{L} 42 \mathrm{~F}$ & 1 & & Follow Stratway+ Display & N3GC & \\
\hline 17 & $20-\mathrm{L3} 2 \mathrm{~A}$ & 1 & & Follow Stratway+ Display & N3GC & \\
\hline 18 & $31-L 32 C$ & 1 & & Follow Stratway+ Display & N3GC & \\
\hline 19 & $51-\mathrm{L} 32 \mathrm{D}$ & 1 & & Follow Stratway+ Display & N3GC & \\
\hline 20 & $68-\mathrm{L} 53 \mathrm{~F}$ & 2 & & Follow Stratway+ Display & N3GC & \\
\hline 21 & $69-\mathrm{L} 54 \mathrm{~F}$ & 2 & & Follow Stratway+ Display & N3GC & \\
\hline & & 2 & & Follow Stratway+ Display & N3GC & \\
\hline & & 2 & & Follow Stratway+ Display & N3GC & \\
\hline & & 2 & & Follow Stratway+ Display & N3GC & \\
\hline & & 1 & & Follow Stratway+ Display & $\mathrm{N} 3 \mathrm{GC}$ & \\
\hline & & 1 & & Follow Stratway+ Display & N3GC & \\
\hline & & 1 & & Follow Stratway+ Display & N3GC & \\
\hline & & 1 & & Follow Stratway+ Display & $\mathrm{N} 3 \mathrm{GC}$ & \\
\hline & & 1 & & Follow Stratway+ Display & $\mathrm{N} 3 \mathrm{GC}$ & \\
\hline & & 2 & \multirow{3}{*}{ CPDS Display } & None - Fly Through & N3GC & $90^{\circ}$ \\
\hline & & 2 & & None - Fly Through & $\mathrm{N} 3 \mathrm{GC}$ & $110^{\circ}$ \\
\hline & & 2 & & None - Fly Through & N3GC & $90^{\circ}$ \\
\hline
\end{tabular}

65

American Institute of Aeronautics and Astronautics 


\section{Appendix G \\ Flight 7}

20150709

Order of Cards

Ver 1

Flight 7

\begin{tabular}{|c|c|c|c|c|c|c|}
\hline Card & Scenario & Priority & Configuraton & Ownship Manuever & Intruder & Notes \\
\hline $\mathrm{x}$ & Altimeter $\mathrm{Ca}_{\mathrm{a}}$ & libration & & & $\mathrm{N} 3 G \mathrm{C}$ & \\
\hline 1 & $22-\mathrm{L} 55 \mathrm{C}$ & 1 & \multirow{22}{*}{ Stratway+ } & Follow Stratway+ Display & $\mathrm{N} 3 \mathrm{GC}$ & \\
\hline 2 & $43-L 55 D$ & 1 & & Follow Stratway+ Display & N3GC & \\
\hline 3 & $65-\mathrm{L} 55 \mathrm{~F}$ & 1 & & Follow Stratway+ Display & N3GC & \\
\hline 4 & $24-L 57 C$ & 1 & & Follow Stratway+ Display & N3GC & \\
\hline 5 & $45-L 57 D$ & 1 & & Follow Stratway+ Display & $\mathrm{N} 3 \mathrm{GC}$ & \\
\hline 6 & $67-L 57 F$ & 1 & & Follow Stratway+ Display & N3GC & \\
\hline 7 & $7-L 57 A$ & 1 & & Follow Stratway+ Display & N3GC & \\
\hline 8 & 3-L55A & 1 & & Follow Stratway+ Display & N3GC & \\
\hline 9 & $4-L 55 B$ & 1 & & Follow Stratway+ Display & N3GC & \\
\hline 10 & $21-L 42 C$ & 2 & & Follow Stratway+ Display & N3GC & \\
\hline 11 & $42-L 42 D$ & 2 & & Follow Stratway+ Display & N3GC & \\
\hline 12 & $64-\mathrm{L} 42 \mathrm{~F}$ & 2 & & Follow Stratway+ Display & N3GC & \\
\hline 13 & $26-L 54 C$ & 2 & & Follow Stratway+ Display & N3GC & \\
\hline 14 & $47-L 54 D$ & 2 & & Follow Stratway+ Display & N3GC & \\
\hline 15 & $22-L 55 C$ & 2 & & Follow Stratway+ Display & N3GC & \\
\hline 16 & $43-L 55 D$ & 2 & & Follow Stratway+ Display & N3GC & \\
\hline 17 & $65-\mathrm{L} 55 \mathrm{~F}$ & 2 & & Follow Stratway+ Display & N3GC & \\
\hline 18 & $24-157 C$ & 2 & & Follow Stratway+ Display & N3GC & \\
\hline 19 & $45-L 57 D$ & 2 & & Follow Stratway+ Display & N3GC & \\
\hline 20 & $67-\mathrm{L} 57 \mathrm{~F}$ & 2 & & Follow Stratway+ Display & N3GC & \\
\hline 21 & $25-L 53 C$ & 2 & & Follow Stratway+ Display & N3GC & \\
\hline \multirow[t]{6}{*}{22} & $46-L 53 D$ & 2 & & Follow Stratway+ Display & N3GC & \\
\hline & & 2 & \multirow{5}{*}{ CPDS Display } & None - Fly Through & N3GC & $110^{\circ}$ \\
\hline & & 3 & & None - Fly Through & N3GC & $110^{\circ}$ \\
\hline & & 3 & & None - Fly Through & N3GC & $110^{\circ}$ \\
\hline & & 3 & & None - Fly Through & N3GC & $90^{\circ}$ \\
\hline & & 3 & & None - Fly Through & N3GC & $90^{\circ}$ \\
\hline
\end{tabular}

66

American Institute of Aeronautics and Astronautics 


\section{Appendix $\mathbf{H}$ \\ Flight 8}

Flight 8

\begin{tabular}{|c|c|c|c|c|c|c|}
\hline Card & Scenario & Priority & Configuraton & Ownship Manuever & Intruder & Notes \\
\hline $\mathrm{x}$ & Altimeter $\mathrm{Cal}$ & libration & & & $\mathrm{N} 3 \mathrm{GC} / 865$ & Multiship \\
\hline 1 & $8-M 59 Q$ & 1 & \multirow{21}{*}{ Stratway+ } & Follow Stratway+ Display & $\mathrm{N} 3 \mathrm{GC} / 865$ & Multiship \\
\hline 2 & 8-M59Q & 2 & & Follow Stratway+ Display & N3GC/865 & Multiship \\
\hline 3 & $28-M 59 V$ & 1 & & Follow Stratway+ Display & N3GC/865 & Multiship \\
\hline 4 & $28-M 59 V$ & 2 & & Follow Stratway+ Display & N3GC/865 & Multiship \\
\hline 5 & $71-$ M59W & 1 & & Follow Stratway+ Display & N3GC/865 & Multiship \\
\hline 6 & $71-$ M59W & 2 & & Follow Stratway+ Display & $\mathrm{N} 3 \mathrm{GC} / 865$ & Multiship \\
\hline 7 & $9-\mathrm{M} 59 \mathrm{U}$ & 1 & & Follow Stratway+ Display & N3GC/865 & Multiship \\
\hline 8 & $27-M 59 R$ & 1 & & Follow Stratway+ Display & $\mathrm{N} 3 \mathrm{GC} / 865$ & Multiship \\
\hline 9 & $48-M 59 S$ & 1 & & Follow Stratway+ Display & N3GC/865 & Multiship \\
\hline 10 & 70 - M59T & 1 & & Follow Stratway+ Display & N3GC/865 & Multiship \\
\hline 11 & $9-M 59 U$ & 2 & & Follow Stratway+ Display & N3GC/865 & Multiship \\
\hline 12 & $27-M 59 R$ & 2 & & Follow Stratway+ Display & N3GC/865 & Multiship \\
\hline 13 & $48-M 59 S$ & 2 & & Follow Stratway+ Display & N3GC/865 & Multiship \\
\hline 14 & $70-$ M59T & 2 & & Follow Stratway+ Display & N3GC/865 & Multiship \\
\hline 15 & $63-\mathrm{L} 12 \mathrm{~N}$ & 1 & & Follow Stratway+ Display & N3GC & \\
\hline \multirow[t]{6}{*}{16} & $63-\mathrm{L} 12 \mathrm{~N}$ & 2 & & Follow Stratway+ Display & N3GC & \\
\hline & & 2 & & Follow Stratway+ Display & N3GC & \\
\hline & & 2 & & Follow Stratway+ Display & N3GC & \\
\hline & & 2 & & Follow Stratway+ Display & N3GC & \\
\hline & & 2 & & Follow Stratway+ Display & N3GC & \\
\hline & & 2 & & Follow Stratway+ Display & N3GC & \\
\hline 22 & $122-\mathrm{L} 31 \mathrm{G}$ & 2 & \multirow{3}{*}{ CPDS Display } & None - Fly Through & N3GC & $90^{\circ}$ \\
\hline \multirow[t]{2}{*}{23} & $125-\mathrm{L} 54 \mathrm{G}$ & 2 & & None - Fly Through & N3GC & $90^{\circ}$ \\
\hline & & 2 & & None - Fly Through & N3GC & $110^{\circ}$ \\
\hline
\end{tabular}




\section{Appendix I}

Flight 9

Flight 9

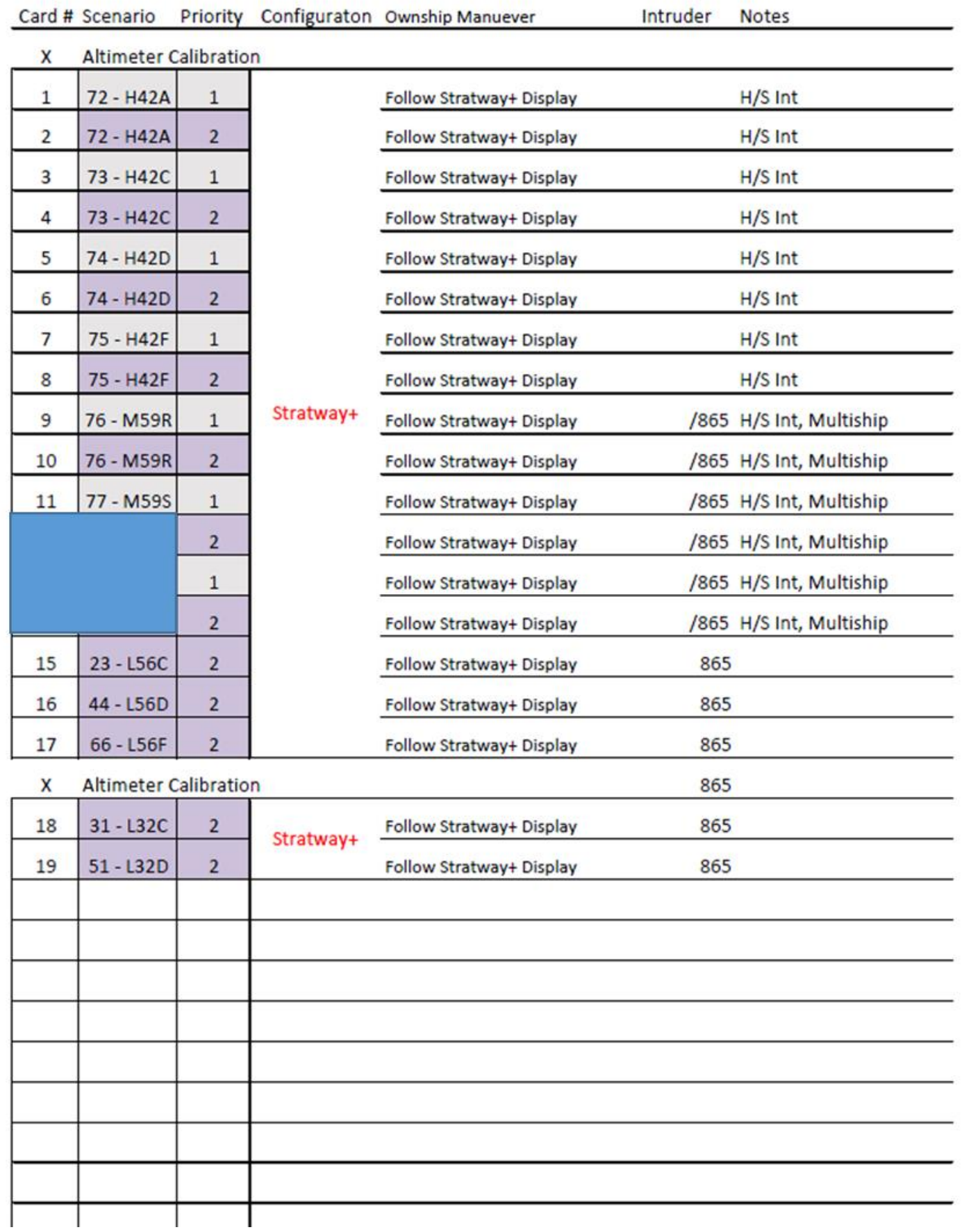




\section{Appendix J \\ Flight 10}

Flight 10

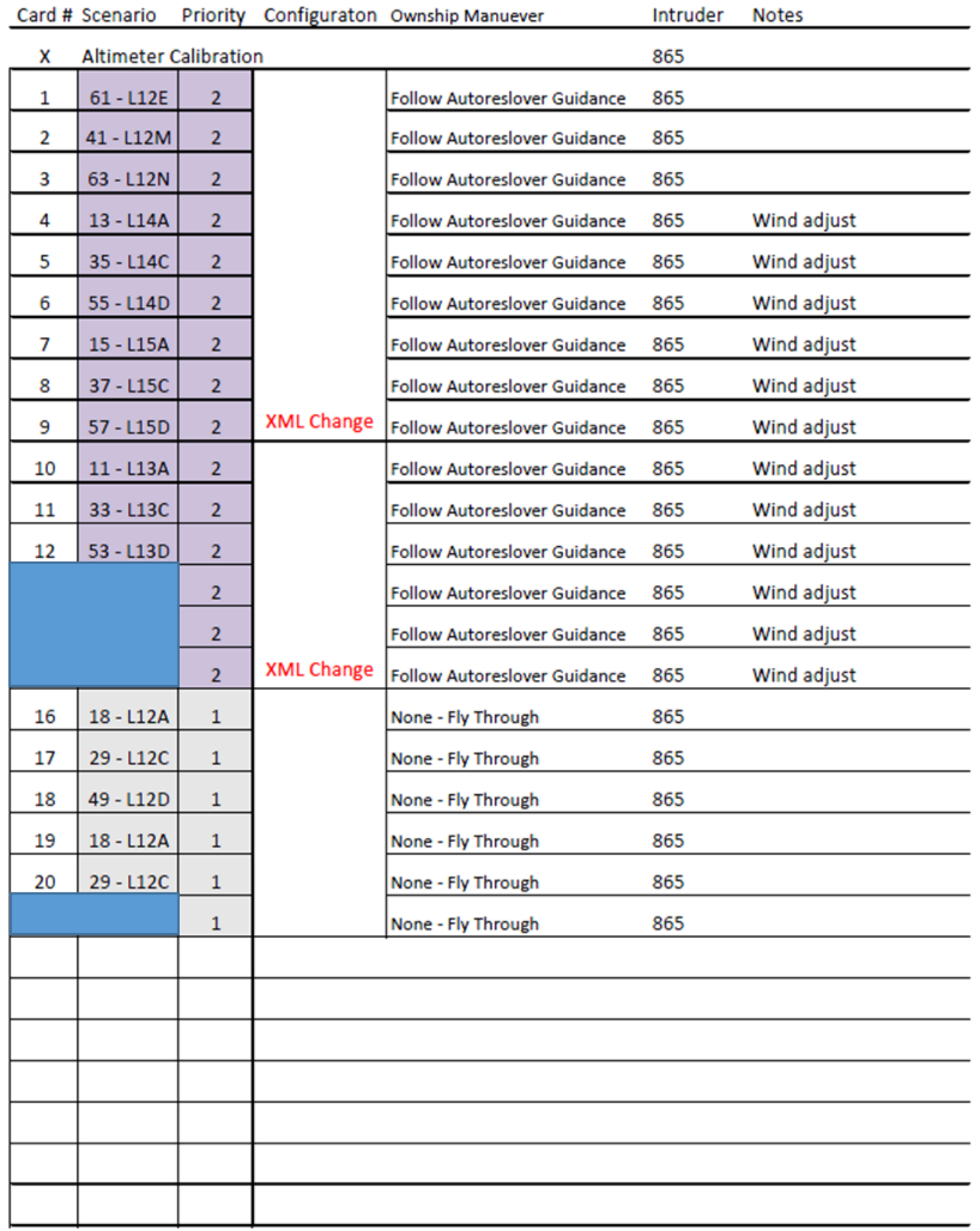

69

American Institute of Aeronautics and Astronautics 


\section{Appendix K \\ Flight 11}

20150724

Order of Cards

Ver 2

Flight 11

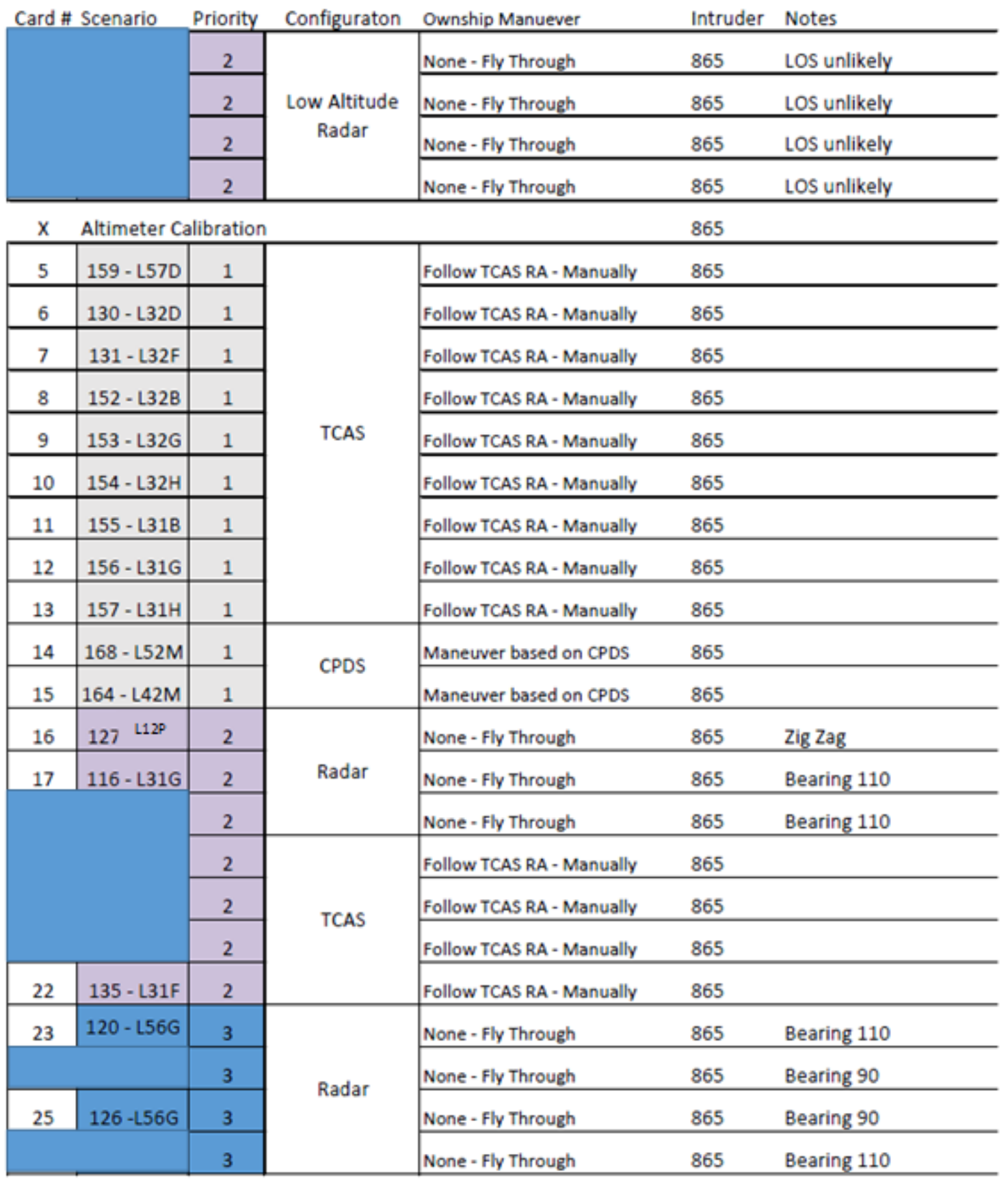

70

American Institute of Aeronautics and Astronautics 


\section{References}

${ }^{1}$ Next Generation Air Transportation System Joint Planning and Development Office, "NextGen UAS Research, Development and Demonstration Roadmap: Appendix A," Version 1.0, March 2012.

${ }^{2}$ Maddox, S., Stuckenberg, D., "Drones in the U.S. National Airspace System: A Safety and Security Assessment," Harvard Law School National Security Journal [online journal], URL: http://harvardnsj.org/2015/02/drones-in-the-u-s-national-airspacesystem-a-safety-and-security-assessment [cited 12 February 2017].

${ }^{3}$ Marston, M., "Integrated Test and Evaluation (IT\&E) Flight Test 3 Flight Test Plan, Rev. E," NASA FT3-FTP-01, 2015.

\section{Figures}

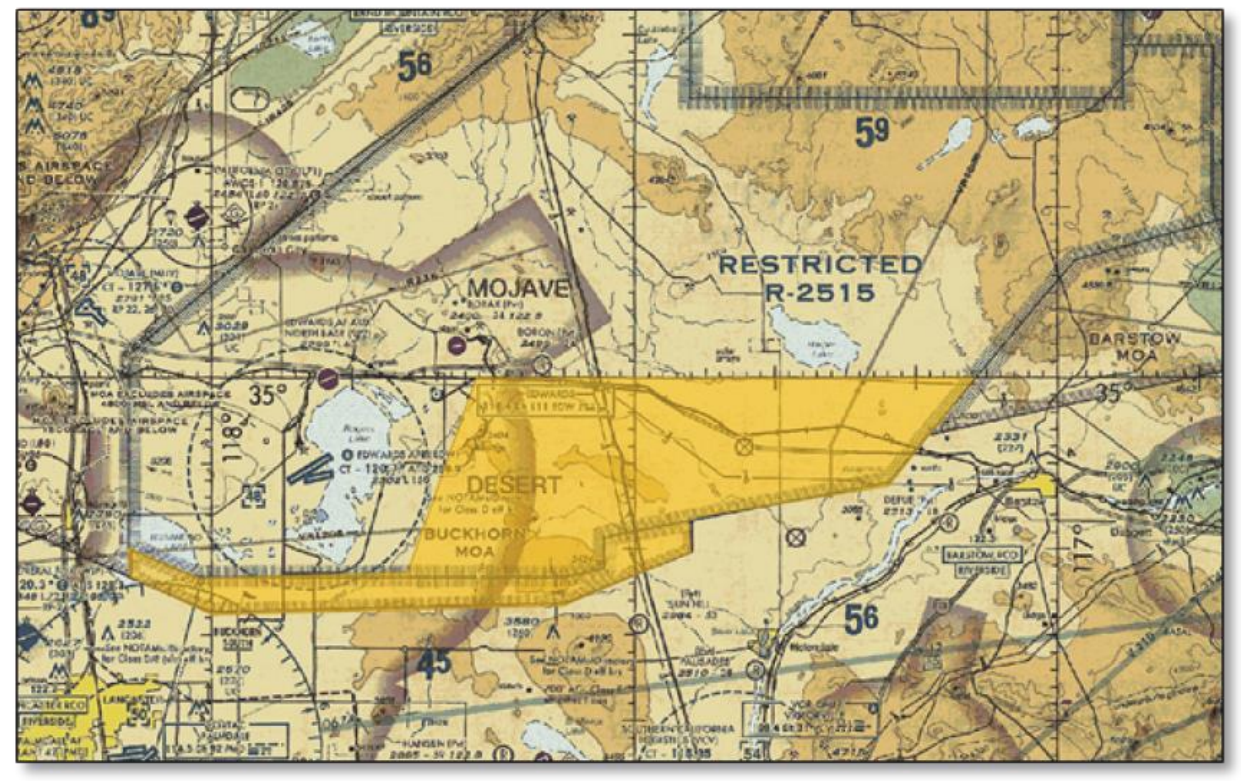

Figure 1. Flight-test area for Configuration 1 (highlighted) was in R-2515 at EAFB and also included the Buckhorn MOA. 


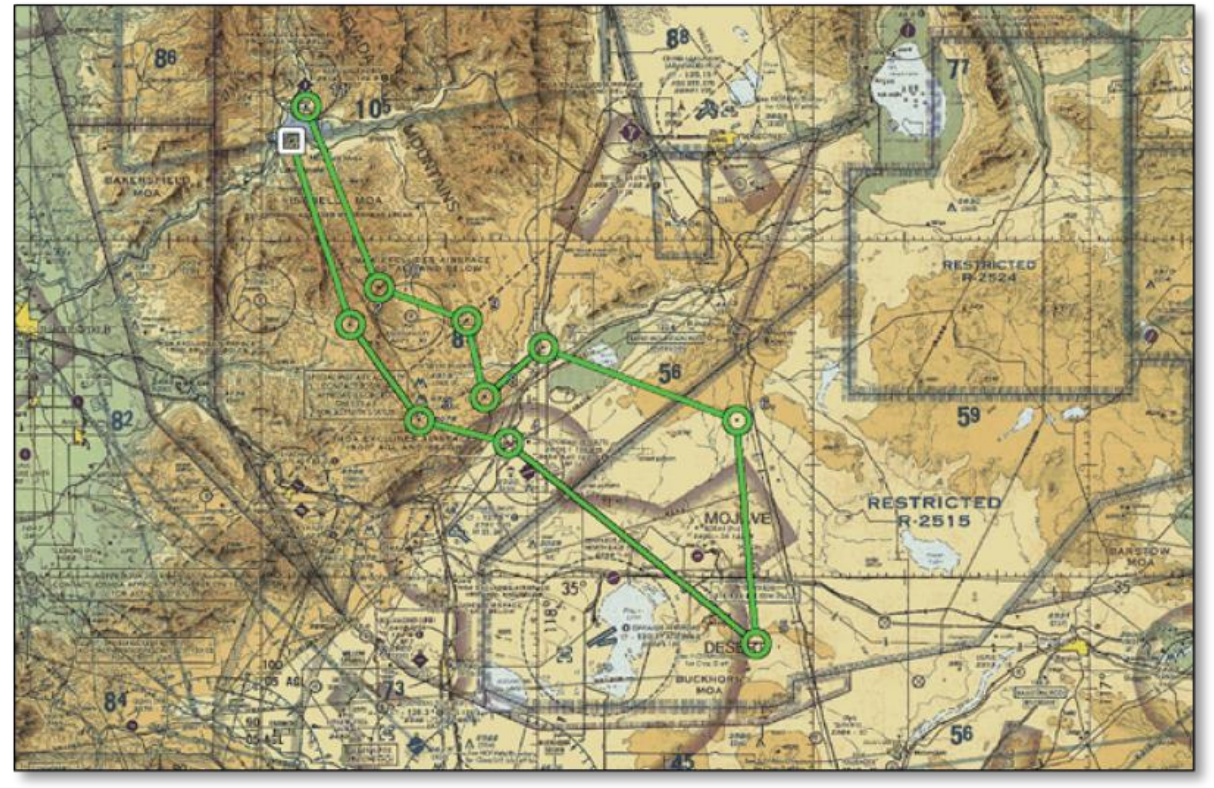

Figure 2. Configuration 2 flight-test area traversed both R-2515 and R-2508, which includes the Isabella MOA.

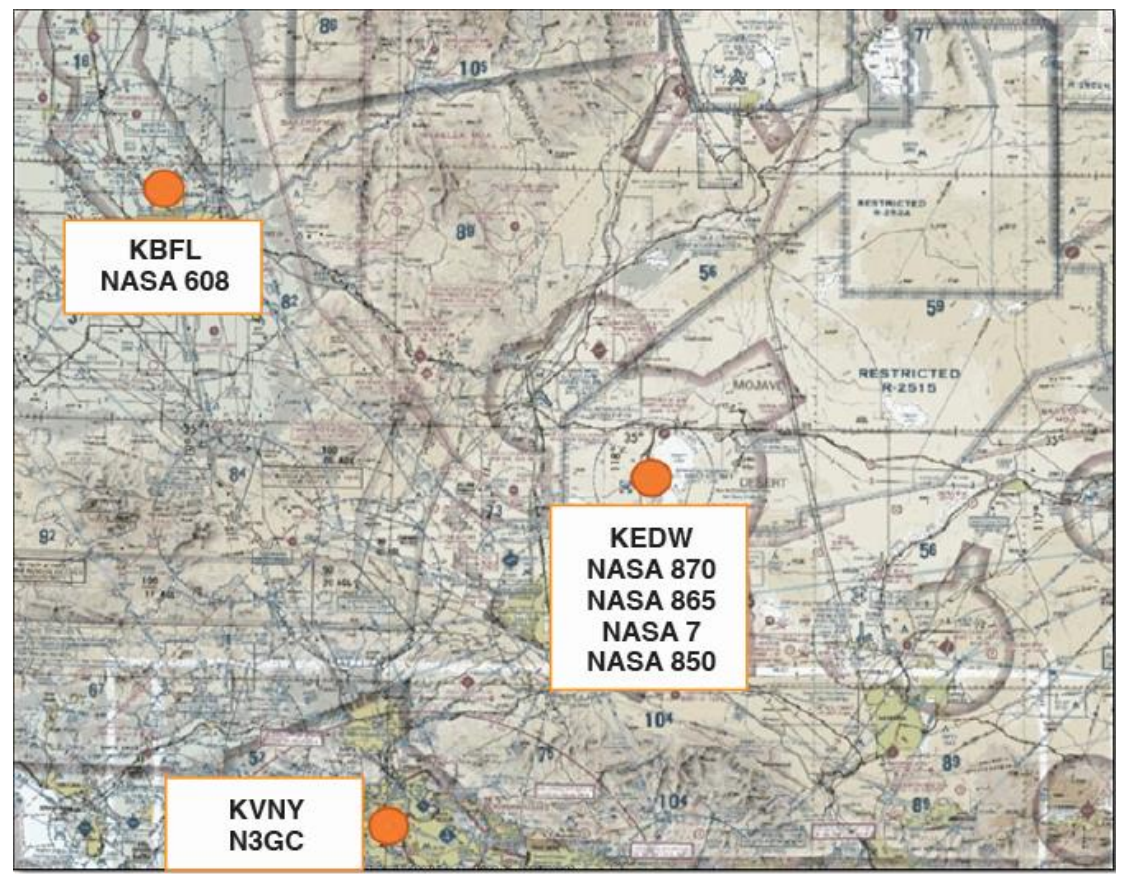

Figure 3. Aircraft staging areas. 


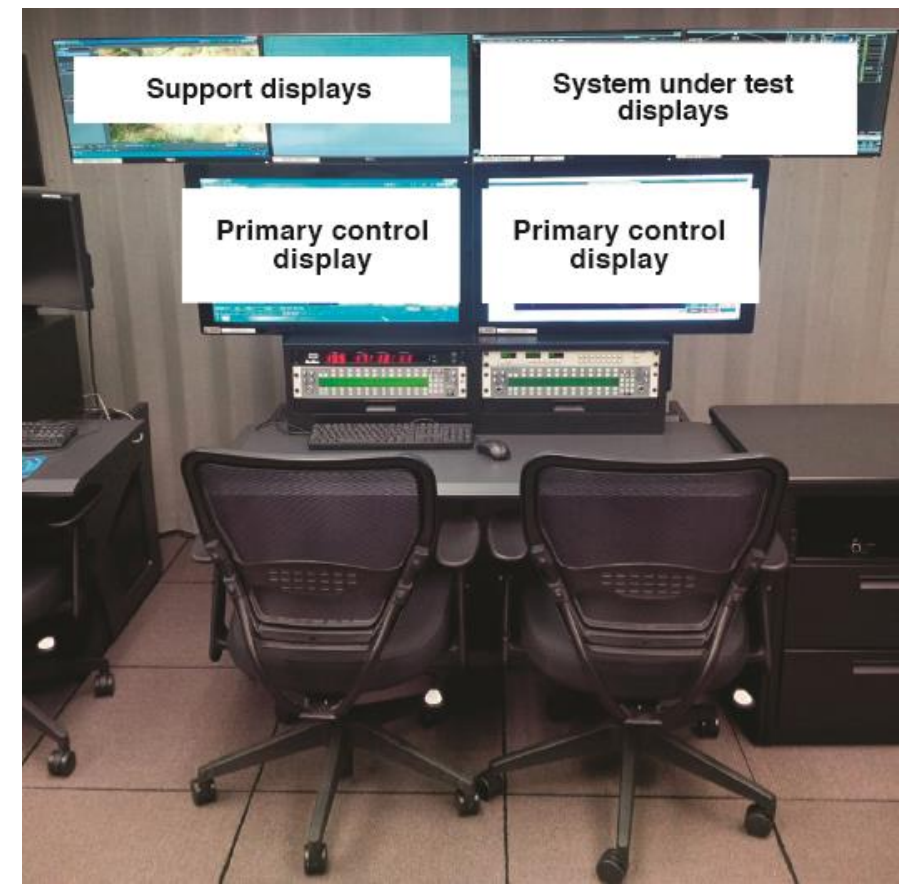

Figure 4. SAF control room displays.

\begin{tabular}{|c|c|c|c|}
\hline Time of day & Ikhana & $\begin{array}{l}\text { NASA850 } \\
\text { F-18 }\end{array}$ & $\begin{array}{c}\text { NASA865 } \\
\text { T-34 }\end{array}$ \\
\hline 1200 & \multicolumn{3}{|c|}{$\mathrm{T}-1$} \\
\hline $\mathrm{N} / \mathrm{A}$ & \multicolumn{3}{|c|}{ Prep } \\
\hline 0415 & \multicolumn{3}{|c|}{ Mass brief } \\
\hline 0430 & \multicolumn{3}{|c|}{ Individual unit briefs } \\
\hline 0500 & \multicolumn{3}{|l|}{ Walk } \\
\hline 0600 & Take off & & \\
\hline$\underline{0620}$ & & Take off & \\
\hline 0630 & & $\begin{array}{l}\text { On station altimeter } \\
\text { calibration }\end{array}$ & \\
\hline 0635 & \multicolumn{3}{|c|}{ Commence exercise (4+00 hours on station) } \\
\hline$\underline{0735}$ & & & Take off \\
\hline$\underline{0800}$ & \multicolumn{3}{|c|}{ Complete 1v1. Start 1v2. } \\
\hline 0840 & & Return to base-fuel & \\
\hline TBD & & & Altimeter calibration \\
\hline TBD & & Take/off on station & \\
\hline 1030 & \multicolumn{3}{|c|}{ Knock-it-off return to base } \\
\hline 1100 & \multicolumn{3}{|l|}{ Land } \\
\hline 1200 & \multicolumn{3}{|l|}{ Debrief } \\
\hline 1415 & \multicolumn{3}{|l|}{ End of test day } \\
\hline
\end{tabular}

Figure 5. Configuration 1 timeline.

American Institute of Aeronautics and Astronautics 


\begin{tabular}{|c|c|c|c|c|c|}
\hline & $\begin{array}{c}\text { Ops\# } \\
2793-1\end{array}$ & $\begin{array}{l}\text { Ops\# } \\
2793-2\end{array}$ & $\begin{array}{l}\text { Ops\# } \\
2793-3\end{array}$ & & \\
\hline $\begin{array}{l}\text { Time of } \\
\text { day }\end{array}$ & $\begin{array}{l}\text { NASA608 } \\
\text { T-34 }\end{array}$ & $\begin{array}{l}\text { NASA } 7 \\
\text { King Air }\end{array}$ & $\begin{array}{c}\text { N3GC } \\
\text { King Air }\end{array}$ & $\begin{array}{c}\text { Ames Research } \\
\text { Center } \\
\text { DSRL }\end{array}$ & HSI activity \\
\hline TBD & \multicolumn{3}{|l|}{ Start of test day } & \multirow{13}{*}{$\begin{array}{l}\text { In the } \\
\text { loop }\end{array}$} & \\
\hline \multirow[t]{2}{*}{1200} & \multicolumn{3}{|l|}{ Mass briefing } & & Attend \\
\hline & & & & & $\begin{array}{l}\text { Human } \\
\text { systems }\end{array}$ \\
\hline \multirow[t]{2}{*}{$\begin{array}{l}\text { Takeoff } \\
\text { LSP }\end{array}$} & $\begin{array}{r}1430 \\
\text { KBFL }\end{array}$ & $\begin{array}{c}1430 \\
\text { KEDW }\end{array}$ & $\begin{array}{c}1430 \\
\text { KEDW }\end{array}$ & & $\begin{array}{l}\text { training } \\
(2.0 \text { hours })\end{array}$ \\
\hline & \multicolumn{3}{|c|}{ DSRL/LVC/RGCS up and running } & & $\begin{array}{c}\text { System under } \\
\text { test ready }\end{array}$ \\
\hline 1445 & Establish data & stem che & & & \\
\hline \multirow[t]{4}{*}{1515} & \multicolumn{3}{|c|}{ Commense exercise run $1(40 \mathrm{~min}+20 \mathrm{~min}$ setup $)$} & & Begin test \\
\hline & \multicolumn{3}{|c|}{ Commense exercise run 2} & & \\
\hline & \multicolumn{3}{|c|}{ Commense exercise run 3} & & \\
\hline & \multicolumn{3}{|c|}{ Finish exercise - return to base (data archiving) } & & End test \\
\hline Recover & $\begin{array}{r}1730 \\
\text { KBFL }\end{array}$ & $\begin{array}{c}1770 \\
\text { KEDW }\end{array}$ & $\begin{array}{l}1745 \\
\text { KVNY }\end{array}$ & & \\
\hline 1845 & \multicolumn{3}{|l|}{ Flight debrief } & & Attend \\
\hline 1945 & \multicolumn{3}{|l|}{ End of test day } & & \\
\hline
\end{tabular}

Figure 6. Configuration 2 timeline. 


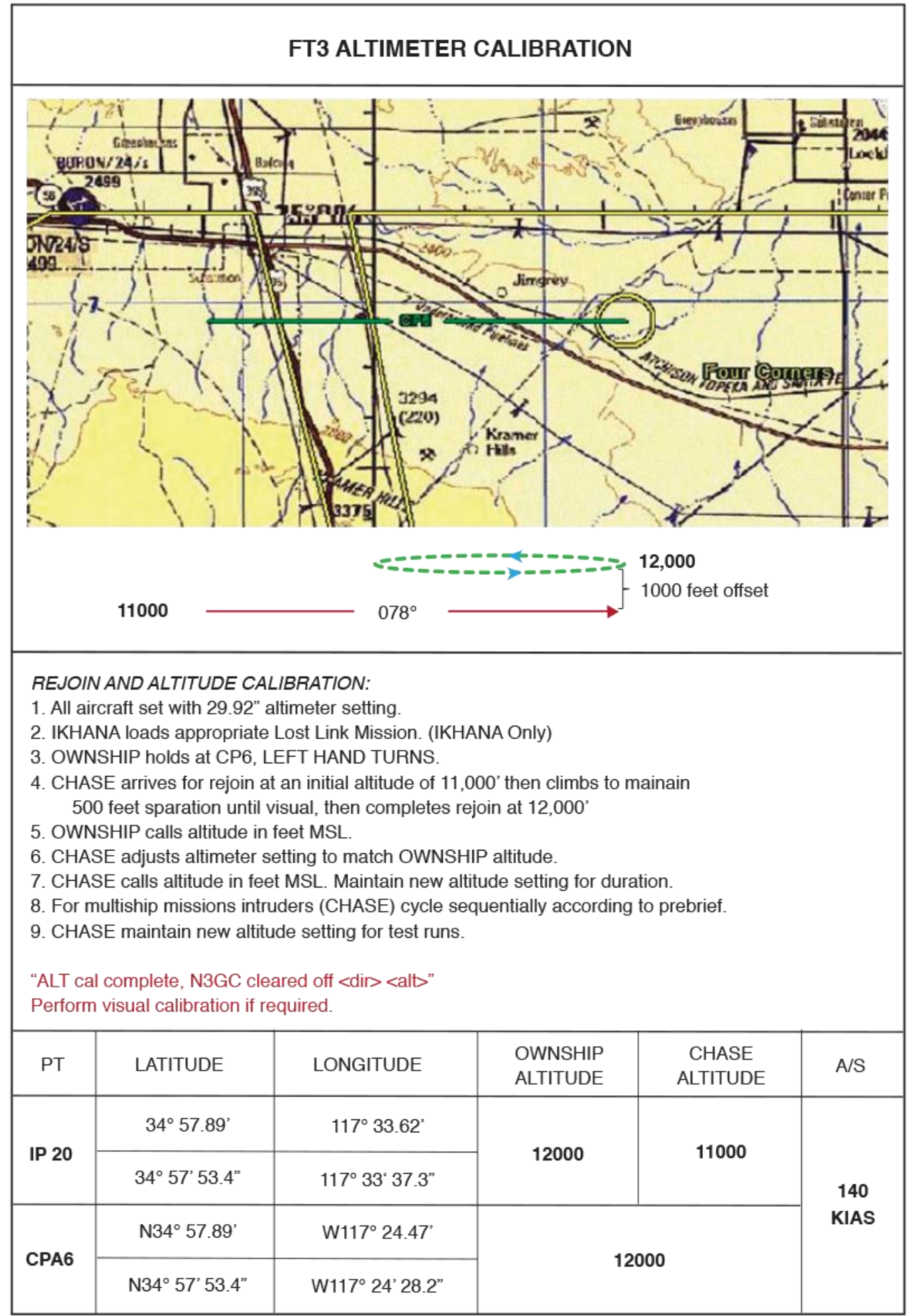

Figure 7. Altimeter calibration flight card. 


\section{Configuration 1 nomenclature}

\section{[Series] [Min altitude offset] [Vertical profile] [Encounter angle]}

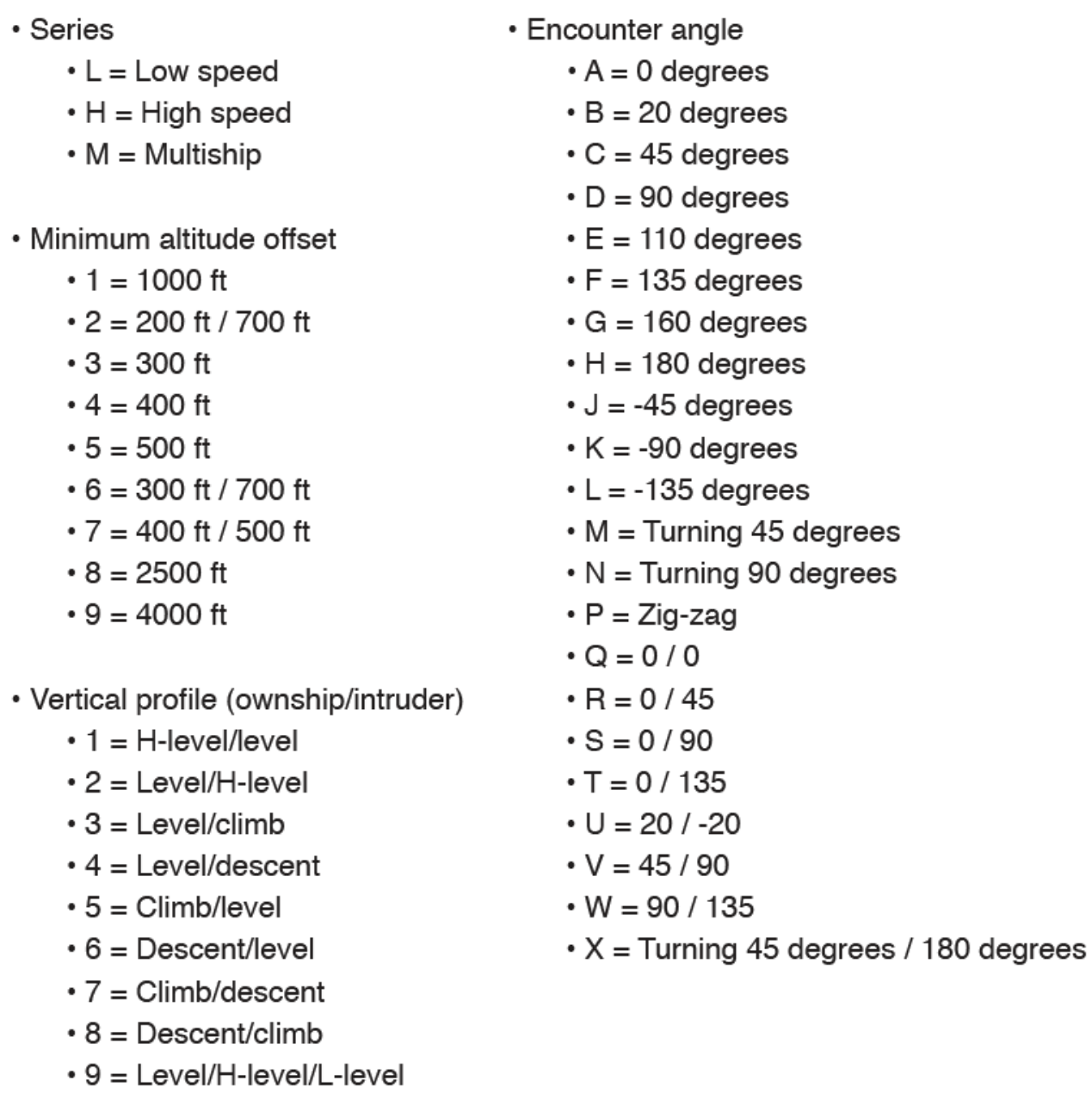

Figure 8. Configuration 1 pairwise encounters nomenclature. 


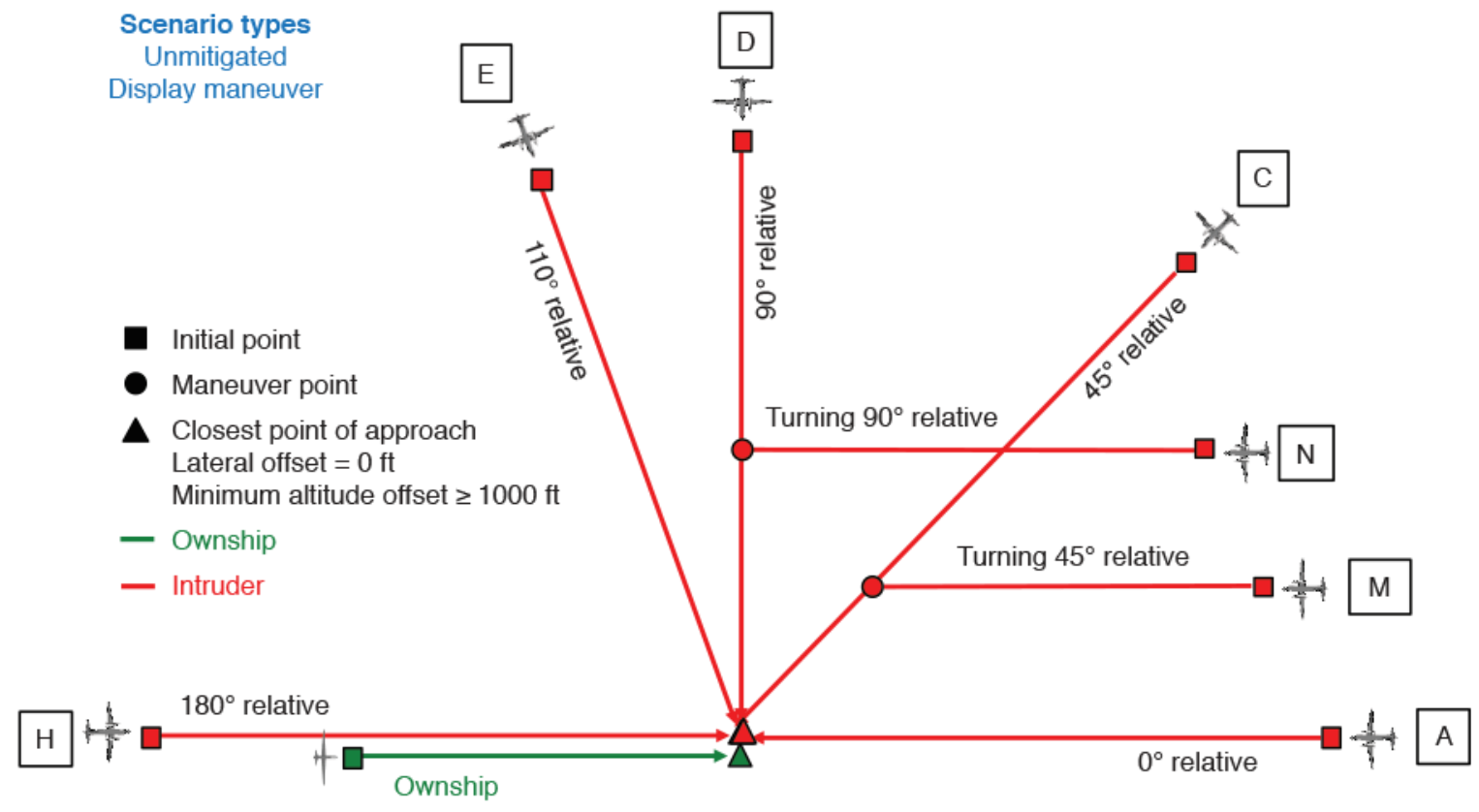

Figure 9. ARC pairwise encounter angles 1.

Initial point

Maneuver point

A Closest point of approach

(2) Lateral offset $=0.5 \mathrm{nmi}$

O Self-separation alerting

boundary $=0.75 \mathrm{nmi}$

Minimum altitude offset $\geq 300 \mathrm{ft}$

- Ownship

- Intruder raffic Alert and Collision Avoidance System
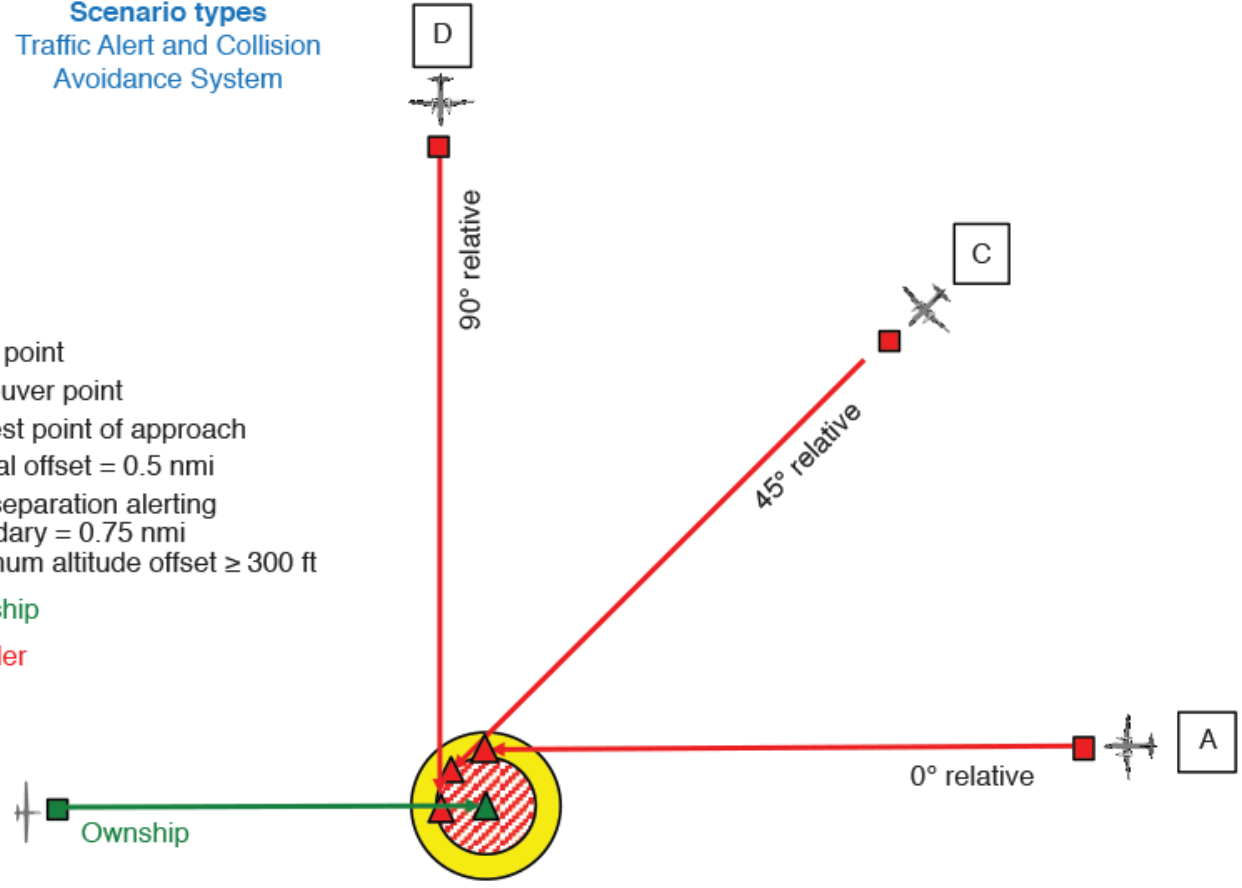

Figure 10. ARC pairwise encounter angles 2. 


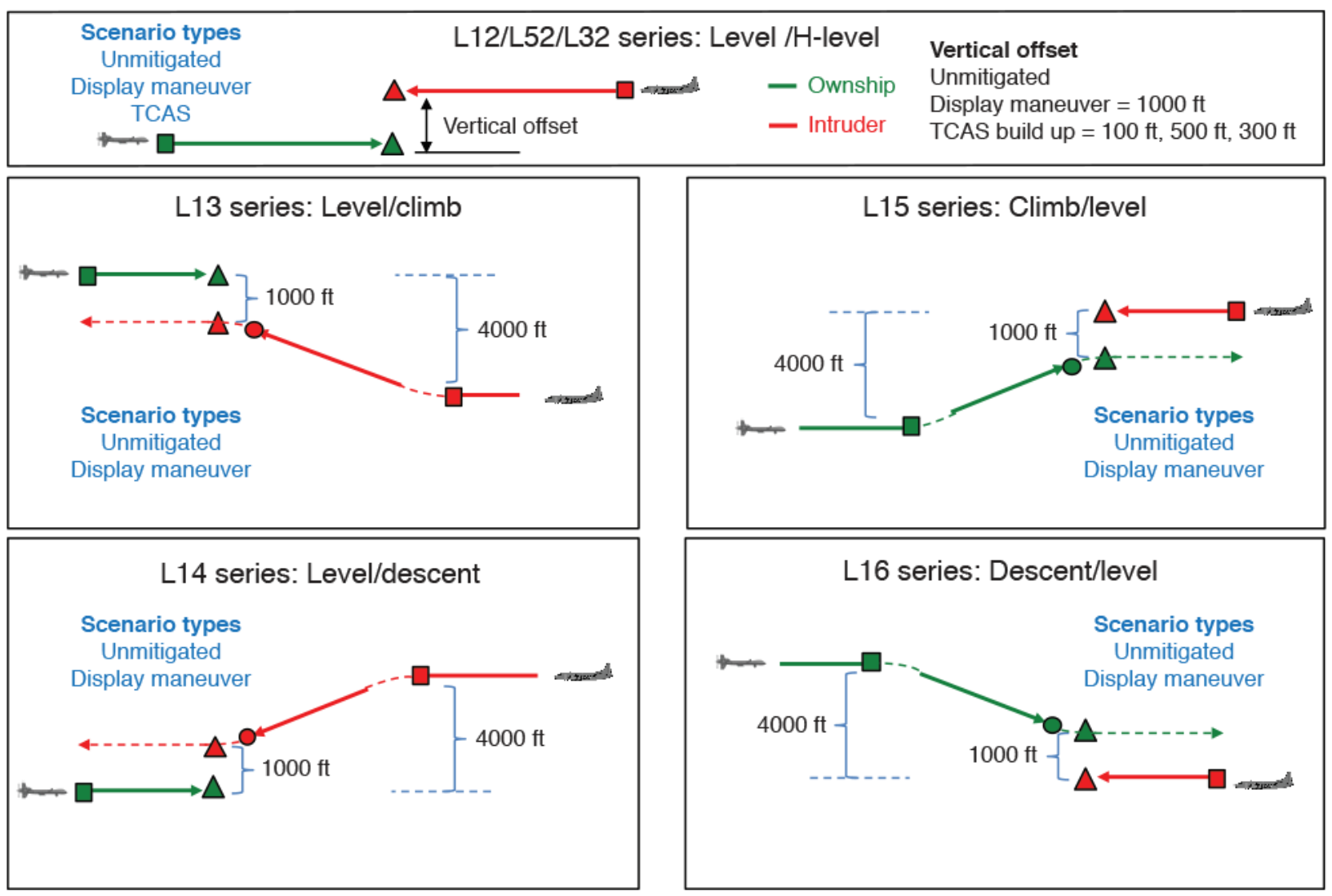

Figure 11. ARC pairwise encounter vertical profiles.

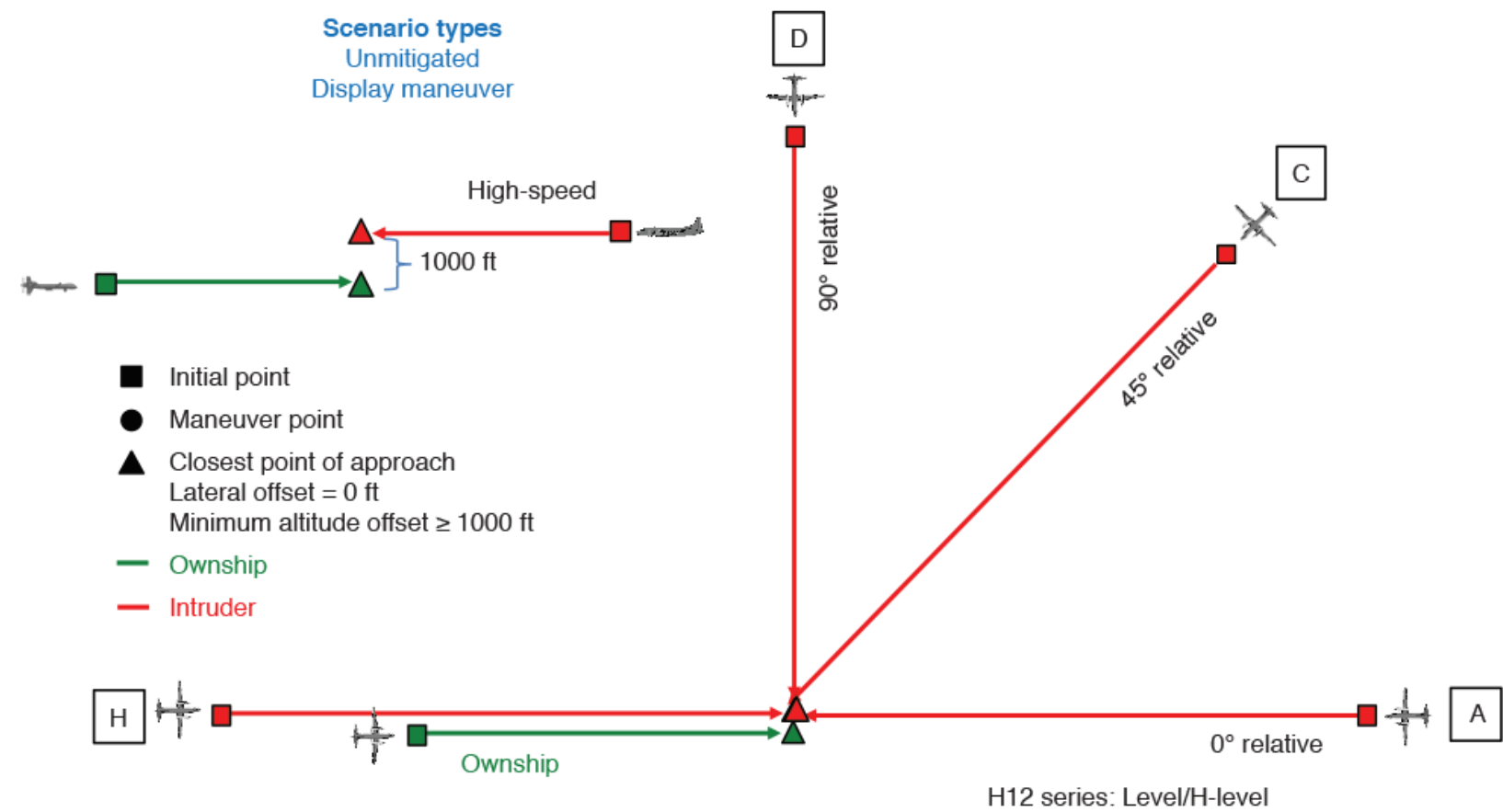

Figure 12. ARC high-speed intruder pairwise encounter angles.

American Institute of Aeronautics and Astronautics 


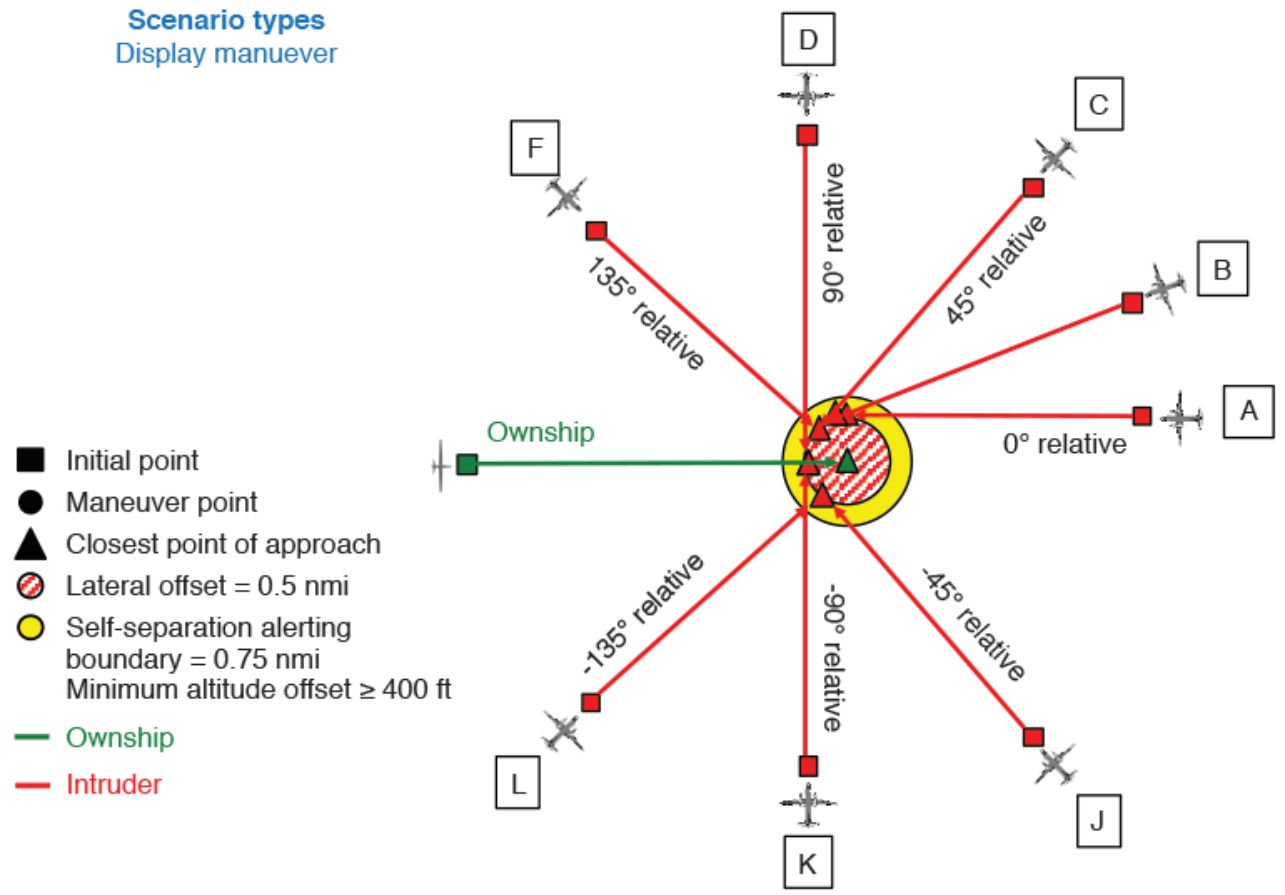

Figure 13. LaRC pairwise encounter angles.

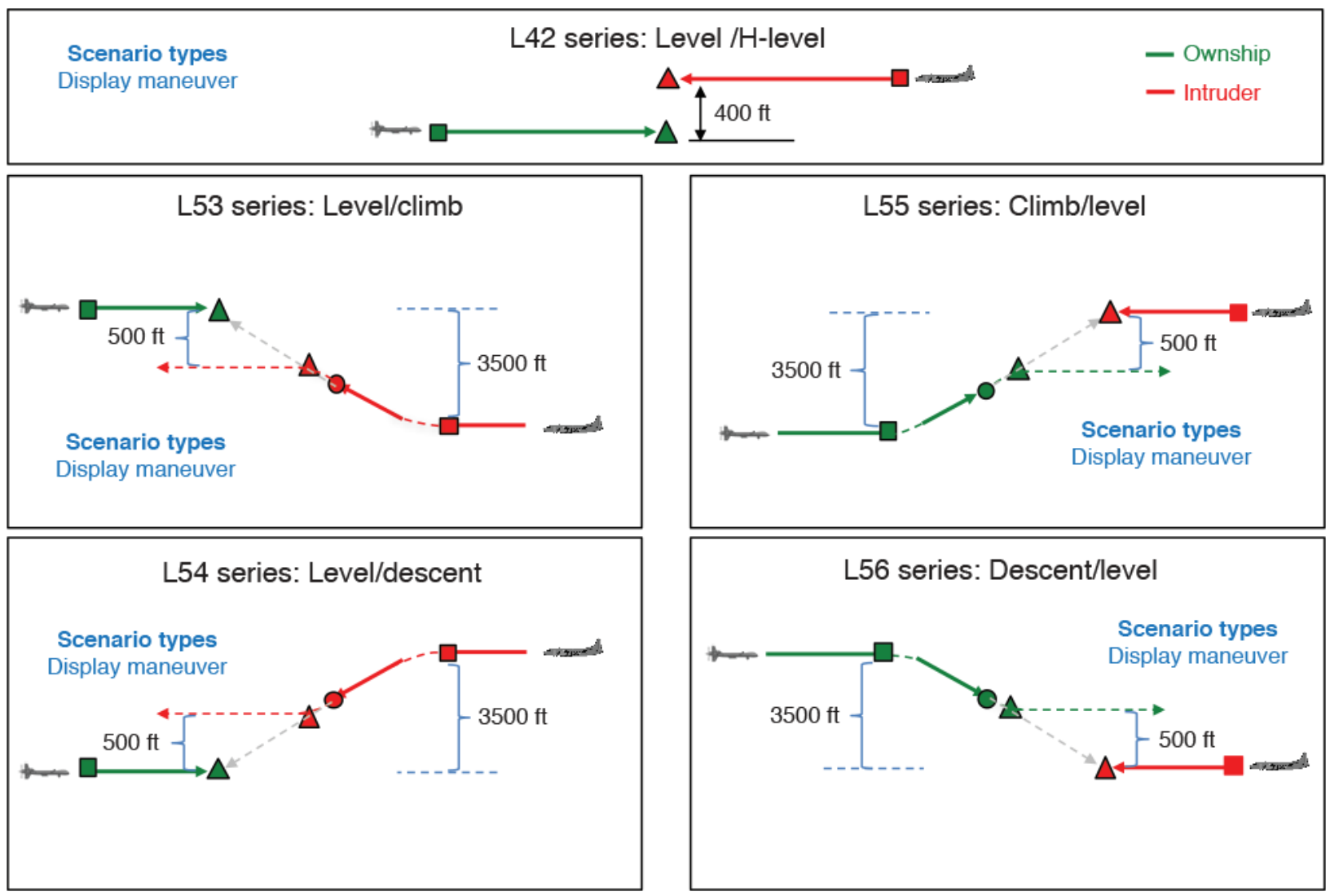

Figure 14. LaRC pairwise encounter vertical profiles 1.

79

American Institute of Aeronautics and Astronautics 


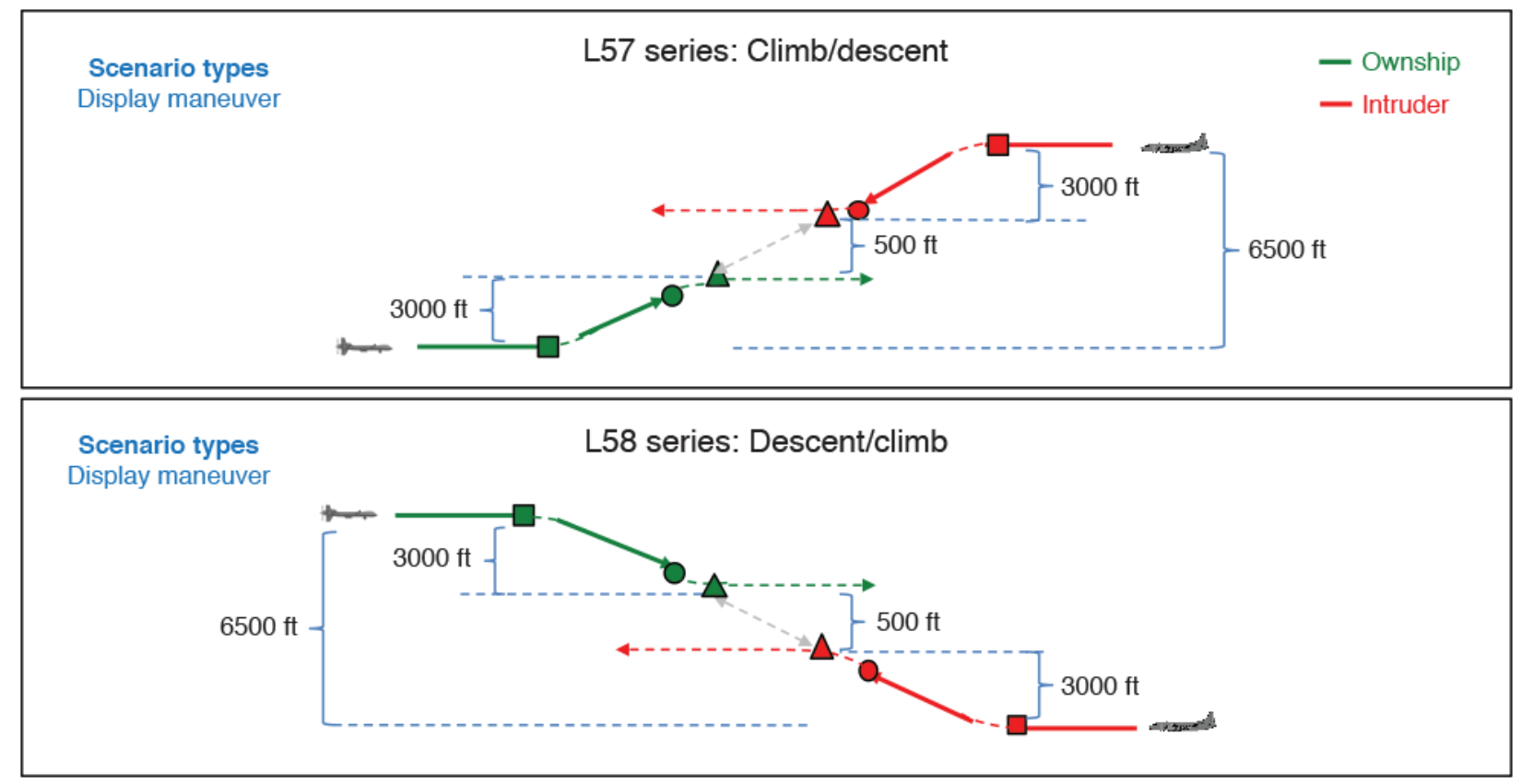

Figure 15. LaRC pairwise encounter vertical profiles 2.

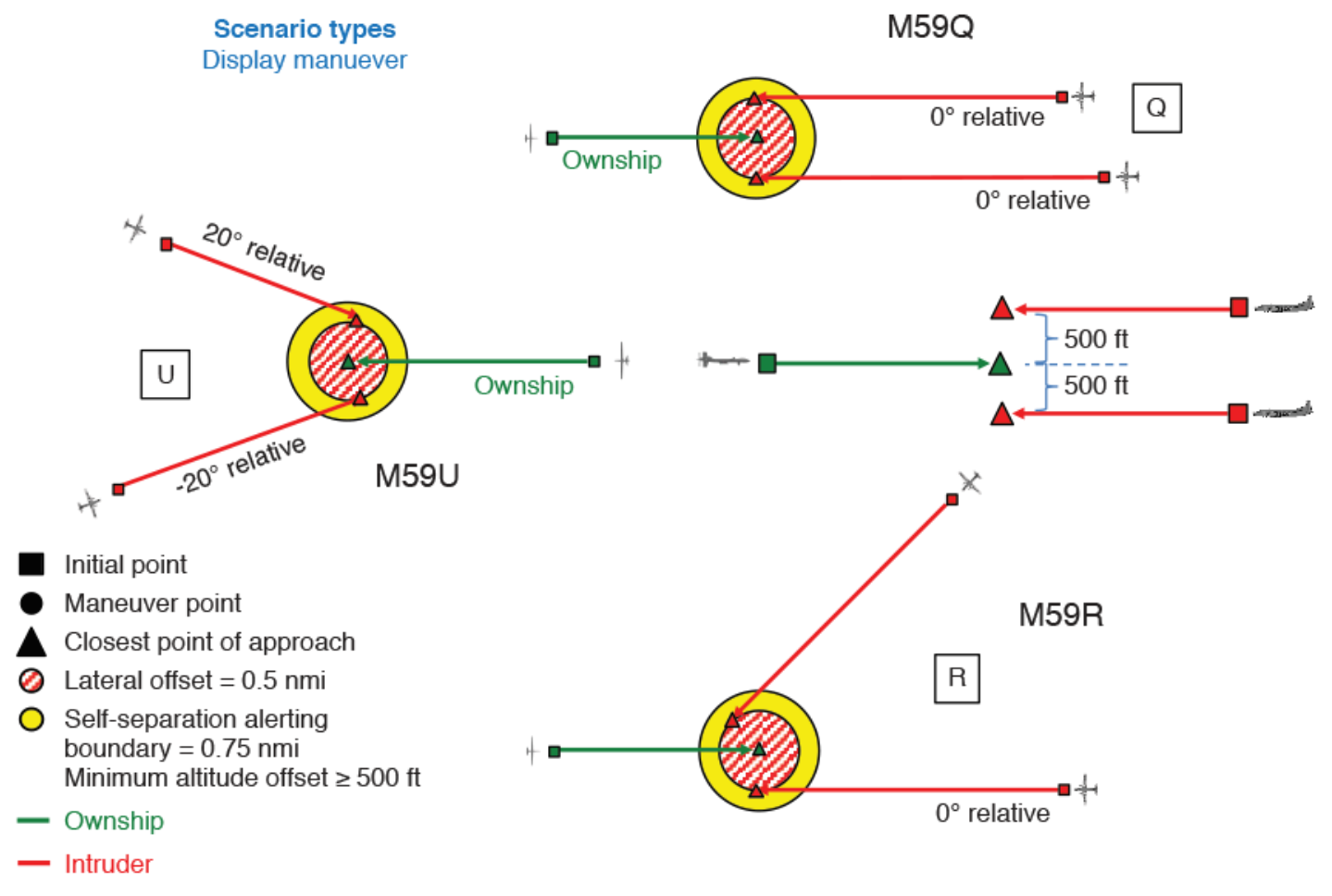

Figure 16. LaRC pairwise multiship encounters 1.

American Institute of Aeronautics and Astronautics 


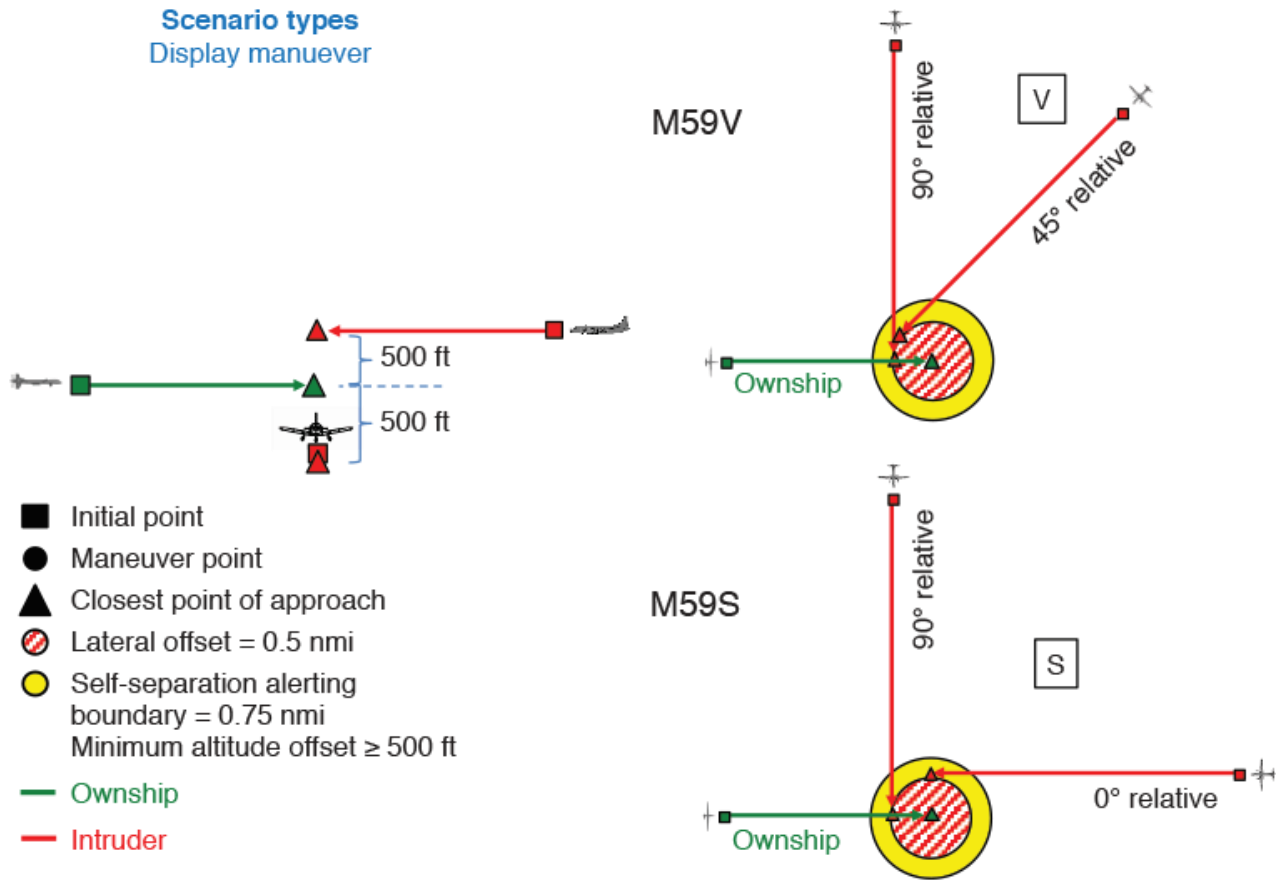

Figure 17. LaRC pairwise multiship encounters 2.

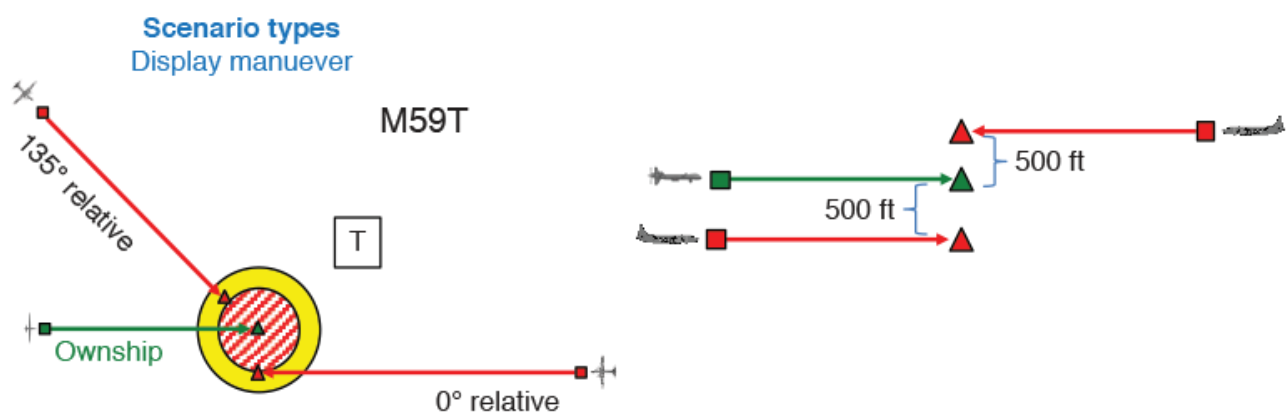

Initial point

- Maneuver point

A Closest point of approach

(2) Lateral offset $=0.5 \mathrm{nmi}$

$\bigcirc$ Self-separation alerting boundary $=0.75 \mathrm{nmi}$ Minimum altitude offset $\geq 500 \mathrm{ft}$

- Ownship

- Intruder

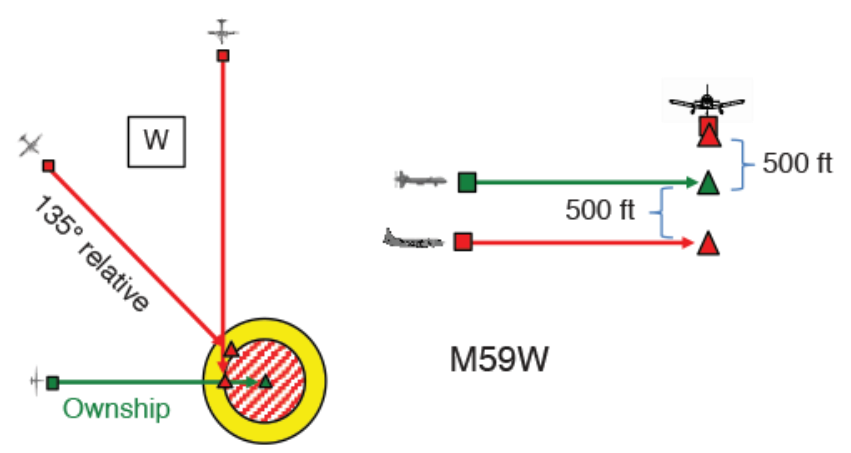

Figure 18. LaRC pairwise multiship encounters 3. 


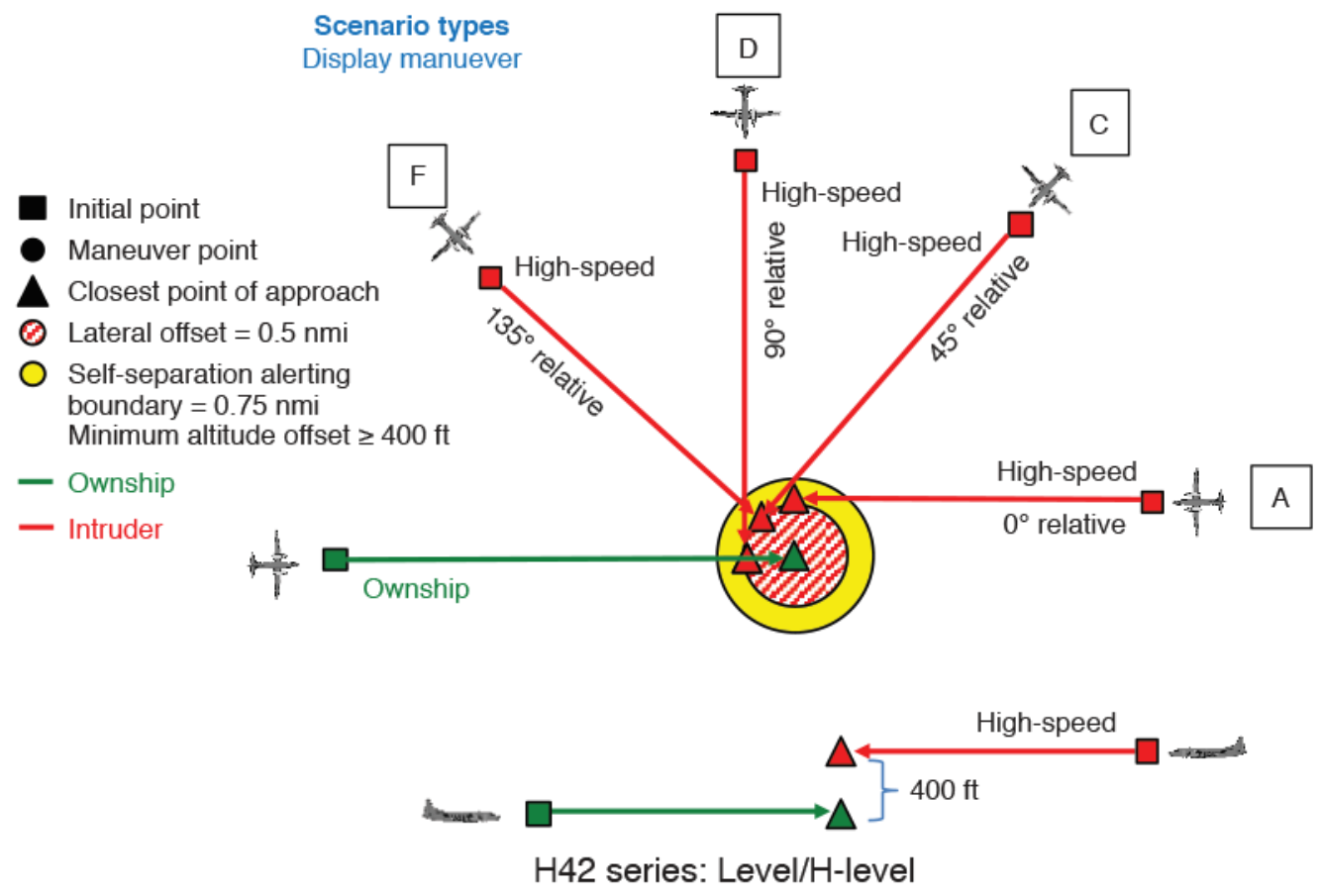

Figure 19. LaRC high-speed intruder pairwise encounter angles.

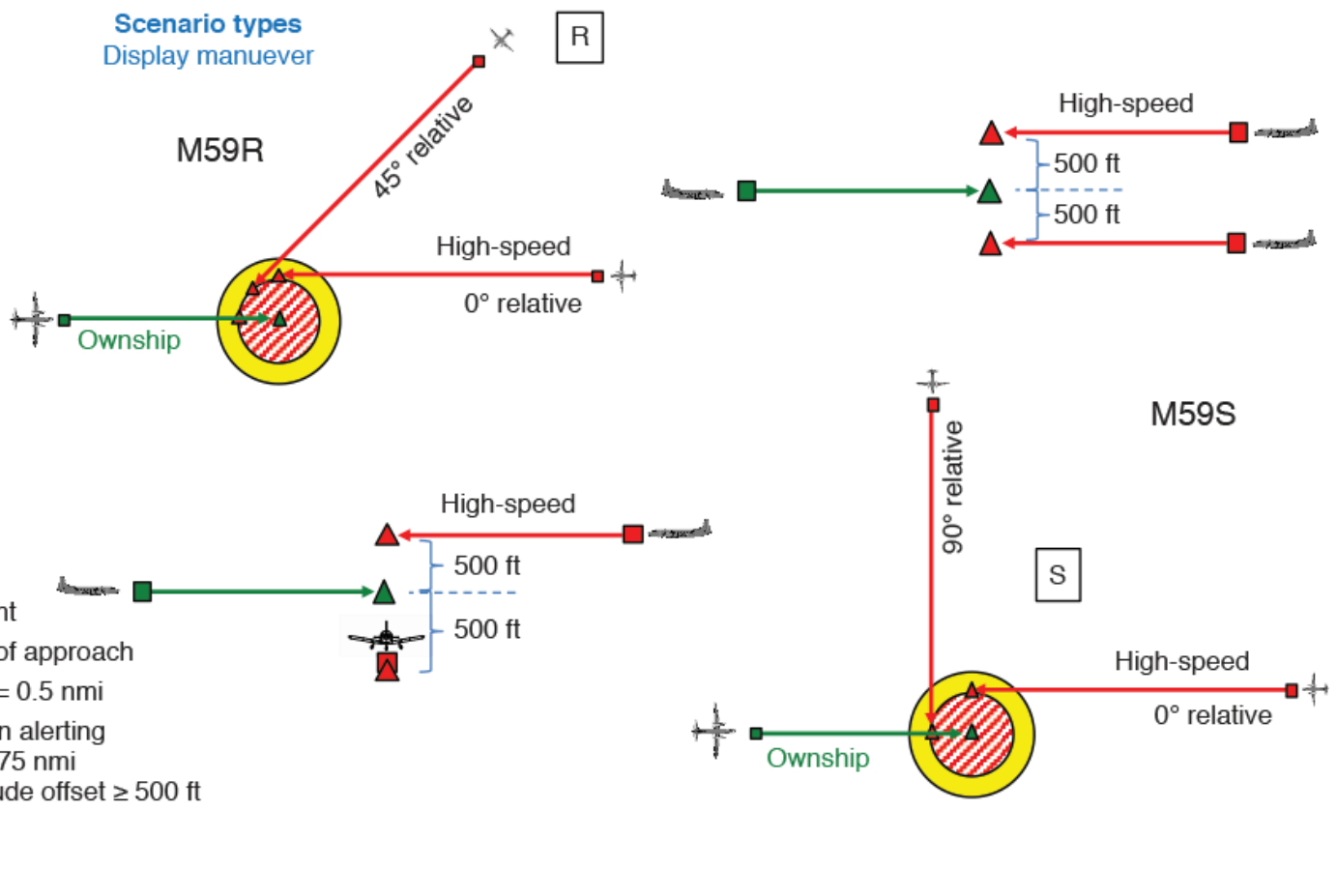

Figure 20. LaRC high-speed pairwise multiship encounters 1. 


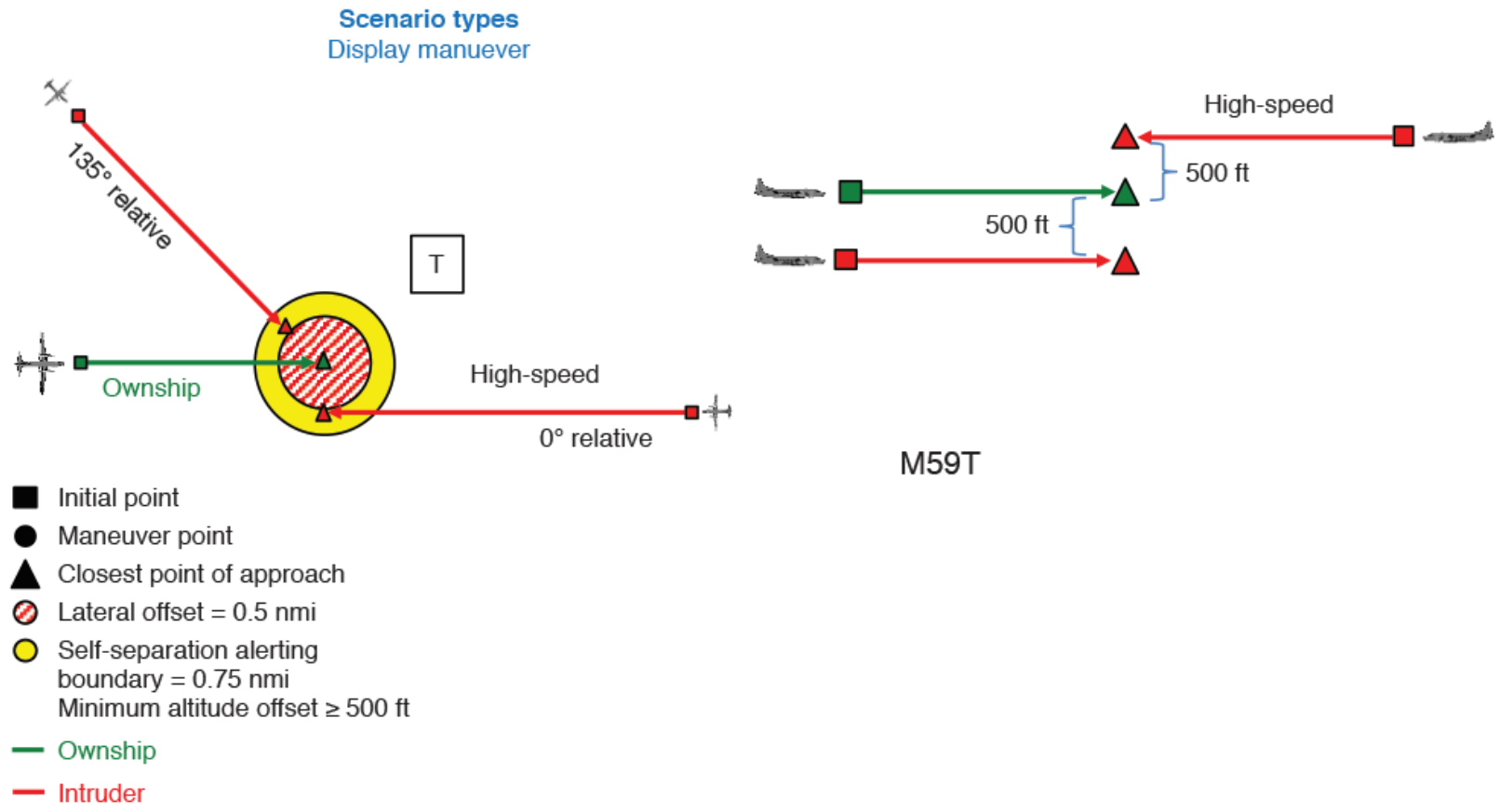

Figure 21. LaRC high-speed pairwise multiship encounters 2. 


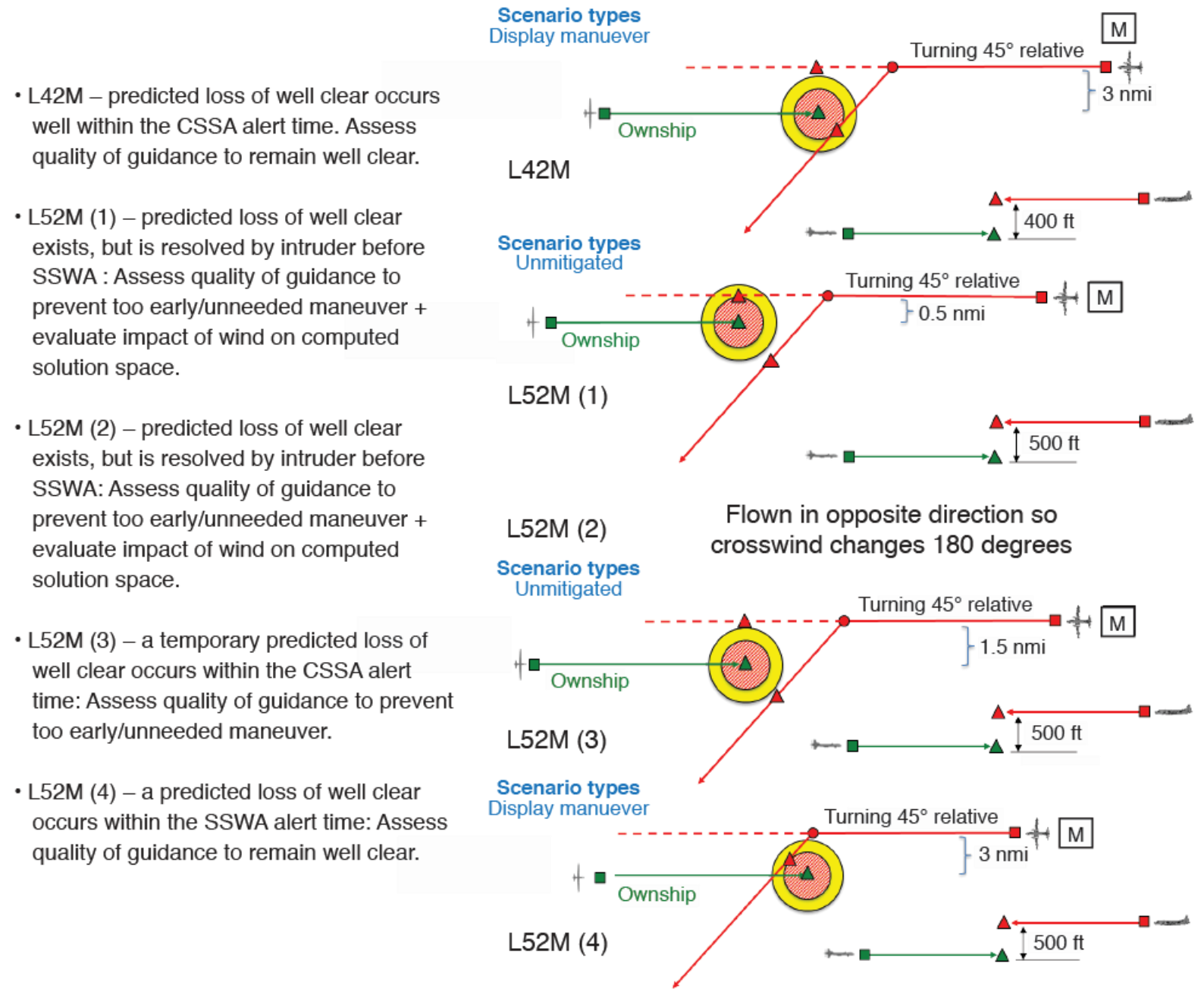

Figure 22. GA-ASI CPDS pairwise encounters. 
- M79X (1) - same as L42M, but with further constrained solution space.

- M79X (2) - same as L52M(1), but with further constrained solution space.

- M79X (3) - same as L52M(3), but with further constrained solution space.

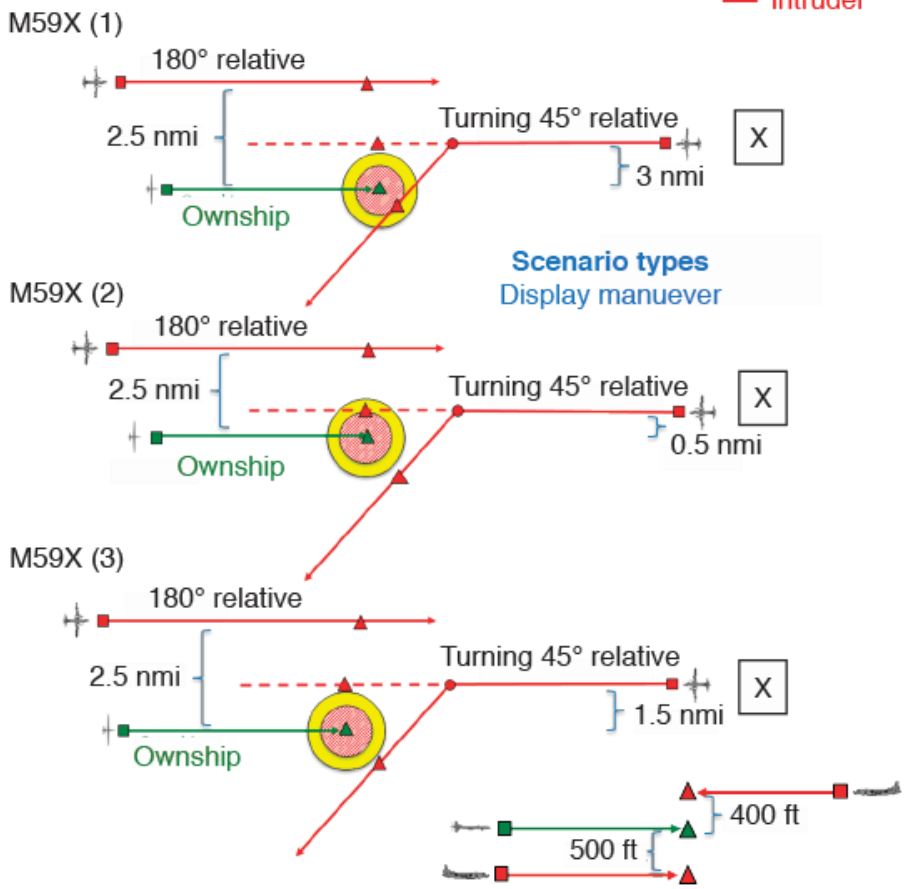

Figure 23. GA-ASI CPDS multiship pairwise encounters.

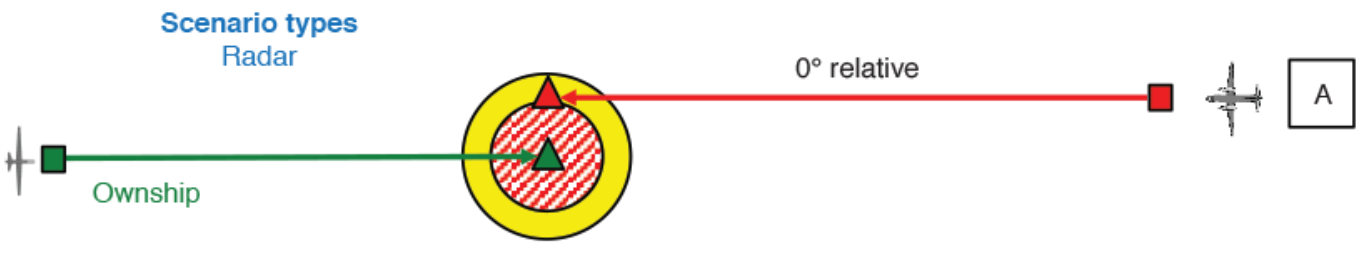

Initial point

- Maneuver point

A Closest point of approach

Lateral offset $=0.5 \mathrm{nmi}$

Self-separation alerting boundary $=0.75 \mathrm{nmi}$ Minimum altitude offset $\geq 1000 \mathrm{ft}$

- Ownship

- Intruder
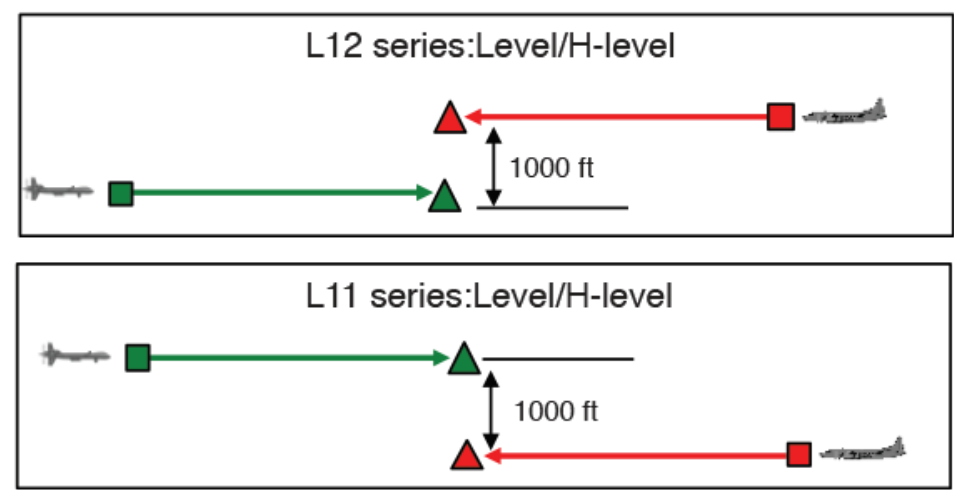

Note: Low-altitude encounters. Lowest altitude $1000 \mathrm{ft}$ AGL.

Figure 24. GA-ASI low altitude pairwise radar encounters. 

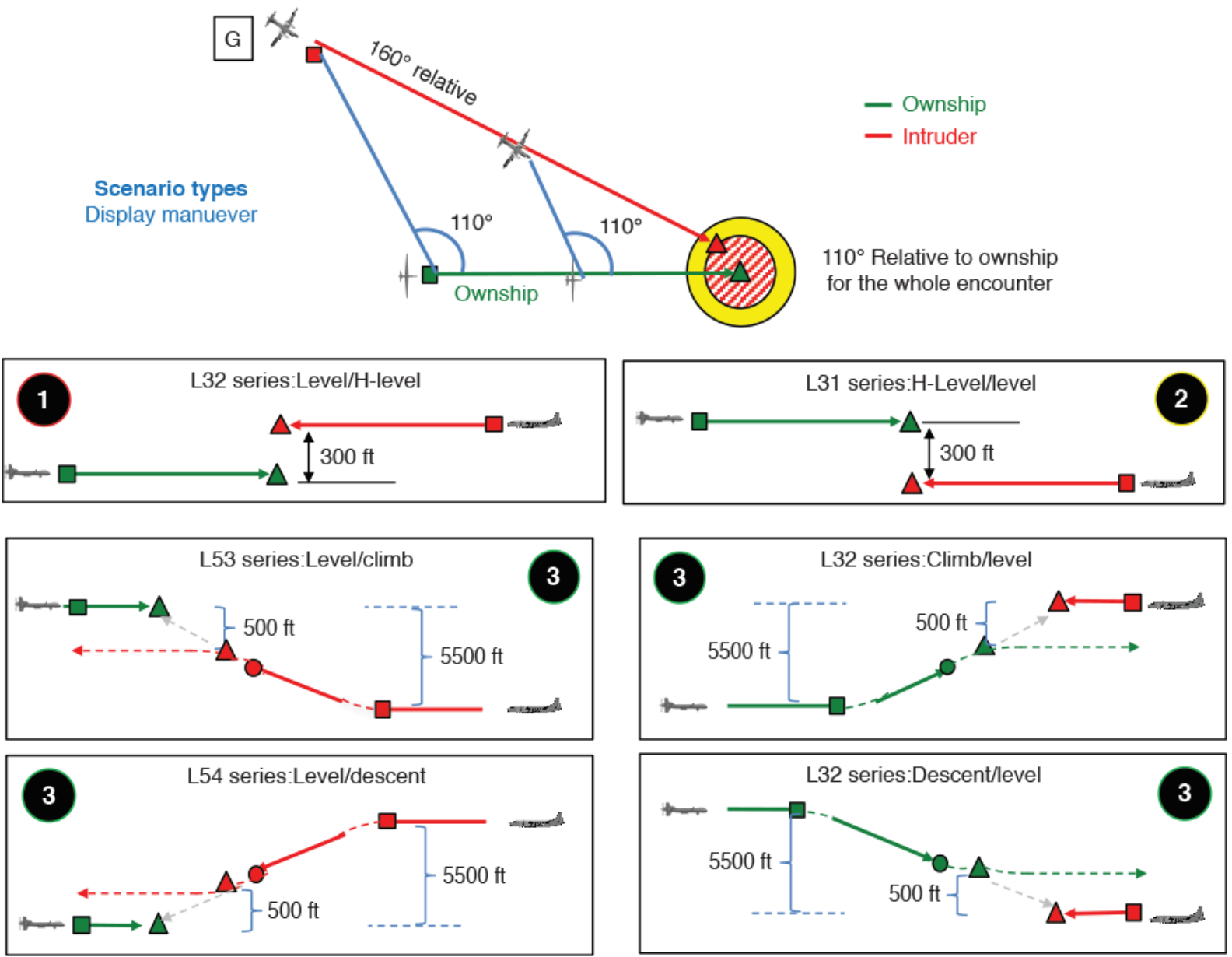

Figure 25. GA-ASI radar CBDR pairwise encounters $\left(110^{\circ}\right)$. 

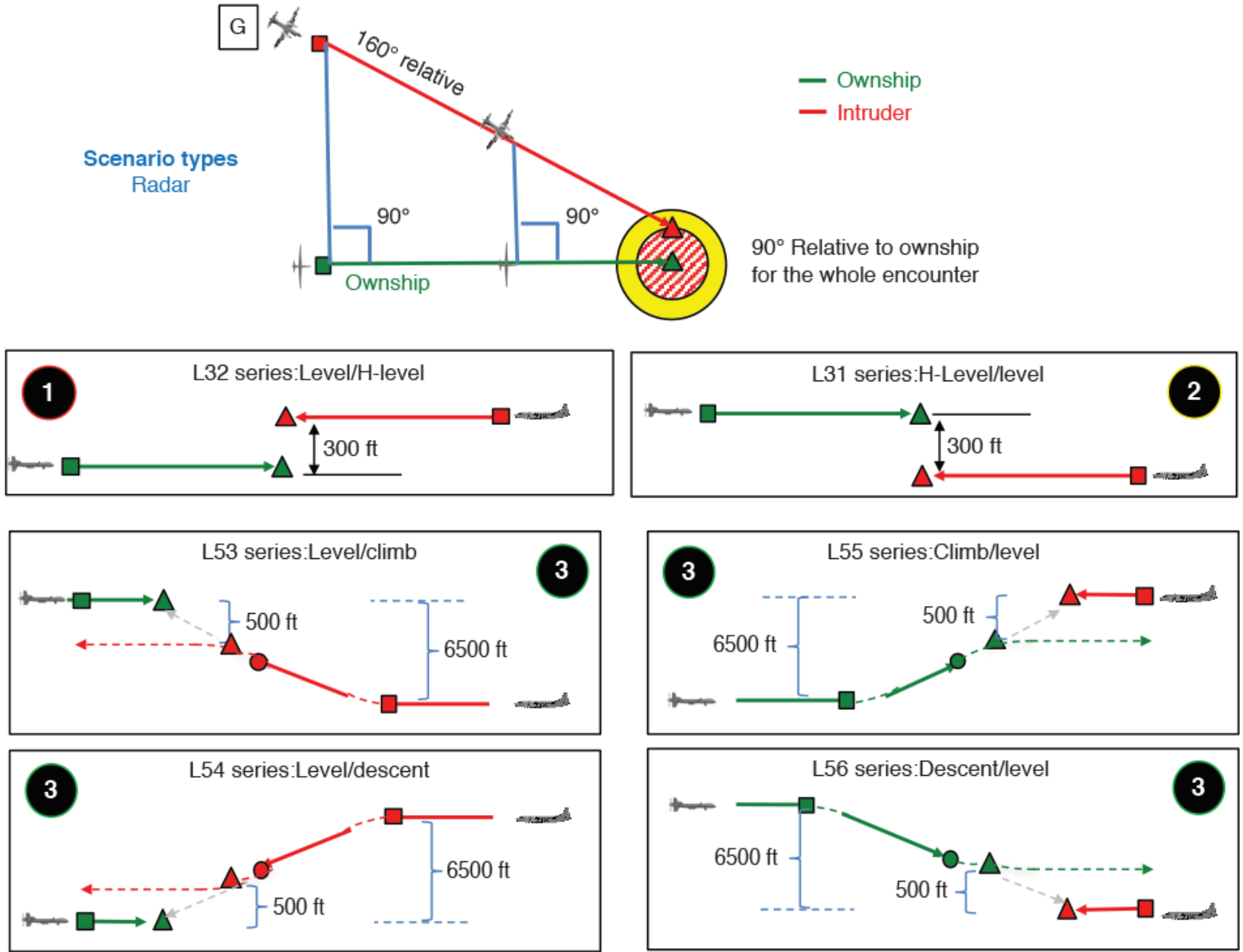

Figure 26. GA-ASI radar CBDR pairwise encounters $\left(90^{\circ}\right)$.

2 L12P Scenario types

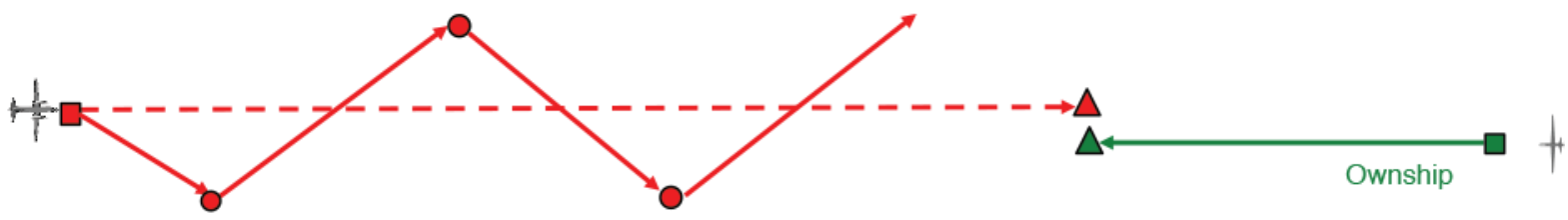

Initial point

- Maneuver point

- Closest point of approach

Lateral offset $=0 \mathrm{ft}$

Minimum altitude offset $\geq 1000 \mathrm{ft}$

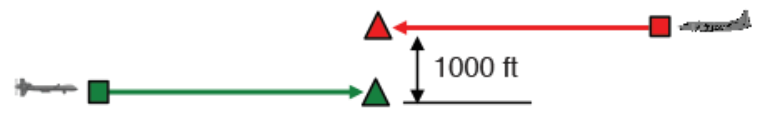

— Ownship

- Intruder

Figure 27. GA-ASI radar zig-zag pairwise encounter.

American Institute of Aeronautics and Astronautics 

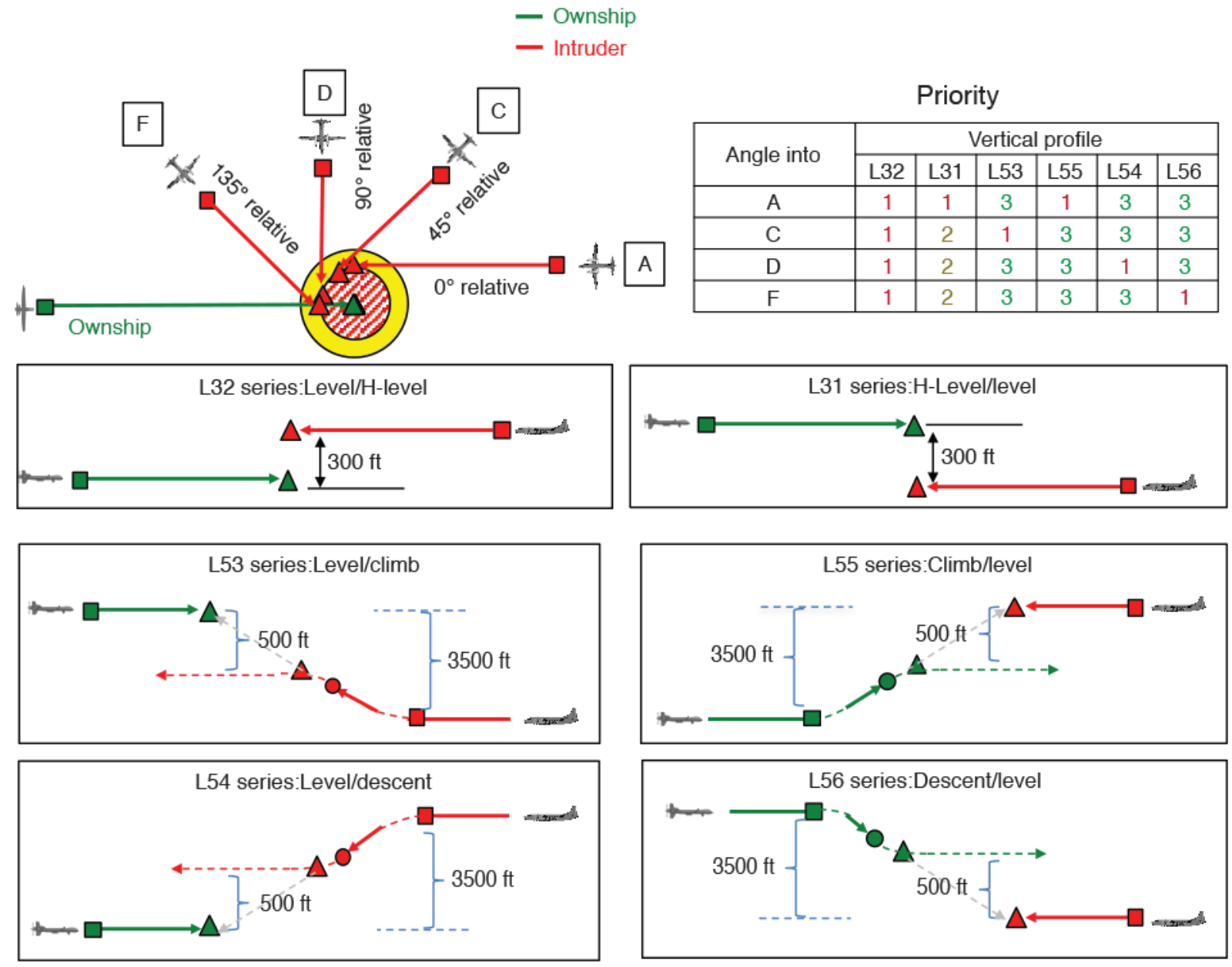

Figure 28. GA-ASI TCAS mitigated pairwise encounters 1. 

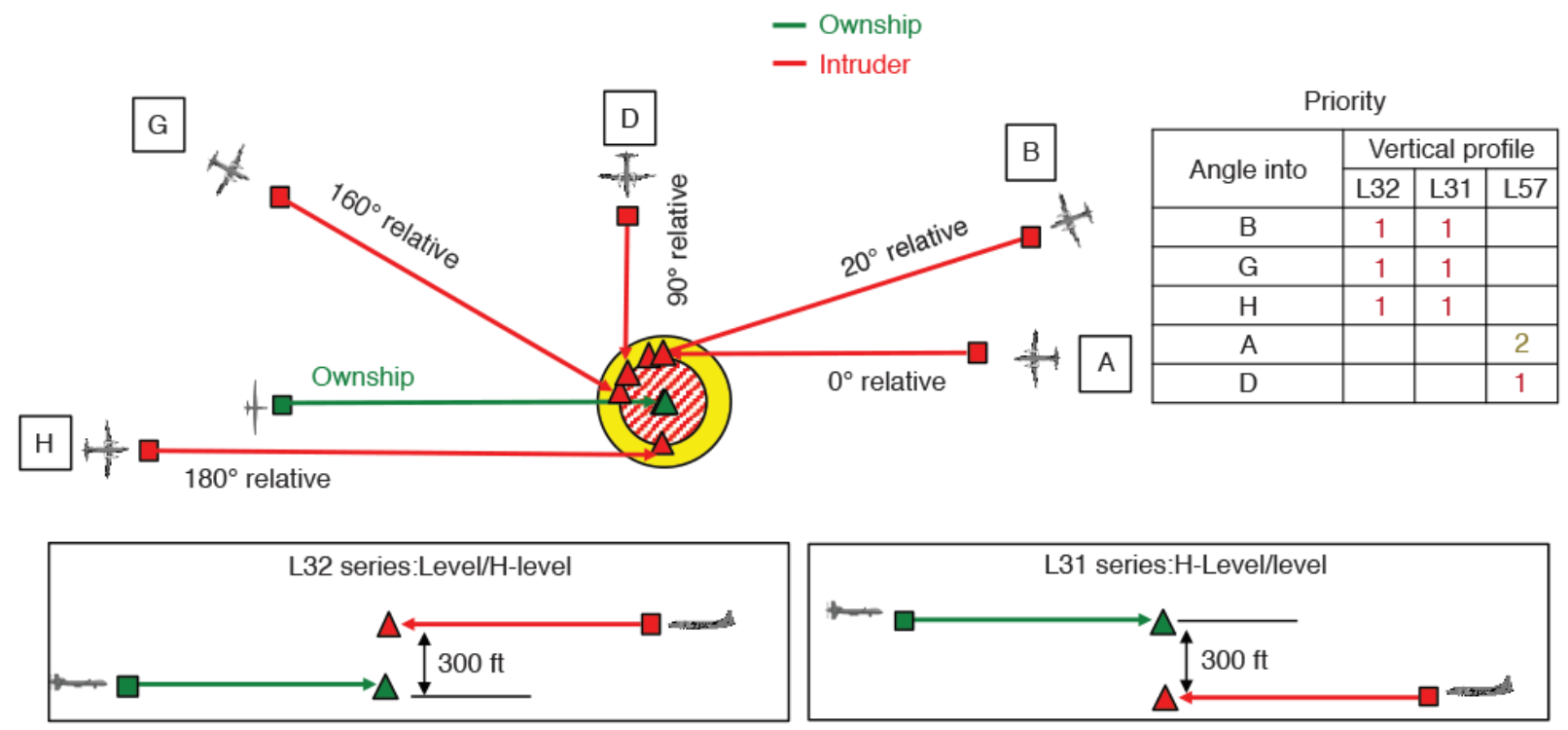

L57 series:Climb/descent

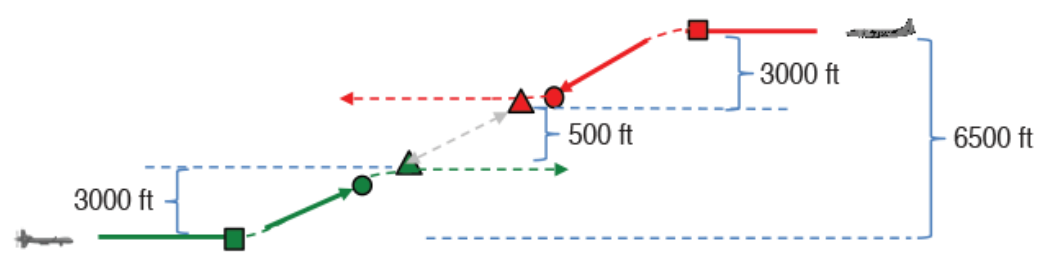

Figure 29. GA-ASI TCAS mitigated pairwise encounters 2.

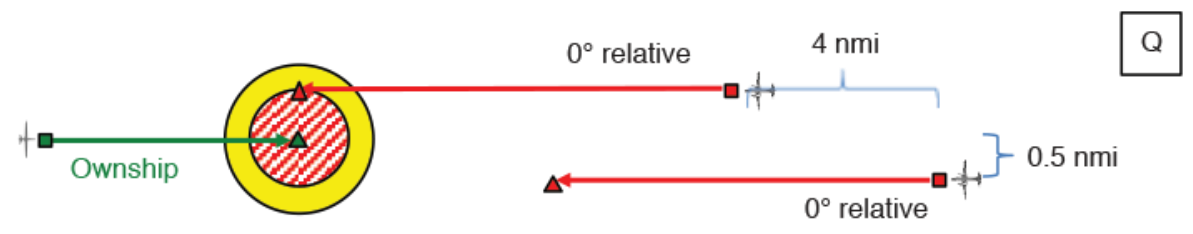

\section{1 \\ M67Q \\ $\mathrm{M} 68 \mathrm{Q}$}

Initial point

- Maneuver point

A Closest point of approach

(1) Lateral offset $=0.5 \mathrm{nmi}$

$\bigcirc$ Self-separation alerting

boundary $=0.75 \mathrm{nmi}$

Minimum altitude offset $\geq 200 \mathrm{ft}$

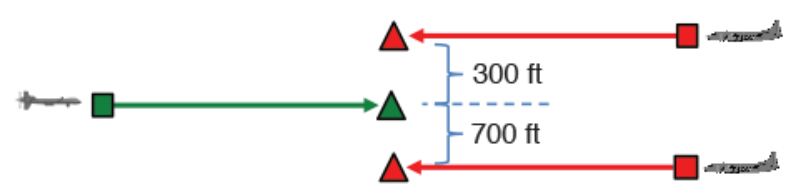

- Ownship

- Intruder

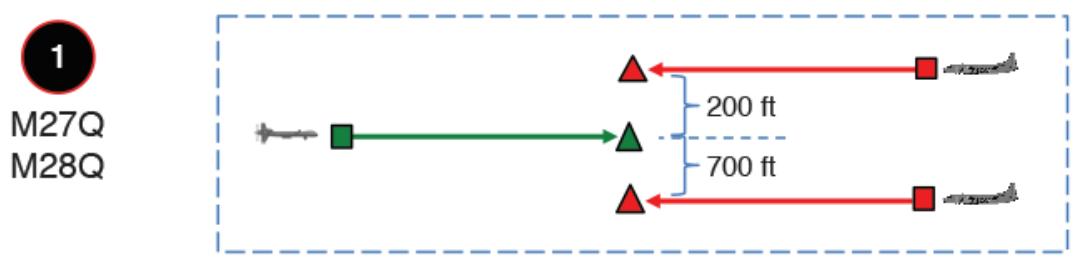

Note: Buildup to this profile, $200 \mathrm{ft} / 700 \mathrm{ft}$

Figure 30. GA-ASI TCAS sequential pairwise encounters.

89

American Institute of Aeronautics and Astronautics 


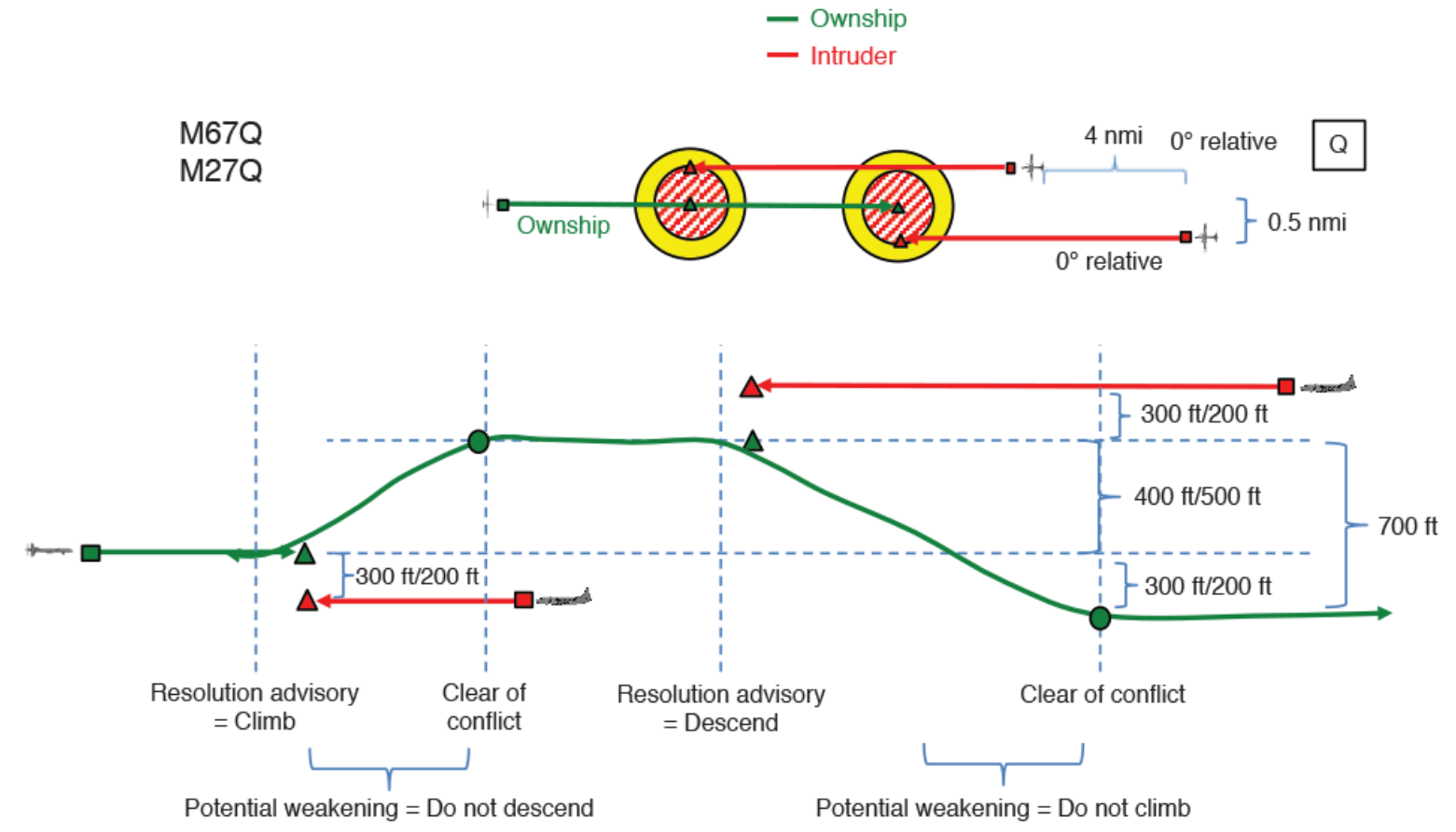

\section{Climb-clear-descend}

Figure 31. GA-ASI TCAS sequential pairwise encounters vertical profile 1.

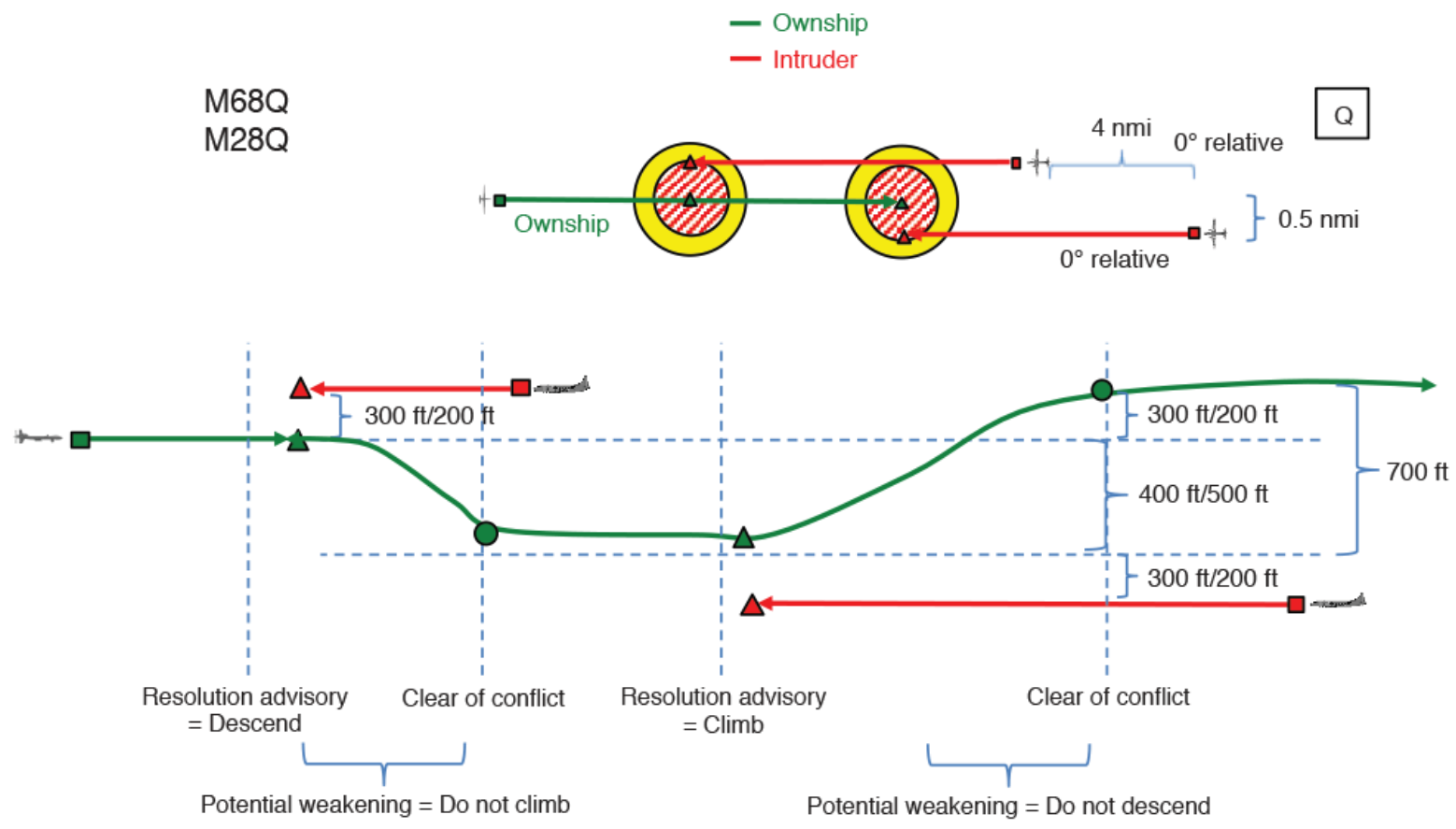

Descend-clear-climb

Figure 32. GA-ASI TCAS sequential pairwise encounters vertical profile 2.

American Institute of Aeronautics and Astronautics 


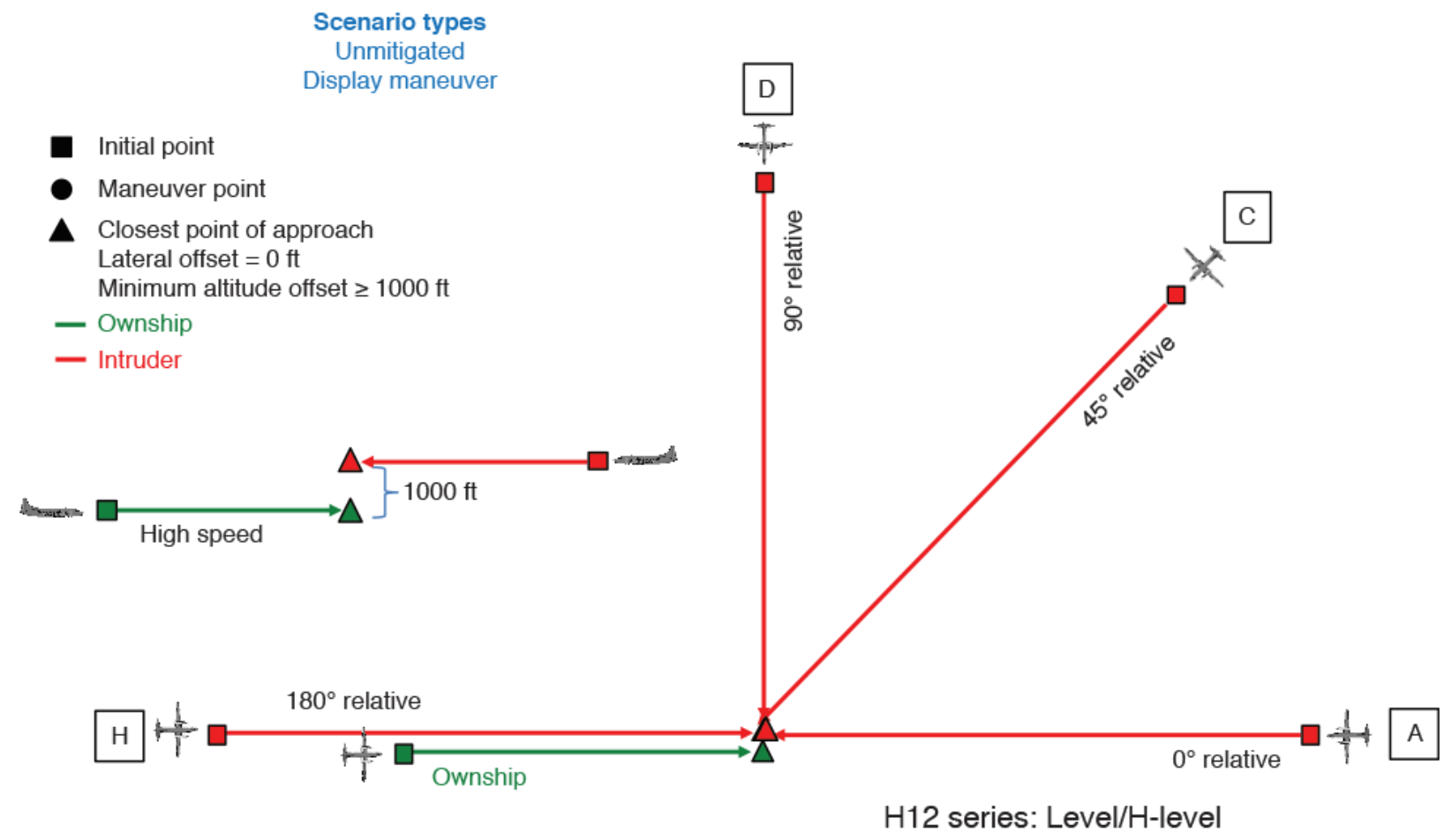

Figure 33. ARC high-speed ownship pairwise encounter angles. 


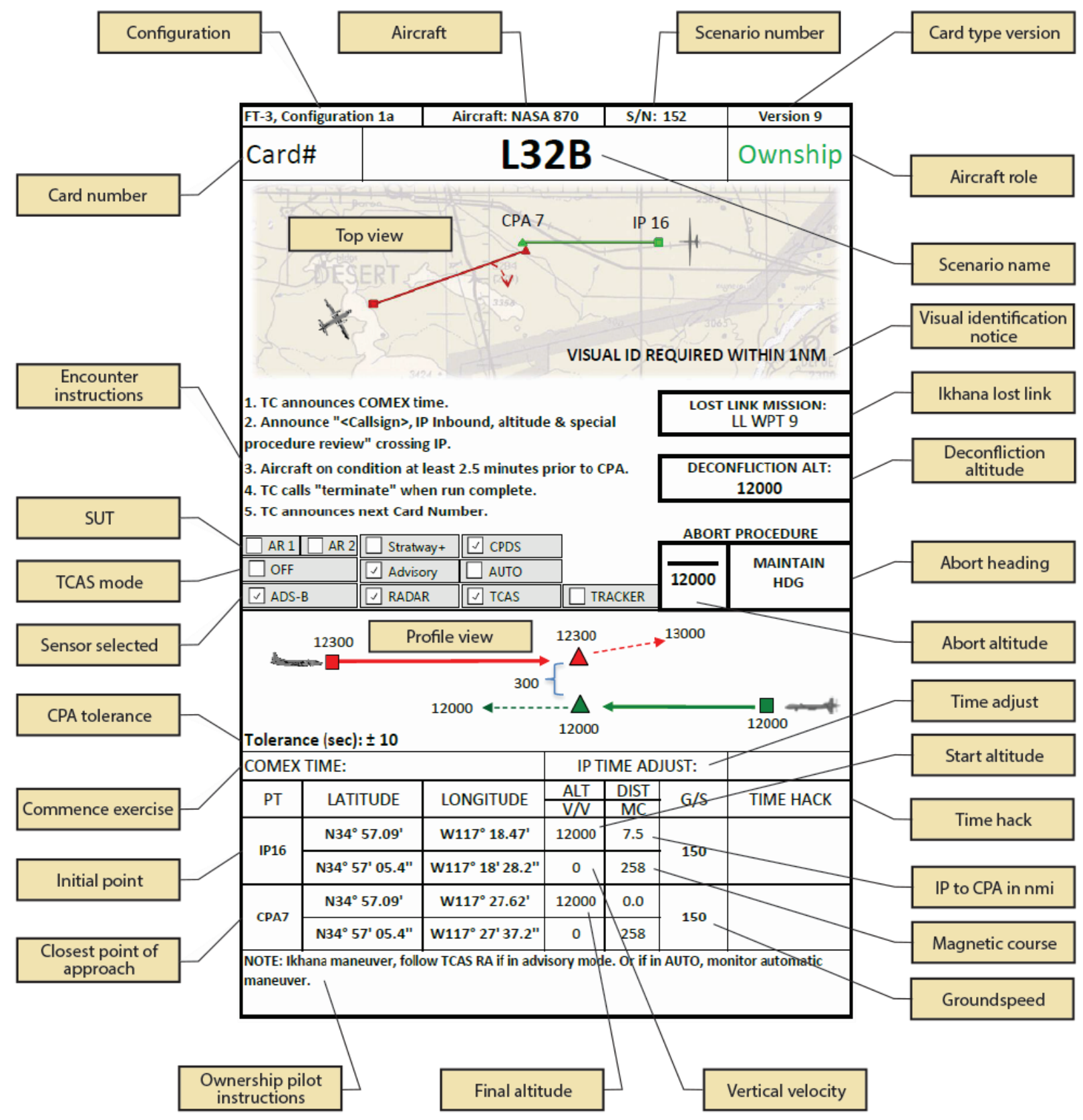

Figure 34. Pairwise encounters ownship example test card.

92

American Institute of Aeronautics and Astronautics 


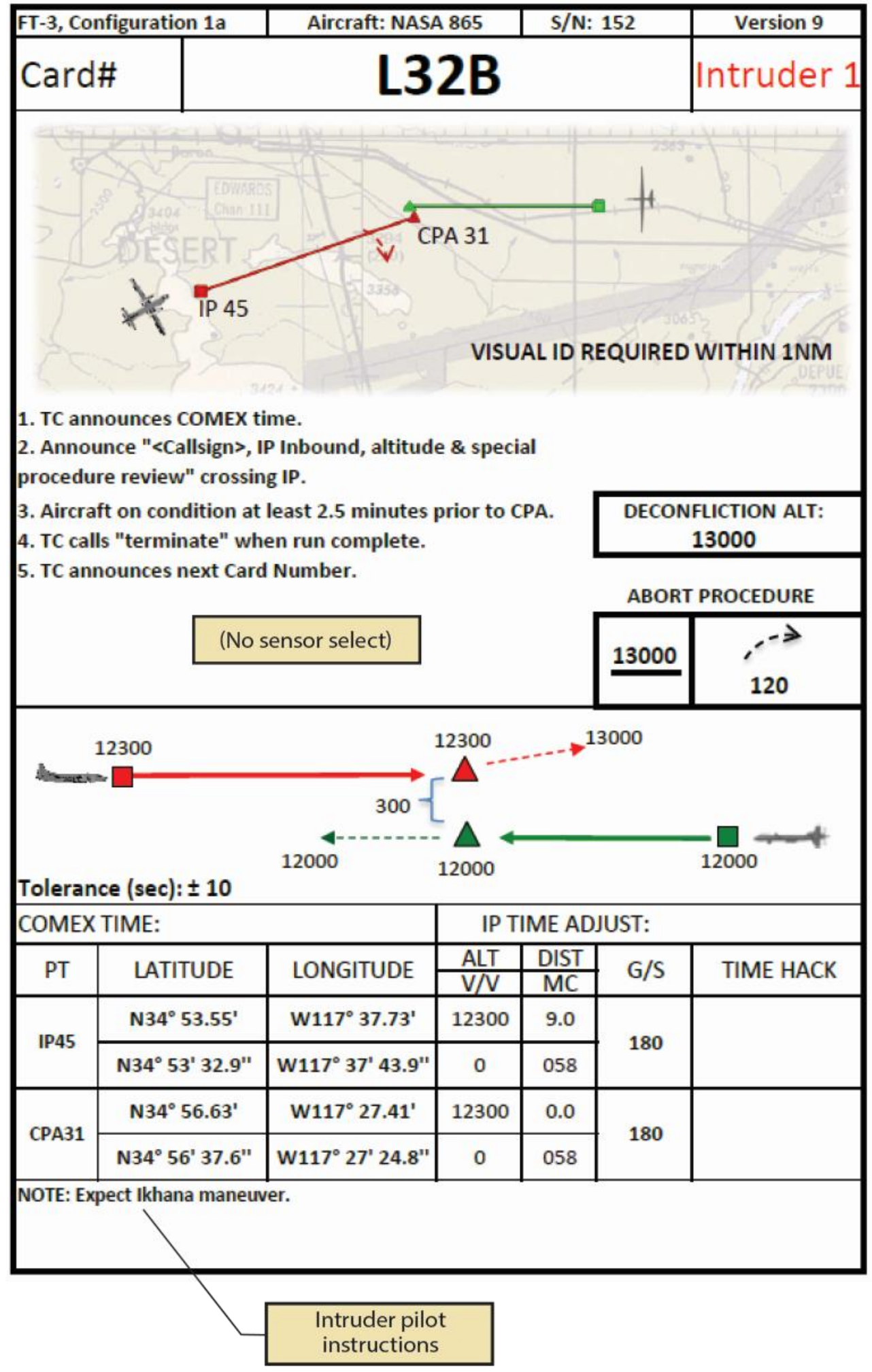

Figure 35. Pairwise encounters intruder example test card. 


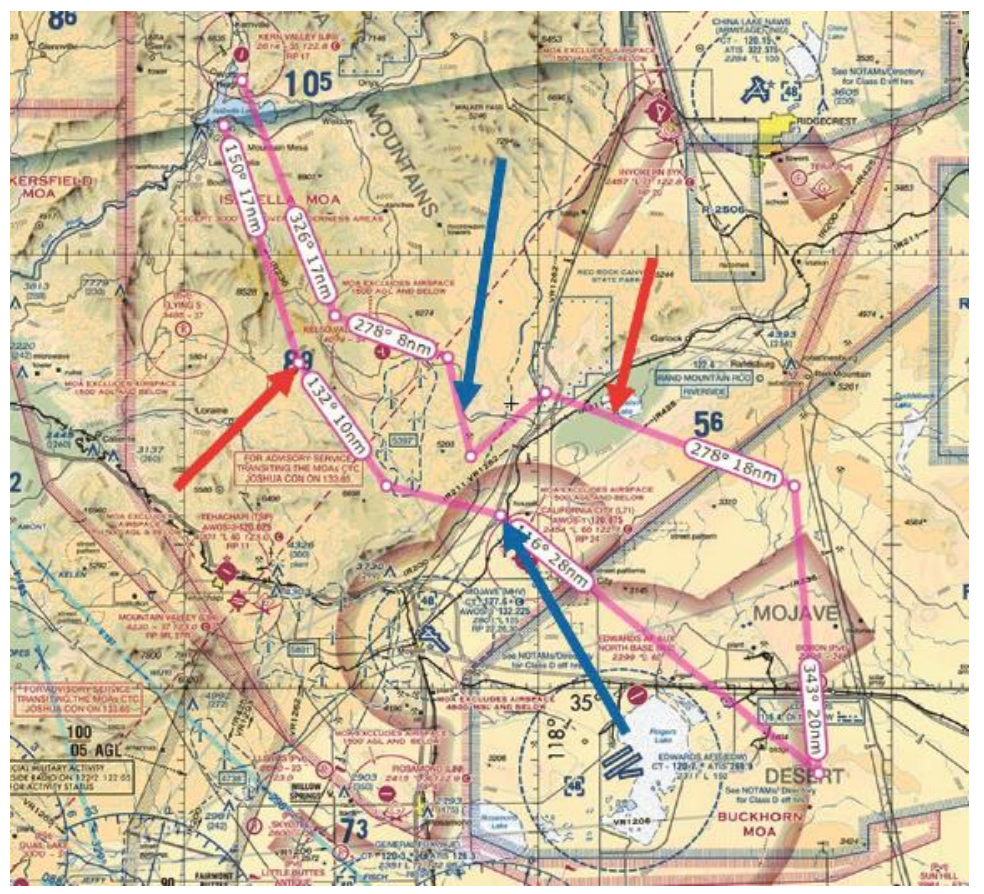

Figure 36. Fireline ownship route with live intruder intercepts.

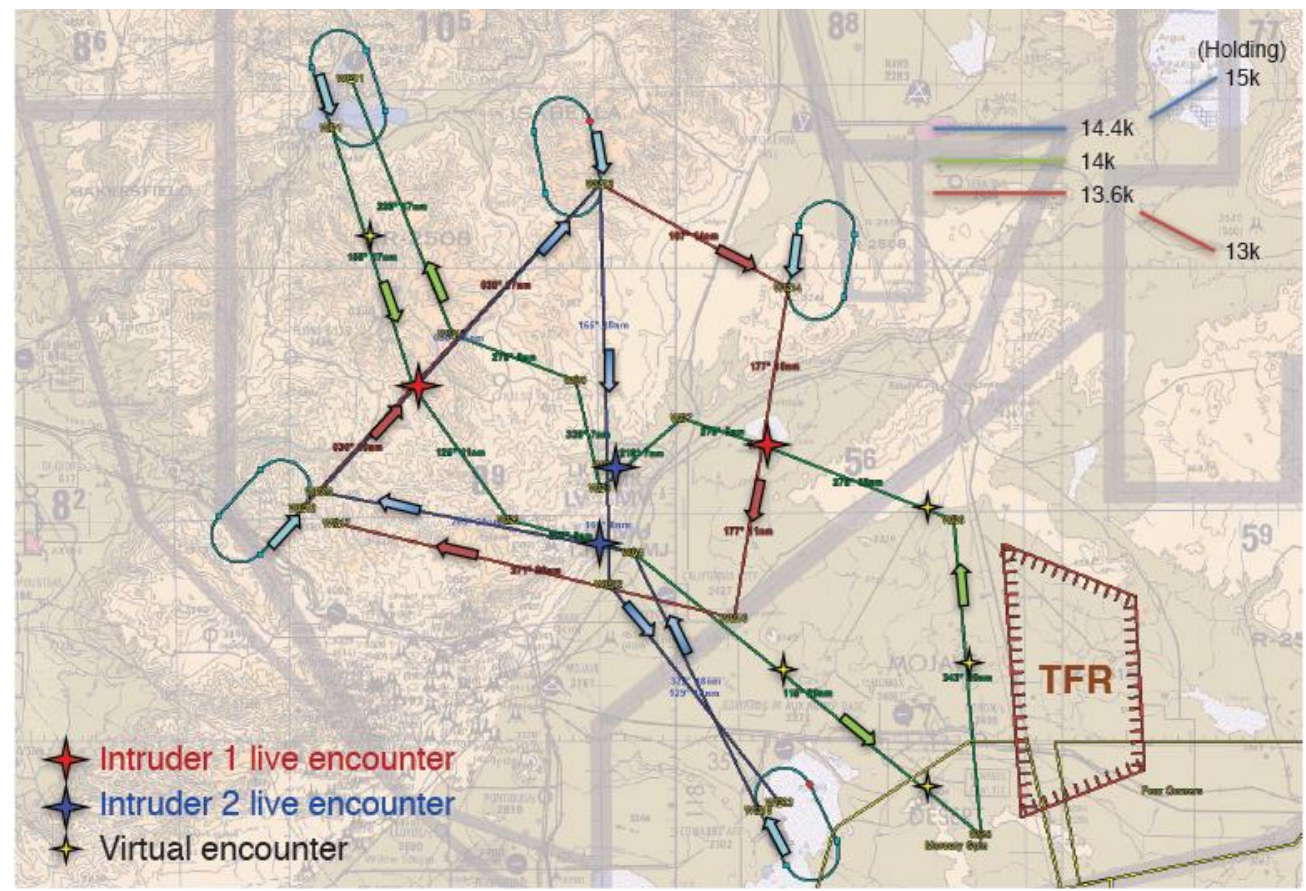

Figure 37. Fireline routing, ownship, and live/virtual intruders. 


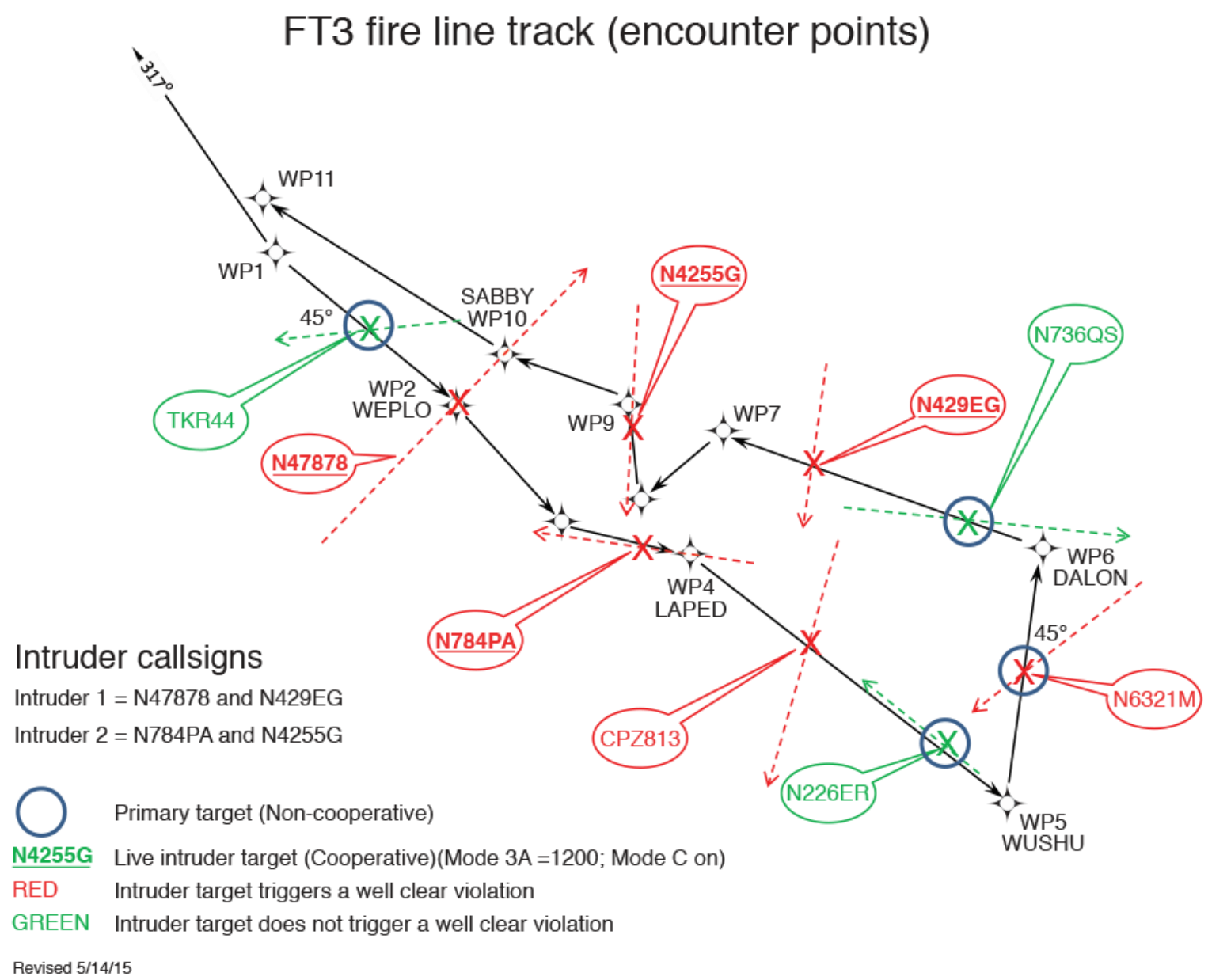

Figure 38. Full Mission fireline route and encounters. 


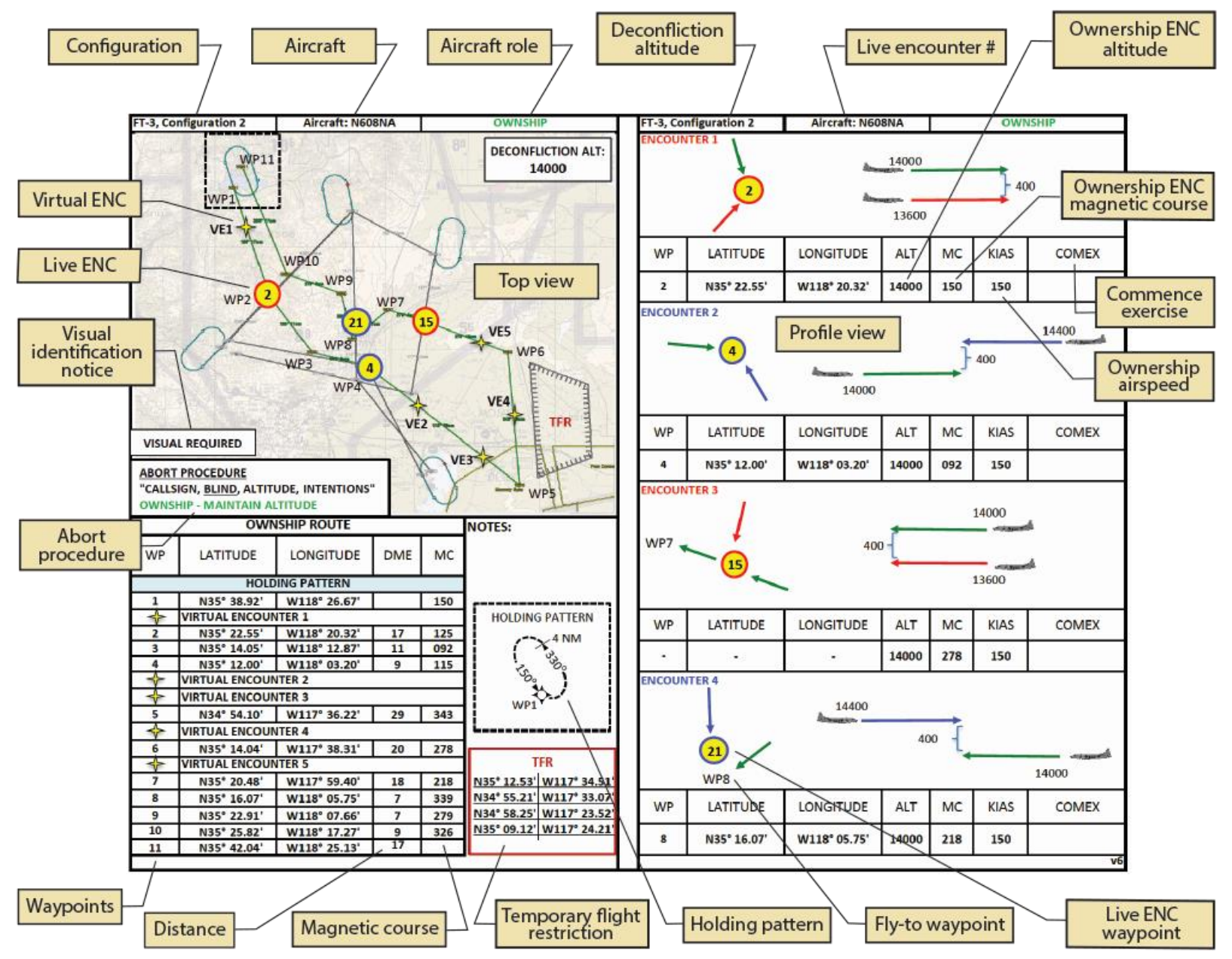

Figure 39. Full Mission ownship test card. 


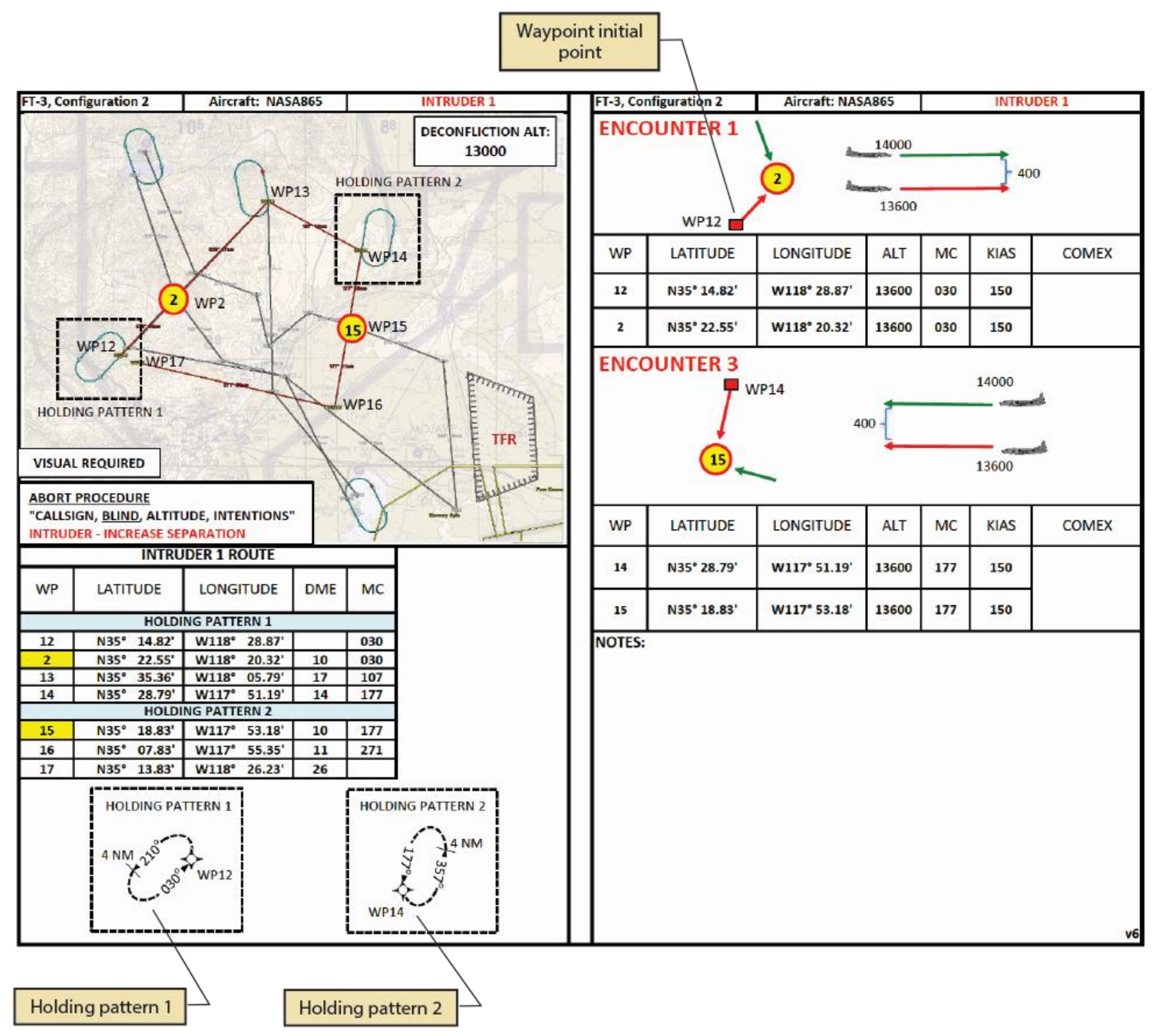

Figure 40. Full Mission intruder 1 test card. 


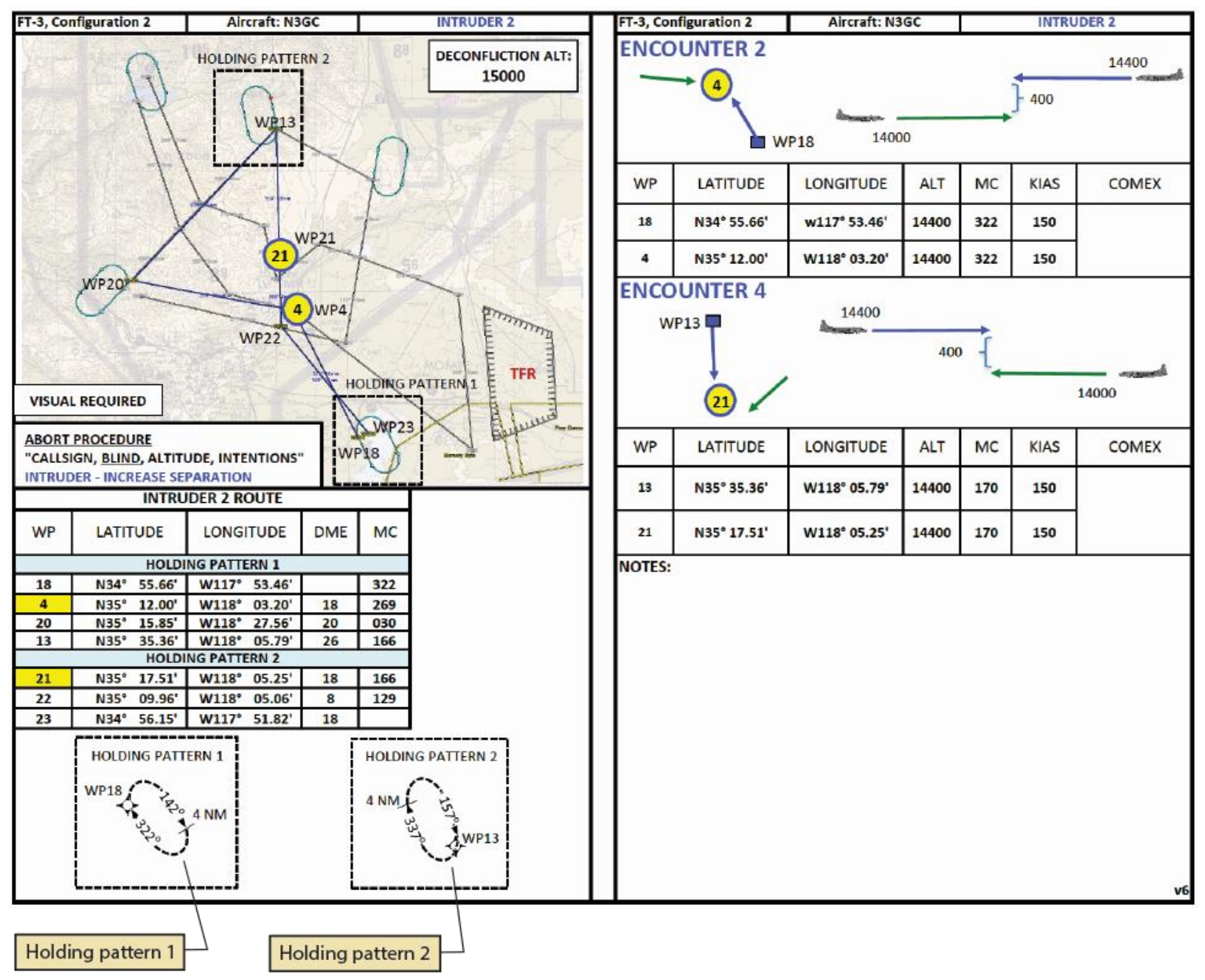

Figure 41. Full Mission intruder 2 test card. 
FT3 configuration 1

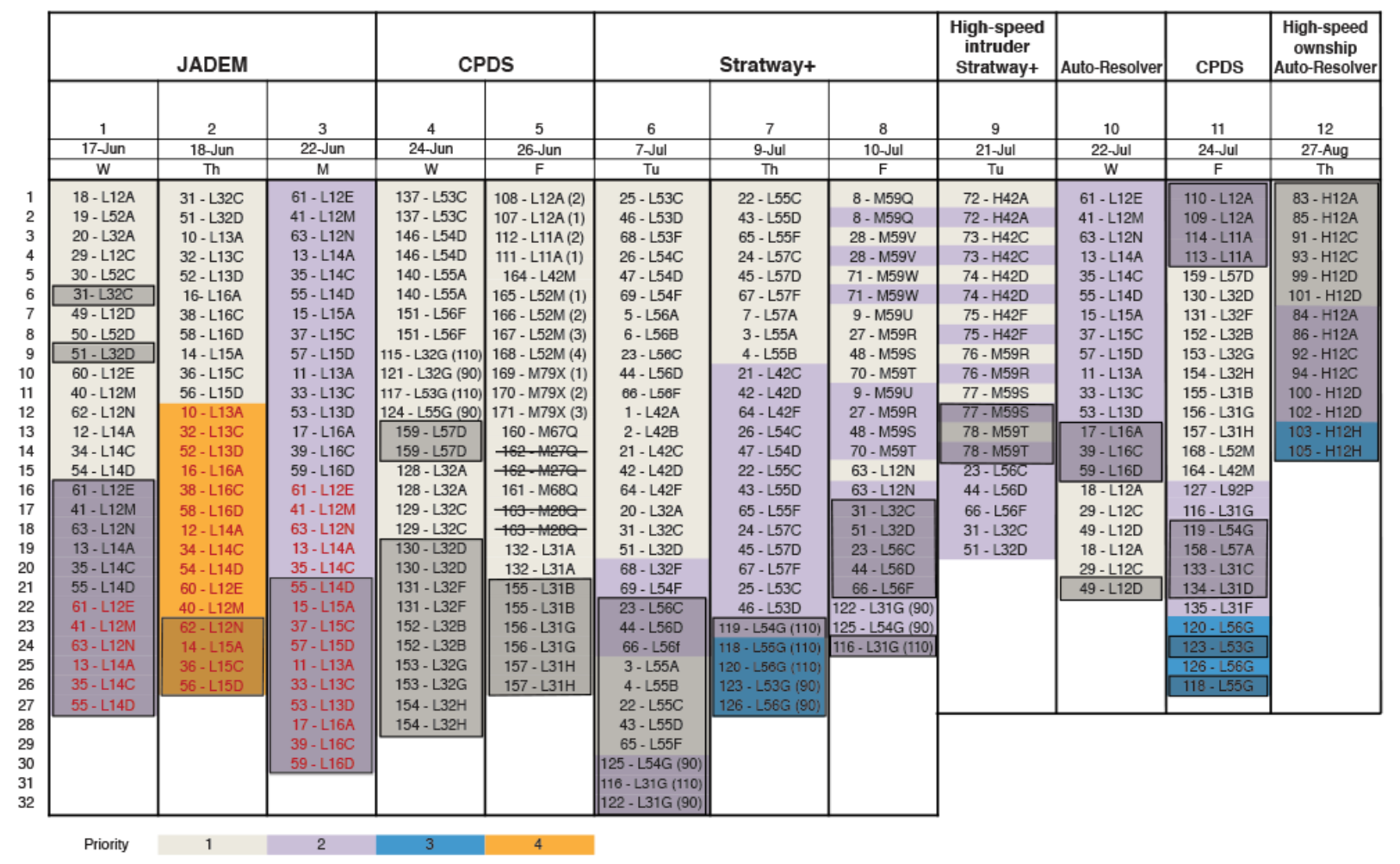

Figure 42. List of planned and flown encounters for each day of flight. The names of the scenarios are based off nomenclature crafted specifically for FT3. 